$$
\begin{gathered}
\text { József Gert Farkas = } \\
\text { Josef-Gerhard Farkas (Hg.) }
\end{gathered}
$$

\title{
Die ungarische Revolution 1956
}

Band I \& II, Edition 2012 mit Index \& Anhang

I) Rundfunk-Dokumente

unter besonderer Berücksichtigung der studentischen Bewegung. Vorwort 1957 Prof.Dr. Alexander Graf Schenk von Stauffenberg

II) Ost-westliche Presseschau

Meldungen, Kommentare, Features, Analysen.

Vorwort 1957 Prof.Dr. Karl d’Ester

Anhang:

Ungarn in Flammen. Dokumentarfilm

The Hungarian revolution 20 years after. Rezension.

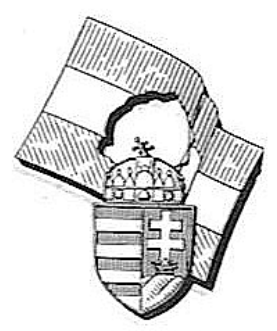

(C) 2012 Gabriele Farkas, gabyfarkas@web.de Habsburger Allee 10 a, D-76767 Hagenbach

Druck: dbusiness.de gmbh . 10409 Berlin 


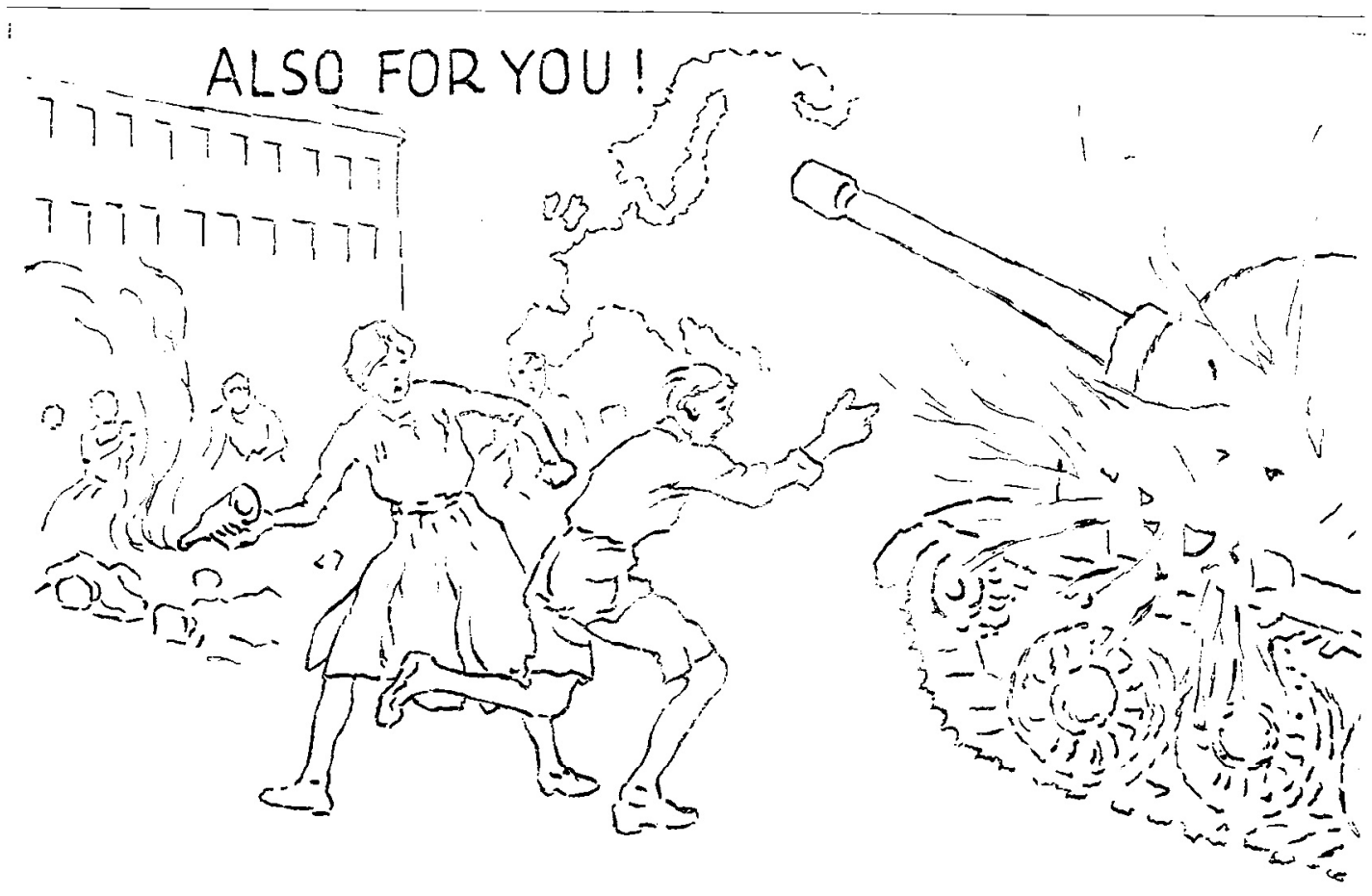

G56. Nov. M. Sz.

MAGYAR SZOLGÁLAT

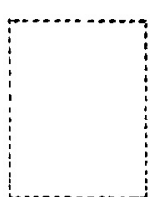


József Gert Farkas =

Josef-Gerhard Farkas (Hg.)

\section{Die ungarische Revolution 1956}

Band I \& II, Edition 2012 mit Index \& Anhang

\section{I) Rundfunk-Dokumente}

unter besonderer Berücksichtigung der studentischen Bewegung Vorwort 1957 Prof.Dr. Alexander Graf Schenk von Stauffenberg

II) Ost-westliche Presseschau

Meldungen, Kommentare, Features, Analysen.

Vorwort 1957 Prof.Dr. Karl d'Ester

Anhang:

Ungarn in Flammen. Dokumentarfilm

The Hungarian revolution 20 years after. Rezension.

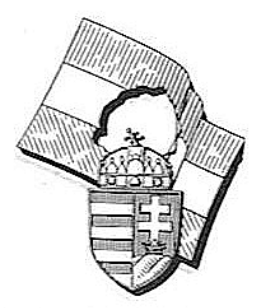

(C) 2012 Gabriele Farkas, gabyfarkas@web.de Habsburger Allee 10 a, D-76767 Hagenbach

Druck: dbusiness.de gmbh . 10409 Berlin 


\section{Inhalt Band I mit Seitenzahlen des Originals, Rundfunkdokumente:}

S. 5: Vorwort von Alexander Graf Schenk von Stauffenberg, München 1. Febr. 1957.

S. 6: Lajos Kossuth über Ungarns verlorenen Freiheitskampf 1849.

Herausgebers Bemerkung, München 1957.

S. 7: 26. 2.56: Radio Kossuth, Budapest:...XX. Kongreß der KPdSU

28. 2.56:

30. 4.56:

S. 8: 29. 6.56:

S. 9: 30. 6.56:

S.10: 3. 7.56:

17. 8.56

20. 8.56

S.11: 28. 8.56:

30. 8.56:
......Nachrichten

.....Kommentar

.....Kultusminister Kiss

......Nachrichten

.....Presseschau

.....Landwirtschaftskollektivierung

.....Antal Apró

.....Leitartikel Szabad Nép (Freies Volk)

.....Kommentar

S.12: $\quad$ Radio Szülöföldünk (Heimatland):....Neue Schulbücher

S.13: 31. 8.56:

Radio Kossuth:...Revue des Tages

19. 9.56 :

.....Presseschau

S.14:

21. 9.56:

.....Revue des Tages

22. 9.56: Szülöföldünk (Heimatland):...Schriftstellerversammlung

23. 9.56: Kossuth:...Presseschau

S.15: 26. 9.56:

.....Abendnachrichten, Kodály über Bartók

14.10.56: Szülöföldünk (Heimatland):...Imre Nagy

15.10.56: Kossuth:...Presseschau, Jugend flieht nach Westen

S.17: $\quad$ …..Kommentar zu Mátyás Rákosi \& Imre Nagy

16.10.56:: Szülöföldünk (Heimatland):...zu Imre Nagy

18.10.56: Kossuth:...Studentenparlament will West-Fremdsprachen

21.10.56:

.....Studenten gründen Organisation $>$ Mefesz

S.18:

22.10.56:

.....Presseschau, über 15 Studenten-Punkte

.....Imre Nagy wieder Professor

.....Presseschau: Leninismus./.Stalinismus

.....Abendschau über Polen: Jugendbewegung

23.10.56:

S.20:

S.21:

......Nachrichten: TH-Studenten gründen Verband

.....Leitartikel Szabad Nép (Freies Volk): Jugend

.....Studentenbewegung

.....Nachrichten: Parteikontakt Jugoslawien

.....Presseschau: Szabad Ifjuság (Freie Jugend)

.....Fehlerhafte stalinistische Klassenkampftheorie

S.22:

.....Studenten demonstrieren pro Polen

.....Sondermeldungen: Demonstration erlaubt

.....Parteijugendverband demonstriert mit

.....Parteijugendverband lenkt Schülerparlament

S.23:

.....Petöfi-Kreis, Kolchosdiskussion vom 17.Okt. Szülőföldünk (Heimatland):...Demonstrationen pro Reformen überall

S.25:

S.26: Kossuth:..Parteigeneralsekr. Gerő warnt vor bürgerlicher Demokratie

S.27: ...Parteisitzung anberaumt

Kossuth:...Parteisitzung vorgezogen

.....Budapester Jugend will Imre Nagy

.....Inlandsnachrichten fallen aus 
24.10.56:

S.29:

S.31:

S.32:

.....Sitzung der Parteileitung für sofort einberufen

......Sowjets sollen gegen Konterrevolution helfen

.....Ausgehverbot wegen Aktion gegen Konterrevolution

...Imre Nagy Ministerpräsident

......Nagy verkündet Todesstrafe gegen Rebellion

.....Gräueltaten "konterrevolutionärer Banden"

......Ausgangssperre

.....Radios in die Fenster für Rede Imre Nagys

.....Konterrevolutionäre kapitulieren

.....Imre Nagy: Kampf einstellen

......Bewaffnete ergeben sich Nagy

.....Radios in die Fenster für Nachrichten

.....Bewaffnete legen Waffen nieder

.....Ultimatum: Ergeben statt Standgericht

......Sowjettruppe als „Freunde“ eingetroffen

.....>Mefesz-Studenten pro Imre Nagy

.....In Fabriken wieder Ordnung

.....Kapitulations-Ultimatum wiederholt

.....Ultimatum abgelaufen

.....Rundfunkgebäude wieder befreit

.....Ultimatum verlängert

S.33:

.....Parteifrauenkomitee gegen Konterrevolution

......Lebensmittelversorgung ist erschwert

.....Kapitulationsultimatum, weiße Fahne hissen

.....Gewerkschaft pro Volksdemokratie

.....Petőfi-Kreis: Jugend soll kapitulieren

.....Militär-Düsenflugzeuge über Budapest

S.34: $\quad$.....Csepel-Autofabrik gegen Konterrevolution

.....Im Komitat Zala ist Ruhe

...Nächtliche Ausgangssperre

.....Ultimatum läuft ab

.....Partei-Jugendverband appelliert an vaterländische Ehre ...Árpád Szakasits gegen volksfeindliche Elemente

S.35:

S.36:

Prof. Erdei-Grúz gegen Konterrevolution

.....Ultimatum läuft $\mathrm{ab}$

.....Gefangene Konterrevolutionäre

......In Szeged ist Ruhe

..Waffenfunde in Parks, abliefern

S.37:

.....Kathol. Friedenskomitee: Ruhe um Christi Willen

.....Partei-Jugendverband erbittet Waffenniederlegung

.... > Mefesz in Eger nennt Demonstranten Faschisten

.....Eltern rufen Söhne namentlich heim

.....Erzbischof Grösz verurteilt Kämpfe

.....Übergelaufener Offizier gefangen

.....Oxygenfabrik will Normalbetrieb

S.39:

.....Gutenachtsendung für Kinder fällt aus

.....Ruhige Budapester Bezirke

.....Kampf an Parteigebäude und Kaserne

...Imre Nagy soll Konterrevolutionäre begnadigen

S.40:

.....Bericht über Verteidigung des Funkhauses

.....Wetterbericht 
S.41:

.....Rede János Kádárs: Regimegegner sind unanständig

.....Partei \& Regierung besprechen Lage

.....Rotes Kreuz erbittet Blutspenden

......Betriebe in div. Komitaten arbeiten

.....Nachrichten: Kaserne erfolgreich verteidigt

.....Filmschauspieler verurteilt Provokateure

.....Sanitäter helfen humanitär statt parteiisch

S.42:

.....Akademiker erbittet Milde für Provokateure

.....Schwesternschülerinnen sind wohlauf

.....Berichtigung Falschmeldung

.....Lagebericht

.....Sendeschluß 0,05 h: geruhsame gute Nacht.

25.10.56: Kossuth \& Petöfi:...Gros der Konterrevolutionäre ist liquidiert

S.43:

.....Waffen und Sprengstoffe abliefern

.....Lage gebessert, Partei \& Regierung sind Herr

.....Gerüchte über Budapester Lage sind falsch

.....Ungarische \& Sowjetkräfte schlugen Konterrevolution nieder, aber Schulen bleiben zu.

S.44:

.....Feuerwehr löschte heldenhaft

......Meiste Betriebe arbeiten

.....Menschenansammlungen bleiben verboten

......Nachrichten: UNO-Sicherheitsrat berät über Israel

.....Leitartikel Szabad Nép (Freies Volk): Konterrevolutionäre entfernten roten Stern vom Verlagshaus

S.45:

.....Verteidigungsminister befiehlt endgültige Vernichtung der Konterrevolutionäre bis Mittag

.....Budapest repariert Verkehrsmittel

.....Busse ersetzen Trambahn, U-Bahn funktioniert

.....Politbüro-Umbildung: Kádár statt Gerő

S.46:

.....Bevölkerung froh; Nationalhymne \& Marseillaise

.....Imre Nagy \& János Kádár gegen jederlei Demonstration

.....Kádár: Jugend soll Partei verrtrauen

S.47:

......Nagy: Kapitulierer erhalten Milde

.....Petőfi-Kreis pro Kádár \& Nagy

.....Nagy \& Kádár verfügen nächtl. Ausgangssperre

.....Ausgangssperre in 35 Minuten

.....Ausgangssperre in halber Stunde

.....Ausgangssperre in 2 Minuten

.....Gyula Háy pro Nagy \& Kádár

S.49:

.....Keine Hausfremden einlassen

.....Gerüchte über Hinrichtungen falsch

......Nagy kündigt patriotische Volksfrontregierung an

S.50: 26.10.56: Kossuth \& Petőfi:...Ausgangssperre ganztags wegen Vernichtungsaktion gegen Konterrevolutionärsreste

.....Leitartikel Szabad Nép (Freies Volk): Ungarn geht nun eigenen

Weg zum Sozialsmus

.....Mediziner haben unbefristet Dienstpflicht

S.51:

.....Lebensmitteleinkauf von 10-15 h erlaubt

.....Rettungswagen beschossen

.....Budapester Werktätige ermahnen Studenten

.....Amnestie für Kapitulanten 
Petőfi:...Gefangene ausgebrochen

Kossuth:...Jugendliche kapitulierten und sind frei

....18 Minuten bis Ultimatum Waffenablieferung

.....Schriftsteller Háy für Waffenablieferung

.....Auslandsnachrichten: Sowjetbotschafter in Bonn

.....Beethovenkonzert: Egmont

.....Ungarn will Nichteinmischung der Sowjets, Abzug

S.53:

.....Ausgangsverbot; Einzelpersonen dürfen einkaufen

.....Kapitulationen

27.10.56:

.....0.16 h Sendeschluß, Nationalhymne

.....Stadtrat dankt Versorgungshelfern

.....Sendeprobleme

......Neue Nationalregierung

.....Ministerliste der Ungar. Volksrepublik

S.54:

S.55:

S.57:

......Nachrichten: Lage, Kapitulationen, Flugblätter, AmtsanmaBungen, Gerüchte, Gefangenenbefreiung. - Jugoslawien über Polen \& Ungarn. - Wetterbericht.

.....Gewerkschaften: Arbeiterräte leiten Fabriken

.....Gewerkschaften: alles wird besser

.....Szolnoker Studenten wohlauf

......Nagys Regierung vereidigt

.....Schriftsteller erhofft nun Frieden

......Neuer Verteidigungsminister befiehlt Vernichtung Widerstandsnester

S.58:

.....Hausgemeinschaften machen Gefangene

.....Ausgangssperre

.....Nachrichten: Flugblätter in Provinzstädten

Rebellensender Miskolc:...Kampf gegen Polizei

Rebellensender Pécs:...Pro Nagy, aber gegen Minister

S.59: $\quad$ Freier Sender Györ:...Staatssicherheitsdienst abschaffen, Sowjets sollen fort

Sender Miskolc:...Pro Nagy, der soll Sowjets wegschicken

.....In Budapest Kampf gegen Widerstandsgruppen

.....Hier übernahmen Arbeiterrat \& Studentenparlament Leitung

.....Aufruf 2sprachig an Sowjets: Aufstand gilt nicht euch

S.60:

28.10 .56

Kossuth:...Ausgangssperre auch morgen, Lebensmitteleinkäufe von Einzelpersonen $10-15 \mathrm{~h}$

.....Wetterbericht

.....Presseschau: Parteijugendblatt Szabad Ifjuság (Freie Jugend) besorgt wegen Olympiateilnahme in Australien

.....Ungar. Armee \& Aufständische vereinbaren Waffenruhe

Freier Sender Györ:...Regierung soll bei Sowjets erwirken Waffenruhe \& Truppenabzug bis 1.1 .57

S.61: $\quad$ ….Auslandssender verleumden Nagy. - Györer Sowjetkommandant beklagt Anfeindungen, will nur Frieden

.....In Györ etc. formieren sich Volksräte

S.63:

.....Gründung Landesrat Revolutionärer Freier Jugend

Kossuth:...Aufstandsgründe, Misere Arbeiter \& Bauern

......Ungar. \& Sowjetmilitärs gegen Aufständische

Győr:...Ausländ. Rotkreuzhilfen eingetroffen. - Sowjettruppen sind Bedrohung

S.65: $\quad$ Freier Sender Győr:...Ab Montag 29. Okt. wieder Schulunterricht 
......Népszava (Volksstimme) fordert Asylrecht für Sowjetüberläufer .....Demonstrationen für Abzug der Sowjetarmee

S.66:

Kossuth:....Leitartikel Szabad Nép (Freies Volk). Rekapituliert Hergang der nicht eindeutig konterrevolutionären Bewegung

Győr:...Journalisten berichten zögerlich. - Kindersendung erklärt sozialen Sinn des Aufstands

S.68:

.....Kaminkehrergenossenschaft gründet Arbeiterrat

.....Österreich hilft humanitär, nicht bewaffnet

S.69:

.....Bäckereien arbeiten, Lkw \& Pferdewagen liefern

.....Auslandsjournalisten fragen, ob auch Kommunisten in neuen Gremien

S.71: Kossuth:...Auslandsnachrichten: Jugoslawien positiv zur neuen ungar. Regierung. - In Polen sind Sowjettruppen nur auf zugewiesenen Stützpunkten. - Sowjetregierung will Deutschlands Wiedervereinigung durch Annäherung beider Staaten

S.72:

Freier Sender Györ:...Sowjets sollen Kämpfe einstellen

.....Arbeiter streiken bis Abzug Sowjets

.....Ölförderung nicht für Sowjetpanzer

.....Sender Kossuth soll an wahrheitsgetreue Schriftsteller

.....Abflug Olympiadelegation verschoben

.....Politische Lage

.....Sport

.....Aus Internierung befreiter Nichtkommunist Tildy ist Minister

S.73: 29.10.56: Kossuth \& Petőfi, Budapest:...Leitartikel Szabad Nép (Freies Volk) rekapituliert berechtigte Volkswünsche inkl. Sowjetabzug \& Fortfall Kollektivierung

Miskolc:...10 Forderungen aller intellektuellen revolutionären Verbände

S.75: Kossuth:...Auslandsnachrichten: DRK-Hilfskonvoi aus München.

.....Bewaffnete Studenten mit Armbinden als Ordnungshüter

S.76:

Freier Sender Győr:...Arbeiterräte Kohlebergbau etc.: Streik bis Russen weg

..... Verteidigungsminister meldet, ung. Militär begann Sowjets abzulösen, hernach legen Widerstandskämpfer Waffen nieder

Kossuth \& Petöfi:...Tito \& Bund jugosl. Kommunisten besorgt über Ungarn wegen Auswirkung auf internationalen Sozialismus

Kossuth \& Petöfi, Budapest:...Sonnenaufgang 06.27 h

.....Wiener Ungarnbotschaft hißte nationalfarbene Fahne

.....Verteidigungsministerium meldet Fortsetzung des Abzugs von sowjet. Truppen, die bewaffneten Gruppen gegenüber stehn

S.77:

....Studentische Landesversammlung, Anreise per Lebensmittel transporten

Arbeiterratssender Miskolc:...Revision des Warschauer Vertrags zwecks Abzugs der imperialistischen Sowjettruppen

.....Sowjetunion verletzte Warschauer Vertrag \& UNO-Statuten .....Appell an die UNO

S.79: $\quad$ Szombathely:...Sowjets raus

Komitatsratssender Miskolc:...Sowjettruppen kommen statt gehen

S.80: .....Presseschau. New York Herald Tribune

Freier Sender Györ:...Ölförderung soll nicht Sowjetpanzern dienen .....Nagyrede: Sowjettruppen sollen abziehen

S.81:

.....Austausch ungar. UNO-Botschafter

.....Ungarns Rundfunkgeschichte beginnt neues Kapitel. Bisher 
Werkzeug der Lüge, künftig der Wahrheit

.....Von Kommunisten verbotenes Blatt erscheint wieder

Arbeiterratssender Szabolcs-Szatmár: Sowjetmilitär verhandelt über

S.82:

Abzug, aber bringt neue Truppen ins Land

.....Kardinal Mindszenty soll wieder amtieren

Kossuth \& Petőfi:...Österreich weist neutralitätshalber führenden Emi-

granten aus

Szombathely:...Regierung soll überlaufenden Sowjetsoldaten \& Zivilisten

Asyl garantieren; soll Rede-, Presse-, Versammlungs-, Reli-

S.83: $\quad$ Miskolc: An Ostnachbarn: wir wollen Freiheit, nicht Faschismus

Kossuth:...Proklamation des Revolutionären Militärrats: Abzug Sowjets und Entwaffnung Staatssicherheit

Arbeiterratssender Borsod:...fordert Sowjetabzug, UNO-Beratung, Mehrparteiensystem

S.84: $\quad$ ….Heldenbegräbnis für Gefallene. - Debrecener Lage normal. Seit 6 Tagen strömen Tausende Sowjetpanzer ins Land

Revolutionärer Arbeitsratssender Szabolcs-Szatmár:...Sowjetmarschall Schukow hat Abzug befohlen

S.85: $\quad$......Theater bleiben zu bis Sowjets raus

Freier Sender Kossuth:...Budapest grüßt \& nennt andere Freie Sender

.....Was Journalisten in Kampftagen erlebten

.....West-Ausland lobt Ungarn, Papst erläßt Enzyklika

S.87: $\quad$.....Schriftsteller hoffnungsvoll

Freier Sender Petőfi, Győr: Nagy schuldlos an Sowjets \& Standgericht Miskolc:..Auf Schukows Abzugsbefehl überall Jubel

.....Überprüfung des Lehrmaterials für Gymnasium

S.88: $\quad$......Andacht \& Gebet

31.10.56: Freier Sender Kossuth:...Ungar. Panzerdivision pro Aufständische

.....Sozialdemokr. Partei arbeitet

......Nationale Bauernpartei

S.89:

.....Sowjets aus Budapest abgezogen

.....Roter Stern soll runter vom Parlament

.....Sowjets verhinderten \& vernichteten Dokumenarfilme

Miskolc:...Abziehende Sowjets kehren um

.....Kardinal Mindszenty aus Staatssicherheitsgefängnis befreit

S.90: $\quad$......Mindszenty segnet ungar. Waffen

Freier Sender Kossuth:...Alkoholverbot

.....Evangelischer Bischof abgedankt, 1950 Inhaftierter übernimmt

Freier Sender Szombathely:...Neutralität für Ungarn wie Österreich

.....Gewerkschaftspräsidium zurückgetreten, neuer Freier .

S.92: $\quad$ Freier Sender Petőfi:... $\quad 140.000 \mathrm{~m}^{2}$ Fensterglas für größte Schäden

Freier Sender Kossuth:...Störsender .....395 polit. Gefangene befreit

.....Bewaffnete Studenten zu ihren Dienststellen

Miskolc:...Beschlüsse Schülerparlament

S.93: $\quad$.....Revol. Studentenkomitee über Regierung \& Nagy

1.11.56: Freier Sender Kossuth, Budapest:...Britischer Luftangriff auf Kairo .....Sozialdemokraten reisen nach Wien

.....Anwaltskammer gegen bisher kriminelle Leitung

.....US-Präsident Eisenhower lobt ungar. Volk 
.....Lagebesprechung Großverbände

S.94: $\quad$ Freier Sender Petöfi:...Bürgerwacht

Freier Sender Petőfi, Győr:...Totengedenken

Freier Sender Kossuth:...Künstler wollen Unabhängigkeit von Politik

.....Studenten teilen Künstlern Lebensmittel zu

S.95:

.....Revolutionsrat übernimmt Universitätsleitung

.....Pädagogen erhalten Gehaltsvorschuß

.....Ehepaar adoptiert durch Kampf verwaistes Kind

Freier Sender Kossuth, Budapest:...Gedicht über Radiopublizistik .....Ungar. Militärstudenten in Leningrad pro Revolution

.....Kleinbauernparteifrauen sorgen für verwaiste Kleinkinder .....Schriftsteller Németh über Kämpfe

S.97: $\quad$ Freier Sender Petőfi, Győr:...München, Prof. Graf Stauffenberg würdigt ungar. Heldenkampf als weltgeschichtlich

S.98:

Freier Sender Kossuth, Budapest:....Nagy erklärt Ungarns Neutralität

S.100: ......Nagy erklärt das dem Volk

......Mindszenty spricht

.....Präsident Katholischer Volkspartei spricht

.....Sowjet-Atomforscher verschwiegen Ungarns Uran

.....Interviews mit jungen Kämpfern

S.101:

.....Kádár gründet Ungar. Sozialistische Volkspartei

.....Sowjetpanzer umzingeln Flugplätze

.....Gründung Ungar. Sozialdemokr. Jugendbewegung

2.11.56: Freier Sender Szombathely: Zeitungsbericht über Kampfszenen

S.102: $\quad$ Freier Sender Kossuth, Budapest:...In Villa geflohenen Rákosis

Rundfunk des Borsoder Arbeiterrats, Miskolc:...bittet auch deutsch \& englisch um Serum gegen Kinderlähmung

S.103: $\quad$ Freier Sender Kossuth, Budapest: Ungar. Juden begrüßen ung. Revolution ......Nagy an UNO: starke Sowjetverbände im Anmarsch

S.104: $\quad$.....UNO debattiert Ungarns Neutralitätserklärung

Freier Sender Kossuth /Budapest \& Freies Radio Petőfi /Győr:...Rede FDPBundestagsabgeordneter Prinz zu Löwenstein

S.107: 3.11.56: $\quad$......Neue Zeitungen erscheinen ..Weltoffenheit

Freier Sender Szombathely:...Begrüßt Neutralität .....Sowjets sperren ungar. Westgrenze, internieren Reisende

S.108: $\quad$ Freier Sender Kossuth /Bpest \& Fr. Radio Petőfi /Györ....Presseschau inkl. .....umbenanntes KP-Blatt Népszabadság (Volksfreiheit)

S.109: $\quad$ Freier Sender Szombathely:...Sowjet-Panzerzüge kommen .....Schulunterrichtsreform, Geschichtsbücher etc. neu

Fr. Sender Kossuth /Bp. \& Fr. Radio Petőfi /Győr....Kodály fordert Sowjetabzug. Laut Sowjets lügt Nagy. England rügt Sowjets.

S.110: $\quad$ …..Sowjets versprechen Truppenverstärkungsstopp

Unidentifiz. Freier Sender:...Sowjets sagen, sie kommen gegen Faschisten

S.111: Fr. Sender Nationalkomitee Dunapentele:...Auf Russisch überall ansagen, faschistisches Blutbad ist unwahr

Fr. Sender Pécs:...Trotz neuer Sowjets ruhig bleiben, nicht schießen

Fr. Sender Kossuth /Bp., angeschlossen Radio Petőfi: Kardinal Mindszentys Rede zu Volk \& Welt

S.114: $\quad$.....Prof. Szalai über Lage der ungar. Wissenschaft

S.115: 4.11.56 Fr. Sender Kossuth /Bp. \& Fr. Radio Petőfi /Győr:...Namenstag Karl 
S.116:

.....Frankreich \& England machen Polizeiaktion in Nahost

......Nagy informiert Volk \& Welt über Sowjetangriff. Alle 2 Minuten wh. englisch, französisch, deutsch, slawisch

......Nagy ruft gestern von Sowjets zum Verhandeln geholte Verteidigungs- \& Armeeführung zurück in Ämter. Wiederholt .....USA erbeten UNO-Sicherheitssitzung wegen Sowjetangriffs ......Regierung an Sowjets ungarisch \& russisch: nicht schießen! ....Ave Maria (Schubert)

S.116-126: Inmitten mehrsprachiger Hilfsbitten an die Weltöffentlichkeit erlöschen Freie Sender. Ein kommunistischer Sender erklärt Nagys Regierung für abgesetzt und die Gründung einer neuen unter Kádár. Während die alsbald unfreien Radios Sowjetbefehle verlesen und Plattenmusik bringen, melden ungar. Kampfsender wie Kurzwellenradios überall schwere Gefechte. Partisanensender Rákóczi verstummt am 7.11.56 beim Kampf in Dunapentele.

Aczél, Tamás 15

Andropov 97

Apró, Antal 10, 117

Babits, Antal 54

Bartók, Béla 15

Bata, István 45

Bebrics, Lajos 54, 59

Bencze, Lajos 89

Bócsa, Elek 35

Boldizsár, Iván 14

Déry 9

Dezséry, László 90

Dulles 104

Eisenhower 93, 125

Erdei[y]-Grúz, Tibor 35

Gerő, Ernő 22, 25, 28, 45, 47ff, 50, 66f,

87, 101

Gieseking, Walter 52

Grősz, József 37

Gyenes, Antal 67

Hammarskjöld, Dag 103, 122

Háy, Gyula 14f, 47, 52

Hegedüs, András 87

Hitler 97

Horváth Imre 54, 122

Horváth, Richard 36

Jánosi, Lajos Prof. 100

Janza, Károly 54, 58, 76

Jobbágy, Károly 95

Józsi 80, 100

Kádár, János 28, 40, 45ff, 50, 55, 101, 117, 122

Kalmár, György 40

Kána, Lörinc 83

Képes Géza 14
Namen auf Seiten im Band „Rundfunkdokumente":

Kéthly, Anna 93

Kis 108

Kiss, Árpád 54

Kiss, Gyula 8

Kodály, Zoltán 15, 109

Kónya, Albert 54

Koós, Péter 81

Kósa, István 117

Kossuth, Lajos 6

Kovács, Béla 54, 67

Kovács, István 116

Lenin 18

Löwenstein, Hubertus Prinz zu , 104

Lukács, György 28, 54, 67

Maléter, Pál 108, 116

Mikojan 108

Mindszenty, József 82f, 90, 98, 100, 111

Molnár, Aurél 85

Münnich, Ferenc Dr. 54, 117, 122

Nagy, Ferenc 82

Nagy, Imre 15, 17f, 25, 27ff, 31, 33, 35, 37, 39, 46f, 49f, 54, 57, 59, 61, 67, 71ff,

74, 79f, 87, 97f, 104, 110, 115ff, 122

Nagy, József Frau 54

Németh, László 96

Nógrádi 15

Non, György 82

Nyers, Rezső 54

Ordas, Lajos 90

Örszegi, József 63

Perus 110

Peti, Sándor 41

Petőfi, Alexander 12

Pieck, Wilhelm 122

Piros, László 22, 34 
Pius XX, Papst 87, 113

Pusztay, Magdolna Dr. 51

Rácz, Ernő 97

Rákosi, Mátyás 17, 21, 63, 101f

Révész, András Dr. 93

Rusznyák, István Dr. 42

Schukow 84, 89

Smyrnow 52

Soboljew 110

Stalin 18, 63

Stauffenberg, Alexander Graf Schenk von $\sim, 5,97$

Stephan d.Hl, König 113

Szakaly, József 12

Szakasits, Árpád 34
Szalai, Sándor Prof. 114

Szepesi, György 39

Szigeti, Attila 61

Szülőföldünk (Unser Heimatland) Sender

für im Ausland lebende Ungarn: passim

Táncos /Tánczos, Gábor 13, 47

Tardos 9

Tarján, Béla \& László 37

Tildy, Zoltán 23, 54, 67, 72, 81f

Tito 76

Tót, István 21

Tóth 95

Varga, Endre Dr. 98

Vas, Zoltán 23

Zelk, Zoltán 14

\section{Inhalt Band II mit Seitenzahlen des Originals, Ost-westliche Presseschau:}

Abendzeitung 22f, 25, 35, 38ff, 50, 55, 73, 87,98, 108f, 114, 123

Allgemeiner Deutscher Nachrichtendienst /ADN 20, 40, 45, 92

Arbeiter-Zeitung115

Associated Press 53

l'Aurore -

Borba 29

BZ /Berliner Zeitung 101

Colloquium 101

Csepeli Ujság 70

Csillag -

Daily Worker -

Deutsche Presse-Agentur /dpa 35ff, 40,

54f, 57, 62, 89, 96, 117, 124

Deutsche Woche 114

Egyetemi Ifjuság 68, 71

Englische Rundschau 72

1'Express 93

Figaro 58

Frankfurter Allgem. Zeitung 7, 24, 29, 34, $53,56,84,122$

Győri Munkás 84

Hamburger Abendblatt 97

Hannoversche Presse 18

Hinter dem Eisernen Vorhang 62

1'Humanité -

Igazság 68, 70

Irodalmi Ujság 64, 68

Kis Ujság 70f, 76

Liberation -

Magyar Függetlenség 70

Magyar Honvéd 68
Magyar Ifjuság 68, 117

Magyar Jövő 68f

Magyar Nemzet 65, 78

Magyar Szabadság 41f

Magyar Távirati Iroda -

Magyar Világ 70

Mittelbayerische Zeitung 29, 62, 76, 80,

83, 85, 88ff, 94, 97, 101

Münchner Merkur 7, 24, 55, 77, 109

National-Zeitung, Basel 90

National-Zeitung, Ost-Berlin 32

Neues Österreich 48

Neue Zürcher Zeitung 24f, 31f, 35, 46f, 85, 92, 96f, 100, 115, 117

Népakarat 69, 78, 100, 103, 105

Népszabadság 69, 100, 111

Népszava 67

News Chronicle 72

New York Times 22, 95

Osservatore Romano $38 \mathrm{f}$

Österreichische Neue Tageszeitung -

Paris-Match 92

Politika 29

Populaire 57f

Prawda 22, 58, 66

Rhein-Neckar-Zeitung 124

Rudé Právo -

Reuter 35, 43, 97, 100

Der Spiegel 97, 116

Süddeutsche Zeitung 17, 26f, 36f, 43, 48, 52, 54, 57f, 72, 75, 80, 82, 86, 91, 94, 96, 100ff, 104f, 107, 109, 112, 116f, 118, 121, 124 
Szabad Ifjuság 8ff, 11ff, 14ff

Szabad Nép 67, 86, 92

Szabad Szó 70

Tages-Anzeiger 116

The Times 22, 24, 36

Time Magazine 112
TASS 22, 59

United Press 17, 38, 73, 89, 91, 100, 110

Valóság 70, 74f, 79f, 82

Vertriebenen-Anzeiger 93

Die Welt 89

Zycie Warszawy 58

Anhang - Dokumentarfilm - Buchrezension - Bezugnahmen auf 1956 ff

\section{6}
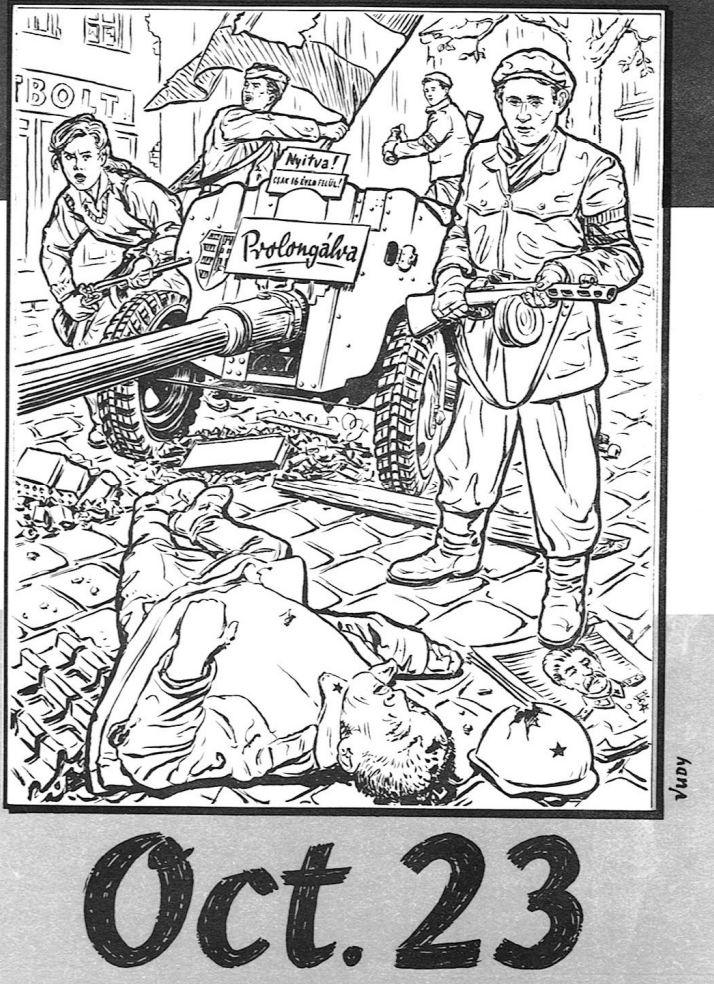

POST CARD

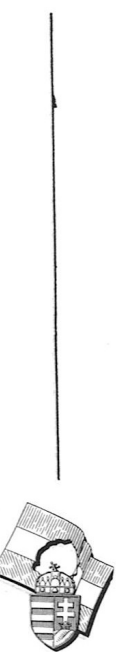




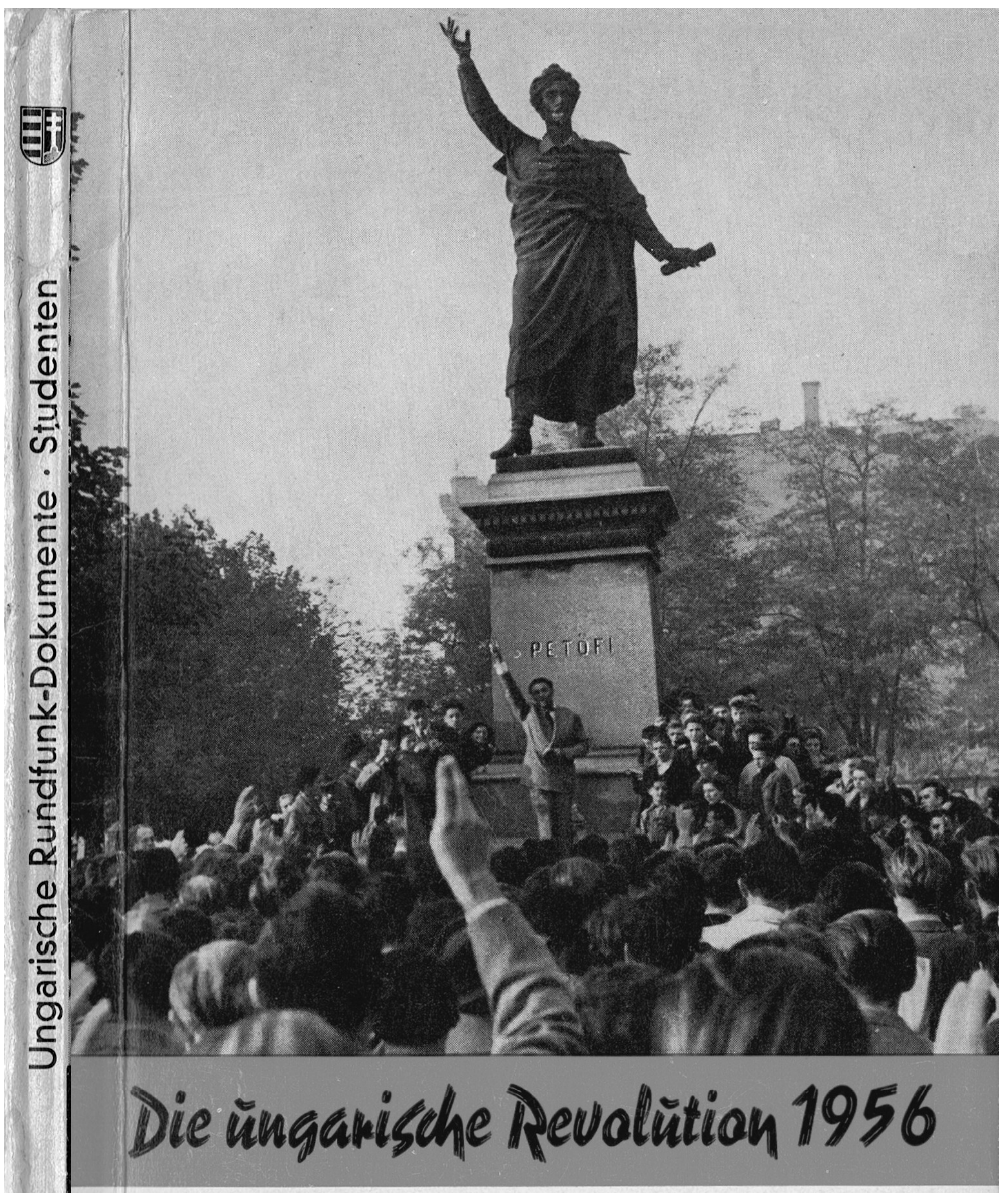

\section{RUNDFUNK-DOKUMENTE}

unter besonderer Beriicksichtigung der studentischen Bewegung 
Zusammengestellt und aus dem Ungarischen übersetzt von József Gert Farkas

Druck: Mittelbayerische Druckerei- und Verlags-Gesellschaft mbH., Regensburg 


\title{
DIE \\ UNGARISCHE \\ REVOLUTION
}

1956

\author{
Rundfunk'-Dökumente \\ unter besonderer Berücksiçhtigung \\ der studentischen Bewegung
}

Herausgegeben im Selbstverlag von J.G. Farkas, München 


\section{VORWORT \\ $\therefore$ $\therefore$}

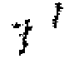

Der ungarischen Revolution vom 23. 'Oktober bis 4 . November. 1956 kommt in jedem Falle, was auch immer ihre Konsequenzen waren, sind oder sein werden, weltgeschichtliche Bedeutung zu. Diesen Aufstand eines ganzen Volkes, unter der führung seiner akademischen jugend und den Opfergang der Nation, in den er einmündete. und dếr. auch heute noch nicht rabgeschlossen ist, vermag nự der in seiner ganzen Tiefe:zu ermessen, derisich das dramatische Geschehen in seinér "dokumentarisch belégten. Aufeinanderfolge Schlag: auf. Schlag zu vergegenwärtigen weiß..

Die ungarische Revolution ist'nicht hur Reaktion gewesen auf eine tieferlittene Not hin, die uberwunden werden sollte, auf.Zwang und Vergewaltigunig, sondern șie-strebt - wie alle echten Revo:lutioneñ - auf eine ideale Neuordnung der Welt, d. h. dé ménschlichen Beziehungen im Gefüge des Volkes, ja, der Menschheit hin.

Da es áleser Bewegung, nicht in erster Linieum materielle Belange, sondern um ideale Ziele ging, und da wir sie auch nicht oder nicht alléin als nationale Empööung gegen die Fremaherrschaft verstehen dürfen, sondern als Aufbruch der Freiheit gegen, einé aufgezwungene ideologie - das große Thema unseres Jahrhunderts $\frac{}{4}$ darf diesem Beispiel eines nicht widerfahren: daß nämlich, unsere innere Teilnahme, wie es im Zuge unserer Zeit so oft der Fall ist, durch Vergeßlichkeit verschüttet wird. :

Ich hoffe, daß diesse der deutschen akademischen jugend gewidmete Veröffentlichung inr den Weg bereitet, die Erhebung unserer ungarischen Kommilitonen - und mit ihr den Freiheitskampf eines ganzen Volkes, das den letzien Einsatz, gewägt hat und wagt in ihrem:europäischen und weltgeschichtlictien Rạng zu erfasssen.

Mú nch en, den 1 . Februar 1957

Alexander Graf schenk von Stauffenberg

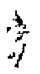


$\mathcal{N}$ ir haben nicht gesiegt, aber gek̈ämpft. Wir haben die Tyrannel-nicht gebrochen, aber ihren Layf aufgehalten. Wir haben unser Land nicht gerettét, aber verteidigt. Ünd wenn élnst unsere Geschichte geschrieben wird; werden wir sagen können, daß wir widerstanden haben.

Lajos Kossuth

- Diese Auswahl aus der größen Zahl ungarischer Rundiunksendungen, die zwischen dem 23. Oktober und 7. November 1956 initgehört und auf Tonband aufgenommen wurden, enthail keine Kommentare. Nichts ist nachträglich hinzugefügt worden; jeder sạtz ist Zitat. Bei der Ubersetzung selbst gíng es in ersier Linie um éne wörtlich genave Ubertragung, nicht um flussigen Stit. Die Ausschnitte qus Sendungen vor dem 23 . Oktober sollen den geistigen Prozeß veranschaulichen helfen, der schließlich zur Revolution führte. Das Einblenden an sich belanglosér Meldungen und üblicher Anșagen ist ein Versuch, beim Lesen der Texte eine' Atmosphậre stärkerer Unmittelbarkeit des Selbstmithörens zu schaffen. Ungárische Abkürungen sind im stichwortverzeichnis erklärt.

József Gert-Farkąs

Fotos: Keystone (5), AP (7), UP (1), FEP (4) 


\section{Februar 1956, Radio Kossuth, Budapest}

\subsection{Uhr}

Der XX Kongreß der Kommunistischen Partel der Sowjetunion, dem die ganze Welt 12 . Tage lang mit gespaninter Aufméksamkeif verfolgt hat, ist zu Ende gegangen, und er geht in "die Geschichte der Sowjetunion 'sowie der gescmten" Menschheit als ein Ereignis von auBerordentlicher Bedeutung. ein $\because$.

\section{Februar 1956, Radio Kossuth \\ 20.00 Uhr}

Nachrichten: " . . . der Kongreß lehrt uns, daß sich in der jetzi-" gén internationalen Situation für viele Lánder die Möglichkeit ergibt, den Sozialismus unter Anwendung der parlamentarischen institutionen aufzubquen . ."

\section{April 1956, Radio Kossuth}

\subsection{Uhr}

Kommentar: "Morgen wird unser Lañd zum 12. Male den 1. Mal in Freiheit teiern : . Der XX Partelkongre $B$ der KPSU hat in der ganzen Welt eine derart frische und reine Atmosphöre geschaffen, 'dạ die Herzen höher schlagen: Viel Bedrückung schwand dahin, und die Merschen sind von nevem Vertraven ertullt.

Noch nie war so Klar; daß die Gestaltung des Schicksals des arbeitenden Volkes in seinen eigenen Händen liegt . . . Wir felern auch, weil seit dem XX. Kongre 3 vieles leichter geworden ist. Wir kennen die Fehler, welche unsern Fortschritt genemmt haben, die fehlerhaften "und falschen Methoden, welche verhindert haben, daß unser volk die große, ge schichtliche Sache, den Aufbau des" Sozialismus, einheitilich und von Herzen unterstutzte 


\section{Junl 1956; Radlo Kossuth}

\subsection{Uhr}

"Eltern, Erzieher, Kinder! In unserer heutigen Sendung befassen wir uns mit dem Unterrichtsplan der Allgemeinen Şhiule. Sie hören den Vortrag des stellvertretenden Kultusministers, Gyula Kiss:

Itn. September beginnt der Unterricht in den ersten vier Klássen, der Allgemeinen Schule nach dem neven Untërrichtspilan. Diese Tatsache ist von größter Bedeutung, nichit nur für die Allgemeine Schule, sondern für unser gesamtes Erziehurigswesen, denn damit beginnen wir die Erziehung und den Unterricht der heranwachsenden Generation auf einer newen Gründlage, die fester ist als alles Bisherige, und wir peginnen damit die Einführunǵ der neven Unterrichtspläne' . . .

Für die Allgemeine Schule, welche eine der größten 'Errüngenschaften der ungarischen Volksbildung seit der Befreiung darstellt, wurden 19.46 und 1950 Unter.richtspläne ausgear.bejtet. Diese Unterrichtspläne haben die Anforderungen nicht erfült ... Der Unterrichtsplan sowie die Schulbücher von 1950" wurden zu, schneil, im Verlaufe nur weniger Monate, ausi gearbeitet : :

In vieler Hinsicht wurden die Schïler vor unerfïlbare Aufgaben gestellt. Nach wie vor aber war nicht genügend Zeit zur Vervollkommnung der Fähigkeiten im Lesen, Schreiben, Rechtschreibung, Aufsatzschreiben und Mathematik $\therefore$ Def Grund dafür bestand unter anderem: darin, daß in den Elementarklassen -der Allgemeinen Schule Diskussión al Hauptfach eingesetzt war, in deren Rahmen die Kinder sich die grundlegenden Kenntnisse der Gesellschaft und der Natur ăneignen soltten.: Aber wozu hätte es denn quch sonst führen sollen, wenn beispielsweise als Diskussionsthemen für die erste Klasse solche Einheiten vorgeschrieben waren: Die große sozialistische Oktoberrevolution'. In diesem Rahmen sollte man mit den sechsjährigen Abc-Schützen über die Stürzung der Macht der Kapitalisten und.Großgrundbesitzer sprechen, weiche das arbeitende 'Volk ausgenutzt hatten, abér auch davon, wie weit sich die Werktätigen der ganzen Welt auf die Sowjetunion stutzen können. - In der zweiten Klasse gab es, folgende Themen: Arbeitskraft Okonomiel:- Die 
planmäßige Hebung des Lebensstandards'. - In der'dritten Klasse: ,Planwirtschaft" - Die Planeten'.

$\therefore$ Auch der als Hilfsmittel zum Unterrichtsplan an die Lehrer ausgegebene , Methodologische 'Wegweiser' enthielt ebenfalls richts Kónkretes ... In inm fandèn die Lehrèr lediglich solches: ,Bringen wir die Schuler zur Erkenntnis der"gewaltigen Kráftanstrengungen des Frledenslagers und weisen auf seine wirtschaftliche Kraft und militärische Uberlegenheit hin! oder: Beim Sternkundeunterricht weisen wir darauf hin, wie die klerikale Reaktion die Astronomen verfolgte, und stellen dem gegenüber, daß in der Sowjetunion und den.Volksdemokratien Pärtei und Staat den Wisserischaftiern jegliche Hilfe geben'...

\section{Juni 1956, Radio Kossuth}

\subsection{Uhr'}

Nachrichten: Resolution des Zentralkomitees der Ungariscien Arbeiterpartei:

"....Ermutigt von der Geduld der Partei und der Kommunisten, haben die parteifeindlichen Eleménte einen immer heftigeren Ángriff gegen die Politik sowie die Funrung der Partei unseres volksdemokratischen Systems geführt. Eines der Zen-

- tren dieser Angriffe ist der Petöfi-Kreis des DISZ (Einheitsverband der Jugend). Anfangs zeigten die Diskussionsabende dieses Kreises eine gesunde Tendenz. Doch benützten in letzter Zeit manche Elemente, welche sich der Politik unserer Partèl entgegenstellen, diese Abende in immer stärkërem Maße zur Verbreitung ihrer parteifeindlichen Anschauungen ... Verschiedene Redner des letzten Diskussionsabends des PetöfiKreises, Déry und Tardos, gingen bereits so weit', daß sie die Führerrolle der Partei sowie der Arbeiterklasse bestritten und bürgerlich-konterrevolutionäré Ansichten verkünd̈eten ... Indem sie mit der außerordentlichen Volkstümlichkeit des XX. Kongresses und der Leninschen ldeen rechneten, traten diese Diskussionsredner so auf als stunden sie auf dem Boden des XX. Kongresses und des Marxismus-leninismus, um auch dadurch inre partei- und volksdemokratiefeindlichen Anschauungen zu verbergen ..."

:... Diese gegen die Partel und Volksdemokratie gerichteten 
Manifestationen werden in der Hauptsache von elner bestimmten Gruppe organisiert, welche sich umilmre Nagy geformt hat..."

\section{Jüll 1956, Radio Kossuth}

\subsection{Uhr}

Presseschau: "Aus dem BeschluB des Zentralkòmitees dês DISZ geht'hervor, daß jeder Versuch verurteilt wird, der darauf hinżielt, den Petöfi-Kreis, diese wichtige-Plattfórm des. Jijgendverbandes, für Angriffe gegen dièPartei, zur Leugnung unserer volksdemokratischen Errungenschaft sowie zum Prägen konterrevolutionärer Ansichten zu mißbrauchen. ilm Sinne der Parteirevolution soli jedes Diskussionstorum âfrecht erhalten und weiter entwickelt werden; welches für die richtige Anwendung des Marxismus-Leninismus und gegen den Dogmatismus kömpft, und die Probleme ehrlich und im

$x$ Geiste unserer Parteipolitik behandelt. Es ist selbstverständlich, daß im Verlaufe von Diskussionen auch unrichtige Ansichten geäußert werden, diese aber müssen auf jdeologischer Grundalage und mit Hilfe uberzeugender Argumente bekämp werden... Im Petöfi-Kreis aber dürfen keine partei- uñd volksfeindlichen Anschau ungen mehr vorgetragen "werden.".

\section{August 1956, Radio Kossuth}

\subsection{Uhr}

„.... Dér Verfasser des Artikels ... sucht eine Antwort auf die Frage, weshalb èn Teil jener selbständig arbeitendeñ Bavern, die sich"im Frühjahr entschlossen hatten; zum Ende dès Wirt"schaftsjahres in die Kollektive einzutreten, jetzt trotzdem vón Ihrem EntschluB zurücktreten

\section{August 1956, Radio Kossuth 10.00 Uhr}

"Liebe Hörer, es spricht jetżt Antal Apró, Mitglied des Polit; büros der Ungarischen Arbeiterpartei, Präsident des Landesrates der Patriotischen Volkstront und Vizepräsident des Mini"sterrates.".

Ungarische Werktätige! 'Arbeiterl. Bauernl intellektuelle! Ungarische Patriotenl Heute, am 20. August, feiern wir den sie, 
benten Geburtstag des höchsten Gesetzes unserer Volksrepublik, der Verfassung des werktätigen Volkes. ."

in den vergangenen Jahren haben wir die Vorschriften unserer Verfassung nicht immer eingehalten. Mitunter haben wir unsere allerhöchsten Gesetze verletżt ..."

\section{August 1956, Radio Kossuth 7.00 Uhr}

"Wir verlesen jetzt den Leitartikel der heutigén Ausgábe von DAS FREIE VOLK (Szabad Nép') : Helfen. wir unserer Jugehd": Die Aktivität unserer Jugend nimmt zu, aúch 'die Arbeit des - DISZ bessert sich. Wie es die Resolution des Zentralkomitees vom 'ं8. bis 21 Juli feststellt: In letzter'zeit ist der Verband der werktätigen Jugend organisatorisch stärker geworden, und auch seine erzieherische Arbeit hat sich" etwas gebes. isert..."

Aber wir müssen viel mehr als bisher an der Lösung der poli- tischen Probleme unserer Jugend mitarbeiten. Auch der DISZ selbst muB viel entschióssener auftreten. Alle Tatsachen beweisen, daß die Anziehungskraft und der Eintluß des DISZ in y dem Maße wachsen, wie er mit der schablonentiaften Nach-

- ahmung der Porteimethoden bricht, und seine Arbeit den wirklichen Wünschen und Interessen der Jugendlictien entsprechend änderi:.."

$\because$. In letzter Zeit hát sich das Interesse der Jugend für Politik und Diskussionen erheblich gesteigert, ihr. Hang zum Kritisierén wächst, ihre gesunde Ungeduld, mit der sie den Fortschritt fordert, resultiert.gleichzeitig in einer, Zunahme des vertrauens und der Arbeitsiust. . ."

\section{August 1956, Radio Kossiuth}

\subsection{Uhr}

Kommentar: "Áls Kettenreaktion der gesunden Kritik können wir die erfreuliche Tatsache nennen, daß in diesen Tagen die Kritik und die oft leidenschaftliche MeinungsäuBèrung in immer . breiteren Kreisen heimisch wird. Man kann es nur begrüßen, daß neben dem Wiederaufleben der parlamentarischen Interpellation nun auch die gewählten Vertreter unserer anderen Organe, beispielsweise der Rätemitglieder, von in inem inter- 
pellatlonsrecht Gebrauch zu machen beginnen. Obglelch es sich hierbel nicht um eine neve Errungenschaft handelt, denn: das Rätegesetz ermöglichte auch bisher die intẹpellation; ist es doch wert, dieser neuen Tendenz Beachtung zu schenken. Tatsächlich bestand dleses Recht, doch wurde nicht, oder nur formell, ohne praktische Bedeutung davon Gebrauch gemacht. Einer der Gründe dafür war, daß an verschiedenen Stellen die. Rätemitglieder weder den Statuten der Verfassung noch den Forderungen der Bevölkerung Rechnung trugen...."

\section{Radlo Szuibfoldünk (Sender Helmatland)}

\subsection{Uhr}

: : 'Llebe Hörerl Dle neven Unterrichtsbucher für die' Allgemelnen. Schulen sind erschienen.... Am 1. September werden 204,700 Kinder in die erste Klasse eingeschrieben. Das ist ein großer felertag. Die Vorbereitungen dauern bereits seit Wochen. - Vor 50 Jahren stand in meinem Lesebuch ein Vers: ,Wir hungern, unsere Brust ist zerschossen, unser ist alle Not, aber wir sind frell' Darunter stand: Alexander Petöfi. Dieser Vers hatte eine unbeschreibliche, unfaßbare Wirkung auf mich. Ich habe in mir immer wieder vorgesagt, der Rhythmus hat mich mitgerissen und war wie Trommelklang in meinen Ohren. Ich konnte mich davon nicht freimachen ... Und dann kamen. die anderen Verse. Dle Erwachsenen lachten über mich; aber Ichilas und las Petöfi, halblaut vor mich hinbuchstabierend. Ein gutes Buch ist ein Weggenosse fürs ganze Leben. Wir stehen vor dem brennenden Problem, wie wir aus der Schatzkammer des ungarischen Volkes so viel Werte, so viel Schönheit wie nur möglich unseren Kindern geben können."."

\subsection{Uhr, Radlo Kossuth}

Revue des Tages: „Heute vormittag begann die fünfte Sitzurig des"Zentralkomitees des DISZ: Zuerst verlas Genosse. József: Szakaly, erster Sekretär des Zentrákomiteés, den.Bericht des Exekutivkómitees. Er sagte, daB seit der Juli-Resolution der -Partel auch in den Jugendorganisationen ein starker Aufschwung fühlbar ist. Selt die Jugendlichen mit ihren Führern offen und ehrilch auch über helkle Probleme sprechen können, sind großartige Initiativen zustande gekommen ...

... In der Diskussion, die der. Verlesung des Berichtés folgte, 
hielten die sprecher Im allgemelnen das Bild als zu beruhlgend; welches der Bericht" des Sekretớrs von der Jugend des Lándes gab...."

\section{August 1956, Ragdio Kóssuth, \\ 10.00 Uhr}

Presseschaú: "Unter der Uberschrift ,Noch einmal - die:Zulassung an die Ùniversität', schreibt DIE'VOLKSSTIMME (Népszava) Üter anderem:

In den Rektoraten, unáim Ministerium läutet das Telefon ununterbrochien. Am anderen Ende der Leitung mélóen sich meist Eltern oder Studenten, die sich beschweren oder wissen 'wollen, ob noch Hoffnung auf Zulassung besteht. Seitdem die Intellektuellen-Resolution. sich der Zulassungsangelegenheitder; Jugendlichen intellektueller Abstammung angenommen hat, beschweren sich vor allem Eltern aus Angestelltenkreisen, daß ihre Kinder trotz ausgezeichnet bestandener Prüfung zum studium nicht zugelassen "worden sind." Es ist allgemein bekannt, schreibtidas Blatt, daß es in den letzten. Jahren immer. schwieriger wird, die Abiturienten in entspiechender AnstelIung unterzubingen. Einestells deshalb, weil wegengewisser Vorurteile es viele rioch als Deklassieruig betrachten, mit dem Maturazeugnis sich an die Werkbank zu stellen . Wie der Hauptabteilúngsleiter des . Unterrichtsministeriums mitteilt, gibtes auchjetzt noch erbitterte Kämp fe um die Zulassung zu der Universität. Als schwierigstes, Problëm erscheint wohl das Ausmerzen der Protektion. Selbst hochgestellte Staats- und Pắrtelfunktionäre machen vò derartigen Methoden Gebrauch ....".

\section{September 1956, Radio Kossuth}

\subsection{Uhr}

Revue des Tages: "Heute abend veranstaltete der ,PetöfiKreîs' seineñ Diskussionsabend. Gabor Táncos eröffnetè die Diskussion. . Obwohl gewisse westliche Presseorgane einen Teil der Diskussionen als Stimmen gegen die Vollksdemokratie interpretiert haben, steht fest, daß die ungarische Jugend, die den Petöti-Kreis des Disz begeistert unterstûtżt hat, treu dem Vaterlánd ụnd der Săche des Sóziclismus ist 


\subsection{Uhr}

Ausschnitte aus dem Diskussionsabend" der" ungarischen Schriftsteller:

Zoltán Zelk: "... Ich habe meine Prinzipien und meinen reinen Glauben aufgegeben, als auch ich noch geglaubt habe, daß man ohne Menschlichkeit und Moralität, unter Aușschluß̈ gewisser nationaler Gefühle, der wahren Sache dienen kann ..." Gyula Háy: ". . Wir wișsen, daß è sehr schwer ist, Wahres zu. schreiben! Es gehört dazu Tapferkeit, Talent, Wissen und manches andere ... Ubrigens tat es uns weh, daß der Artikel im FREIEN-VOLK ('SzabadNép') das Wichtigste, unseren konsequenten Kampf für die Wahrheit, nicht erwähnt hat ... Als wir schlechtere ,Wohrheitsschreiber' und schlechtere Schriftsteller wurden, wibrden wir auch schlechtere Marxisten und Kommunisten...."

\section{September 1956, Radio Kossuth 20.00 Uhr}

Revue des Tages: „...Wissenschaftler, Schrift'stelter, Arzte, Ingenieure und Professoren, die bisher geschwiegen haben oder gezwungen waren zu schweigen, sind dabei, șich und, ihre stimme wiederzufinden. Sie kritisieren, sie machen vorschläge, sie diskutieren. Sie kämpfen für das Recht der Kritik, der Initiative und der Diskussion ... Sie nagen nicht an ihren eigenen Próblemen und den an ihnen begangènen Fehlern, sondern betrachten alle großen Fragen der Heimat als inre Herzensangelegenheit ..."

\section{September 1956, Sender Szülöföldunk (Heimatland)}

\subsection{Uhr}

Iván Boldizsár kommentiert die Schriftstellerversammlung:

".: . Der Beruf des Schriftstellers in Ungarn beruht auf johrhundertealter Tradition. Schriftsteller zu isein bedeutet nicht nur ;...zu schaffen ...., sondern auch Verantwortung fiur des Schicksal der Heimat zu fühlen .... Géza Képes forderte: Ganze Freiheit, ganze Verantwortung!"

\section{September 1956, Radio Kossuth}

\subsection{Uhr.}

Presseschau: ,.... Jede Zeitung bringt wenigstens einen Artikel uber Probleme der Literatur, iuber literarische Frageñ und uber 
die lëtzte Vérsammiung der Schriftsteller... In DAS FREIE VOLK (szabad Nép) schreibt Genose Nógradi eingen langenArtikel. Er teilt mit, daß er nicht mit allen. Reden derlkommus nistischen Schriftsteller elnverstandèn ist, $\because$ : In diesem.Zusammenhang erwähnt er die Redeñ von Tamas. Acżel und Gyula Háy: : ".

\section{September 1956, Radlo Kossuth \\ 20.00 Uhr}

Abendnachíchten: Zoltán Kodaly sagt ubèr Béla Bartók an dessen elftem Todestag: „.... Der Name Bartók ist ein symbolgroßer Gedanken. Die vornehmste Aufgabe ist das Suchen nach absoluter Wahrheit in den Wissenschaften und in der Kunst..."

\section{-. 22.00 Uh?}

Iniandnachrichten: Dér Vorstand des Schriftstellerverbandes. hat in seiner heutigen Sitzung den 'Entschluß gefaßt; die Redaktionskomltees der Zeitschritten DER STERN "("Cs!llag") ind LITERARIȘCHE ZEITUNNG ("Irodalmi Ujsá") Ihrer Aimter zu entheben:

\section{Sonntag, 14. Oktober 1956, Sender Szulbtöldunk ("Heimatiand")}

\section{9:30 Unir}

Der Brief Imie Nagys an das Zentralkomiltee:" . . Ich erkläre mich mit dem leninistischen Prinzip des demokratischen Zentra"lismus einverstanden. Ich erachte deșalb die Parteibeschlüsse verbindlich tür mich, guch wenn ich: mit ihnen - tellwelse oder im ganzen - nlcht einverstanden bin.

\section{Montag, 15. Oktober 1956, Radlo Kossuth \\ 10.00 Uhr}

Presseschau: Warum" flieht die Jugend nach" dem Westen? Wegen unserer schlechten erzieherischén Arbeit und Propaganda. Wir haben die Jugend jahrelang irregetuhrt. Das Ausland ist immer interessant. Es wäre angebracht', jedem unga$\therefore$ rischen unbescholteñen Ștaatsbürger über 18 Jahre ohnè die Notwendigkeit besonderer Begründung einen Reisepab fur weśtliche Länder aúszústellen. 


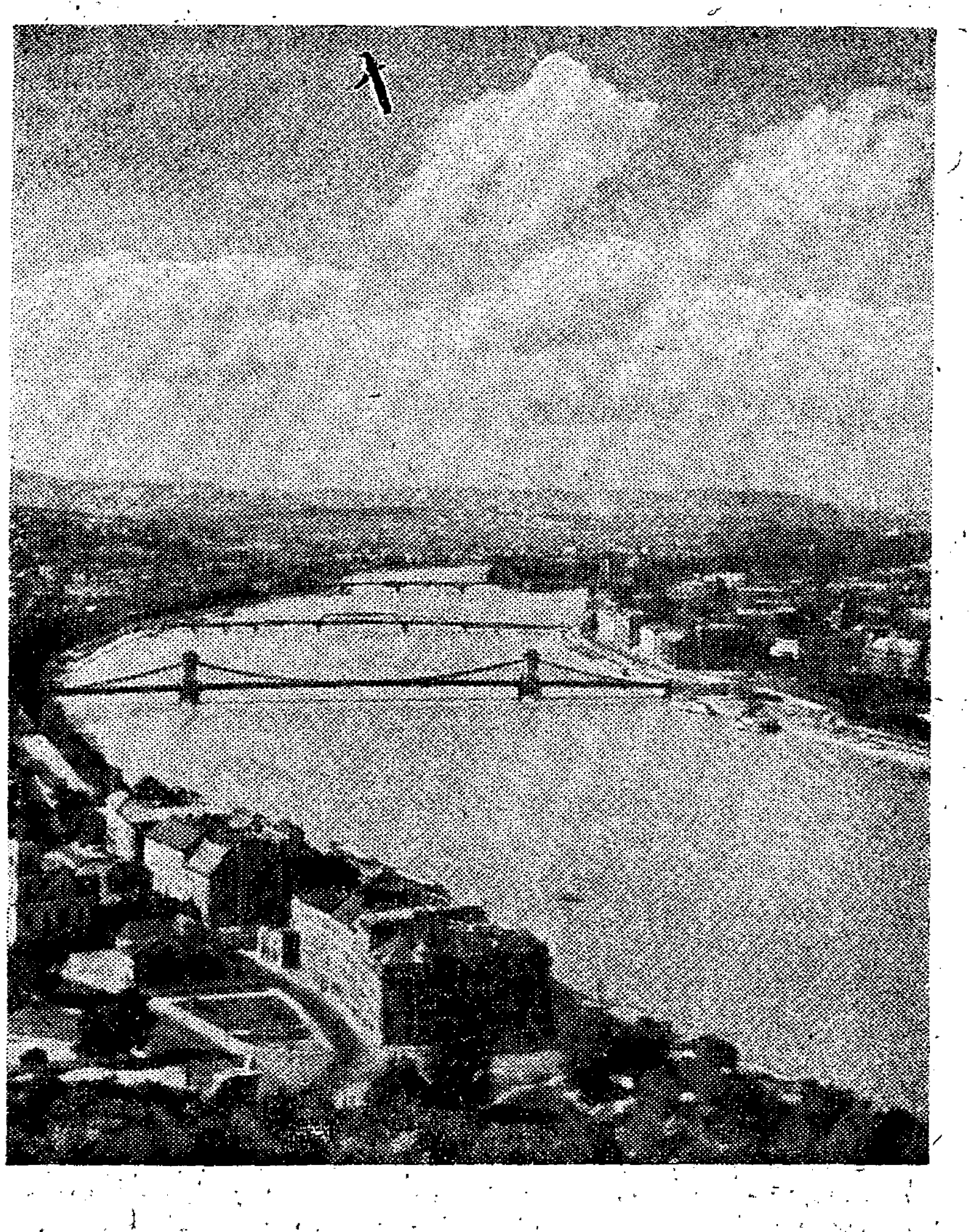

Búdapest, im vordergrund die Keftenbrucke, rechts das Parlament (init Kuppét) 
Komnentar: Mátyás Rákosi danf in Zukund imolitischen leben Ungans keine Rolle mehr spièlen . . . Der Fall lme Nagy war der unter Verletzung von Recht und Gesetz erfolgte Ausschluß̧ eineš.Parteimitgliedes, das anderer Meinung war.

\section{Dienstag, 16. Oktobar 1956, Radio szulötöldünk ( „Heimatiand")}

\section{$19: 30$ Uhr}

Der Brief imre Nagys an die Partei und der Beschluß des Zentralkomitees, Imre Nágy wieder in die Partel. qufzunehmen, waren die Sensation des 14. Oktober. Nach Imre: Nagy soltte die politische Freiteit die Garantie des Fortschritts werden. Die Gesetzlichkeit soll.hergestelit, die:Unschuldigen entlassen werden, die indüstrielie und landwirtschaftiche Politik revit $\because$ diert und eigene Wege zur Errichtung des Sozialismus gesucht werden "Die Tatsache, daß Imre Nagys Brief veroffentlictit.

$\because$ wurde, ist ein Zeichen dér politischen Entaltung.

\section{Donnerstag, 18, Oktober 1956; Radio Kossith} $20.00 \mathrm{Uhi}^{2}$

a Kommentar: Die Teilnehmer des ersten Studentemparlanen$\because$ tes möchten inr schicksal selber lénken, die fremdspraché lernen, die sie wollen, reisen, die zeitgenössischen Schrift: steller des Westens kenrienlernen und auf Grund ihrer Talente und nicht, auf Grund ihrer Herkunft zum Universitätsstudium zugelossen werden.

\section{Sonntag, 21: Oktober 1956, Radio Kossuth}

8:00 Uhr

Nachrichten aus deminand: Dié ákddemischejugena von

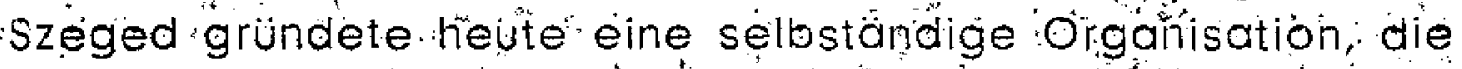
MEFESZ, die der Partei auf dem Wege zur Erichtung des Sozialismus folgen wird Der DISZ warraủberstande; die Inter essen der akádèmischen Jugend zu vertreten ....

\subsection{Uhr}

Presseschau: Wohin geht die akademische Jugend? - fragt 5 die FREIE JUGEND. Wir sind einverstanden mit den 15 Punkten $\therefore$ der Szegediner Studenten, aber nicht mit der Drohung, in den Straßen zu demonstwieren. Wir müssen eine Waffe wähten, die picht nach rückwärts losgenen kann. 


\subsection{Uhr}

Aus dem Inland: Imre Nagy ist wieder Universitätsprofessór.

\section{Montag, 22. Oktober 1956, Radio Kossuth}

\subsection{0 Ühr}

Presseschau: Lenins Lehre ist heute lebendiger als whend der letzten Jahrzehnte, als der Stalin-Kult sie in den Schatten gestellt hatte ..."

\subsection{Uhr}

Abendschau: $\therefore$ Erst die hinreißende Bewegung der jugend "und der demökratischen öffentlichen Meinung hat die polni-. schen Ereignisse möglich gemacht $\therefore$ Die Redaktion der TRIBUNA -LUDU hat den BeschluB des Zentralkomitees mit den, Worten begrüßt: jetz̧t können wir endlich arbeiteri!

\subsection{Uhr}

Nachrichten aus dem Inland: Die Versammiung der Technischen Hochschule beschloß, ohne provokative und demagogische Töne aus dem DISZ auszuscheiden und einen "verband der Akademischen Jugeñd" zu gründen.

\section{Dienstag, .23. Oktober 1956, Radio Kossuth}

\subsection{Uhr}

Liebe Hörer, wir verlesen jetzt den Leitartikel der heutigen Ausgabè von DAS FREIE VOLK ("Szabad Nép"):

"An unseren Universitäten und Hochschulen folgt eine Ver: sammlung der anderen. Versammlungen in Budapest, Zusammenkünfte in Szeged, Konferenzen in Pécs, - Diskússionen der Hörer der technischen Fakultät, der Philosophen; Juristen und bildenden Künstler. Die Atmosphäre dieser Jugendversammlungen ist hei $B$. und stürmisch, sie ährielt eher eirem anschwellenden Strom als einem Bach, der in seinem künstlichen Bett : datiinplötschert. Diese feurige' Bégeisterung ist gut; geben wir zu, daßß uns die vergangenen jahre vor solchen. Massenmanifestationen entwöhnt haben! Der Sektarianismus, die stalinistischen Fehler:thaben "in uns die. Empfänglichkeit für eine mit Elementärgewait hervorbrechende Massenstimmurig und Massenbewegung abgestumpit, und auch heute noch gibt es leute, die sich nicht frél machen können vòn dem Gewohnten und dorum mit Sorge una Mißtraven auf die versammlungen unserer Jugènd blicken. 
Unsere Poirtel und thre Zeitung, BAS FREIE VOLK, stellt sich neben die Jugend! Sie billigt diese Versammlungen und wünscht der Jugend viel Erfolg zu ihren weisen, produktiven Beratungen!

Wir wissen wohl, daß die Jugend, und innerhalb ihr unsere studentische Jugend, jahrelang von der Möglichkeit, ausgeschlossen war, in Angelegenheiten des Landes sowie eigehen Sactien ihre Stimme zu erheben. Wir wissen wohi, daß der. DISZ (Einheitsverband der Jugend) an organisatorischen Fehlern leidet und, auBer Phrasen, unserer Jugend nur wenig wahren sozialistisctien Inhalt bieten konnte. In diesen Jahren haben" sich viel. Bitterkeit, viel unterdrückte sehnsucht und Emotionen in- unserer Jugend aufgespeichert. Viele berech"tigite Unżufriedenheit war" in unseren Jugendlichen begraben, wen kann'es, also wundernehmen, daß nach mehr ais 5.Jahren all dies "mit elementarer Gewalt hervorbicht! Wer jetzt von unserér Jugend fordern will, daß sie threr. Meinung mit vorisicht und kühlem. Maßhalten Ausdruck verleihe, vergißt die konkreten, geschichtlichen Eritwickiungen und Gegeberiheiteri dieser Jugeridbewegung; und vergiBt.vor. allem, die seelische Beschaffenheit: der ungarischen Jugend in Betracht zu zielien!

$\therefore$ Die Atmosphäre dieser Zusammenkuhfte erinhert uns alle an die Universitätsversammiungen, Hochschulberatungen in der Jahren nach 1945, und heute ist bereits jedem klar, daß jene Jahre gesunde; gute Früchte getragen haben. Doch gibt es auch Unterschiede zwischen den versammlungen von da. mals und heute. Einer dieser Unterschiede muB bèsonders betont werden. An den versammlungen nach der Befreiung hat lediglich erst ein kleiner Bruchteil der Studenten als jünger des sozialismus und der marxistischen Weltanschauning teifgenómmen Unmittelbar nach der.Bétreiung gab es an den Universitäten noch bedeutende Kräfte der bürgerlichen Reaktion, und in den Universitätsstatistiken waren die Arbeiter-" und Bauernjungen nur mit wenigen Prozenten vertreten: Inzwischen hat sich das Bild grundlegendigeändert. An diesen * Versammlungen, nimmt die überwältigende Mehrheit der unj- versitätshörer teil, und zwar als Jünger des Sozialismus, bei diesen versammlungen sind die Hörer ous der. Arbeiter- und 
Baveinklasse nlcht etwa nur mit 5 oder 10 Prozent vertreten, sondern mit einem weitaus höheren Prozentsatz, und sile nehmen teil an dem Aufbau des sozialistischen. Ungarn in einer Wèise, die dem Leben ihrer Väter würdig ist I

Aber es gibt noch andere Gründe, weswegen wir diese Versammlungen so warm begrủßen. Die Vertreter der sektarianil. stischen Politik haben nur in Worten verkündet, daß die politisierende Jugend für den sozialismus lebenswichtig sei. In Wirklichkeit jedoch haben sie alles unternommén, um unșere studentische Jugend vom selbständigen Denkeñ abzuhalten und ihnèn die Mọglichkeit zu freier Meinungsäuß̧erung zu verbauen ...

Wir "unterstützen jedoch die studentischen. Vérsammilungen nicht nur in politischen Fragen des Landes, sondern quch die Entşchlössenheit, mit der unsere Universitäts- und Họchschuljugend, die' Reform des akademischen Unterrichts fordert. . Eiñ Tell der studentischen Forderungen betrift die Verbesserung der sozialen Lage. Diese Forderungen sind zumeist be: rechtigt, von der Mensaverpflegung bis zur schaffung der Mögiichkeit von Ausiandsreisen, vom Problem der überfüllten Studentenheime bis zur Hebung der Anfangsgehälter. Die wirtschaftliche Lage des Landes in Betracht ziehend, muB aber gesági werden, daß wir nicht alle Forderungen sofort "Oder innerhalb einer kurzen Zeitspanne erfüllen können. "Wir sind nicht einverstanden mit den Androhungen vón Demonstrationen, für den Fall, daß die eine oder andere Forderung wirtschiaftlicher Natur nicht eirfullt würdel $\therefore$..

Vergeß̣t nle, daß unser Kampf die Förderung des sozialistischen Demokratismus zum Ziele hat!.. Seid durchdrungen vón der Verantwortung, daB der konsequente Kampf igegen den Sektarianismus zugleich ein Kampl gegen die Gefahr der Restaurierung der.Boürgeoisie ist ... So begrüßen wir denn dile guten Bestrebungen unserer Universitäts- und Hochschul-. studenten..."

\subsection{Uhr}

Möntag nachmittag versammelten sich rund 400 Hörër der philosòphischen Fakultät der Loránd-Eötvöș-Universität und gründeten den Kreis "15. März”. . .. Die Versammlung kạ izu dem einstimmigen Beschluß, $A Q B$ die akádemische Jugend mit 
der Arbelter- und Bavernjugend Hand in Hand schrelten müsse. Es wurde deshalb beschlossen, dringend Delegatio-

nen in verschiedene Budapester Betriebe zu schicken, damit man sich uber die konkreten. Formen der Zusammenarbeit mit der Arbeiterjugend verständige...., $\because$,

10.00 Uhir

Nachrichten: Die Delegation des Zentralkomitees der Ungarischen Arbeitérpartei kehrte heute früh von Jugosilawien nach Budapest zurück...

\subsection{Uhr}

Presseschau: Die Zeitungen schreiben ausführlich über dle Versammlungen der studentischen Jugend am Montag - und dereń Beschlüsse. Die FRElE JUGEND ("siabad Ifjuság") berichtet, daß das Zentralkomitee des DIsZ heute nachmittág eine Sitzung hält, und dả ferner für den 27 . Oktober dás Parlamént der studentischen Jugend einberufen wurde, um die - Vorschlage bezüglich der. Neuorganisation des Jugendverbandes zu debattieren. AuBer deñ Versammlungeri der Budapester Studenten behandelt das Blatt die studentischen Zusammenküntte in Miskolc, Debreceñ, Sopron; Gödóllö und Eger. Mit den meisten Forderungen der Jugendichen sind wir einverstanden und unterstützen sie, erklärt das Blatt. Ge"wisse Punkte der Beschlüsse, wie z. B. Fragen der Struktur des ungarischen Wirtschaftslebens oder Probleme des AuBentiandels, können lediglich als Diskussionsbasis dienen. Die Fragen, welche wir auf Grund der Prinzipien kommunistischer Pressefreiheit veröffentlichen, wird das Zentralkomitee unserer Partei sowie unser Parlament zweifellos mit unserem ganzen Volk erörtern, - schreibt die FREIE JUGEND:

10.15 Uhr

... Unter der Regierung von Mátyás Rákosl wurde die fehler-. - hafte stalinistische Theorie von der ununterbrochenen Verschärfung des:Klassenkampfes nicht nur angewandt, sondern übertrieben. Man kann sich nicht vorstellen, daß diê Ára des rhythmischen Applaudierens, der Gedankenlosigkeit und Gesetzlosigkeit je wiederkehren könnte, wie ès unter Rákosi der Fáll war, - schreibt der Arbeiter István. Tót in der FREIEN JUGEND. 


\subsection{Uhr}

Al, mehreren Budapester Universitciten, wo gesterm Großversammlungen abgehalten wurden, beschlosseri die Studenten, heute nachmittag einen Schweigemarsch zur Gesunatschait der Polnischen Volksrepublik zu veranstalten. Ziel der Denoinstration ist, daß'die Jugend ihre tiefe Sympatinie und Solidari-

"tät mit den Ereignissen.in Polen bekunde... . : :

\subsection{Uhr}

"(Die mittägliche Zigeunermusik wird unterbrochen): "Liepe Hörer, wir verlesen eine Mitteilung des Imnenministeriums:

". "Im lnteresse der Aufrechterhaltung der offentichen Ordnung verbietet das Innenministerium bis auf weiterès jegliche. An-

$\therefore$ - sammlung von Personen in den Straßen sowie Demonstrationen! gez. Lásżló Piros, Innenminister."

\section{4:23 Uhr}

(Die Sendung "Musikalische. Zeitung für die Jugend" wird unterbrochen): Liebe Hörer, das innenministerjum teilt nit:

* "Innenminister László Piros hat das verbot zur Ánsammiung von Personen in den Straßen sowie für Demonstrationen aufgehoben."

\section{(Kurze Pause, dann Gong)}

"Heute abend um 20.00. Uhr hält Genosse Ernö Gerö, Erster - Sẹketär des Zentralkomitees der Ungarischen Arbeiterpartei, eine Rundfunkansprache." .

(Gong)

(Diese Mittellung wird um 14.34. Uhr, 14.40 Uhr, 14.45 Uhr, 14.50 Uhr und 15.00 Uhr wiederhoit.).

\subsection{Uhr}

Heute um 14.00 Uhr hat das Zentralkomitee des DISZ seine 6. Sitzunğ begonnen. Das'Zentralkomitee ist mit der solidaritätserklärung der Budapester Jugend für die Polnisché Volksrepublik einverstanden. Es hat beschlossen, an der.Demonstration teilzunehmen und hat deshalb seine Sitzung auf eine spätere Stunde vertagt. Das Zentralkomitee ersucht die Studenten sowie an der Demonstration teilnehrnenden Jugendlichen, alle eventuellen Provokationsversuche zu verhinderm $\therefore$.

\subsection{Uhr}

Das Budapester Komitee des DISZ teilt mit, daB - im Gegensatz zur früheren Vereinbarung, die Beratung des Schüler- 
parlamentes der Oberschulèn am Donnerstag, dem, 25. Oktoiber, umi 15:00 Uhr fortgesetzt wird, und zwar an der Volkswirtschaftlichen Üniversität Karl Marx.

\subsection{Uhr:}

Am 17. Oktober fand im Petöfi-Kreis eine Diskussion statt, aus der wir itirien jetzt Ausschinitte bringen:

Der nächste Śprecher ist Zoltán Vas:

\#...Um es klar auszudrucken: damit wir in der Landwirtschaft einer entscheidenden Schritt vorwärts tun, ist es notwendig, daß wir Frieden, schließen mit der Bavernschaft und Frieden schließen mit der Lándwirtschaftl". (Starker Applaus) ... "Ich glaube, Genossen, es .liegt ebenfalls "auf der politischen Hauptlinie, daß wir nach der Bitterkeit so vieler Jahre, in denen wir so oft' die Intellektuellen béleidigt, mißhandelt und unterschätzt haben, nun die zeit gekommen ist, offen zu reden und mehr Raum zu fordern für die int llektuellen urid ihrem Schaffen größere Möglichkeiten zu eröffnen!" (Heftiger Applaus)

Es spricht nun Zoltán Tildy: "Liebe Freundel Ich weiß, daß heute lelder das am wenigsten volkstümliche Thema in Ungarn die Kolchosen sind. Einfache ungarische Leute haben mich besucht: tch habe sie gefragt: wie lebt ihr zu Hause? Da antwortete mir der eine; - es ist aus mit uns, denn wir sind ein sozialistisches Dorf geworden!" $\because . .$.

\subsection{Uhr, Sender Sziblötöldunk}

Senolung "Unser Helmatland" (fur Exllungarn im westlichen Ausiand):

"Nationalfarbene Flaggen, Jugendliche mit rot-weib-grünen Kokardén, das Kossuth-Lied, die Mórsélllaise und Internatio"nale, - so können wir in șchlagworten den heutigen Tag charakterisierén." Am Nachmittag fand in der Hauptstadi eine: gev

Schon seit Febrúar dieses jahres, man könnte aber auch sagen seit Juni 1953, forderri die Arbeiter, Bavern; Beămten, Studenten, Schriftsteller und Journalisten immer drängender, da ${ }^{\prime}$ das wirtschaftliche und politische Leben unseres Londes auf die richtigen sozialistisction. Fundamente gestelk worde. 


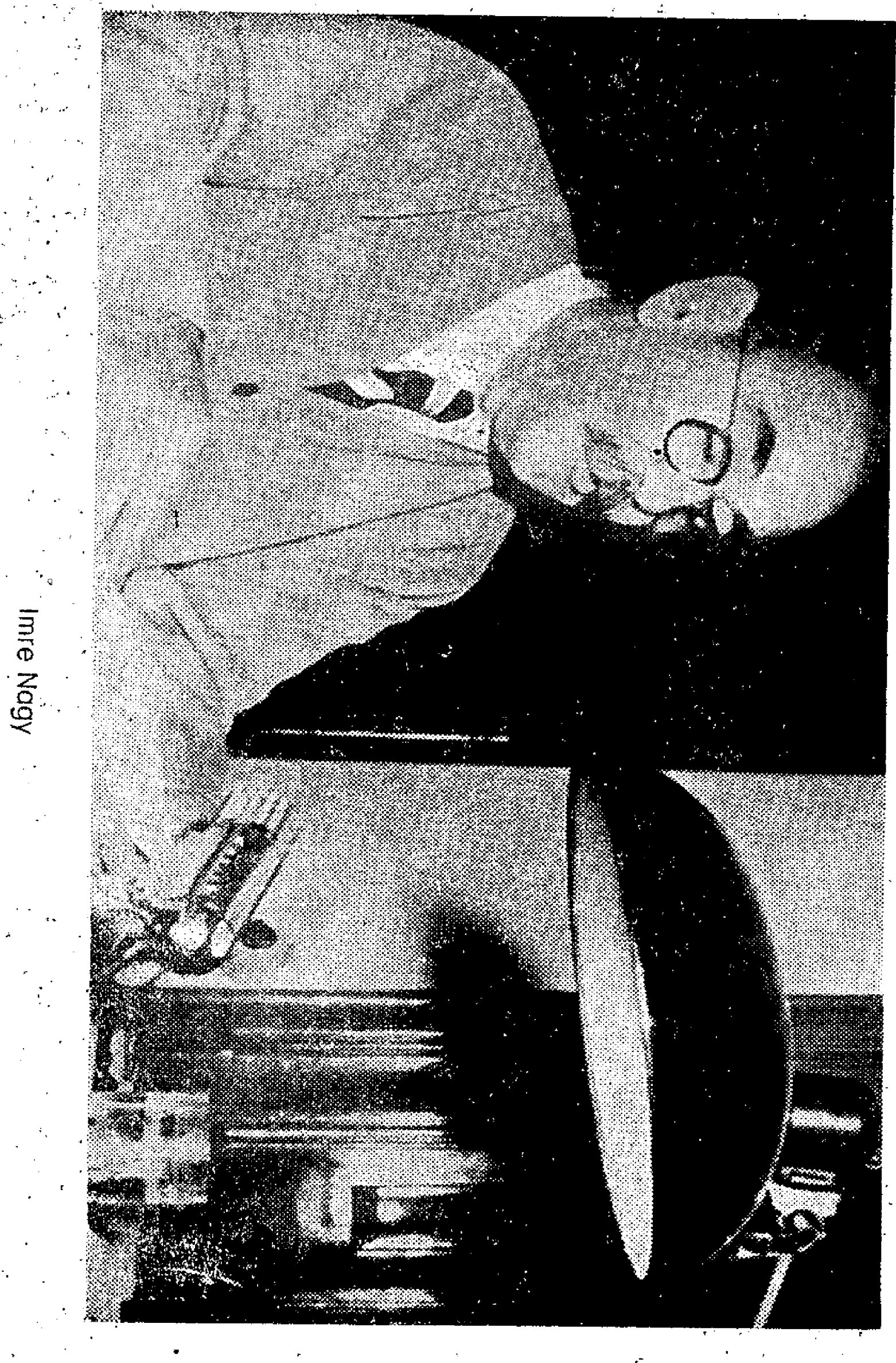


In den vergangenen Tagen fand an unseren Universitäten eine versammlung nach der anderen statt, und unsere Jugend nahm Entschlüsse an, wie die zur Umbildung der Regierung unter der Führung von Imre Nagy. Sie forderten, daß die Freundschaft zwischen Ungarn und der Sowjetunion sowie Jugoslawien sowohl wirtschaftlich als auch politisch auf die Basis völliger Ebenburtigkeit gestellt werde; onne Einmischung in die inneren Angelegenheiten des anderen. .

Die Studenten forderten ferner die Zulassung des Kossuth: Wappens AuBerdem sollen der 15. März sowie der 6. Oktober wiederzu Felertagen erklärt werden.

Es gab Universitäten; an denen die Forderungen in zwolf Punkten zusammengefaßt wurden, anderswo waren es zwanzig Punkte, aber überall wurden die. Beschlüsse mit klarem Kopf und heißem Herzen gefaßt . . Heute mittag hat zwar der Innenminister -jegliches Demonstrieren 'verboten, 'aber das Politische Komitee der Ungarischen Arbeiterpartei hat diesen BeschluB abgeändert.! Studierende der medizinischen, technischen, philosophischen, juristischen," volkswirtschaftlichen und anderen Fakultäten : sind hinausgezogen, an ihrer Spitze die Professaren und die Führer der Hochschulorganisationen der. Urigàrischen Arbeiterpartei.

Erst waren.es nur Taüsende, doch dann schlossen sich die Jungarbeiter an, Fußgänger, Soldaten, Greise, Gymnasiasten und Straßenbahnschaffner, und der mächtige Menschenstrom zahite: bald Zehntausende. Die Straßen hallten wider von, Sprechchören: "Wir.'Wollen eine neve Führung, "wir vertraven Imrenagy!"...

$\therefore$ Die Trikoloren flatterten, die Fenster, der Häuser wurden aufgerissen um den neuen, freieren Wind einzulassen; der durch Budapests Straßen blies. $\ldots$

\subsection{Uhr, Radio Kossuth}

Liebe Hörer, wir ubbertragen jetzt die Rundfunkrede des Ge. hossen Ernö Gerö, dem Ersten sekretär des Zentralkomités der Ungarischeri Arbeiterpartei.

"Liebe Genossen, liebe Freúnde, arbeitendes Volk von Ungarnt. . Wir aber wollen natürlich eine sozialistische Demokratie und: keine bijgentiche Demokratiel ... Heute ist es das 
Hauptbestreben der feinde unserés volkes, zu versuchen, diel Macht der Arbéiterklasse ins Wanken zu biringen, die Eimheit zwischen Bavern und Arbeitern zu lockern, in lunserem Lande die führende Rolle der Arbeiterklasse zu untergraben und ihren Glauben an die Partel zu erșchütern sié versuchen unsere enge Freundschaft mit den andern Ländern, welche ebenfalls den Sozialismus bauen, zu stören, vor allem aber "die Freundschaft zwischen unserem Lande und der sozialistischen Sowjetunion ... Sie verleumden die Sowjetunion sie behaupten, daß wir mit der Sowjetunion kénen ebenbürtigen Handel treiben, dả angeblich unser Verhăltnis zup sowjetunion nicht auf Ebenbürtigkeit beruhe, und da unsere Selbständigkeit nicht gègen die "Imperialisten, sondern gegen die Sowjétunion verteidigt werden müsse. All dos ist erlogen, all doss ist nichts als Feindpropaganda, die kein Quentchen Wahrheit enthält!. . Deshalb verurteilen wir diejenigen, die innerhalb der Kreise unserer Jugend versuchen, das Gift des Chauvinismus zu streven und weiche die demokratische Freilieit, die unser staat dem arbeitenden. Volk garantiert, zu pemonstrationen mit nationalistischem Charakter ausgenutzt haben. Aber auch diese Demonstration vermag nicht den Entschiuß unserer Parteileitung zu erschüttern, nämlich weiterzuschireiten auf dem Wege des sozialistischen demokratischen Fortschritts $\ldots$ Es ist unsere felsenfeste Uberzeugung, daß in. Ger Landwirtschaft der sozialistische Weg der einzig richtige ist Vor allem müssen wir unsere Kolchosen schützenl Wir mussen unsere sozialistische Landwirtschaft uniterstützen:

Unsere Parteiorganisationen sollen überall diszipliniert und einheitlich gegen alle Versuche dér Ordnungslockerung, der nationalistischen Brunnenvergiftung und Provokation auftretten:

Genóssen, Arbeiterí. Es muß offen gesaght werden, dẩ és jetzt darum geht, ob wir eine sozialistische Demokratie wollen oder elne burgerllche Demokratie? . Es ist der unerschüterllche Entschlüß uriserer Partei, auf dem Wégè "dèr sozialistischen Demokratie unbeirrbar vorwärtszuschreiten, dër vollen Entfaltung entgegen!"

20.15 Uhr

Das Polítische Komitee des ZK dér Ungarischen Arbeiterpartel 
: hat auf seiner heutigen; Sitzung beschlossen, das zentral20.23 Uhr

(Das Tanzmusikprogramm wird unterbrochen, dann folgt das (Pausenzeichen.) Liebe Hörer, wir machen sie daraut aufmerksam, daß uhsere vorhin verlesene Mittellung auf einem Irrtum - béruhte. Das. Zentralkonitee wird nicht an 31 . Oktober, sondern bereits in den nöchsten Tagen zu einer "Sitzung einberufen.

$\therefore$ (Nach langer Pause wird das Tanzmusikprogramm fortgesetzt.)

\subsection{Uhr}

Heute nachmittag ist die Jugend von Budapest vor das. Pár- lamentsgebaude gezogeri. Am Abend sprach Genosse imre Nagy zu den Jugendichen. Im Augenblick verhandeit Genosse Imre Nagy mit Jugenddelegationen und mit mehreren Abgeoraneten des Parlaments.

\subsection{Unr}

- Liebe Hörer, wir bringen jetzt Auslandsndehrichten:

(Nach einer Pause von 30 Sekunden)

Liébé Hörer, unisere Nachrichtensendung ist beendet, sie hören Kammermusik.

\subsection{Uhr}

Liebe Hörer, eine wichtige Mitteilung: "Das Politische Komitee - der Ungarischien Arbeiterpartei hat das Zentralkomitee für sofort einberufen, um die Lage zu analysieren und die Aufgaben zu besprechen."

(Pas Musikprogramm wird alle zehn Minuten unterbrochen ưnd die Mittëilung wiederholt.).

\section{Mittwoch, 24. Oktober 1956, 4.30 Uhr}

Guten Morgen, liebe Hörer: Wir beginnen unsere musikalische Morgensendung. (Statt Musik Pause, dann): Liebe Hörer, wir verlesen eine Mitteilung: "Faschistische, konterrevolutionäre Elemente haben einen bewafneten. Angriff lgegen unsere öffentlichen Geböude geführt und unsere Ordnungstruppen angegriften. Im Interesse der Wiederherstellung der Ordnung sind bis auf weiteres jegliche Ansammlungen und Aufmärsche verboten. Polizel und Militar sind angewiesen, allen Personen gegenuber, die diesem Befehl zuwiderhandeln, "die-volle 
Strenge des Gesetzes anzuwenden. gez.: Der Ministerrat der Ungarischen Volksirepublik."

\subsection{Uhr}

"Achtungl Achturigl Achtung! Achtung! Das Inneriministerium der Ungarischen Volksrepublik fordert die Bévölkerung von Budapest auf, bls.9 Uhr in den Häusern zu bleiben, weil die Sầuberungsaktion gegen die plündernden konterievolutionären Gruppen noch im Gange ist."

(Die üblichen Sendungen von Radio Budapjest fallen quś. Statt dessen verzerrte Schallplattenmusik, von óbigen Durchisagen unterbrochen. Ab 7.45 Uhr sendet Budapest ischwächer.)

\subsection{Uhr}

Wir. verlesen eine Mitteilung:

Auf seiner Sitzung am 24. Oktober 1956 ihat das ZK der Ungarischen Arbeiterpartei als neve Mitglieder gewählt:... György Lukács, .. I Imre Nagy... Mitgliedér des neugéwähl-. ter Politbüros sind: . . . Ernö Gerö, . . Jạnós Kádár. .... Imre Nagy .. Das ZK hat den Geriossen Ernọ Gerö, als Erstên Sekretär bestätigt... Das ZK empfiehit dem Prösidiưm der Volksrepublik die Einennung des Genossen limre Nagy zum Ministèrprásidenten..."

\subsection{Uhir}

"Achtungl Achturigl Eine Mittellung des Ministerrates der Ungarischen Volksrepublik: (folgt fünfzeilige Aufzöhlung von vèrschiedenen, strafbaren Handlungen', wie: Anstiftung zur. Rébellión, verbotener Waffenbesitz und Besitz von Sprengstoff): solche Verbrechen werden mit dem Tode bestraft. Die Standgerichtsvercranung tritt sofort in Kraft. Gez.: Imre NAGY, Ministerpräsident."

\subsection{0 Ụhr :-}

„Achtungl-Achtungl Der niederträchtige bewaffnete Angrlff kónterrevolutionärer Banden im Laufe der Nacht hat elne auBerordentlich ernste Lage geschaffen. Die Banditen sind in Fabriken, öffentliche Gebäude eingedrungen, sie haben zahlreiche Zivilpersonen, Armeeangehörige und Staatsslcherheitskämplér ermordet. Dle Regierungsorgane... haben auf Grund des Warschaver Vertrages die in Ungarn stationierten sowjetischen Einheiten um Hilfe ersucht ..." 


\subsection{Uhr}

"Achtung! Achtung! Das Innenminlsterium ordnet bls 14 Uhr die Ausgangssperre anl"

\section{0:41 Uhr}

"Im Interesse der Wiederherstellung vor Ordnung und Ruhe fordern wir die Bevölkerúng. von Budapest auf, hre Rundfünkemplänger ln die geöffneten Fenster zu. stellen, denn wir verlesen wichtige Mittellungen. In Kürze übertragen wir eine Ansprache des Genossen Imre NAGY, des Präsidenten des Ministerrates."

\subsection{Uhr}

¿Achtungl Achtungl Vor der Kettenbrücke hat eine Gruppe von 120 Konterrevolutionären und irregeleiteten. Jugendichen die. weiBe Fahne gehiBt und sich ergeben...".

\subsection{Uhr}

"Hier spricht Imre NAGY; als Ministerpräsident der Ungarischen Volkśrepublik. Bevölkerung von Budápestl Alle, die bis 14 Uhr den Kampf einstellen und die Waffen niederlegen, entgehen dem Standgericht! Zugleich versichere ich, daß wir mit allen unserén Kräften die konsequente, Demokratislerung un-. seres Landes auf allen Gebieten des Partel- unid Staats-' wesens sowie der Politik und Wirtschaft verwirklichen werden, auf der Basis des Regierungsprográmms vom juni 1953, so wie lch es seinerzelt dem Parlament vorgetragen habe: Folgt unserem Aufruf, stellt den Kampf,ein . . Dieverste, und oberste Aufgabe ist jetzt die dringende Konsolidierung der Läge. Nachher werden wir uns in allenifragen verständigen, denn die Regierung und die Mehrheit des ungarischen Volkes wollen jo das gleiche... Arbeiterl Schützt die. Fabriken und Maschinen . . I Stellt euch hinter die. Régierung I Vertraut darouf, daß wir aus den Fehlern ợ Vergangenheit gelernt haben und den rechten Weg zum Aufblühen uniseres Landes finden werden." (Ungarische Nationaihymné)

\section{'12.19 Uhr'}

in Auftrag der Bewaffneten in der Umgebung des BarossPlatzes hat eine Delegation von fünf "Pálamentariern den Genossen Imre NAGY aufgesucht. Falls ihnen volle Amnestie zugésichert würde, seien sie zurr Waffenniederlegung bereit. Ihr Angebot wurde angeriommen!" 


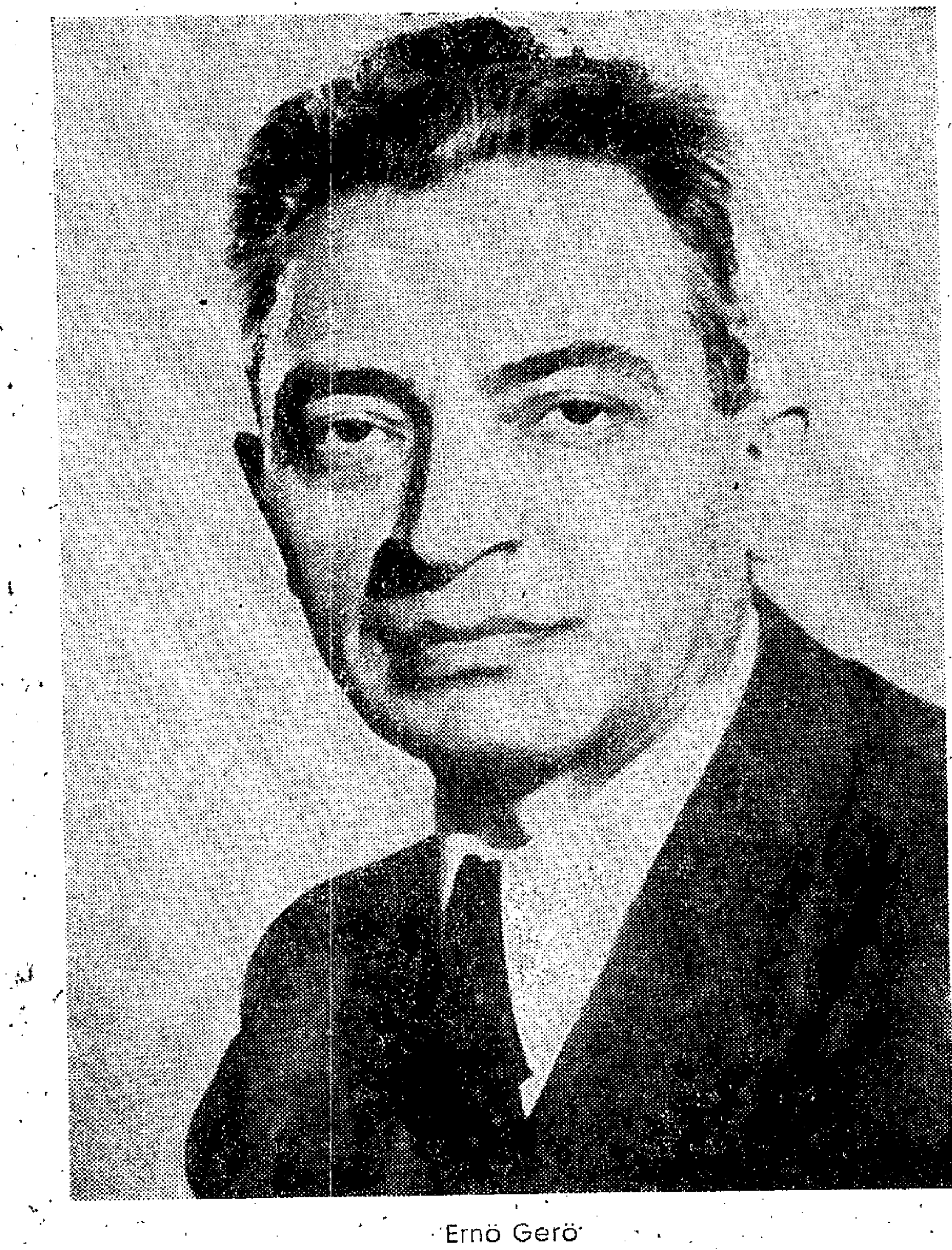




\subsection{Uhr}

"Wirfordern die Bevölkeríng Budapests aút, hire Radiogerate in die Fenster zu steplen

"Achtungl Achtungl Die im Metallröhrenwerk. Ráday-Straße kämpfende Konterrevolutionare Gruppe hat die weiße Fahne gehibt und sich ergeben."

"Die konterrevolutionären Banden haben ijunge Leute in die Provinzstadte und Fabriken geschickt, damit ssie dort Unruhe verbreiten und zur Arbeitsniederlegung aúfwiegeln. In Tatabánya und Salgótarjạn wứden diese Abgeordneten der Volksfeinde von den Bargleuten vertriebeh und den Behorden übergebèn:"

\subsection{Uhr}

"Ecke Szondi-Straße/Vörösmarthy-Straßè hatiteine größerebewaffiete Gruppe die Waffen niedergelegtl'

\subsection{Uhi}

"Wer bis 14 Uhr die Waten niederlegt; einhegriffen Ange hörige des Militärs, kommt nicht vor's ștándgericht!"

\subsection{6 Úhr}

"Hier unsere Antwort auf die Bitte mehrerer Hörer, ihnen die Ärivesenbeit sowie Aufgaben der nach Budapest gekommenen sowjetischen Armee-Einheiten zu erklären: Diese so"wjetischen Truppen sind auf Grund des Warschauer Vertrages,

In Ungarn stationiert. Am Dienstag háaben die Feinde unseres Volkes den Aufmarsch unserer Universitätsjugend in eine órganisierte konterrevolutionäre: Provókation verwandelt, und durch bewaffnete Angriffe die Ordnung dés Landes sowie -das Leben der Bevölkerung gefährdèt vo verantwortungsbewuBtsein durchdrungen sowie um Ordnüh und șitherheit wiederherzustellen, hat die ungarische Regierung die sowjetischén Truppén gebeten, die mörderischẹn Angriffe der kontèrrevolutionären Banden stoppen zu helfen Dié sowjetischen soldaten riskleren ihr Leben zum schutze der friedlichen. Bevölkerung Budapests . A Arbejter von Budapest "Empfangt" unsere Freunde und Verbundete mit Liebe!"

\subsection{Uhir}

"Ungarische Jugend, Budapester Kommilitonen!"

".. Der wichtigste Punkt uníserer Forderungen ist erfült. Stellen wir uns hinter den Genossen Imre NAGYI , gez.: ME- 


\subsection{2 uhr}

Fesz, Komitee der Budapester Techntschen Unlversität sowle der Universitöt für Architektur und Verkehr."

Nennung von fümf Fabriken, in deren "die Ordnung wiedèrhergèstelt ist, wie das Parteikomitée meldet".

\subsection{Uhr}

"Achtungl Achtungl in wenigen Minuten ist es 14 Uhir. Wer bis 14 Uhr die Waften niederlegt, kommt nicht vors Stand-

\subsection{Uhr} geri"cht"

$\therefore$ "Es ist 14 Uhr. Wer die Waften niederlegt, kommt nicht vors.

Standgericht! Wir bitten unsere Hörer, ihre Radiogeräte in die Fenster zu stellen. Sagt den Konterrevolutionären und irregeführten, sie sollen sofort die Waffen. niederlegen, dann kommen sie nicht vors Standgericht!"

\subsection{Uhr}

"Achtung! Eine wichtige Meldung! Die in das Studiogebäude eingedrungenen bewaffneten Angreifer, - nachdem sie von ordnungsschaffenden militärischen Einheiten eingéschlossen worden sind, - haben sich auf den Aufruf. des Genossen Imre NAGY hin bereit erklärt, sich zu ergeben, nachdem man ihnen freien Abzug zugesichert hat. Die Gruppe der Angreifer legt soeben die "Waffen nieder."

$14.09 \mathrm{Uhr}$

"Achtung! Achtungl Eine außerordentlich wichtige Nachricht Die Regierung hat das Ultimatum von 14 Uhr bis 18 Uhr verlängert! Wer bis 18 Uhr die Waffen niederlegt, kommt nicht vors Standgericht....!"

\subsection{Uhr}

¿Budapester Hausfrauen und Mütterl Die gutgläubige Demonstration unserer Universitätsjugend wollen konterrevolutionäre Elemente zur Verwirklichung ihrer verbrecherischen Ziele nutzen!... Frauen! Laßt Eure Männer nicht ins Verderben rennenl... Mütterl Laßt eure liebevoll behüteten und großgezogenen Jungen nicht auf die Straße und vor die todbringenden Gewehre!... Frauen, laßt euch und eure Fomilien nicht irreführen! Vertraut der Ungarischen Arbeiterpartei und dem Arbeiterstaat!... gez.: Das Budapester Frauénkomitee der.Patriotischen Volkstront." 
"Die Lebensmittelversorgung Budapests ist infolge der konterrevolutionären Versuche sehr.erschwert. Eine Milion sich nach Frieden und Ruhe sehnender Menschen, darunter Unzählige Säuglinge, Kinder, Frauen und Greise, warten auf regelmäßige Versorgung mit Brot, Mehl und Milch ... Im interesse unserer Kinder arbeite jeder an der alsbaldigen Wiederherstellung der Orönung."

\subsection{Uhr'.}

"Die Regierung hat das Ultimatum zur Kapitulation bis 18 Uhr verlängert. Wer diese letzte Chance nicht wahrnimmt; entgent seinem verdienten Schicksal nicht. Die Mitgliedér dér noch verstreut kämptendén Gruppen mögen deshalb Vernunft annehmen und mit dem sinnlosen Blutvergießen' aufhören! Bis spätestens 18 Uhr sollen sie als Zeichen der be'dingungslosen Kapitulation die weiße Fahne hissen! "

\subsection{Uhr}

"Arbeiter, Arbeiterjugend, Intellektvelle, Angestellte! Das Präsidium des Ratés der Gewerkschaften spricht zu Euch! .. .

- Unsere Volksmacht wurde zur Notwehr gezwuingen, und die dramatișche Entwickiung 'der Ereignisse hat sich übersturzt. In den, Straßen Budapests ist Blut geflossen, aber die Regierung ist Herr der Lage -geblieben. In diesen schicksalsentscheidenden Stunden mobilisiert das Präsidium der Gewerkschaftsverbände die zwei Millionen organisierten Arbeiter des Landes, und ruft sie auf zum Kampt für die Errurigenschiften unserer volksdemokratie..."

\subsection{Uhr}

Aufruf der Leitung des Petöfi-Kreises:

"Junge Intellektuelle, ungärische Studenten! Wir wenden uns an Euch in den tragischen Stunden unserer Nation, in einer ernsten. Situation! .. Als die Demonstrationen stattanden, wurde eine richtige Entscheidung getroffen; durch welche Ge-

$\therefore$ nosse Imre NAGY an die Spitze der Regierung gestellt wor-

$\because$ den ist ... Deshaib fordern wir euch auf, |ungarische Jugend-

$\because$ liche. $\therefore$ die ihr an den kämpten teilnehmt, macht von der Amneștie Gebrauch!"

\subsection{0 Ühr}

in diesen Minuten sind über dem Kossuth-Platz und ijber 
Budapest fünt Düsenflugzeuge erschienen, welche unseren " Kampf gegen die Konterrevolutionöre unterstützen!"

\subsection{Uhr:}

Achtungl Von Csepel wird gemeldet:

"Wir, die in der Csepeler Autofabrik befindlichen-Arbèiter, melden, daß uns die Wahrung von Ordnung und Disziplin gelungen ist. . Glelchzeitig fordern auch wir die irrégeführten Arbelter auf, legt die Waffen nieder, kämp̈t nicht gegen die Arbeitermacht."

\subsection{0 Ühr}

\subsection{Uhr}

"lm Komitat Zala herrscht völlige Ruhe."

"Achtungl Achtung! Wir verlesen eine wichtige Mittellung des. Irnenministers! - Für das Gebiet von Budapest wird von heute 18 uhr bis morgen 6 Uhr Ausgangssperre angeorodnet. Diese Maßnahme wurde im Interesse dér friedlictien Bevölkerung getroffen, da die Stadt von einzelnen "isolierten kon-. terrevolutionären Gruppen noch nicht gesäubert ist. Während der sperrstunde müssen die Tore aller Mietshouser verschlossen bleibeni gez.: László PIROS, Innenminister."

\subsection{Uhr}

"Nóch"15 Minütent - Wer unseren Árbeiterstaat mit der Waffe angegriffén hat, der hat rioch 15 Minuten, um von der Großzügigkeit unserer R'egierung Gebrauch zú mächen und dem Standgericht, der Todesstrafe, zu entgehen. . l

\subsection{Uhr}

"Jungarbeiter! Studenten! Schüler! Jugend von Büdapest I Denkt an ever Vaterland, an èure Ehre, eure Eltern, Ge. schwister und Freundel Laßt euch nicht" länger irrejuhrenl gez.: Das Zentralkomitee der DISZz:"

\subsection{Uhr}

Sie hörèn jetzt den Aufruf des ehemáligen Präsidenten der Republik, Árpäd SZAKASITS:

\#. Um so besturzender ist, daß es den volksfeindlichen und; verantwortungslosen Elementen, die der Welt von früher nachweirien, geláng, die anfänglich friedliche und begelsterte Demonstration der Jugend"sowie des carbeiteriden volkes für ihre. gegen den Sozialismus gerichteter" Ziele "zu miB'brauchen..." 
Wir verlesen jetzt den Aufruf von Universitötsprofessor Tibor ERDEI-GRUZ:

"Studenten der Univèrsitäten, meine jungen Freunide! Gestern wolltet ihr euren politischen deen durch einen friedlichen Auf-

o. marsch Nachdruck verschaffen, aber obgleich ihr von Gutwitligkeit gejeitet wart, hatte die Demonstration doch schwerwiegende Fólgen, weil konterrevolutionäre Kräfte eure Demonstration ausnutzten und ëinen blutigen, aufrührerischen versuch begannen: Partel- und Staatsleitung wissen, daß die ungarische studentenschaft sich ihrer Verantwortung bewußt 'ist" und keinen Aufruhr wollte. Hieraus -könnt ihr auch sehén, wie wir: die Rolle der Jugend in den gestrigen Ereignissen werten... Meine jungen Freunde! Beweist, daß ihr verantwortungsvolle Faktoren sein wollt beim Baven von Ungarns Zukunft, daß ihr euch uber eure Pflichten gegenüber Familie und Vaterland in klaren seid. Vertráut der Pärtei und der Imre-NAGY:Regierung : . . !"

\subsection{Uhr}

"Nur noch wenige Minuten! - Wer unseren Arbeiterstaat mit der Waffe angegriffen hat; der hat nur noch ein par. Miruten, um von der Großzügigkeit unserer Regierung Gebrauch zu machen ....!"

\section{7:55 Uhi}

"Unterden Gefangenen. - Man führt mich in den geräumigen Kellervorraum eines vierștöckigen Hauses. Im Kreise; der Wand entlang, stehen junge und altere Leute. Naherder Tür ein Tisch, beladen mit Indizien. Haufen von Patronen, Watfen, vervielfältigte und gedruckte Flugblätter. Darunter, als Beispiel, solche folgenden Inhaits: Wir haben watfen, laßt uns kömpfen!..."

"Schauen wir unis die Gefangenen an. Man führt den ersten vor, einén 19jährigen Jungen... Er begegnete einer großen bewaffneten. Gruppe, "schloß sich ihr an und ging mit" zum Funkhaus. Bei der Gefangennahme hatte er 80 bis $100 \mathrm{Ge}$ wehrpatronen bei sich sowie verschiedene im Funkhaus geraubte Dinge $\therefore$ Seinem Vater, Elek BOCSA senior, teilen wir mite obwohi sein Sphn sich der volksmacht gegenüber stratbar gemacht hat, kormmt ej nicht vors Standgericht, weil er 
nlêht mit der Waffe in der Hand gefangen wurde. - Warum -hat er das gemacht? ,Ich verlor den Kopf, als die Meñge lọs'zog', sagt er. ;Haben dir die Staatssicherheitsdienstler was 'getan, seit du hier bist?', tragte ich. ,Als ich gefangen wurde, gab mir ein Soldat zwei Ohrfeigen, aber seither hat man mich niçht angerührt.'

- Der zweite ist ein 24jähriger. Er wurde heute morgen in der Szikra-Druckerei gefangen genommen. Die Nacht über. hatte er mit etwa zwei Dutzend Bewaffneter die Druckerei besetzt: gehalten... Auch er kommt nicht vors Standgericht, denn er yerließ die Druckereil mit erhobenen Hönden.

Für den dritten jédoch gilt dies nicht... Er hât schon einmal zwei Jahrè wegen politischer Verbrechen gesessen, d'och ist nicht das der Grund, weshalb er vors Standgericht kommt, sondern'weil er im Kampf gefangengenommen wurde.

Die Regierungsverordnung bezüglich der sonderbehandiung erlischi heute um 18 Uhr, in diesen Minuten gilt sie noch. Es ist der letzte Augenblick für die noch kömptenden Gruppén; siè zu nutzen!",

\subsection{Uhr.}

"Die Bevölkerung der. Stadt Szeged hat Ruhé bewatirt, wie wir soeben erfahren... Auch die bis Dienstag mitiernacht stattgefundene." Studentendemonstration. "verlief" diszipli-

\section{8:10 Uhr} niert"...

"Liebe Hörer, wir setzen unser Prögramm fort." (Muṣlk)

\subsection{Uhr}

Au's verschiedenen Stadttellen wird gemeldet, daß die an - den bewaftneten, Aktionen beteiligten Jugendlichen ịre Waf-: fen in Parks, Nebenstraßen und Torbögen liegen lassen... Wir fordern die Zivilbevölkerung auf, gefundene waffen den: nächsten Ordnungsorganen zu Ubergeben."

\subsection{Uhr}

Mit inniger Liebe rufen wir euch zur Ordnurig, Rutie und. Friedfertigkeit im Namen jenes Christus, der tür én bèsseres Leben gekommen ist und den Frieden will... Gez.: Richard HORVATH, Präsident des Friedenskomitees Kátholischer Prie"ster...". 


\subsection{Uhr}

$\therefore$ Das Zentralkomitee des DISZ fordert alle Jugendichen auf, welche die Waffen noch nicht nledergelegt haben, dieses schändliche Blutvergleßen zu beenden, denn sle kämpien für eine verlorene Sache, nicht fur dle sache unseres Volkes und der Júgend, sondern gegen die Sachè des Volkes, der Nation und der jugerid... Heltt der" Partel und der vom Genossen

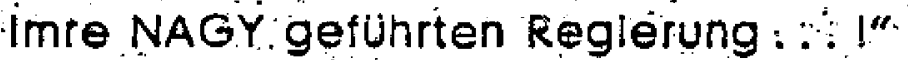

\subsection{Uhr}

-. "Die MEFESZOrganisation der Padagogischen Hochischule von Eger ... betrachtet die faschistischen Demonstrátionèn als eine gegen die Volksdemokratie gerichtete Aktion." " "

\subsection{Uhr}

"Béla TARJAN tellt selnem Sohn, dem 17jährigen Laszlo; TAR-' JAN, mit, seine Eltern tiätten erfahren, daB er an den bewaffneten Kämpten tellnimmt Sêine Mutter hat eineñ Nervenzusammenbruch eriltten. Ihr Zustand ist errist. Wenn er seine "Mutter lebend" wiedersehen will, soll er sofort năch Hause gehen."

\subsection{Uhr}

1) $\therefore$ Der Standpurikt der kdthollschen Kirche ist offen und klar. Wir veruftellen das Töten und Zerstören... I Gez.: Jozsef GROSZ, Erzblschof von Kalocsa, derzeitiger Präsident des Bischotskonzils.".

\subsection{Uhr.}

"Liebe Hörer, der Reporter des Urigarlschen Rundfunks führt "Sie'jetzt in den Tórbogen elines unserer offentlichen Gebäude. Soeben führen unsere Soldaten sleben Gefangene herein. Drej von ihnen wurden mit Maschinenpistolen In der Hand gefangen genommen, zwel hatten Pistolen; die anderen beiden waren nicht bewaffnet. Bei der Durchsuchung thrè Taschen kamen jedoch Patronen zum Vorschein : :

Der érste, der jungste, Ist 16 Jahre alt . . :

Auf den vierten bllcken die Soldaten mit agrimmigem .Zorn. Seine Achselstucke haben sie bereits heruntergerissen. Und siè reden inn so an: ,Der ehemalige Offizier soll hereinkommen"...".

\subsection{Uhr}

"Die Direktion der Budapester Oxygenfabrik sowie das Par- 


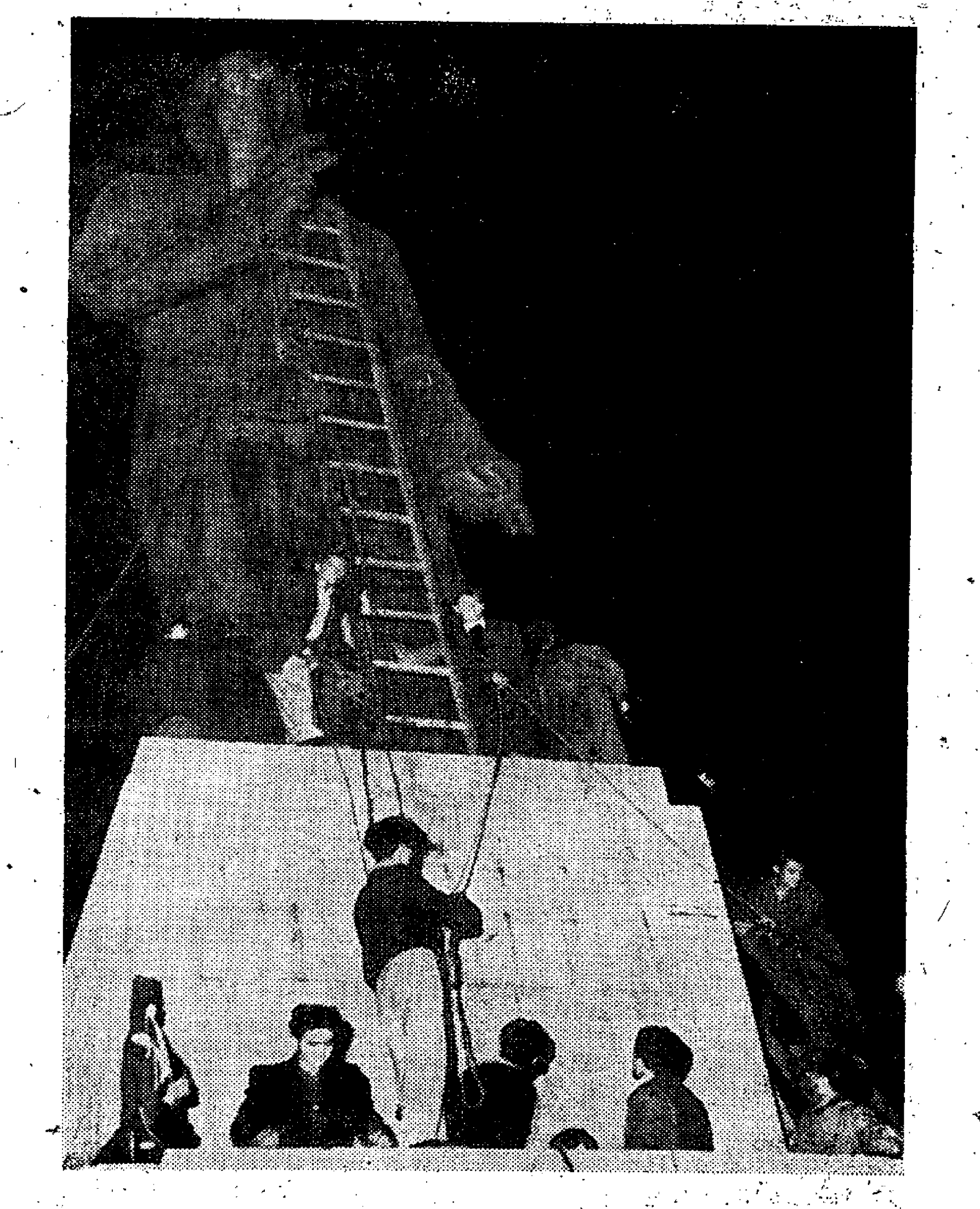

Die Stalinstatue wird gesturzt

$\bullet$ 
teikomitee fordert die Arbeiter auf, morgen frun unbedingt im Betrleb zu erscheinen, dámit dje Krankenhoúser und Betriebe mit oxygen versorgt werden kọnnên

\section{$19.55 \mathrm{Uhr}$}

"Liebe Kinder, seid nicht böse dạ heute abend unsere so beliebte Gute-Nacht-Sendurig ausföllt Ich bitte euch, hört auf eure Mutti. Legt euch rasch hin schlaft gut und traumt heute auch othe Mărchen schon Liebevolle Küsse von eurem György SZEPESI."

(SZEPESI ist nicht der Märchenonkel sondern bekanntester Sportreporter von Radio, Budapest Bä seit Djenstag nacht die Ublichen sprecher nicht Denst tur macht SZEPESI den Ansager..)

\subsection{Uhr:}

Bie Gegend um den Barossplatz, die Bela-Bartok Straßo sowie Umgèbung sind ruhig

\subsection{Uhr:}

Vor dem parteikomite é ebaude des XIII. Bezlrks und an der Karl-Robert-Kaserne tobt noch immer" schwerer "Kampf. Mit Maschinenpistolen, automatischen Waffen, Handgranaten und anderen Waffen ausgerustete reaktionäre Gruppen wollen das Parteigebaude und de Käserne besetzen. Unter dèr Fuhrung des Bezirksparteikomitees befinden sich die Arbeiter der umiliegenden Betriebe zusammen mit bedeutenden ipanzèreinheiten der Armee schion den zweiten Tag in heldenhaftem Kampf ...."

\subsection{Uhr}

"Wir, die Bewohner Jes Jeno-Landner-Studentenwohnheims der Technischen Univerșităt Budấpeșt, stehen einmütig hinter dem neuen Zentralkomitee und dem Ministerpräsidenten Genossen lmre NAGY vonuns hat keiner an den kámpien teilgenommen, an dem Blutvergießen, welches wir zutiefst verurtenten. Man wollte den Stagt sturzen der uns das Universitatsstudium ermöglicht hat wir bitten den Ministerrat und den Genossen Imre NAGY, soweit als möglich den irregefürten und aufgestachelten Studenten Gnadè zutell werden zu lassen, obwohl siẹ auf seiten der Konterrevolutionäre gekömṕft haben." 


\subsection{Uhr}

iWás geschah im Rundfunkgebäude? Bericht unseres Reporters György Kalmár... , Da brach die Menge schon das Tor des sendehauses ein. Die Wachen versuchten sie mit Feuerlöschgeräten zurückzuhalten... Als auch das nichts halt, waren sie gezwungen, Tränengasbómben anżuwendeñ. Die

7. Lage verschärftesich vor Minute zu Minute ... Die Wachen schossen in die Luft und versuchten die Angreifer mit Platzpatronen èinzuschüchtern. Sie versuchten alles, um das Rundfunkgebäude ohne Anwendung von. Waffen wieder zu säuberri. Kein einziger Mensch wurde durch sie ernsthaft verwundet. Aber aus der Menge fielen immer mehr Sctüsse. Erșt wurde ein Major des Staatssicherheitsdienstes, dann - in den ersten Stunden -6 Soldaten tödich getroffen. Selbst da eröffneten die Staatssicherheitswachen dás Fever noch inicht! Erst als vom Gutenbergplatz her 2 Lastkraftwágen mit bewaffneten Halbstarken eintrafen... und als schon viele der Wachen getötet oder verwundet waren, bekamen sie den Befehi, zurückzuschießen... Auch die Angestellten unseres Senders sorgten dáür, daß dẹr Mob sein Ziel-nicht èreichte. Die Provokateure sollten. den" Kosșuth-Sender nicht zum Schweigen bringen. Gewiß, liebe Hörer, wẹcht unser-Sendeprogramm von der Vorschau erheblich ab; aber Ungarns Radio, der Sender Kossuth, ist in Betrieb. Keiner konterrevolutionären Bande ist es gelungen, unsere Stimme zum Schweigen zu bringen . . ! !" .

\subsection{Uhr}

Wetterbericht des meteorologișchen Institutes: In unserem Lande herrschte heute trockenes, stellenweise nebliges wetter.

\subsection{Uhr}

Sie hören jetzt die Rede des Genosșen Janos Kádár; des Sëkretärs des Zentralkomitees.

"Arbeiter! Genossen! Die Demonstration der Universitäts. jugend, die anfangs vorwiegend akzeptierbare Fórderungen stellte, wuchs sich rasch zu einer Demonstration gegen unser volksdemokratisches System aus, und endete, in einem bewaffneten Angriff. Nur mit glühendem Zorn kann man uber diesen Angriff sprechien, den konterrevolutionaúre una reak- 
tionäre Elemente gegen die Háuptstaḍt unseres. Landes, unsere volksdemokratische ordnung und die Macht unserer Arbeiterklasse fuhrten... Um jedoch weiteres Blutvergießen zu verhindern, gaben und geben wir alt den Irregefithten, die sich treiwillig ergeben, Gelegenteit, ihr Leben ind: ihre Zukunft:zu retten und unter die anstc̈ndigen Menschen zurück-

\subsection{Uhr} zukehren. $\therefore "$

"Liebe Hörer, hiler der Lagebericht nach dem Stand von 20.00 Uhr: Die Partel "und unsere Reglerung sirid Herr der Lage."

\subsection{Uhr:}

$\therefore$ Die: Leitung des ungarischen Roten kreuzes bittet alle seine Aktivisten und Blutspender um sofortige Meldung ...

\subsection{Uhr}

Die Arbeiter der'schmelzwerke von Diósgyör, einer der größten Fabrikstädte unseres Landes, verrichten ihre Arbeit in diesen schicksalhaften Stunden mit größter Disziplin. In del Zeit vom bienstag zum Mittwoch háben: sie 300 Tonnen über dem Plan produziert . . Die Bäcker des Komitates Veszprem - haben sich verpflichtet, eine "größere Menge Brot über" dem ;Plan zu backen und dér Bevölkerung von Budapest zü schikkèn...

\subsection{Uhr}

Nächrichten auś dem Inlànd:

... Die Kaseme in der Kari-Robert-Stráße wurde von Provokateuren angegriffen... Wie uns die Kommandantur mitteilt, hat die ganze Belegschaft der Honvéd-Einheit gégen die Konter. revolutionäre gekämpft und sie zurückgeschlagen. Diẹ Soldaten haben beschlossen, auch im Falle einer Wiederholung des Angriffs ihren Mann zu stehen:

\subsection{Uhr}

Wir haben telephonisch mit Sándor-Peti, dem volkstümlichen Filmschauspléler, gesprochen, und auch er verurtelit die Provokation zutiefst ...

\section{3:30 Uhr.}

Die Budapester Sanitäter nehmen sich. der verwundeten :selbstverständlich ohne Unterschied von Freund und Feind an. Sämtliche Mitarbeiter werden hauptsächlich von dẹ Geiste der Menschilichkeit geleitet.... 


\subsection{Uhr}

Wir verlesen jetzt ẹine Erklärung des Akademikers Dr. István. Rusznyók: „... Eine organisierte Gruppe vérsuchte, die gesunôde Bewegung unserer Universitätsjugendi in einen mörde. rischen Vandalismus zu wandeln, der den Sturz der Volksmacht zum Ziele hatte... Eine große Hilfe in deroseitigung der Schäden wäre meiner Ansicht nach, wenn ùnsere Regierung. großzügigerweise einen Weg fände, um unsere irregeleiteten, aber gutwilligen Jugendlichen durch das Geseiz. weniger hárt zu treften, als die organisierten Provokateure es verdienen."

\subsection{8: Uhr.}

Die Hörerinnen des Pflege- und Heilgymnastischen Institutes in der Puschkinstraße teilen ihren Eltern mit; daß alle 150 von ihnen gesund sind und sich wohlfühlen:

\subsection{Uhr}

Liebe Hörer, um 20.00 Uhr meldeten wir, daß die Kä́mpfe vor dem Parteigebäude im XIII. Bezirk mit unverminderter Heftigkeit geführt würden. Diesen Mitteilungen lagen talsche Infor: mationen zugrunde. Weder damals noch jetzt fanden dort Kómple statt.

\section{oo,01 Uhr}

Seit dem Lagebericht von 20.00 Uhr hat sich die:Situation wel: terhin verbessert...

\section{oó.05 Uhr}

Unsere Nachrichten sind damit zu Ende. Wir beenden unser heutiges Programm. Die genaue Uhrzeit ist 0.05 Uhr. Wir wünschen allen unseren Hörern eine geruhsame gute Nacht!:

\section{Donnerstag, 25. Oktober 1956, Radlo:Kossụth und Pétôi!}

\subsection{Uhr}

Guten Morgen, liebe Hörer. Heute ist Donnerstag, der 25. OKtoper 1956. Sonnenaufgang 6.17 , Sonnenuntergang $16.39 \%$ "Einwohner von Budapest, Genossen! Das Gros dèr'Konterrevolutionären Banden haben wir liquidiert. Es jst jedoch möglich, dẩ kleinere Gruppen während ihrer. Flucht versuchen, sich in einzelnen Häusern einzunisten. Unsere bewaffineten Kräfte setzen die endgultige Vernichtung der konterrevolutionären Gruppen fort. Das Parteikomite von Budapest ... ruft 
alle Houserkomitees quf, Wachgemeinschaften zu organisieren, um zu'vérhindern, daßs sich bewaffnete Elemente in den Wohnhäusern verstecken."

Liebe Hörër, wir beginnen nun mit unserer musikalischen Morgensendung.

\subsection{Uhr}

Dos Innenministerium der Ungarischen Volksrepublik ruft alle diejenigen auj; die ohnę.Genehmigung im Besitz von Waffén, Munition-oder sprengstoff sind, diese innerhalb von 24 . Stunden abzuliefern...

\subsection{Uhir}

Wir berichten thrien nun über die Lage nach dem Stand von heute früh 4.00 uhr: "Im Vergleich zu dem heute Nacht gegebenen'Bericht hat sich die Lage wesentlich gebessert. Die Angreifer strecken die Waffen und ergeben sich... Eine Gruppe zieht sich nach Soroksár. zurück, offensichtlich in der Aosicht, zu fliehen. Eine andere Gruppe ist quf gestohienen Lastkraftwagen nach Transdanubien gelangt und flieht in Richtung Westgrenze... Partel und Regierung sind vollkommen Herr cler Lage : :"

\subsection{Uhr}

Liebe Hörer auf dem Lande! in Budapest war gestern noch Belagerungszustand. In diesen Minuten jedoch fahren bereits $\therefore$ Wieder die Straßenbahnen und Omnibusse. Budapest befindet sich auf dem wege der wahrhaft konsequenten Verwirklichung der Juliresolution... Glaubt den Gerüchten nicht! Unser Sender wird Sie wahrheitsgemäß informieren', so wlo wir es auch bisher getan haben :..

\subsection{3 Ühr}

Achtung; Achtung! Auf Befehl des Ministerrates iháben dis Ammee, die Staatssicherheitsorgane, die bewaffneten Arbelterwachen und die sowjetischen Truppen in der Nacht zum 25: Oktober den konterrevolutionären Putsch niedergeschlagen : Sämtliche Schulen und Hochschulen bleiben jedoch bis auf weiteres geschlossen...

\subsection{Uhr}

"nibudapest haben die bewaffneten konterrevolutionären Banden mehrere öffentliche Gebäude, Wönhäuser und Lagergebäude angezündet. In heldenhattem Kampl hat unsere. 
Feverwehr in Zusammenarbelt mit Mlltär und Bevơlkerung die

\subsection{Uhr}

meisten Fever gelöscht . . .

Wie wir erfahren, sind trotz aller Schwierigkeiten die meisten Werktätigen cuf ihren Arbeitsplätzen erschienen und haben die Arbeit sofort aufgenommen.

\subsection{Uhr}

Wir machien die Bevölkerung aufmerksam, daß Ansammlungen

\subsection{Uhr} jeder Art gucti weiterhin verboten sind ....

Die genave Uhrzeit ist 8.25 Uhr. Wir bringen Nachrichten.New York: Heute tritt der Sicherheitsrat zusammen, um sich zum zwelten Male mit der Klage jordaniens über die isrádischen Grenzubergriffe vom 10. und 11. dieses Monats zu bë. ratén.

\subsection{Uhr}

Liebe Hörer, einer alten Gewohnheit entsprechend, verlesen wir jeden Morgen den Leitartikel v́on DAS FREIE VOLK ( „SZa. bad Nép). Heute müssen wir davon absehen. Gesțern ist das Zentralorgan der Partel nicht erschienen, und auch heute morgen $\mathrm{kam}$ es nicht in die Hände der Leser, sondern wird erst in den Mittagstundén erscheinen. Der Grund hierfür ist die Reihe tragischer Ereignisse, welche sich in der Hauptstadt seit Dienstag abend abspielteri, und deren Zentrum unter anderem das Verlagsgebäude von DAS FREIE VOLK war.

Am Dienstag, bereits am frühen Nactimittag, folgtè eine De. legation der Universịtätsjugena nach der anderen; sie bạten, daB DAS FREIE VOLK ihren EntschlieBungen. und wünschen Platz einräumen sollte. In den Abendstunden jedoch änderte sich der Ton der Delegation sowie der Inhalt der Fórderun: gen . . . Nach 10.00 Uhr wandelte sich die Lage vollends. Nur noch das Lärmen von Konterrevolutionären und irregeleiteten Halbwüchsigen klang herauf von dem Platz vor dern verlags. gebäude. Sie forderten, DAS FREIE VOLK solle einen Aufruf zum allgemeinen Streik veröffentlichen. Der Sturm auf das - Verlagsgebäude begann. Die Provokáteure griffen mit șteinen an ... Mehrere der Angreifer erreichten den 4. Stock und entfernter den roten Stern. Dann nahmen die Angreifer das Geböude ganz in ihren Besitz : $\therefore$ 


\subsection{Uhr}

i) Organisierte konterrevolutionắre Kräfte benutzten die Studentendemionstration vom. 23. Oktober zu einem bewaffneten Putsch gegen unsere friedliche Volksmacht, um ihre volksfeindlichén und niedertröchtigen Ziele zu verwirklichen. Die Soldaten, Unteroffiziere und Offizlere der ungarischen Volksarmee'standen am 24. Oktober im Kampf gegen den konterrevolutionären Mob ehrenhaft ihren Mann. Zusámmen mit den Streitkräften des Innenministeriums und den Einheiten dër brüderlichen Sowjetarmee verteidigten sie unsere volksdemokratischen Errungenschaften . . Ich befehle, daB die Soldaten unserer Volksarmee durch erhöhte. Aktivität und mit völliger Entschlossenheit bis heute mittag die noch in unserer Haupt= stadt anzutreffenden konterrevolutionären Kräfte endgültig vernichten. ... Ruhm jenen, die Ihr Leben für die Macht des Volkes geopfert habèn! Gez. General István Bata, Verteidigungsmiñister."

\subsection{Uhr}

Das Leben in Budapest hat wieder begonnen. Auf den straßen sieht man "hastende Menschen, Auch die Arbeiter "der "VerKehrsbetriebe haben die Arbeit wieder aufgenommen, selbstverständlich vorläufig nur'die Instandsetzungsarbeiten; mán hofft aber, daß der.Verkèhr in Kürze auf mèreren Linien. einsètzt....

\subsection{Uhr}

-... Wo noch keine Straßenbahnẻn verkehren, werden Omnibusse eingesetzt. Die Untergrundbáhn verkehrt aü der ganzen Strecke $\therefore$

\subsection{Uhr}

$\because$ Liebe Hörer, in Kurze verlesen wlr elne wichtige Mittellung.

\subsection{Uhr}

Auf seiner heutigen Sitzung hat das Politburo des $Z K$ der Ungarischen Arbeiterpartei den Genosšen Ernö Gerö seines Amtes als Sékretär des ZK enthoben. An seiner Stelle. wurde Genóse Janos Kádár zum 1. Șekretär des ZK ernannt ... (Diese Mitteilung wird mehrmáls wiederholt, dann kommt die Aufforderung:)

1. "Ungarn! HiBt "die nationalfarbené Flaggel" - Die Nationaf- 
hymne wird gespielt und obige Mitteflung in Abständen von etwa einer Minute wiederholt.

\section{3:13 Uhr}

Erst vor wenigen Minuten haben wir die Nactiricht von der Sitzung und dem Beschluß des Politbüros geseridet, und schion berichten unsere Reporter; daß die Bevölkerüng von Budapest den Beschluß mit großer Freude bégrüßt Im Bezirk Angyalföld haben sich die Arbeiter umarmt und gekußBt Die Bevölkerung hat ihre Häuser mit den Nationalfarbenbeflaggt. Uberall erschatlen Hochrufe Unsere Reporter in den anderen Bezirken berichten über die gleiche ungetellte freude. (ADspielung der Nationalhyme sowie der Marsêllaise.)

\subsection{Uhr}

Die Genossen Imre Nagy und János Kádár bitten die Bệ̀̂lkerung von Budapest in inre Wohnungen zu gehen oder sich an den 'Arbeitsplätzen autzuhalten. Keinesfalls sollen sie an irgendwelchen Demonstrationen, auch nicht an partei- und regierungstreundlichen, teilnehmen. Sie sollen die in Küre ubertragenen Rundfunkansprachen in Ruhe abwarten.

\section{5:18. Uhr :}

Wir übertragen jetzt die Rede des Genossen Jánós Kádár: "Urigarische Werktätige, liebe Genossen! . . Die von unserer Volksrepublik verkörperte Macht des werktätigen Volkes, der Arbeiterklasse und der Bouernschaft ist uns heilig und mu $B$ all denen heilig sein, die nicht wünschen, daß sich die Kapitalisten, die Bankiers und Großgrundbesitzer dem-Volk wieder auf :den Nacken setzen .... Ich bitte auch die Jugend ihre Unterstützung nicht denen zu geben, welche die Ordnung stören, sondern sie vertraue darauf, daß die Parteileitung inre Vorschiäge mit den interessen des ganzen Volkes, prijfen, in Einklang bringen und lösen wird ..."

\subsection{Uhr}

Sié hören nun die Rede des Genossen Imre Nágy Mitglied dés Politbüros und Präsident des Ministerirates.

¿Eine kleine Anzahl von konterrevolutionären Provokateuren und "Aufwieglèrn hat einen bewatfreten Angrif gegen die Ordnung unserer Volksrepublik geführt, welchen ein Teil der Budapester Arbeiter aus Verbitterung uber die Lage des landes unterstutzte. . Gegen all jene, die nicht mit der Absicht 
$\therefore$ izu den Waffen gegriften haben unsere valksdemokratische ordnung zu sturzen, und diejenigen, dierden Kampf sofort beenden und die Waffen ablietern - gégen aille die jugendlichen, Arbeiter und Soldaten, welche das tun wird die

* Reglerung im Geiste der Versöhnung und Befriedung: weitgeheride Milde walten lassen; gegen sie werden wir nicht das standgerichtliche. Verfahren anwenden ....!"

\section{6:48 Uhr}

Im Namen der Leitung des Petöfi-Kreises verliest jetż Gábor Táriczos, Sekretär des Petofi-Kreises, einèn Aufruf "Freunde, ungarische Jungen und Mädchen!... Die schlechte Fujrung des soeben abgelösten "Érnö Gerö that vielè mit Bit. terkeit erfült und zu Handlungen hingerissen, an ofie sie ur. sprünglich gar n!cht dachten. Aber jetz haben wir eine gute Fuhrung Erster Sekretâr der Partei ist jetžt János Kádar der die Gefängnisse der Persönlichkeitswillkür durchlief, und an der Spitze der Regierung Imre Nagy hür dessen Recht wir. so senr gekämpft haben Wit mussen nun endlich die Arbeit wieder aufnehmen ..."

\subsection{Uhr}

Achtung, eine Mittellung! lmre Nagy und Janos Kadar bitten die Bevökerung; möglichst bald nach Hause żu gehen und sich nicht auf den StraBen aufzuhateniyon 18.00 uhr bis 06.00 Uhr: früh herrscht Ausgangssperre, undubis zum Beginn der Ausgangssperre ist jetzt weniger als eine stunde Die Haustore sing überall verschlossen żu halten.

\subsection{Uhr}

Nurnoch 35 Minuten bis zum Beginn der Ausgangssperrel

\subsection{Uhr.}

\subsection{Uhr}

Achtung, nur noch eine halbe Stunde

\section{: Achtung, nur noch 2 Minuten!}

\subsection{Uhr}

"Liebe Jugend, meine lieben Freunde! Hier spricht Gyula Hay: Ich war unter euch, bin gemeinsam. Arm in : Arm mit euch durch $\because$ die Straßen von Budapest gezogen a Unsere wichtigstén ... Forderungen sind erfültt: Imre. Nagy ist unser Mañr, sein Programm ist auch unser Programm. János Kádár hat in den Getängnissen Rákesjs gelernt, wovor die Ungarn geschützt wef: 


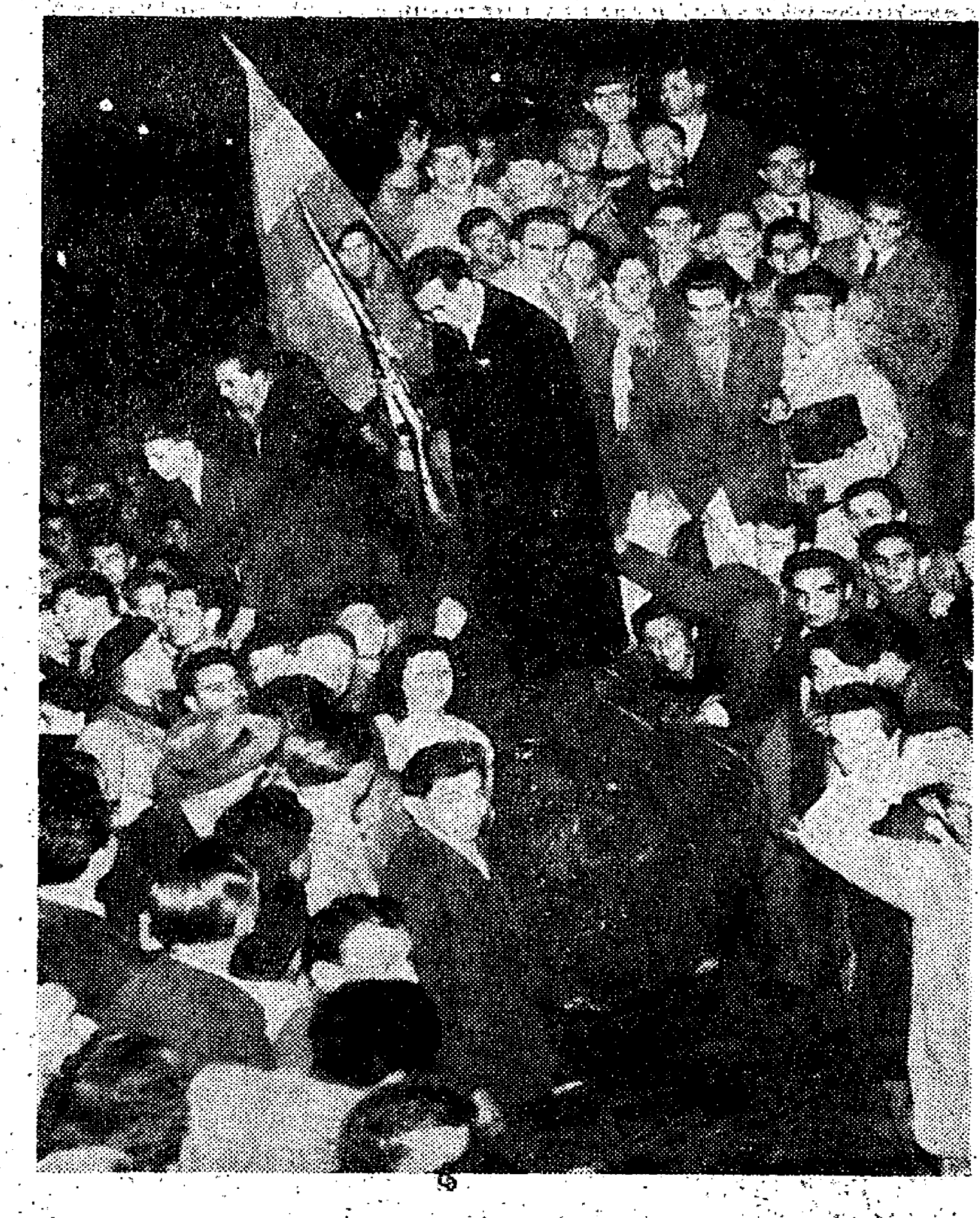

Bewanmete Studenten auf dem Kopt des gestüzten Standbila statins 
den müssen. Jene Krëfte, deretwegen man sich euretwegen sorgen muBte, verlassen mit Eno Gero die Regleruig Eure patrotischen Gefuhle haben verstandnis gefunder lint braucht keire Vergeltungsmaßnahmen zu befurchten ... Bewahrt jetzt euer Leben dos Vaterlandwir euch dringend benotigen dieses neve ungarn, welches dabeirst, sich von der Personlichkelswillkurzu befreien Dieses sagt evch ever alter freund, der Schrifteller Gyula Hay."

\subsection{Uhr}

Achtungl Achtung Ene Mittelung des Justizmintens:

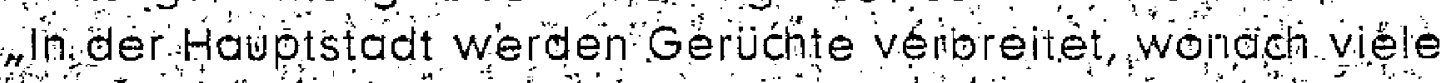
Personen die in Laufe der bewaffneten Aktionen gefangengenommen wüden, hingerichtet worden seien. Dés jústizministerum stell test, daß diese Gerụchte nicht, den Tatsachen entsprechen Bisher wurdé keine de fesigenommenen Personen vor ein Kriegsgericht oder ein ordentiches Gericht gestelt, alsokonnte auch kein Urteil gefallit werden, geschweige dennivoltstreckt werden li:

\section{$22: 55$ Uhr}

1 Laufe des Abends kam es in manchen straßen der Hauptstodt vor daß Hausfremde die Blockwaite aus den Häsern gejagthabenundnún de Ruhe der Mieter storen. Wir appellieren ande Blocklorte und Mieterkómitees, die Haustore

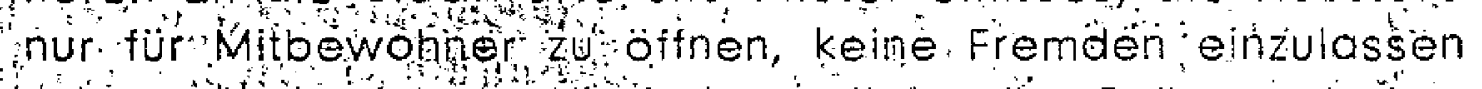
und auch dam zur wiederherstellung der ordnung beizutrogen.

\subsection{9 uhr}

In Kurze vellesen wir ene Enklarug des Ministerprósidenten irie Nogy!

\section{$0.35 \mathrm{Uhr}$}

Lebe Horer wir verlesen jetzt die Ekkarung des Genossen mire Nogy:

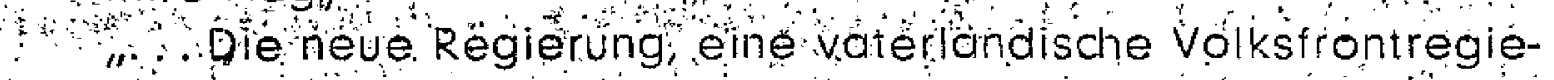
rung, wird bald gebildet sein! In der Pérsonalzusammensetzung der Regierung wird der, Wunsch der Offentlichkeit sowie deren vorschlage weitgenendst berucksichtigl sein In dem Programm der neven Regierung werden die vorschlage der offentlichen Meinung entralten sein. Das Regierungsprogramm wird in Kürze dem Parlanient untërbreitet . : 


\section{Freltag, 26: Oktober 1956, Radlo Kossuth und Petöfl, Büdapest}

\subsection{0 uhr}

Der Ministerrat der Ungarischen Volks republik, ruft die Bevölkerung Budapests auf, heute den ganzen tag über nicht auf dié Straße zu gehen, Diese Maßnahme ist notwendig, weil von den frühen Morgenstunden an im ganzen staditgebiet von Budapest eine Vernichtungsaktion gegen die Reste der bewaftheten konterrevolutionären Gruppent stattindet. Die Arbeiter der lebenswichtigen Betriebe, des Wasserwerkes, Gasund E-Werkes. . , sollen unbedingt itre Personalausweise. mitnehmen, da auf deri Straßèn Ausweiskontrollen vorgenom. men werden.

\subsection{Unh}

Wir verlesen jetzt dern heütigen Leitartikel vón-DAS FREIE VOLK ("Szabad Nép"):

"Genug des Blutvergheßens, 3 Tage lang floß Blut in den straBen von Búdapest, wir brauchen jetzt Ruhe, Ordnung und Frieden.' Jetzt soll das verwirklicht werden, wëshálb so viele gestorben sind, und was die Mehrheit de's ungarischen volkes vertarigt Ungarn werde ein unabtängiges demokiratisches Land, welches seinen eigenen Weg zum Sozialismus be: schieitet

Die Ablösung Enö Gerös, dié ersten. Ansprachen vọn lmre Nagy und Jánós Kádár sowie die in Kürze erwartete Regiè. rungsumbildung béweisen, daß wir ęndlich mit richtigen Maß: rahmen begonien haben. Aber nóch mussen wir sehr, sehr. viel tun, um sagen zü kọnhen, daß auch in de" Praxis die nationalen und demokratischen. Förderúngen unserer Jugend sowie des werktätigen volkes verwirklicht sind. $\because " \ldots$ " .

\section{Sovishr}

In diesen Stunden Ist die Arbeit der Sanitäter, Arzte, Schwestern-und Pfleger von älergrößter. Bedeutung. Vön ihrer Aushaltẹfähigkeit hängt das Leben von Menschēn ab. Dárum teilen sie Ihren Angehörigen mit, daß Sie vorfäufig nicht zu hren Familien zurückkehren können.

\subsection{Uhr}

Die Regierung erlaübt den Einwohnern, die Lebensmittel. kaufen wollen, zwischen to.0o Uhr und 15.00 uhr auf die straße zu gènen, um beil in unmittelbarẻr Nähe gelegenen täden ền- 
Z zu kaufen Das Innenministerium macht jedoch ausdrücklich daraúf aufmerksam, das auf alle, die mit der Waffe in der Hand angetroften werden, von den sauberungstruppen ge"schossen "wird. Nach 15.00 Uhr darf niemand aú." die Straßé. Den ganzen Tag uber ist das Betreten dé Brücken verboten. leth wiederhole...

\subsection{Uhr.}

Viele Retungswagen wurden demoliert. Ein Saritatswagen emielt eirien Volltreffer und die in itm befindichen zwei Verletzten samt einem Arzt wurden sofort getötet: Auch Frau Dr Mágdoina Pusztay vón unserem Reltungsdienst wurde schwer verletzt...

\subsection{Uhr}

Univers itätsstudenten l lhr habt die volksmeinung wahrhaft ausgedrückt Hinter eure berechtigten-politischen Forderungen stellte sich die Mehrheit der Budapester Werktätigen. Jetzt aber, da eure Forderungen erfullt sind, seid Pioniere der Diśziplin und der wiederherstellung der ordnung $\ldots$

\subsection{Uhr}

- Die Ámnestie bedeutet, daßß diejenigèn, die die Waffen niederlégen oder wegwerfen, freien Abzug enalten. Wer also bis heute 22.00 Uhr ale Waffe streckt oder fortwirti, erhält ifreien Abzúg!

\subsection{Uhr, Radio Petöfi}

Wir teilen der Bevölkérung von Szuhakállo und Umgebung mit, ¿aß aus dem Lager bei Szuhakálló, in dem sich Gefangene mit langen Freiheitsstrafen befanden, eine größere Anzahi Gefangener ausgebrochen ist. ...

\subsection{Uhr, Radio Kossuth}

Auf dem Móskover Platz haben.20 Jugendliche, die im Besitz von 4 lkw waten, die Waffen vor einer motorisierten Einheit unserer Volksarmee gestreckt: Im Sinne des Amnestiegeset2 s. wu den sie freigelassen. In Buda haben sich $12 . \mathrm{LW}$. voll Jugendlicher ergeben und die Waffen miedergelegt. Auch sie erhieltén freien Abzug.

\subsection{Uhr}

Noch 8 Minuteil bis zum Ablauf der Waffenablieferungsfrist. Noet 18 Minuten bis wir auch in Budapest dem Biutvergießen elr Ende bereiten . Vielleicht glauben manche, daß dio Am- 
nestieverordnung dle Schwäche der Reglerung bewelst. Neinl Davon ist keine Rede"...

\subsection{Uhr}

- Wir verlesen jetzt den Aufruf des Schriftstellers Gyulo.Hay an die Jugendichen:

„.., Ich spreche zu. euch, meine lieben Kinder, die "ihr von patriotischén idealen und voller Begeisterung die Waffén ergriffen habt: Viele verzweifelte Mütter sprechen durch mich $z u$ euch. Furchtbare Augenblicke werden jetzt folgen . . Der Zeiger der Uhr rückt gnadenlos vor. Die Frist ist abgelaüten, ihr habt nur noch etwa 10 Minuten. Aber vor euch, wenn ihr. wollt, liegt ein garizes Leben..."

\subsection{Uhr}

\section{Ausiandsnachrichten:}

Bonn Heute trat Smyrnow, Botschafter der Sowjetunion, in der Deutschen. Bundesrepublik ein. Bei seinem Eintreffen auf dem Flugplatz sagte er: "Als Botschafter der Sowjetunion überbringe ich die Freundesgrüße sowie die besten Wünsche der Sowjetunion allen Arbeîtern, Bauern und Bürgern der Bundesrèpublik:"

Londọ: Heute morgen verstarb Walter Gieseking, dèr weltberühmte deutsche Pianist, im Alter von 60. Jahrên in einem Londoner Krankentiaus.

\subsection{Uhr}

Wir bringen jetzt ein Konzert mit Werken von Beethovén. Hören Sie zuerst die-Egmont-Ouvertüre.

\section{4:00 Uhr}

Das Zentralkomitee unserér Partel sowie dér Ministerrat haben an einem Tag folguride Beschlüsse gefaßt:

„...zweitens: Die neve Regier.ung beginnt Verhandlungen mit. der Sówjetregierung über die Regelung der Beziehungen ziwischen den beiden Ländern auf der Basis völliger Gleichberechtigung und Nichteinmischung in die internen Angelegênheiten." Nach Wiederherstellung dèr Ordnung wird über den Abzug dè sówjetischen Truppen verhandelt ...".

\subsection{Uhr}

$\therefore$ Das Ausgangsverbot für Budapest bleibt bis auf. Widerrut auch am Samstag, dem 27., bestehen. Vormittags bis 10.00 Uhr. 


\subsection{Uhr}

durfen Einzelperșonen die notwendigsten Elnkăụfe tătigen. Auf Gruppen von mehr als 3 Personen wird geschossen!

In den Abendstunden hat sich in der MuseumstraBe eine bewafinete Gruppe von 500 Mann ergeben.

\subsection{Uhr}

Unsere heutige Sendung ist damit beendet. Wir wünschen unseren Hörern eine gute Nacht (Natiónalhymne).

\section{Sámstag, 27. Oktober 1956, Radio Kossuth; Budapest}

\subsection{Uhr.}

Der Stadtrat von Budapest bittet uns zur Ubertragung folgender Mitteilung:

.....Es Ist heute der vierte Tag, daß in den Straßen von Budapest blutige Kämpfe stattfinden. Die Lebensmittelversorgung der Bevölkerung der Hauptstadt ist auBerordentlich erschwert. In den vergangenen Tagen haben' die Arbeiter der 'Städtisclien Betriebe in vielen Fällen unter. Einsatz ihres Lebens gearbeitet, "um die Bevölkerung von Budapest sowie die arbeitenden Betriebe mit Wasser, Gas und Strom zu versorgen . . Im Namen der Einwohner sagen wir allën diesen Werktätigen Dank und vertraven darauf, daß sie am heutigen $\mathrm{Tag}_{\mathrm{g}}$ ihre Arbeit mit der gleichen Opferbereitschaft tun wer"den:"

$\therefore$ Liebe Hörer, unsere Nachrichtensendung ist hiermit beendet. Wir bringen jetzt volkstümliche Operettenausschnitte.

\subsection{Uhr}

$\therefore$ Mehrere Hörer haben sich bei uns über mangelhaften Rundfunkempfong beschwert. Wir bitten unsere Hörer sich noch eine kurze Zeit zu gedulden. An der Behebung der technischen Störungen wird gearbeitet.

\subsection{Uhr}

Achturigl Achtungi Wir bitten unsere Hörèr, an thren Empfän= gern zu bleiben. In Kürże verlésen wir die Namensliste der : neven Nationalen Regierung.

\section{$11.18 \mathrm{Uhr}$}

Der Rat des Präsidiums der Ungarischen Volksiepublik hat aut Vorschlag des Zentralkomitees der Ungarischen Arbeiterpartei sowie des Präsidiums der Patriotischen Volksfront die Regierung der Ungarischen:Volksrepublik neu gewöhlt: 
Präsident des Ministerrates: Imre Nagy; Stcatsminister: Zoltán Tildy; AuBenminister: Imre Horváth; Innenminister Ferenc Münnich; ....Verteidigungsminister: Károly Janza; Landwirtschaftsminister: Bela Kovács, ehemaliger Géneralsekretär der Kleinen-Landwirte-Partei; Gesundheitsminister Antal $B O-$ bits, Universitätsprofessor; ... Minister fur Leichtindustrie: Fray Jözsef Nagy; Post und Verkehrsmnister: Lajos Bebrics; Kultusminister: György Lukács, Universitätspórofessor; Unterrichtsminister: Albert Kónya; Prásident des Landésplanungsbüros: Arpád Kiss .. Der Posten des Ministers ür Stạtskontrolle bleibt vorläufig unbesetzt. - Nach ihrer vereidigung tiat die neve Nationalregierung sofort inr Amt angetreten.

\section{2:00 Uhr}

Nachrichten: Soeben hat unser Berichterstatter mit Erinahruligsminister Rezsö Nyers gesprochen. Er teilte mit, dẩ in den Schlachthöfen Fleisch in genügenden Mengen vorhanden ist ... . Wie der Enährungsminister mitteilte, reichen die Lebensmittếlvorräte für Wochen...

Der Widerstana der die Stadt Budapest terrorisierenden Gruppen îst gebrochen. Gestern abend gegen 22 Uhir streckten die Aufständischen in großer Zahl" ihre Waffen vor unseren Militäreinheiten. Viele haben ihre Watfen Weggeworten und den Kampf aufgegeben. Heute vormittag waren nut hoch drei Zentren konterrevolutionärer Elemente übrig. Ahre Liquidierung ist im.Gange. Jene bewaffneten Aufständischen, die bis gestern 22 Uhr die Wafen niederlegten, wurden quf Grund des Amnestieerlasses sofort nach Hause geschickt im den Straßen von Budapest sammeln unsere Militäreinheiten zuammen mit Einheiten der sowjetischen Airmee die weggeworfenen Waffen ein!

Die Bevölkerung von Budapest sowle mehrere Provinzstädte machten uns darau aufmerksam, daß die bewaffrietet Gruppen in der Hauptstadt und auf dem Lande flugblatter verteilen, welche - angeblich im Namen der Regierung und anderer Organe - Erklärungen enthalten, die Verwirrung stiften. Wir wurden zu.der Mitteilung ermächtigt, daB es sich bei diesen. Flugblättern um fälschungen handelt ....

in unseren vorangegangenen Nechriehten teiltea wir mit; ddB 
क: às dem Gebâude der Landwirtschaftlichen Universitöt auf die anmarschierénden Truppen geschossen wurde. Auf Ersúchen der Univerșitătsleitung stellen wir fest; daß nicht von dort, sondern aus den gegenüberliegenden Häusern "einzelne Scharfschützén auf die Panzerfahrzeuge geschossent haben.

Wie bereits géstern gemeldet, haben bewaffnete Grüpen, die in der Mehrhelt aus Mobelementen bestehen, in verschie. denen Provinzorten die gewöhnlichen Verbrecher aus den. Gefängnissen befreit, die seither Besitz und Leben der triedllchen Bevölkerung gefährden. Heute elfuhren wir ab in Oroszlány mehrere Hundert Gefangene befreit wurden und die Umgebung unsicher machen ....

Achtungl Genosse János Kadar bittet, daß der Aufrúf des szoT ...(noch einer Pquse von etwa einer Minute): Wir bilngen jetzt Auslandsinachrichten:

Belgrad: Am Freitagabend brachte die halboffizielle jugosia: wische Nachrichtenagentur JUGOPRESS einen "Kommentar zu den Ereignissen in Polen und Ungarn, demzufolge die Bedeu-" tung dieser Eréignisse über die Grenzen der beiden lände" hinauswächst: Dér Gang:der Ereignisse in den beiden Ländern beweist, wie notwendig und richtig die Richtlinie des XX. Konigresses der. KPSU war und zeigt die enormen Auswirkurigen dé "Kongréßbéschlüsse aút den Verlaut des soziălistischien Fortschritts, schreibt JUGOPRESS.

Lièbe Hörer, unsere Nachrichtensendung ist beendet. Das Meteorologische Institut gibt folgende Wetterviorausságe für die nöchsten 36 Stunden: Meist bewölkt, für Transdánubien Bewölkungsauflockerung, in vielen Tejlen des Landes, hauptşächlich im Osten, Regen. "Auftrischende Winde von Süden ünd Südwesten. In Transdanubien dreht sich der Wind nach Westen: Wesentliche Temperaturanderungen sind nicht zu erwarten. Die Voraussage fû́r Budapest für die nạchsten 'zwölf Stunden: Bewölkt mit" Niederschlạgsneigung. Mäßige Winde. Temperaturen nachmittags zwischen 10 und 12 Grad, abends zwischen 7 und 9 Grad:

\subsection{Uhr}

Mittélung der Landesżentrale der Gewérkschaften (SZOT):

"Arbeiter! Der Wunsch der Arbeiterklasse ist verwirklicht, die Betriebe, werden durch Arbeiterräte geleitet! Ab. jetzt .könnt 


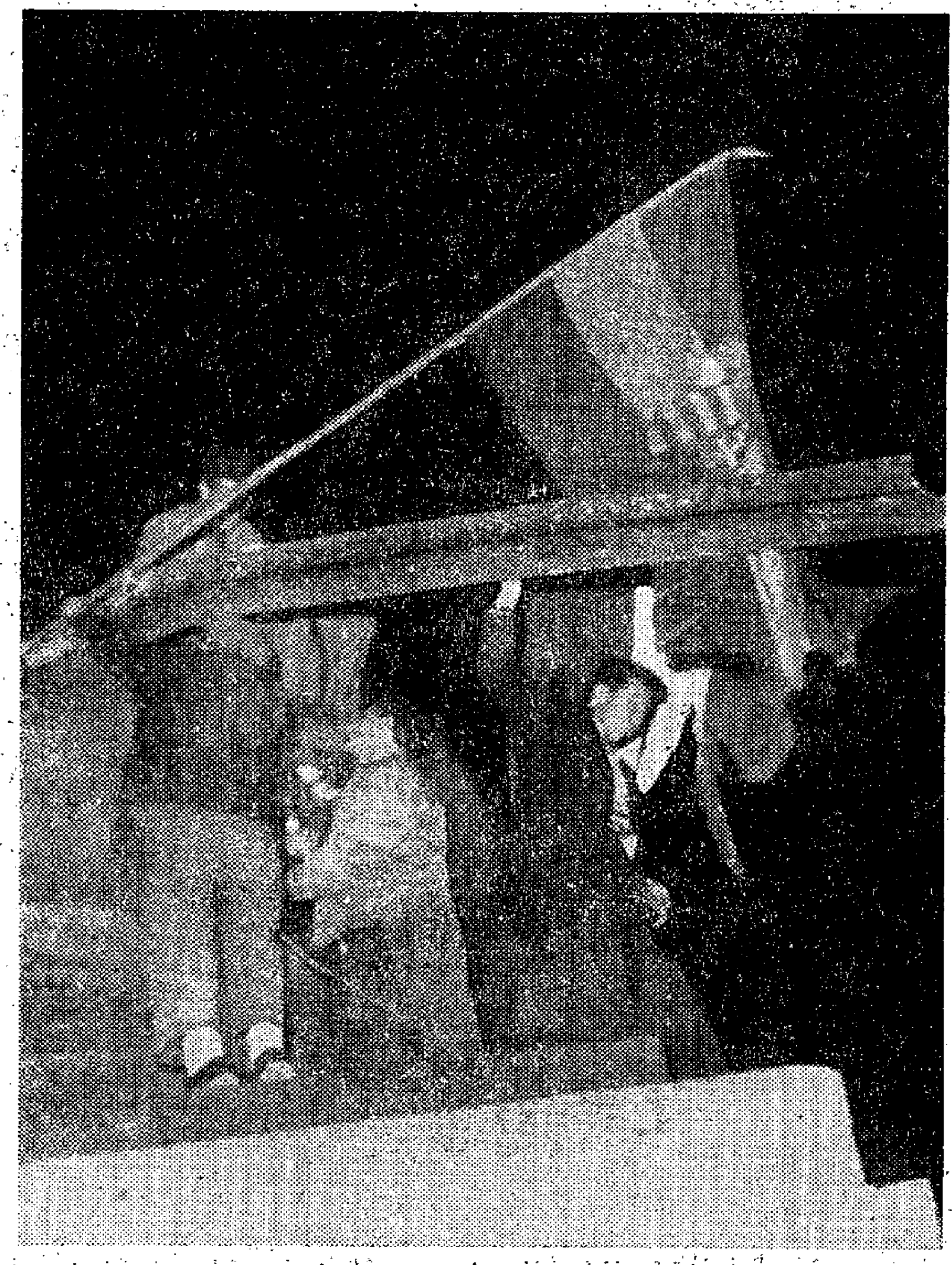

Aut. dem Sockel des gestürten Stalindenkmals wird die Făhne mit dem Kossuth-Wappen gehißt 
The euch gamz als Besitzer der Fabriken fuhlen, die ihr von nun an selbst leiten werdet

\subsection{Uhi}

Ulingorische Ingenieure und Techniken Die nêu Regierung wird alle Angelegenheiten mit dem volk erortern Bei der Umorganisierung der volkswirtschaft sowie in wich igen technischen Fragen, wird sie das Urteil der Ingenieure und Techniker eintiolen. Es wird nie wieder vorkompien, dá brennende Probleme ohne fachwissen gelost werden. Von nun an werden unsere, Fachleute ein gewichtiges wort nitzureden haben hationalen Einheit. Das Präsidium der Landeszentrale dêr $G$ é werkschoften."

\subsection{Unr}

Gesternteilten wir mit, daß in Szolnók bewafnete Zusammenstöße stattgefunden hábén.; Offenbar waren wir jedoch falsch informiert. Die Schüler und Studenten vôn Szónộk teilen itiren Angetorigen mit, daß sie gesund und wothlaut sind ...

\subsection{Uhr}

Kommentar:

Bie neve nátiónale Regierung unter der Führung. vón Geriosseñ Imre Nogy wurde heute veréidigt. Sie hat dámit die Autgabe duf sich genommen, unser Volk aus der tragischen situation herauszuführen, in die es die politischen Fehieriund verșäumnisse dèr vergangenen Jahre gestürzt habèn $\because$. .

Die zusammensetzung der hevgebildeten Regierung beweist, dab menrere, lange Jahre hindurch beiseitegeschoberie elhbare und befahigte ungarische Politiker an den ihnen gebujt. rènden Platz zurückkehren, nämlich in das politische Leber. Ungarns

\subsection{Uhr}

András Sándor, Schriftsteler: „:Vielleicht wird. nun Friede enziehen, denin unsere wichtigsten forderungen sind" erhört worden $\because$

\subsection{Uhr}

"Ber Prásidentschaftsrat hat mich heutex mit den Aufgaben des Verteidigungsminịsters betrout... I lch berehle, dỏ $B$ die militörischen Einheiten in pausenlosem Einsatz die bewaffneten 
Widerstandsnester vernichten und die ordnung wieder her stellen... gez: General Károly Janza."

15.10 Uhr

Das Mieterkomitee eines Hauses im Krisżtina-Bezirk hạt dis Wohnungen nach versteckten Waffen durchsucht Die Housbewohrer haben diese Maßnahme freudig begruß 3 Aus einem Haus in der Baross-Straße.wurde gemeldet, daß im Laufe der Nacht Bewaftnete im Hause Zuflucht gesucht haben. Dem Wunsche der Mieter entsprechend führten die ordinungsorgane elne Hausdurchsuchung durch urd nahmen 6 Personen fest :

\section{Uhr}

in Budapest wurde der Widerstand der bèwafneten Gruppen gebrochen... Die Ausgangssperre bleibat bis zưr völligen Wiederherstellung der Ordnung in Kraft.

\section{7:05 Uhr.}

Nachrichten:

In Budapest..und mehreren Provinzstädten vertelien die be? waffneten Gruppen Flugblätter. Schenkt: ihnen keinen Giaubenl

16.45 Uhr, auf $1340 \mathrm{~m}$, wahrscheinlich Miskolc (in Händen der Aufständischen)

"Diejenigen, welche gegen die Aufständisctien vón Miskolc Waffen gebrauchten, haben es gebüitl Gestern vormittag um 10.00 Uhr haben 500 ‘ugendliche demonstriert, . . eine Delegation".. Studentengruppe. Die Studentengruppe ging ins Polizeipräsiäium und verlangte die Freilassung einiger verhafteter Kommilitoneñ... ein. junger student. . erkundigte sich persounlichi, ob noch mehr studenten auf dem Polizeiprásidium sejen. Da trat eine neve Gruppe von demonstrierenden Studenten, ein". . die nationalfäbene Fahne... "der Lêter der Polizè befahi den Polizisten.. Maschinenpistolengarben, Handgranatensplitter prasśelten auf die nationalfarberien? Fahneh und auf die Demonstrierenden. Im Laufédes Tages ergriffen die Demonstranten die. $:$ und zogen sie zur Vêrantwortung ... !"

(Empfang durch starken Störsender beeinträctitịgt)

17.15 Uhr, "Hier ist der Sender Pécs! (Ebenfalls Sender in Hand der Aufständischen) 
Wir stehen geschlossen hinter dem Genossen lmive Nagy Wir sind jedoch sehr entrüstet über die Radiomeldúng, ; wolnach der neve Minister für Verkehr und Post jener Lajos Bebrics ist, welcher die Willkür und den Terror bei der Eisénbahtin éngeführt hat ...!".".

19.00 Uhr, "Hier ist der Freie Sender Györ (Raab), wir senden aúf Welle 188,5 sowie 223,8 ....

Mitbürger, Genossen! ... Wir forden Auflosung des Staatssicherheitsdienstes sowohl. in Budapest als auch im ganzen Land. Die. Staatssicherheitsorgane sollen ientwaffnet werden. Die Wơffen sollen die Einheiten der ungạ risclien Volksarmee ubornehmen. Die Parteileitung und die Regierung solién Setritte unternehmen, damit die in: Ungarn befindictien be: waffneten sowjefischen Einheiten den Kampt einstellen und bei der Zusicherung freien. Abzuges das Land verlassen... Wir verurteilen zutiefst jene, die gegen die demonstrierenden Arbeiter und unsere Jugend mit Waffengewalt vorgingen. Wir betrachten die Opfer der Kämpfe als unsere Märtyrer . :"

\section{9:30 Uhr, „Hier ist der Sender Miskolc}

Unser volk vertraut Imre Nagy. Wir bitten ihn darum, die sowjetischen Einheiten nach. Hause zu schicken, damit in Buda: pest und anderswo nicht mehr ungarisches Blut velgossen wirc Er soll den Mut aufbringen; sich von. jenen Politikerin freizumachen̆ die nur regieren konnen, indem sie sich auf fremdé Watten und volksunterdrickung stütżen $\because$ :"

\section{2:10 Uhir}

Im Bereich von Budapest wurde heute nachmittag die Liquidierung der bewaffneten Widerstondsgruppen fortgesetzt ...

22.25 uhr Sender Miskolc: "Sie horen das Sonderprogramm von Rodio Miskolc:

- Heute ist der zweite Tag, seit in Miskolc der Arbeiterrat und das Studentenparlament die Leitung übernommen hạben..."

\section{2:45. Uhr}

Wir verlesen jetzt den Text des Aufrufs, den die Arbeiter und Studenten von Miskolc an die sowjetische Almee irichteten (erst in Russișch, dann ungarisch):

- Soldaten, Offizierel Kämpft nicht gegen eure Brüour, gegen die ungarisctien Arbeiter, Studenten und.Jugend. Unser Volk hot sich inient gegën euch erhobon, sondern um seine berech. 
tigten Forderungen durchzusetzen ... Seld kelrie Werkzeuge bei der Unterärückung des berechtigten Kamples des ungari: "schen Volkes! gez.: Die Arbeiter und Studenten von Miskölc.".

\subsection{Uhr, Radio Kossuth}

Wir teilen der Bevölkerung von Budapest mit, -daß die Ausgangssperre auch für morgen, den 28 . Oktober, gilt. Zúgleich wird jedoch Einzelpersonen gestattet, zwischen 10.00 und 15.00 Uhr die notwendigsten Lebensmittel zu besorgen.

Damit, liebe Hörer, beenden wir unser heutiges Sendepró. gramm. Wir wünschen thnen allen eine geruhsame gute Nacht! (Nationalhymne.)

\section{Sonntag, 28. Oktober, Radio Kossuth}

\subsection{Uhr}

Guten Morgèn, liebe Hörer! Diề genaue Zeit ist 4.30 Uhr. Heute ist Sonntag, der 28. Oktober. Im Kalender steht der Name Simon. Sonnenaufgang 6.21, Sonnénuntèrgang 16.34 Uhr. Wettervorhersage des Meteorologischen Instituts bis heute abend: Bewölkt, in, vielen Teilen des Landes; vor allem im Ostén, Regen. Mäßiger Wind aus Südwésten ....

\subsection{Uhr}

Presseschau: Die FREIE JUGEND ("Szabad Ifjuság".) schreibt:

"Im Augenblick' ist es zweifëlhaft, ob" die olympische Auswahlmannschaft nach Melbourne abreisen kann." ". . .

\subsection{Uhr}

Nach wiëderholten vorhergegangenen Verhándlungen habén géstern abend die Parlamentäre der ungarischen Armee mit den Aufśtändischen vom Moskau-Platz eine Waffenruhe beschlossen.

\subsection{Uhr, „Hier ist der Frele Sender Györ!}

.. Das Nationale Komitee des Komitates Vas hat in seiner Proklamiation Nr. 1 die Budapester Regierung aufgefordert, mit der sowjetischen Kommandantur von Ungarn auf der Basis: der Gegenseitigkeit die sofortige Waffenruhe zu beschließen. AüBerdem soll dle ungarische Regierung :erwirken; "daB' die Regierung der Sowjetunion vor der Weltöffentlichkeit erklärt, daß die in Ungarn stationierten sowjetischen Einheiten bis. spätêstens 1. Januar 1957 vollständig und endgültig aus Ungarn abgezogen werden .... I" 


\subsection{Uni}

Erkiörung von Attila Szigeti: „... Die ausländischen Radios und elnzelne Elemente versuchen ĺmre Nagy, den Präsidenten des. Ministerrates, in Verruf zu bringen. Es ist meine Uberzeưgung, daß ich kéinen ehrbarerén; Ungarn als Imre Nagy kenne, Ihm gehört mein ganzes menschliches Vertrauen, denn er hat während der Jahre der Willkürherrschaft unerschütter" lich für das Volk gekämpft, urid er tut dies auch heute, in den tragischen Tagen unserer Nation ..."

Wir verlesen jetzt die Erklärung des sowjetischen Militộrkom-' mandanten von Györ:

"Wir können uns nicht in ihre innerpolitischen Angelegenhelten einmischen. Ich betrachte die Volksbewegung der. Ungarn den sle unterdrückenden Führern gegenüber áls berechtigt. Der Kommandant bedauert, daß einige Provokateure Stimmung gegen die sowjetischen Soldaten machen. Man hat die sowjetischen Soldaten beworfen und sie angespuckt, obwohl sie selbst sich nicht einmal durch ihre Gegenwart in das Leben der Stadt einmischen wollen. Der Kommandant von Györ bittet die Einwohner, daß die nüchtern denkenden Menschen diesen schädlichen Elementen Einhalt gebleten". . Die söwjetischen Soldaten haben mit den ungarischen Soldaten eng zusammengearbeitet und viele ihré Familien und fraven haben sich mit ungarischen Familien angefreundet. 'Unsere Kinder haben mit den ungarischen KIndérń gespielt ... Sollte die Bevölkerung von sowjetischen Soldaten molestiert werden, 'bitten, wir um Mitteilung. Wir. werden alle Vergehen strengstens bestrafen. In diesem Zusammenhang erinnere ich an das in öffentlicher Verhandlung gebrachte Urteil gegen elinen sowjetischen Soldaten im Januar 1956 . . . der zu 23 Jahren verurtelt, wurde ... Die sowjetischen Truppen hegen keinerlel Angriffsabsichten, well ihrer-Meinung nach der Weltfrieden mindestens ebenso wichtig ist wie der Friede der Stadt Györ."

\subsection{Uhr?}

j... In Györ und in unserem ganzen Landkreis formieren sich dié Arbeiterräte, Bouernräțe, Soldatenräte, Intellektuellen und Studentenräte. Siè sind wirkliche Volksräte, die ohne jeden äuBeren. Zwang im Feuer der Freiheltsbewegung unse- 


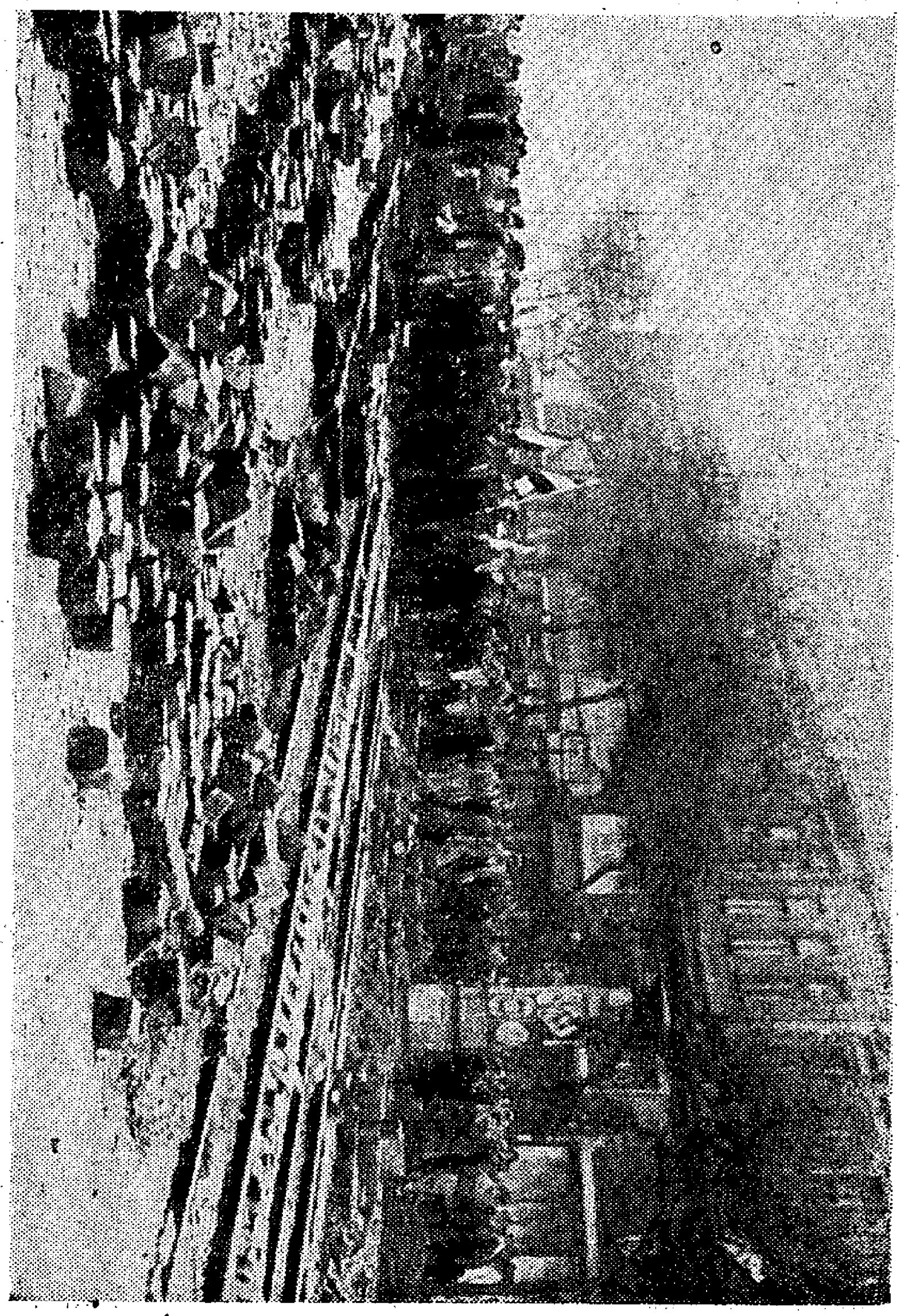


res Volkes zustande gekommen sind. Sle entstehen zu einem Zeitpunkt, wo die sich vön Minute zu Minute ündernden Anforderungen schnelle Entschlüsse und weise, wohluberlegte Handiungen verlangen, damit in diesen Jagen der, geschichtlichen Entwicklung die Werte unserer Nation erhalten bleiben :...". .

\subsection{Uhr}

Aufruf an die Jugend des Komitats Györ-Soprọn: Jugendliche, Jungarbeiter, Jungbauern und Studentenl In Budapest hat sich, dér Landescrat der Révolutionären Freien Ungarischen Jugend konstituiert. Dem Landesrat hat sich die Budapéster. Universitätsjugend und die. Arbeiterjugend angeschlossen. Ever Kampf ist berechtigt I Hunderte und Tausende von jungarbeltern und Studenten haben gegen das Willküregime Stalins und Rákosis zu den Waffen gegriffen. Alle eure Forderungen sind berechtigt.$\therefore$ Nicht nur die Budapester Jugendichen, sondern auch die von Györ: haben Mörtyrer für die Sache geopfert jugendifche! So: wie ihr in der Fèverlinie die Fahne getragenhabt só stellt euch jetzt auch an die spitze der Bestrebungên umiederherstellung der Ordnung . . Nehmt teil an der Tätigkẹt der Arbeiteriäte der Betriebe $\therefore$ Gez:: Das Revolutionskomitee der Freien Ungarischen Jugend von GyörSopron.".

\subsection{Uhr, Radio Kossuth}

"Liebe Hörer, wir unterhalten uns mit józsef Örszegi, Studienrat für Ungarisch und Englisch des Mädchenlyzeums, am istvónPaiaki-platz. Er ist 26, Jahre alt und hat, von dér Demonstration auf dem Bem-Platz angefangen, als aktiver Teilnehmer und Führer sämtlicher Bewegungen teilgenommen. Er war es, der am Dienstagabend an der Spitze "der Jugendlichen, welche die Szikra-Druckerei sturmten, die in 17. Punkten zusammengefâsten Forderungen der Jugend drucken ließ." Mittwoch früh als "die Polizei die Druckerei räumte, wurde er zusammen mit den sich dort die Nacht über aufgehaitenen Jugendlichen treigelassen. Donnerstagnachimittag führte er dann die von der Lehel-Straße kommende Menge zur "Vörös-Csillag "'Drukkereisum dort die 17 Punkte enneut zu drucken, mit der Unterschrift der neuen provisorischen Revolutionsregierung. Dort. 
hat er vor der Menge elne Rede gehalten. Fragen wir jetzt József Orszegi, wie all dies gekómmen ist:

$\therefore$. Dér Arbeiterschaft ging es schlecht. Auch den Buvérn ging es schlecht. Auch die Bavern lebten in unmenschlichen Verhälthissen. Wer also hatte es gut? Einige Führer, die sich an den Beschluß der Partei klammerten und das Volk als Kinder bétrachteten! Ja, nur für sie war diese Welt gut I Wir kämpften und verzweifelten bereits oft an der. Möglichkeit zur Entfalturig. Darum freven wir uns so, daß jetzt unser Volk.von einer Regierung geführt wird, die hoffentlich den Willen der Bevolkerung in Betracht zieht. Es ist nur schade; daß. Wir einen . Blutzoll dafür zahlen mußten."

\subsection{0: Unr}

"Achtung! Achtung! Wir rufen die Aufständischen der GyörgyKilian-Kaserne und des Corvin-Bezirks! Diese Mitteilung kómmt von den beiden Parlamentären, die vor.kaum einer Stunde bel euch waren. Eure Antwort haben wir dem Kommandanten der sowjetischen und ungarischen. Truppen übermittelt. Sie halten eure Bedingungen für unannehmbar. Unserer Uberzeugung nach repräsentiert die neve ungárische Regierung, -deren Namensliste in dem euch, überlassenen Exemplar von DAS FREIE VOLK (Szabad Nép') enthalten ist, die Interessen des gesamten ungarischen Volkes, und sie wird die Hauptforderung verwirklichen, die in den 16 Punkten enthalten sind. Davon sind wir überzeugt. Liebe Freunide; , ihr kennt uns, einer von uns war ever Arźt . . Das Ultimatum zur Waffenstreckung werden wir euch später durch-Lautspiecher-

1. wagen bekanntgeben. Bitte, setżt euch jetzt zusammen und überlegt gut, was wir euch mit größter, Liebe gesagt haben."

\subsection{Uhr, Sender Györ}

Liebe Hörer, wir haben uns mit der Bitte um Auskunft an das Honvéd-Hospitai in Györ gewandt. Wir wollten wissen, wann die Spende des Internationalen Roten Kreuzes in Györ ángekommen ist. -

"Gestern. in den Abendstunden und auch in der. Nacht traf eine größere 'Sendung ein. Wir dürfen von allen bisherigen Sendungen behaupten, daß sie die verschiedensten Dinge enthalten, so auch die modernsten Antibiotika und sämtliches Verbandsmaterial ..." 
"In Veszorem herrscht derzeit Ruhe, aber die lage sieht so aus, als ob es wahrscheinlich noch zu Zusammenstößen kommen wird, weil - wie es heißt - keine Einigung mit den sowjêtischèn Truppen erzielt werden konnte." "

\section{0,40 Uhr, „Hier spricht der Freie Sender Györ:}

Liebe Eltern, Schüler und Pädagogeri! Am Montag, dem 29: OKtober 1956, nehmen die Mitte!schulen, technischen Schulen, Berufsschulen, allgemeinen Schulen ... den: Unterricht wieder auf. Jeder unentschuldigt fehlende Schüler verstößt gegen die Schulordnung ....

Soeber ist der Abgeordnete des provisorischen Nationalrates von Györ mit den Delegierten der Jugend nach Budapést ab-. gereist, um der sich neu konstituierten Rëgierung die Forderungen: von Györ sowie der gesamten Enwohnerschaft zu überbringen."

\section{0:50 Uhr}

Gestern abend trafen zwei italienische Journalisten, von Budapest kommend, in Györ ein. Sie hab́en ais Augenzeugen uber die Eréignisse in Budapest berichtet. An der Seite dér. Jugendlichen standen die Arbeiter und sogar die Frauen. $1 \mathrm{~m}$ wesentlichen hat der Staatssicherheitsdienst oufgehört zu existieren. Die SSD-Einheiten lösen sich selbst auf; ihre Mitglieder ziehen die Uniform. aus und verstecken sich! Die Journalisten berichten auch von Fällen, wo sich sowjet ische Panzer auf'die Seite der. Aúfständischen gestellt haben ... In der Samstag-Aüsgạbe der VOLKSSTIMME (,Népszava') erschién die Forderunğ, daß den zu den Aufständischen überlaufendén Sowjetsoldaten das Asylrecht und Amnestie gewährt werden soll." "

"Gestern suchten Jugendliche aus Csorna das Nationalkomitee von Györ auf. Sie erklärten.sich mit den Albeitern und. Jugendlichen von Györ solidarisch. Sie waren aut Kraftfalirzeugen gekommen und wollten nach Budapest ..."

\subsection{Uhr}

"In diesen Minuten führt die Bévölkerung von Szombethely eine friedliche Demonstration durch. Die Menge führt nationalfarbene Fahnen mit und 'fordert: Volie demokratische Freiheit und Abzug der sowjetisctien Armee aus Ungarn.' Die demonstzierende Menge hält grö́̈̉te Diszipitin ...". 


\subsection{Uhr, Radio Kossuth}

Liebe Hôrer, wir verlesen jetzt den heutigen Leitartikel von DAS FREIE. VOLK ("Szabad. N'ép"):

"Wir teilen nicht die Meinung derer, welche dle Ereignisse der letztenjigge summarisch als konterrevolutionären; faschistischen Putsch bezelchnen. Wir haben die Entwicklung mit Aufmérksamkeit verfolgt und uns uber die verschiedenen $B e-$ wegungen bestmöglich informiert. So können, wir feststellen: Die Ereignisse nahmen ihren Anfang mit der Demoñstration der Buddapester Universitäts- und Hochschuljugend.' Es 'wäre jedoch ein schwerwiegender frrtum, darin lediglich die Bewegung der Jugend zu sehen. Die Budapester Jugendlichen haben dás von iHerzen kommende Gefühl sowie die edle unid heiße Leidenschaftlichkeit des ganzen Volkes zum Ausdruck gebracht. Wir müssen endlich einsehen, daß sich in unsèrer Heimat eine das ganze Volk einschließende und zusammenschweiBende große nationale demokratische Bewegung entfaltet hàt, welche durch die Willkür der vergangenen. Jahre unter die Oberfläche gepreßt wurde, abèr von dén ersten Hauch der Freiheit in den letzten Monaten zur lodernden Flamme entfacht wurde...

- Betrachtèn wir völlig objektiv einige Tatsachen; die uns bei der Beurteilung der Lage helfen könnén. Am ${ }^{2}$ 23. Oktober demonstrierten 150000 bis 200000 Budapester jugendliche,

- denen sich ubrigens auch elne gróße Anzahl der Alten anschló, für die bërechtigten demokratischen und nationalen. Forderungen .... Dienstagabend wurde diè": Rundfunkanspràche Erno Gerós mit größter Spannung erwartet Diese Rede jèdoch war eine große Enttäuschung, weil'sie 1. bekundete, daß ein.Teil der damaligen Führér das ,Wesen dér Demonstration nicht erkannt hatte oder erkentren wollte; und $2 .$, daß jene führer nicht gewillt waren, aus der Demonstration konkrete Lehren zu ziehen . $\therefore$.

Es ist wichtig zu bemerken, daß auch nachher, am zweiten und Eritten Tag, Demonstrationen vor öffentlichen Gebaúden statttanden, unter anderem mit folgenden Schlagworten: Unabhängigkeit! Freiheit! Wir sind keine Faschisten!" Es ist ebentalls wahr, dạ Plünderungen lediglich in geringem Maße stattfariden, verübt durch ehrlóse Elemente, die sich untế die 
Demonstranten mischten; dagegen konnten wir uns vielerorts uberzeugen, dab die hinter den zerbrochenen schaufenstern ausgestellten waren nicht ange ührt wurden. Aufgrund all des. sen können wir feststellen, daß es sich auch nach Ausbruch der Kampife nicht enfach darum händelte, daß auf der einen Seite die Konterrevolutionáre standen una auf der anderén dem Regime loyale Einheiten. Dié Wahrheit ist daß unter den am Kamp teilnehmenden Aufständischen anfangs die Zohil jener ehrbaren Patrioten auberordentlich groß war darunter aveh Kommunisten, die bisher die sozialistiscine Demokratie "ncht gesichert suhen Auch die tragischen Ereignisse durfen unseren Blick nicht so weit trüben, daB wir die wahrheit vor Ávgen verlieren: Die Studenten aus Arbeiter- und Bavernkreisen sowie hitellektueller Abstammung, und auch die Arbeiterkinder können wir nicht als Fènde der volksdemokratie bezeichnen. Wir müssen ebenfalls bemerken, daß die Offentlichkeit die Ernennung von Imre Nagy vertravensvoli begrubte Aber der BeschiuB, welcher Énô Gero als Ersten Sekretär bestätigte, goß ol au das Fever. Die Erklarung Imire Nagys, dann die Ablösung Ernö Gerös und die Ennennung János Kádár als Erster Sekretar, dazu die Erklárung des erneverten Zentralkomites und die Tatsache, daB in der neuen Regierung beispielsweișe Zoltán Tildy, Bela Kovács, Görğ Lukaçs und Antal Gyenes warei, fand den Beifall bedeutender Massen Doch der Kamṕ ging weiter Seit Donnerstagriachmittag abschwachend. Der. Widerstand ließ keinesfalls in èrster Linie wegen der sowjetischen Truppen nach, sondern weil ein bedeutender Tell der Aufstandischen die Erfülung seiner demokratischen forderungen gesichert sah und ab Donnerstag die Amnestie zur Niederlegung der waffen be: nutzte Bezeichnend tưr die Mentalitat dieser demokratischen schichten ist, das nachtier mehrere von hren gemeinsam mit den ungarischen Soidaten und Polizisten sich an der wieder hierstellung der Ordnung beteiligten . ."

\section{0:55 Uhr, Sender Györ}

"Auch Zalaegerszeg meldet sich nicht. Bisher kam auch von Zolae gérszeg ke ne Melaung journalisten, itr wibt, wie ihr Gyor und den Freien Sender Györerreictien könnt Meldet eựl Nationalräte der Städte und Dörfer von Vas, zäla und 
Veszprém: Schickt Meldungen an den Sender Gyọrl Ünsere Teléfonnummer ist 3641 und $3741 . "$

"Llebe Kinder! Seit nicht böse, daß'wir euch wegen der vielen Arbeit vergessen haben. Die kleineren unter euch schauen milt verwunderten Augen auf das, was in diesen "Tagen in eurer Umgebung und im ganzen Land geschieht. Ihr habit vōn einer Revolution, von Kämpfen und Forderungen vernommen, und von vielem anderen, was ihr vielleicht noch gar nicht verstehen könnt. Wenn wir mehr Zeit hätten; würden wir uns mit euch zusammensetzen und eure Fragen hier vor dem Mikrofon beantworten. Auch solche Fragen, die zuerst vielleicht dumm klingen, und andere gescheite fragen, wie'ihr sie bestimmt" stellen würdet. Leider haben wir dáfüu jetzt keine Zeit. Aber wir wollen all eure Fragen folgendermaßen beantworten: Eure Eltern und älteren Geschwister kämpfen, damit 'es euch besser gehen soll, damit mehr sonnenschiein in ever Leben fälit. Ihr sollt öfter Grund haben zum Lachen als zum Weinen. All dies geschieht, damit zwischen euch 'Kindern kein anderer Unterschied sein möge al's der; daß der eine blond und der andere braun ist, dèr èine ausgelassener. und der - andere ruhiger. Es soll aber nicht deri Unterschied geben, dá $\dot{B}_{\text {t, }}$ den einen von euch ein schönes, glänzendeș Auto zur Schule fähtr, während die anderen mit Tränén in den Augen und neidisch züschauen. Wir wollen nicht, daß man auch in zukunft euch nach eurem Papa und eurer Mama in Kategorien ein'teilt. "Wir wollen, daß dies nie wiederkehre. Sicher versteht ihr das, weil ihr kluge Kinder seid. Aber unterhalten wir uns eli andermal darüber. Schaut jetzt aus dem Fenster es regnet! Nehmt eure Hefte, Bleistifte und. Bücher zur Hand und macht eure Aufgaben, denn morgen ist wieder schultag. GewiB werden jetzt eure Lehrerinnen und Lehrer eine gröBere Ein's' in ever Heft schreiben, wenn ihr eure Aufgaben schön schreibt..."

\subsubsection{Uhr.}

Die Arbeiter der Káminkehrer-Genossenschaft der Kommitate Györ und Sopron haben einen provisorischen Arbeiterrat gegründet...

\subsection{Uhr}

„.. Im veriaufo des interviews erklärte dêr ôsterreichischo 
Minister, daß das österreichlsche Volk mit ungetellter. Begel-" sterung und vollstem Verständnis die Ereignisse in Ungarn verfolgt .... Um die Lelden einigermaßen zu lindern, wurden be-

- reits bisher Medikamente im Werte von mehreren Millionen Schilling gesammelt ... Der Minister berichtete weiter, daß die Bevölkerung von Wien, Preßburg und Westberlin die Vorgänge in Ungarn mit größter Aufmérksamkeit und Mitgefüh! verfolgt ... Auch in Belgien, Frankreich und Holland werden Medikamente gesammelt . . Bewaffnete Einheiten können die Grenże in keiner Richtung überschreiten; weil siè von der österreïchischen Armee entwaffnet werden.' Schweren. Herzens erkiớrte er, dạB keine Hilfe anderer Art geleistẹt werden könne. . ."

\section{2:00 Uhr}

$\therefore$ "Wie das Ernährungsministerium meldet arbẹten alle, 228 Budapester Böckereibetriebe. Heute bringen bereits 150 Lastkraftwaged und eine Anzahl von Pferdewagen Brot in alle Stadtelle von Budapest ... Schritte wurden unternommen, um $\therefore$ in den Mühlen die Arbeit wieder aufzunehmen, um damit Mehlvorräte für die Bäckereien bereitzustellen."

\subsection{Uhr}

„.. diè dicken Notizblöcke werdèn hervorgezogen, die belden englischen, drei holländischen und vier österreichischen bzw: deutschen Journalisten stellen eine Unzahl von Fragen. Wie ich sehe, Ist der junge Reporter des Hamburger Abendbláttés' der lebhafteste. Er stellt die erste Frage.

Frage: Welche politische Grundlage vertritt der provisorische Nationalrat?' -

Antwort: Unser provisorisches Organ stellt den Zusammenschluß dé nationalen Strömungen auf breitester Grundlage dar. Deshalb besteht er aus Männern verschiedener Anschau. ungen, dle sich jedoch über den dringendsten Aufgáben einig sind - unbedingt demokratisch empfindénde Männer..... Welches sind diese politischen Richtungen?"

im weșentlichen können Sie das meiner vorangegángenen Antwort entnehmen. Es handelt "sich alșo um die Vertreter der ehemáligen Demokratischen Partel, wahre Patrioten, die sich dazu berufen fühlen, eine gewaltige nationale Einheitsfront zu schatfen.' 


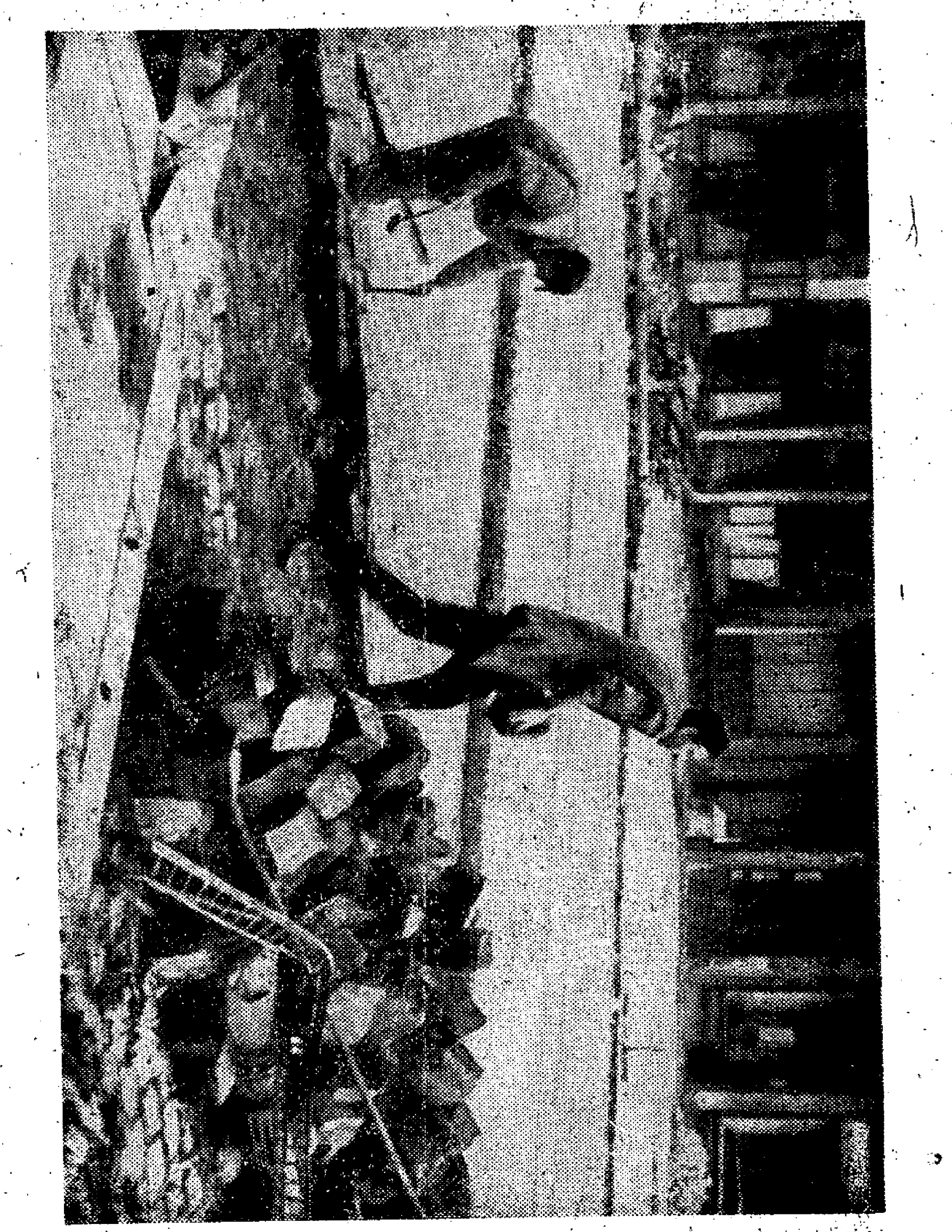


Das helist also, daß auch die Kommunistische Partel im Rat vertreten ist?'

Ja, es sind auch Kommunisten unter ihnen: Aber nur solche, welche die schweren Fehler der Parteileitung zutiefst verurteilen und ein freies, unabhäingiges Uungain wollen ..."

\subsection{Uhr, Radio Kossuth}

Auslandsnachrichten: "Die heutige Ausgabe, der. BORBA schreibt über die neue ungarische Regierung. Sie begrüßt die Zusammensetzung der sich in nationaler Eintieit konstituierten. ungarischen Regierung und stellt fest, dạ șie in der Mehrtieit ous Pérsonen besteht, welche weder mit Rákósi nochn Gerö kolloborierten, und sich vor dem, Volk: nicht kompromittiert haben:".

"Wie der Warschaver Rundfunk am Samstag meldete, isind die auf Grund des internationalen Abkommens in Polen befindlichen sowjetischen-Truppen nunmehr ausschließlich auf den

"ihnen vertraglich zugewiesenen stützpurikten stationiert."

$\therefore$ Bie, sowjetische Regierung hat ihre Antwort auf die Note der - Westmöchte vom 10 . Oktober betreffs der Deutschlanafrage $\therefore$ Uberrelcht: Laut AFP betont die sowjetische Antwortinote, daß ies für die:Wiedervereinigung. Deutschlands lediglich den Weg i der:Annäherung beider :Stadten gibt: ... Die : sowjetische Regierung:erklärt sich bereit, die Annäherung der beiden, deutschien Staaten zu fördern und fordert die-Westmächte quf, dazü beizutragen:"

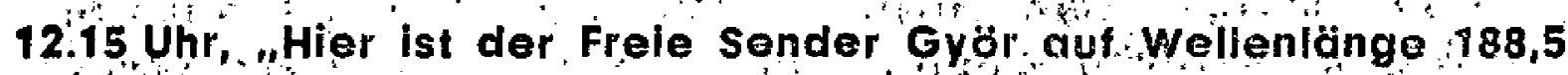
und 253,8 .

Dle genaue Uhrzeit ist 12.15 Uhr. Wir verlesen die Radiomel"dung vom Nationalrat des Komitates Györ fur Budapest. Im Namen von Transdanubien fordern Wir Ministerpräsident Imre Nagy, aut, bis zum 28: Oktober 1956, 20.00 Uhr, Maßnahmeñ zur Beendigung der Kämpfe zu ergreifen. Im Interesse der Durchifuhrung solcher Maßnahmen ersuche er das ober-" kommando der sowjetischen. Truppen, sich an den Kämpfen nicht länger zu beteiligen. Wir übermitteln unsere forderung auf dem Rundunkwege und erwanen eine personliche Antwort Imre Nagys bis heute abend 20.00 Uhr. Gez.: Der. Nationalrát des Kommitates Györ." 


\subsection{Uhr}

"Die Arbeiter der Kráftán rzeugreparaturbetriebe thabeln er$k$ ärt, daß sie die Arbeit nicht aufnehmen, solange sowjetische Truppen in Ungarn stationiert sind."

\subsection{Uhr}

"Auf den Olfeldern herrscht Ordnung und die Forderung geht "unter der Leitung des Arbeiterrates diszipliniert vor sich Die Arbeiter werden jedoch kein Oi liefern, weil sie nicht wollen, daß mit dem von ihrien geförderten ol sowjetische Panzer betonkt werden..."

\subsection{Uhr}

"Im Einvernehmen mit der Bevölkerung des. Kónmitats stellt der provisorische Nationalrat von Györ mit Bedauer ren fést, daB der Sender Kossuth in diesem drämatischien Kanpf der Nation seine Informationstätigkeit nicht dem Interesse des "Volkes entsprechend verrichtét. Deshatb fordert der provisorische Nătionalràt von Györ, daß die Regierung dén Sender Kossuth an: die ungarischen Schriftsteller übergibt, damit sie die Nation wahrheitsgetreu unterichten..."

\subsection{Uhr}

Die Abreise des ersten Teils unserer olympischen Delegation mußte heute verschoben werden. Die Mehrzahl der Mitglieder ist im. Hotel, Roter Stern' untergebracht... Alle hoffen, daß sie - wenn auch mit Verspätung von einigen Tagen - bald abreisen köninen."

\subsection{Uhr, Radio Kossuth}

"Die Ereignisse des heutigen Tages gruppieren sich um drei Nachrichten von auBerordentlicher Bêdeutung: 1: der Woffenruhe-BeschluB des Ministerrates, 2. die Rundfunkanisprache von Imre Nogy, 3. dos Kommuniqué ubber die dritte Sitzung des Zentralkomitees."

\subsection{Uhr}

Sport: Auf dem Rückweg von ihrer Tournee durch Westeuropo ist heute die ungarische JugendfuBbalmonnschaft per frugzeug von London in Wien eingetrotfen.

\subsection{Uhr}

Jetzt steht Stadisminister Zoltón Tildy vor dem Mikrofon: "Ungarn, meine teuren Brüderl Nach achtjöhriger intemierung kann ich nun wieder frei zu euch sprechen. Es war dos sefuhl 
dèr Verantwortung euch, eurem schicksal und dem Schicksal des vateriandes gegenuber, das mich dazu bewegte, an der Regierung Imre Nagys teilzunehmen. Imre Nagy ist Kommunist, ich bin es nicht - wir sind jedoch, zusammen mit den übrigen Mitgliedern der Regierung, in erster Linie Ungärn ... Wir verwerfen auch jene Wirtschaftspolitik, welche vón unserem Volk, von dieser Generation; ubertriebene und oft unertrögliche opfer gefordert hat im interesse einer fernen Zukunft. Auch die heutige Generation will ein freies und ruhiges menschliches Leben leben..."

\section{Montag, 29. Oktober 1956, „Hier sind die Sender Kossuth und Petöfi, Budapest}

\subsection{Uhr}

Guten-Morgen, liebe Hörer! Die genaue Zeit: 4.30. Uhr. Heute ist. Montag, der 29. Oktober. Im Kalender steht der Namé Zèno..."

\section{7:00 Uhi}

Wir verlesen jetzt den Leitartikel der heutigen Ausgabe vón DAS FREIE VOLK ("Szabad Nép"): -

Die Uberscinrift látet: Es wird Tag!

"Wenn wir lediglich auf unsere Herzen hören würden, könnten wir auf die Rede von Imre Nagy jëtzt nur dies eine sagen: warum ist all das nicht schon früher erlaubt worden, warum ist alles nicht schion. früher: geschehen, westialb konnte man nicht verstehen, was das ganze volk will, worauf es mit heiBer, jahrelang unterdrückter, aber jetzt unwiderstefilicher Leidënschäftlichkeit besteht, daß Ungarn wirklich Ungarn sèi, dảß 'wir ein nationalès Wappen habèn sollen, dả der 15. März das großartige Fest der ganzen Nation sei, daß die sowjetischen Truppen aus unserem Land abgezogen werden, daß die berechtigten Forderungen der Arbeiterscháft verwirklicht werden, daß uns die Regierung statt versprechungen und blumenreichen Worten ein besseres Leben ermöǵliche; daß die Verfolgungen aufhören, daß die gewaltsame Kollektivisierung eingestellt werde; und so weiter und so fort. Warum nicht eher? ...WWieviel Blut, das Blut wie vieler wahrer ungarischer patrioten, mubte geopfert werden ...." 


\subsection{Uhr, Séndệr Miskolc}

Brief des Revolutions-Komitees der Intellektuellen:

"Ungarn, Mitbürger! In heldenhaftem Freiheitskampf hat das ungarische Volk den Endsieg errungen! Wie thr im Radio gehört habt, hat Ministerpräsident Imre Nagy die Erfüllung unserẻr wichtigsten Forderungen angekündigt: die. Auflösung des Stáatşsicherheitsdienstes und den Abzug der sowjetischen Truppen aus Budapest... In dlesem Land gehört jetzt die Macht dem ungarischen Volk. Die Volksarmee hat sich auf die Seite der kämplenden. Jugend gestellt; zusammen mit der Polizel, den Arbeiterröten und Baúern, und gemeinsam haben wir auch die Kraft, uns ein unabhängiges, demokratisches Leben zu.schaffen ...

Ứgarn! Mögen auch Meinungsverschiedenheiten zwischen uns existieren, so sind wir uns in den wichtigsten forderungen doch einig: wir fordern folgendes:

:1. Die Regierung soll unverzüglich unsère Bëziehungen zür Sowjetunion auf der Basis der Gleichberechtigung ordnen. Die Sowjettrúppen sollen sofort mit demiabzug aus dem ganzen Lând beginnen.

2. Die Regierung soll unsere nachteiligen AùBenhan Álsverträge annulieren. Die Schătze der ungarischen Erde, Uran; Bay$x i t$, und auch die Früchte der Arbeit unserer Bauern sollen nicht auf Grund von Geheimverträgen zu Schleuderpreisen ins Ausland gelangeñ.

3. Allgemeine, geheime Wahlen. Das Volk soll frei seine Kandidaten qufstellen können.

4. Dié Fabriken und Bergwerke sollen wirkich den Arbeitern gehören. Fabriken, Felder gében wir den Kapitalisten und Groß̧grundbesitzern nicht zurück! Die Leitung der. Betriebe soll freigewählten Arbeiterräten übertragen werden. Die Regierung soll die Entfaltung des privaten Handwerks und des privaten Handels ermöglichen.

5. Die Reglerung soll das ausbeuterische Normensystem abschatfen. Unseren wirtschaftllchen Möglichkeiten entsprechend sollen die njedrigen Löhne und Rưhegelder erhöht werden.

6. Die Gewerkṣchaften sollen wirkliche InteressenschutzOrgane sein ... 
7. Die-Regierung garantiere die Freihelt-landwirtscheftlicher Produktion:. Das verhaßte Ablieferungssystem, durch das Böuern ausgeplündert werden, soll abgeschafft werden.

8. Gerechtigkeit soll geübt werden, und die durch ungesetzliche Maßnahmen geschadigten Bavern sollen mâterielle Entschäaligung erhalten.

9. Vollige Freiheit der Redé, der Presse und Versammüng.

$\therefore 10$ Den 23: Oktober; den Tag, an dem unser Freiheitskampt begann, soll die Reglerung zum Nátionalfelertag ërkiâren.

Gegeben zu Büdapest am 28 oktober $195^{\circ}$

gezeichnet:

das Revolutionskonitee und das Kômitee Ungarischer intelléktueller;

Revolutionskomitee der Ungarischen universitâtsstudenten;

Verband der Ungarischen Schriftsteller:

Landesverband der. Ungarisctien Journalisten;

Verband der Bildenden Künstler;

Verband Ungarischer, Musiker:

die Universitätsdozenten;

die volkskollegien;

der Petöti-Kreis:

der MEFESZ (Studentenverband):

\subsection{Uhr, Radio Kossuth.}

Ausiandsnachrichten:

Müchen: Der motorisierte Hilfszug des Deutschen Roten Kreuzes, hat heute München in Richtung Wien verlássen von dort wird er nach Ụngarn weitergeleitet Ein Arzt zehn Schwestern und 30 , Gesundheitsangestelle begleiten den Transport. Dje Wagen führen eine kómplette chirurgische Klnik, siêben Tonnen Lebensmittel, viel verbandsstoff, Medikamente und Blutplasma mit.

\subsection{Uhr.}

Reportage: „A... Am. Eingang des Ratsgebaudes kontrolleren bewaffnete Studenten unsere Ausweise Alle trogen die nationalfarbene Armbinde ..."

\subsection{Uhi, "Hier ist der Freie Sender Györ:}

- Es ist unser Wille, daß die Russen sotort abziehen. Wir haben - Mur eine. Waffe, um dies durchzusetzen: den Streikl Die Sprecher der Arbeiterröte von. Pécs, Dorog und Tata haben gè- 
schworen, daß kelne Kohle gefördert wird, bis die letzte russische Division aus Ungarn abgezogen ist!

Die Jugend. von Györ nimmt die Arbeit nicht eher auf, bis die letzte russische Divisioniunser Land verlassen that $\therefore l^{\prime \prime}$

\subsection{Uhr}

"Achtung! Achtungl Einheiten der Ungarischen Volksarmee haben heute abend im VIII. Bezirk von Budapest mit der Áb: lösung:der' sowjetischen Truppen begonnen und sichern ihren Abzug. Bis zum Morgengrauen wird das mit dem Kommandeur der. Widerștandskräfte vereinbarte Gebiet von sowjetischen Truppen evakuiert sein. Um 9 Uhr werden die Widerstandskämpfer dann die Waffen niederlegen. "Károly Janza, Verteidigungsminister:"

\subsection{Uhr, Hiẹr sind die Sender Kossuth und Petöfi!}

Auslandsnachrichten. Aus Belgrad meldet TANUG Titó... hat folgendes Schreiben an das. Präsidium des Zentralkomitees der Ungarischen Arbeiterpartei gerichtet:

"Bereits seit mehreren Tagen verfolgen das jugoslawische Volk und der Bund jugoșlawischer Kommúnisten die Nachrichten yon den tragischen Zusammenstößen im benachbarten Ungarn mit Spannung und Sorge . .. Die Bedeutung diesèr Vorfälle geht weit über die Grenzen Ungarns, weil sie auch die Interesșen der internationalen sozialistischen Entwicklung unmittelbạ "berühren..."

Dienstag, 30. Oktober, „Hier sind die Sender Kossüth und Petöfi,

4.30 Uhr

\section{Budapest!}

Guten Morgen, lieba Hörer. Heute ist Dienstăg, der 30 Oktober 1956. Sonnenaufgang 6.27 औ.

\subsection{Uhr}

Auslandsnachrichten: Wieñ: Die ungarische Botschaft in Wien "hát die nationálfarbene Fahne gehiBt."

\subsection{Uhr}

Achtung, eine wichtige Mittelung! Dás 'Verteidigungsôninistêrium teili mit: :

-Wie bereits gemeldet, wird in Budapest der Abzug der sowjetischen Truppen; die den bewaffneten Gruppen gegen- 
überstehen, fortgesetzt. Elnheiten der' ungarischen :Armee und Polizei sowie bewafnete Verbände der Arbeiterschaft und Jugend übernehmen die Aufrechterhaltung der Ordnụng: . L Liebe Hörer, wir werden Sie auch weiterhin regelmäBig über den Abzug der sowjetischen "Truppen von Buda-

\subsection{Uhr} pest unterrichten."

"Dás Revolutionskomitee der. Universitätsstudenten bittet alle Universitäts-, Hochschúl- und MEFESZ-Komitees, jë Fokultät zwẹi Delegierte nach Budapest zu schickén, und zwar ins Gebäude der Philologischen und Literaturwissenschaftlichen Fakultät der Loránd Eötvös-Universität, damit sie an der Arbeit zur Vorbereitung des Landesstudentenparlaments teilnehmen. Für Verpflegung ist gesorğt. Zür Zeit ist die Hauptstadt am leichtesten ouf Lebensmittelransport-LKW zu erreichen. Ersucht unterwegs die Militärkommandanturen um Untérstützung."

\subsection{Uhr, "Hier ist Miskole, der'Sendor des Arbelterrates des Komitats Borsod!}

... In den vergangenen Tagen haben sich die Führer der So; wjetunion wiederholt auf den Warscháuer vertrag berufen. in diesem Zusammenhang möchten wir bemerken. $\therefore$ (starke . Störung)... Es geht nicht an, daß sich imperialistische Trup-

- pen auf ungarischem Boden befinden . Wir bitten deshalb um unverzügliche Revision des Warschauer Vertrages I .

\subsection{Uhr}

„... Whe die Beispiele beweisen, hat die Sowjetunion in der gegenwärtigen Lage sowohl den. Warschauer Vertrag als auch die UNO-Statuten gröblichst"verletzt. Es ist nicht wahr, daß in. Ungarn dieser Kampl, der von "gewisseñ Kreisen als Gegenrevolution bezeichnet wird, von Imperialisten vorbereitet und entfacht wurde. Lenin hat gelehrt, und diese these ist auch heute guiltig, daß eine Revolutión "weder exportiert noch importlert werden kann. Dementsprechend kann auch diese Revolution nicht eine Gegenrevolution genannt werden. Dies ist keine Gegenrevolution, sondern die dynamische Explosion der im Volk seit vielèn Jahiren aufgespelcherten Sehnsucht noch Freiheitl. .." 


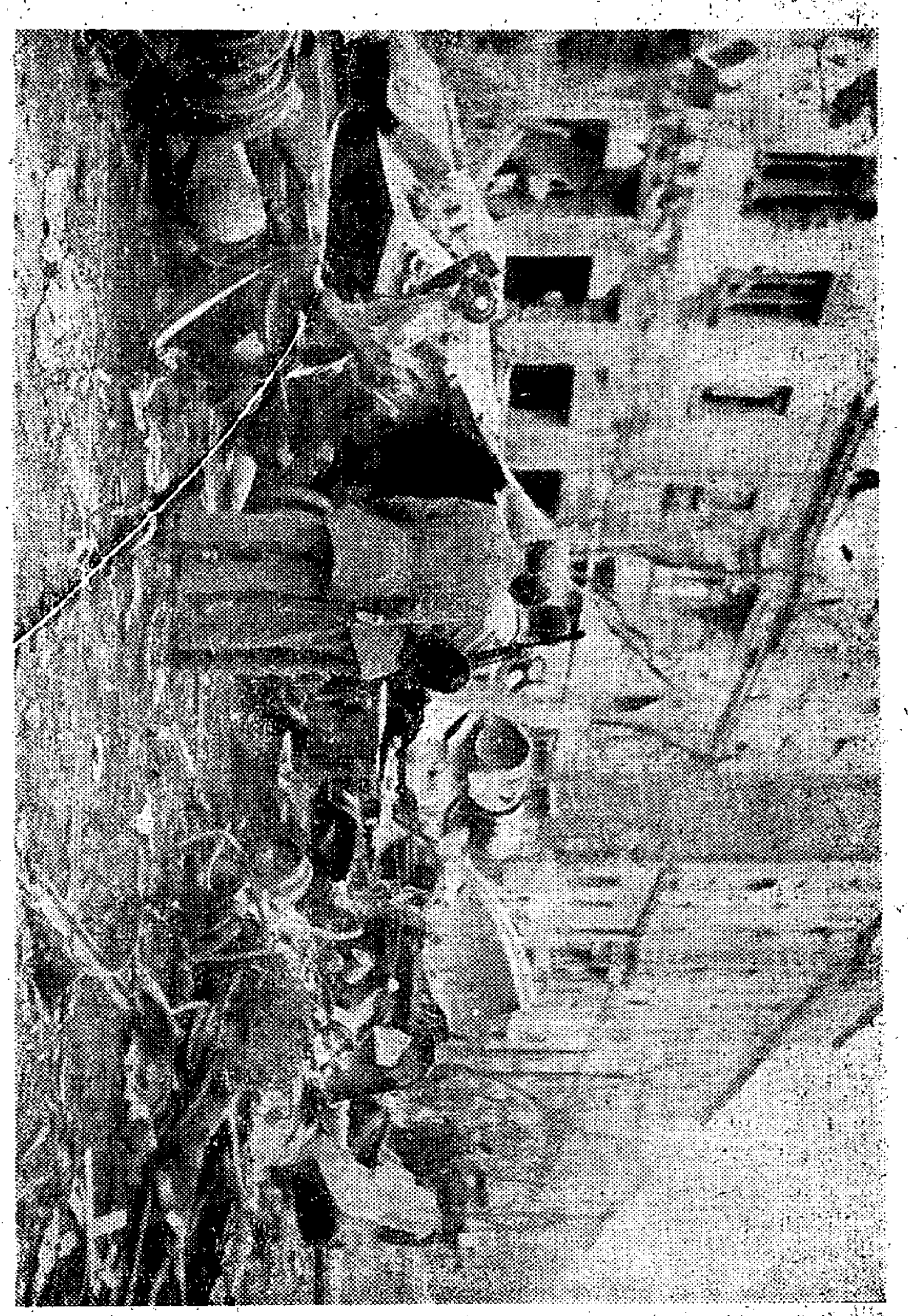




\subsection{0'Uhi}

"Appell an die UNO Appeli an die UNOOI.

Das ungarische Volk bittet die Vereinten Natonen den Landesverräter peter Kóos nicht anzuerkentnen und seine.im

Namen der früheren șówie derzeitigen Regierung abgegebenen Érkärungen zu verwerfen. Gleichzeitig ersucht das ungafische Volk den sicherheitsrat, im Sinne der Artikel 4, 7 und 8 destwarschaver vertrages unverzüglich im Interesse des für séne Fleiteit kämpteriden Ungarn einzüschreiten! Außßerdem bittet es den sicherheitsat, einen neutralen stad mit der Vertretung der ungarischen Belange zu betrauen! Dás unga" rische volk hat im Augenblick keine Möglichkeit" "einen Delegierten zu entsenden, solange és seine Regierung nicht nact eigeinerr Gutdünken wählen kanni" ".

"In diesen schweren Tagen frağ sich jeder Ungar: wem sol- len wirglauben, wem können wir noch traven?! 12 Jahre lang sind wir durch die kriminelle Politik der Rákosi-Leute so oft betrogen worden, daß dieses Mißtrouen gegenüber allen "Versprechungen sehr verständilich ist :..."

\subsection{Uhr, "Hier ist Radio Szombathely!}

Volg unseren heldenhaíten Brüdern, die auch jetzt noch in Budapest kämpfen, hat Ministerpröșident line Nagy in seiner

$\therefore$ Rundfunkrede vom Sonntag selbst gesagt; daß sie keine. Kon-

$\because$ terrevolutionäre sind; sondern daß sie fúrdie Erneverung des ungarischen Staates und der ungarischen Nation zu den Wäfén gegriften haben... Niematid zweifelt; daß morgen, in einer Woche oder vielleicht erst in einem Monat; einesitages. aber gewiß die Panzer der tremden streitmacht über die. Leiber unserer letzten kämṕtenden ungarischen Briuder rolien, werden. Ein Zwerg führt einen, zwar hèroischen, aber aussichtslosen Kampf gegen einen Riesen. Wie lange noch will unsere Regierung mit der Anordnung warten, welche die Feüerpause herbeiführt und den fremden Truppen den Äbzug aus unserer Hauptstadt befiehlt? Warum knupht sie diese Maß̉nahme an Bedingungen, die für unsère Helden unannehmbar sind? ..."

12.00 Uhr, "Hier ist Miskolc, der Sender des Rates des Komitats Borsod!

Seit der Nacht zum 24. Oktober zieht die sowjetische Armee 
mit zähilreichen Einhèiten in unser Land ein! Alles spielt sich vor unseren. Augen bei Beregsurány ab! Den letzten Regierungserklärungen zufolge sollen die Sowjettruppen seit Beginn der feverpause aus Budapest abziehen. Warum also ist es notig, daß neue Sowjettruppen ins Land gebracht werden? Wir fordern sofortige Maßnohmen, welche das Eindringen weiterer sowjetischer. Einheiten unterbinden und den Abzug der sowjetischen Streitkräfte aus Budapest Gewährleisten! Die Regierung soll der Bevolkerung die Whilheit sagen und ihr versprechen erfülien, den nur so wird in unserem Land Ordnung und Ruhe einkehrent"

\subsection{Unr Radio Kossuth}

Presseschau: Die "New York Hercid Tribune" betont; daß riach den Erelgnisseñ in Ungarn die heutige Welt mit der gestrigen nicht mehr identisch ist.

\subsection{Uhr, iHier ist der Freie Sender Györ!}

Vor unserem Mikrofon steht Onkel Józsi...; den die Arbeiter der olfelder géschickt haben:

$\therefore$ Für die sowjetischen Panzér geben wir keinen Tropfen Oll Wir fordern kein Ol, bis uns die Regierung - an besten Imré Nagy persönlich über den Kossuth-Sender sagt, wer unser ol kriegt." -

"Was wollen Sie tôn, wenn die Regierung die Garantie nicht gibt?

,Dón werden wir im Envernehmen mit den olarbeitern von Nagylengyel und $B d z$ akerettye der Olproduktion ein Ende bereiten Billionenwerte würden verlorengehen ... aber die sowjetisctien Panzer sollen das ungarische volk nich mit ungarischem Treibstoff angreifen! Wir bitten dritigerid um antwort."

\section{$14.28 \mathrm{Uhr}$.}

Wir joertragen jetzt die. Ansprache des Ministerpiósidenten der National regierung, Imre Nagy: „.. Die Nationalregierurig fordert die Befehtshaber der sojetischen Truppen auf, unverzüglich mit dem Abzug ihrer Truppen von Budapest zu beginnen. Gleichzeitig teilt die Regierung der Bevölkerung mit, daß sofort Verlandlungen mit der Regierung der Sowjetunion wegen dem Abzug der sowjetitischen Truppen aus Ungain aufgenommen werden 


\subsection{Uhr}

Es spricht jetzt Staatsminister Zoltan Tildy:

„Meine ungarischen Brưder! . . : Die Regierung hat Péter Kóos seiner Aufgabe als UNO-Delegierter enthoben. Eine neve Delegation wird ausgesandt, welche bereits den Standpunkt der ineuen Regierung vertritt. - Ich gebe bekannt, daß das Ab"lieferungssystem, welches die Bavernschaft so schwer tifft, mit dem heutigen Tag abgescháft ist. . . Das Volk selbst solt ohne Einmischung uber das Schicksal des tandes entscheiden. Wir werden also freie wahlen vorbereiten ...."..."

\subsection{Uhr}

ithebe Hörer! In dieser Stunde bëgininen wir êin neves $\mathrm{Ka}$ pitel in der Geschichte des ungarischen Rundfunks. Lange Jahire hindurch war das Radio ein Werkzeug der Lüge Es hat Befehle ausgeführt. Es hat nachts gelogen, es hat tags gelogen, es hat duf allen Welleniängen, Lügen ausgestrahlt. Selost in diesen -Tagen, in der Stunde der: Wiedergeburt unseres Heimatlandes, hat es das Lujgen nicht lassen kọnnen. Aber der Kampf, der auf den Straßen die Freiheit und Unabhängigkeit der Nation errang, ist.auch Zwischen den Wënden des Rundfunks aufgeflammt. Diejenigen, welche Verkünder der Lüge waren, sind von dieser Minute áb nicht mehr Mitárbeiter des ungarischen Rundfunks, der von nun ab die Namen Kossuth und Petöfi zu Recht tragen darf:"

"Wir die wir jetzt vor dem Mikrofon stehen, sind an dieser Stelle zum Großteil neue Leute. In Zúkunft werdẹ Sie duf den calten Wellenlängen neve Stimmen hörén. Wie es die berühmt gewordene alte. Eidesformel vertangt, wollen wir die Wahrheit sagen, die ganze Wahthelt, und nichts als die wahrheit! : . gez.: Revolutionskomitee des Rundrunks."

\subsection{8: Uhr}

Staatsminister Żoltán Tildy bittet alle ehemaligen Mitarbeiter der KIS UJSAG ("Kleine Zeitung" ... von den Kommunisten verboten), sich noch heute in seinem Büro im Parjamentsgebâde einzufinden, damit die KIS UJSAG so bald als möglich wieder érscheinen kann. Ich wiedertiole

\subsection{Uhr, "Hier ist der Sender des Arbeiterrates yom Komitat szaboles-Szatmar!}

Achtungh Achtung! Während der Ministerrat Aufrufe an das 
Volk richtet, mit den sowjetischen Befehlshabern verhandelt oder duch nicht, und verkündet, daß die sowjetischen Truppen aus Budapest, abgezogen werden, durchqueren von; Osten stäke Verböride die Stadt Nyiregyhaza in Richtung des. Herżens unseres Landes! - Genug der Volksverdummung! Wir sehen ja mit eigenen Augen, was vor sich geht, umsonst wird von Marschall, Zhukow behauptet, daß. keine sowjetischen Truppen mehr nach Ungarn kommen Falls sie zu verhandeln begonnen haben und nicht nach unserer freiheit trachten, -watum kommen sie dann ins Land?!"

\subsubsection{Uhr, Radio Kossuth}

Achtung! Achtung! Eine Durchsage: Wir unterbrechen unsere Sendung wegen einer wichtigen Mitteilung: Staatsminister. Zo tán Tildy hat vor einer Arbeiterdelegation erklär er hielte es fur wünschenswert, daß Kardinal József Minjascenty nach. "Esztergom zurückkehre und durch Ubernahme seines' Amtes als Primas teilnéhme an dem noblen Kampf dér in dieser. historischen Stunde unseres Heimatlandes jeden wahrhaften Patriotén beansprucht.

\section{$16.45 \mathrm{Uhr}$}

Hevte mittag habon die Arbeiter der Obersten Ş Satsanwaltschaft ihr Revolutionskomitee gewähit und obersiadianalt György Non zum Rücktritt aufgefordert! - György Non hat aktiv an der Deklarierung des Ausnahmezustands und dessen Durchführung mit allen Mitteln mitgewirkt! Gleichzeitig drückt das Revolutionskomitee allen staatsanwälten seine Anerkennung aus, die in den vergangenen Tagen die Befehte György Nons bezuglich der. Aburteilung eines Telles der Gefangenen sowie noch gestem bezüglich der Inhattierung von Gefangenen sabotiert haben!....

\subsection{Uhir, "Hier sind die Sender Kossuth und Petöfi!}

AFP meldet qus Wien, daß Ferenc Nagy, der in "der Emigration lebende ehemalige ungarische Ministerpräsident' nach einem Aufenthalt von wenigen. Stunden wieder nach Paris zurückge-

$\because$ reist ist Die österreíchischen Behördén gáben ihm zur Kenntnis, daB seine Anwesenheit in Osterreich mit der Neutralität des Landes nicht in Einklang gebracht werden könne."

\subsection{Uhr, Sender Szombathely}

5. Wir fordern von der ungarischen Reglerung, dab sie 
uber Radio:Kossuth in ungarlscher sowie russischer sprache eine Erklörung abgibt, wonach volle Amnestie und politisches Asyl allen sowjetischen Militärs und Zivifpersonen garantiert wird, die sich auf die Seite der ungarischen Revolution stellen;

-.9. daß im Land die vollständige Rede-, Presse-, Versammlungs- und Religionsfreiheit garantiert wird. AuBerdem sollen Kardinạ József Mindszenty und andere benachteiligte Mit. glieder des Klerus in küzester Zeit-voli rehabilitiert werden und ihre kirchlichen funktionen baldmöglichst wieder aufnehmen können.

. Wir fordern von der Regierung die Revision der Abortus-Veroranung, weil unser Arbeiterrat der Meinung, ist, dăß sie den Bevölkerungszuwachs verhindert ... .

\subsection{Uhi, Sender Miskolc}

"Rumänische und șlawische Brudder!

Wir bluten und ihr schweigt?

Wir kämpien um unsere Freiheit, und ihr nennt uns Faschisten??! ..."

\subsection{Uhir, Radio: Kossuth}

Wir verlesen elrie Proklamation an die Einheiten der ungarischen Armee:

"Ungarische Brüder, Kameraden!. . Unsere Armee steht auf der Seite des Volkes zum Schutz der Errungenscháften unserer glorreichen Revolution! Wir fordern: 1. den sofortigen Abzug der sówjetischen Truppen von Budapest, und in küzester Zeit aus unserem Land. . . . 4. Der Stactssicherheitsdiënst hat auch unsere Armee- terrorisiert. Der Revolutionäre Militarrat der Armeefürung hat die sofortige Entwaffnung des noch bewatfneten. Staatssicherheitsdienstes beschlossen. gez: Gene;

" rạlöberst Lörinc Kạna."

\subsection{Uhr, , Hier ist der Sender des Arbeiterrates vom Komitat}

\section{Borsod!}

Dos sozialistische Revolutionskomitee von Debrecen fordert:

1 Sofortigen Austritt Ungarns aus dem Warschaver Pakt;

2: wir ersuchen die UNO, sich auf wirksame Weise mit der Sache Ungarns zu befassen, weil die Einmischung der Sowjetunion unsere internen Angelegenheiten zur internationalen Affäre gemacht hat; 
3. wir fordern die Zurückrufung des stalinisten Kós von der UNO:

4. bis zur Wiederherstellung der friedlichen Ordnung betrachten wir. die Regierung nur als provisorisch; nach Ábzug der sowjetischen Truppen sollen in Ungarn freie; demokra-. tische und geheime Wahlen auf Grund des Mehrparteien:systems stattfinden.

5. Bis zur Erfüllung unserer Forderungen setzt die Einwohnerschaft unseres Komitats den Sitzstreik fort."

\subsection{Uhr}

"Lokalnachrichten aus Debrecen: Mórgen vormittăg um 10 Uhr werden die bei den Freiheitskämpten in Debrecén getạlienen Helden mit militärischen Ehren bestattet. - - -

In Debrecen herrscht vollstöndige Ordnung und Diszizplin., Die Geschäfte sind geöffnet. Zucker, Brot und andere Lebensmit"tel sind überall erhältlich."

\subsection{Uhr}

„... was ich nicht verschweigen kann: vorhin erhielten wir von Kisvárda die Meldung, daß bereits seit sechs Tagen éine Fluf von tausenden Panzern, leichten, und schweren Waffen, in unser Land strömt! Auf Lkw werden Infanteristen, in Richitung Nyiregyhaza gebracht! Neue russische Kampfeinheiten! Marschall Zhukow, ist Ihnen da's bekannt? Sie müssen es wis. sèn!..."

\subsection{Uhr, ;Hier ist der Sender des Revolutionären Arbelterrates} von Szaboles-Szatmár!

Achtúng! Eine wichtige Mitteilung: Marschall Žhukow hat den Befehl zum Abzug der sowjetischen Truppen erteilt l Aus dem Stadtgeblet von Budapest ist die "Evakuierung der sowjeti-schen Truppen in Kürze beendet! In Záhony wird der geordnete Auszug der sowjetischen Truppen auf schiene und Straße bereits organisiert!"

20.03 Uhr, „Hier ist der Freie Sender Kossuth (Musik)

Liebe.Hörer, nicht wahr, auch Sie haben den neuen Namen unseres Radios mit Freude vernommen? Der EREIE SENDER KOSSUTH; Budapest ! .. WWir grüBen den Freien Senáler Petöfi In Györ, die Freien Sender Miskolc, Szolnok, Pẹcs, Balatonszabad und Fehérvár und jeden, einzelnen ihrèr Mitarbeiter $\therefore$. 
20.10 Uhr

Die ungaríschen Schauspieler sind nicht gewillt, die Theater zu öffnen, ehe nicht der letzte sowjetische Soldat unser L'and veriassen hat . . .

\subsection{Uhir}

"Hier ist Aurél Molná:

Liebe Hörèr, dem Titel unserer neven: Sendung entsprechend müte ich sie jetzt mit meinen ersten.Worten über den Freien Sender Kossuth davon unterrichten, was ', von früh bis abend" vorgefallen ist. Ich möchte aber lieber davon sprechen, wie unser Erwachen aus der langè, lange Jahre daúernden Nacht ausgesehen hat. . $\therefore$ Ich habe die vom Blut rosafarbenen Steine gesehen und auch die Toten Fünf Tage lang dröhnten die

- Panzer durch die Straßen der Stadt, fünf Tagé schritt der Tod in den Spuren der Panzer, und trotzdem lebte heute die Demonstration wieder auf, wieder erschällen die" Kampfrufe, der unsterbliche, unausrottbare Geist der Revolution spielt. Die Menge marschiert auf dem Museumșing weiter - übrigens ist diese Straße durch ein improvisiertes Schild be reits in ,Straße des. Aufstandes umbenannt. Aber der. Kanonendonner kam von der Rákóczi-Straße. Ein Flugzeug ,brauste Über die Stadt, und wie ein Schiwarm schwarzèr Krähen verfolgten es die Garben der Flugabwehr-MGs: Welch ein Gefuhll wo immer auch in diesen Tagen die, Waffen erklangen, es. wär als pfiffen die Kugeln uns um die Ohren, und am sechsten Tag gingen wir bereits herum wie unbewaffnete Frontkämpter - ich mèine diejenigen̂, die kelne Wáffer hatten. ich bin leider 'kein HeldensproB, so haben "mir halt oft die.Knie geschlottert, während ich zum Museums-Ring strebte

\section{0:30 Uhr} oder schlich..."

"Der Widerhall der ungarischen Revolution In der großen Welt:

Während in der Rákóczi-Straße und aúf dém Großèn Ring englische, amerikanische und französische Fotoreporter die Spuren der Kämpfe im Bild testhalten, schreibt die gesamte Weltpresse in Worten der Anerkennung und des Mitgefühls über das ungarische Volk:...

In den Fenstern von West-Berlin brennen Millionen Kerzen zum 


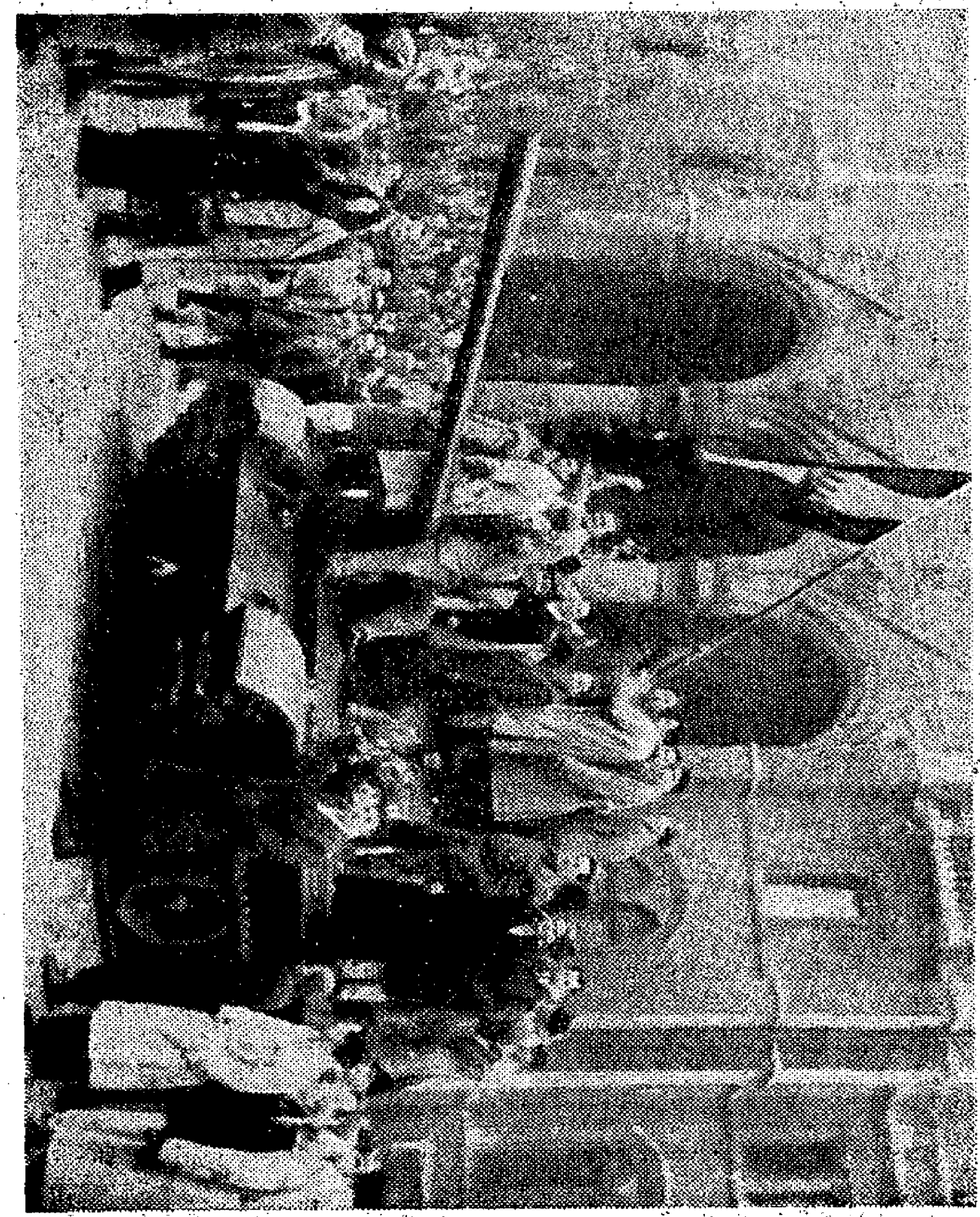


Gedenken für dis Opfer des ungarischen Freiheltskampfés. Die New York Times' schreibt in ihrem Leitartkel, "Ein tapferès Volk hat dem Lauf der Geschichte eine neve Richtung gegeben'...

20:45 Uhir

Der Popst hät eine Enzykliko herausgogében ...

Sendung "StImmen ungàrischer schriftsteller" „... die stadt blutet, unsè ganzes Land blutet, aber es kann lében es wird lebèn $\therefore$ !"

\subsection{Uhr, „Hier ist der Frële Sender Petöfl, Györ!}

Mitteilung des Ministerrates:

"Ungarnl Unser Schmerz, unser Schamgefuhl und unseré Leidenschaftlichkeit wurden aufgepeitscht "durch zwel Verordnungen; deretwegen Aberhunderte verbluter mußten Die eine: das Anrufen der sowjetiachen Truppen die zweite: die Verkündung des schändlichen Standrechts gegen die freihètskämpfer. Unserer Vërantwortung vor der Geschichte be« : WuBt; stellen wir fest, daß Imre: Nagy von diesen beidén Beschlüssen keine Kenntnis hatte. Sein Name ist euf kelrier dér beiden Resolutionen des Ministerrates enthalten. Die: zwei Maß̉nahmenistammiten von András Hégedus und Errö Gerö... I Sie, traǵen dafür die Verantwortung vor der Nation und vor "der Geschichte."

\subsection{Uhr, Sender Miskolc}

Auf die Bekanntgabe des Senders Borsod hin, uber den die Arbeiter von Ozd von dem Be ehe Marschall Zhukows und dem Abzug der sow wetischen Truppeherfuhren, sammelte sich im Nu eine gewaltige Menschenmenge bel den Lautsprechern. Hüte und Mützen flogen in die Luft, Hochrufe brausten durch die Straßèn: Freunde und Unbekanntè fielen sich um den Hals: "Wir haben gesiegt, es lebe Ungarns 'Freiheit, es tebe unser $\therefore$ Helmatiand : . : !"

\subsection{Uhr}

¿Wir, die Studienräte, Arbeiter und Schüler des György:KillanGyminasiums, schlagen vor: ... jede schule bllde einen aus Fachlehrern bestehenden. ArbeltsausschuB, der den allgemeinen Lehrplan überprüft. Vor aliem $m u ß$ dás Lehrmaterial der Fächẹr Geschichte, Ungarisch, Russisch und Geographie umgearbeitet werden:..." 


\subsection{Uhr}

. "Meine ungarischen Brüder, Christen!

Uberall auf" der Welt lesen sehr viele gläubige Ménschen die Bibel nach den sogenannten Tageslosungen. Die heutige lautet: Herr, es ist kein Unterschied vor Dir zwischen dener; die zahlreicti sind, und denen, die kraftlos sind, damit Du innen hilfst! ...

Tiefe Dankbarkeit zu Gott erfullt unsere Herzen. Jetzt Kommen Tage des Jubels. Weg mit der 'Kleinglâubigkeit Aber' fört auch mit der Rache. Wir wollen kein Blut séhen, $\therefore$ son: dèrn die Sonne. Von nun ab sollen die Strahlen der Sonne duf Frevdentränen glitzern, und statt Todesröcheln sollen Dankgebete von Ungarns Erde gen Himmel steigen... .

Ungarn! Christen! Danken wir. Gott, der uns befreit hat. Beten wir Gnädiger Herr, Dein ist der Ruhm. Wir fühlten uns so verlassen, aber Du hast Dich auf unsere Seite gestellt. Es ist kein Unterschied vor Dir zwischen denen, die stark, und denen, die kraftlos sind... (Orgelmusik setzt ein) ... fülle uns mit reiner Liebe. Stähle unsere Arme, damit wir stark sind für die Arbeit. Gib, daß unser ganzes Leben ein einziges. Dankgebet seil Amen."

Mitwoch, 31. Oktober 1956

4.30 Uhr, „Hler ist der Freie Sender Kossuth!

Guten Morgen, liebe Hörer. Heute ist Mittwoch, der 31 -Oktober...

\subsection{Uhr"}

Mitteilungen: Die ungarische Panzerdivision des Standortes Esztergom hat sich in voller Stärke den bèwaffieten Aufständischen angeschlossen und erklärt sich mit deren Żielen solidarisch.

\subsection{Uhi}

$\mathrm{tm}$ Laufe der Nacht wurde uns mitgeteilt daß die Zentrale dér. Sozialdemokratischen Partei ihre Arbeit begonnen hat.

\subsection{Uhr}

Die Nationale Bauernpartei hält heute nachmițag un 2:00, Uhr eine Versammlung $a b$... 


\subsection{Uhr}

Nachrichtệ: Nach eingegangenen Meldungen haben die sowjetischen Truppen bei Morgengrauen das Stadtgebiet von Budqpest verlassen.

\subsection{Uhr}

In diesen Stunden wird von vielen Seiten gefordert, daß der rote Stern von der Stirnșeite des Parlamentśgeböudes unverzưglich entfernt werde Vom technischen Personal dès Parla"ments ènlelten wir jédoch die Aúskunft, daß dieser rote Stern einen Durchmesser von $3,5 \mathrm{~m}$ hat, mehrere tonnen wiegt und in $100 \mathrm{~m}$. Höhe angebracht ist: Zur Entfernung sind daher bedeutende technische Vorbereitungen notwendig, damit das Parlamentsgebäude nicht beschödigt wird. Bis dahin thaben wir veranlaß̉st, "daß der rote Stern mit der nationalfarbenen Fahne bedeckt wird.

\subsection{Uhr}

Die Mitarbeiter des Spielfilmbetriebs und der Wochenschau haben statt mit der Waffe in der Hand mit ihren Kameras an dem Freiheitskampf unseres: Volkes teilgenommen. Im, Kugelregen und Granathagel haben sie die Tage des heldenhaften Kampfes festgehalten, als Dokument für die ganze Welt und als Erinnerung für die Nachweit... Die Aufnahme-Teams. arbeiteten unter schwierigsten Bedingungen, denn die Russen und Staatssicherheits-Leute nahmen einen Teit der Kameraleute gefangen und rissen die filme aus den Kameras... Kameramann Lajos Bencze wurde verwundet . :

\section{3:17 Uhr; Radio Miśkolc}

Aćtung! Liebe Hörer, gestern waren wir die ersten, die der Bevölkerung des Landes mitteilten, daß Marsahall Zhukow den sowjetischen. Truppen befanl, aus: Ungarn abzuziehen. Wie wir meldeten, hatte der. Abzug der sowjetischen: Armee begonnen: Aus unverständlichen Gründen haben jedoch starke sowjetische Streitkräfte, darunter Flak- und Panzereinheiten, ihre Marschrichtung geändert. Uber Záhony und Nyiregyháza marschieren sie wieder in unser Land einl :

\section{3:37 Uhe.}

Gestern abend gegen 8.00 Uhr erfuhren 4 Offiziere und eln - Fahrer, daß Kardinal József Mindszenty in einem Zimmer im obergeschoß des Schlosses von Felsöpetény gefangengehat 
ten werde ... : Sle entwafneten die 14 Mann starke SSD-Wache und nolhimen József Mindszenty zu sich in die Koserne ron Rétság Der Kárdinal war unendilch glucklich, nach 8 jahren von den Soldaten der Revolution befreit worden zu sen und woilte noch in der Nach nach Budapest reișen - Da jedoch die Straße unsicher schien, brachten sie den primas heute - früh gegen 6 . Uhr in einem Wippon-Wagen; "begleitet vor 3 Panzern und einem Sturmgeschütz, nách "B́dá $\mathrm{Ble}$ Straßen entlarig begrüßte die tandbevölkerung den obersten Prlester mit isturmischen Hochrufen und einem Blumenregen

\section{3:40 Uhir}

Vơ ềiner Vièrtels̀tunde gab der Primas das erste interview, alch habe mit Bewuriderung gesehen, was die Waffer àer Jugend, was die Soldaten, "die Universitätsstudenten, die Landbevốlkerung, die Bavern und A bëite vollbracht haben lch habe es mit Staunen gesehen l Nach 8 Jahren haben sie die Tür meines Gefängnisses aufgerissen $: "$ "Ich schickè den ungarischen Waffen meinen oberhirtlichen Segen . . "l"

\subsection{Uhr, Der Frele Sender Kossuth}

Auf Érsuchen der Regierung teilen wir der Bevölkerung von Budapest mit, dạ das Alkoholverbo auch weiterhin bestehen bleibt.l

\subsection{Uhr}

-Daś evangelische Bischofsamt Süd tellt mit, daß Bischof Laszló Dezsery abgedankt hat. Die Leitung des evängelischen Kirchenbezirks hat der seit 1950 ungerecht inhaftierte Bischof Lajos Ordas ubernommen : . .

\subsection{Uhr, Hier ist der Freie Sender Szombathely!}

"Die Schüler des.Nagy-Lajos-Gymnasiums fordern ... . für Uungarn elne der Schweiz ähnliche Neutrậlität . . :"

\subsection{Uhir, Freler Sender Kossuth}

"Dás" Revolutionskomitee der Landesluftschutzzentralé fordert. : Neutralität für Ungarn nach dem Muster Osterreichs "

\subsection{Uhr}

Aut der heutigen außerordentlichen sitzung dès Landesrates der Gewerkschaften ist das Prósidium zuruckgetreten. Die Lelturig hat das provisorische Verwaltungskomitee des landes-. rats dér Freien Ungarischen Gewerkschaften übernommen. 
$\because$

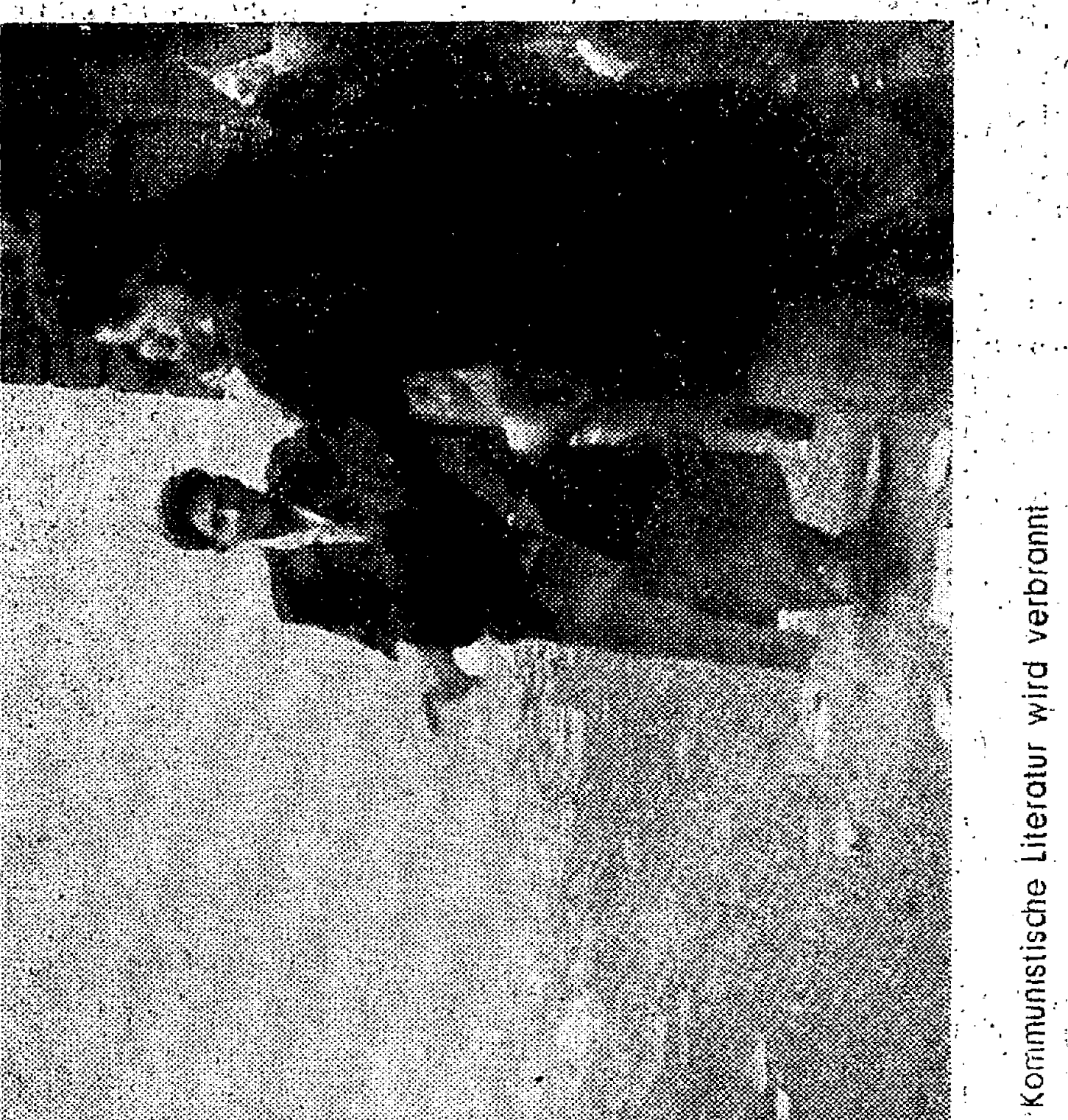

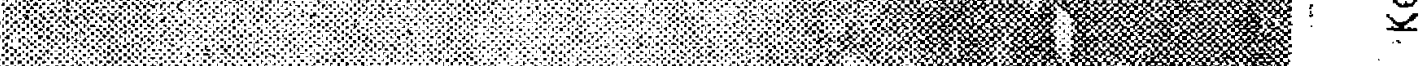

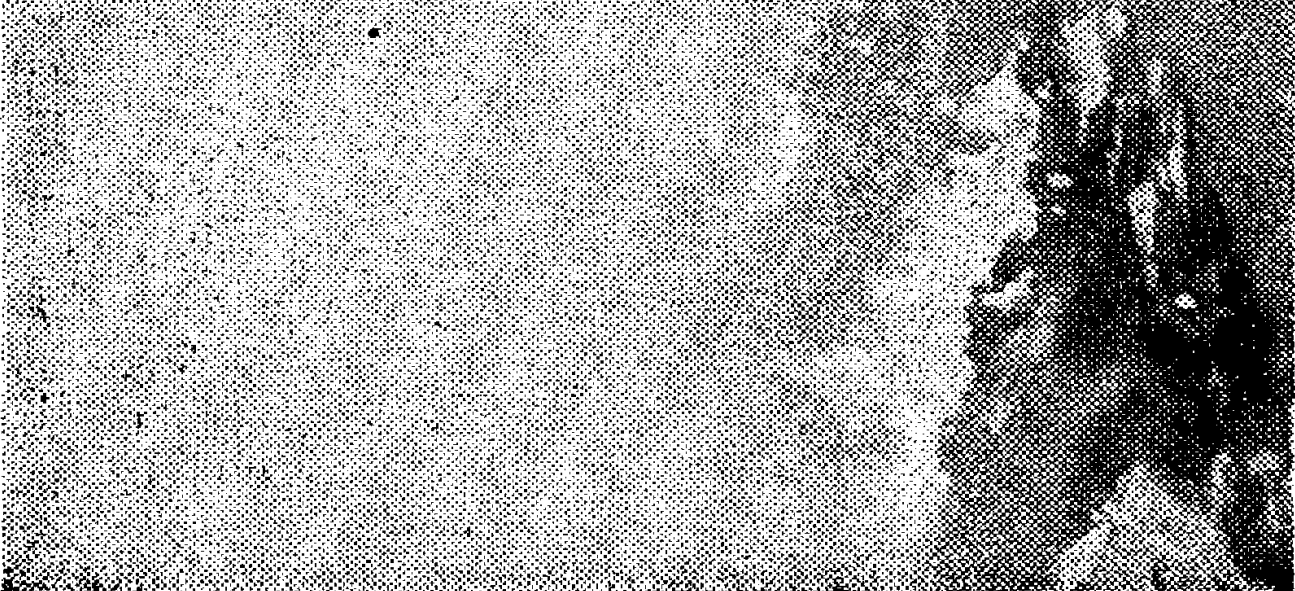

6. 
Das provisorlsche Verwaltungskomltee besteht aus alten, blisher beisseitegeschobenen und eingekerkerten Gewerkschaftsführern. sowie aus neven revolutionaren Gewerkschaftsfijhrern...

\subsection{Uhr, Freler'sender Petöfi}

(I). Ministerium gibt bekannt, daß zur Zeit zunächst 140000 Quadratrieter Fensterglas zur Behebung der großen Schaden in:Budapest zur Verfügung stehen. . ."

\subsection{Uhr, Freier Sender Kossuth}

Wir êrhielten zahlreiche Bitten um Intervention bel den betreffenden Stellen, damit die ungarischen Rundfunksendungen aus dem Ausland nicht mehr gestört werden sollen. Auch wir vóm Freien Sender Kossuth sind der Melnung, dá $\beta$ niemand den Kampl der Worte und Ideologien im Ather behindern soll. Jeder soll als erwachsener Mensch selbst entscheiden kör-

- nén, wem und was er glauben will. Trotzdem steht es nicht in unserer Macht, etwas gegen die Störsender zu unternehmen, denn - wie uns von betrefiender Stelle érklärt wúrde - die. bisher auf ungarischem Gebiet betriebenen störsender sind ausnahmslos eingestellt. Die störungen kommen also nicht aus dem Landesinnern...

\subsection{Uhr}

Bei Marlanośtra verließen 395 politische Gefangene in größter Ordnung das Gefängnis ... Sie wurden auf Lastwagen und iń Omnibussen nach Szob gebracht, vón dort kehrten sle per Bạhn oder anderen Fahrzeugen nach Hause.

\subsection{Uhr}

Mittellung des Revolutionskomitees der Studenten:

"Alle bewaffneten Studenten werden gebeten, in kurzestep Zeit bei ihren Dienststellen zu erscheinen!":

\subsection{Uhr, Sender Mlskole}

Das Schulerparlament der Mittelschulen von Miskolc hat beschlossen: ... :

$\ldots 3$. Sofortige Freilassung der in der Sowjetunion beflndlichen ungarischen Kriegsgefangenen und anderen Gelangenen : : 1

7. Zurückweisüng des sowjetischen Kreditangebotsl....

19. In den Schulen soll der Geschichtsuñterricht von der Tagespolîtik unabhängig sein ... !" . 


\subsection{Uhr}

Aufruf des Revolutionskómitees der Universitätsstudenten: "Wir betrachten die derzeitige politische führung als proviso- risch. Imire Nagy werden wir in dem Maße unterstützen, wie er"unsere Forderungen erfültt..."

\section{Donherstag, 1. November 1956}

\subsection{Uhr, , ,Hier ist der Freie Sender Kossuth-Budapest!.}

Guten Mörgen, liebe Hörerl Heute ist Donnerstag, der 1: No- * vember ...

\subsection{5 Ühr}

Auslandsnachrichten:

Nach einer Meldung aus Kairo haben die britischën Luftstreitkrâfte einen Anğriff auf militärische Ziele der'ägyptischen Hauptstadt unternommen.

\subsection{Uhr}

Im Auftrag der Leitung der Sozialdemokratischen' Partel reisen heute. Anna Kéthly u. Dr. András Révész, dér stellvertretende Generalsekretär, nach Wien, um sich mit den Delegieŕten der dort versámmelten 2. internationale der sozialdemokratischen Parteien zu beraten. Seit 9 Jahren ist dies das erste Mal, daB die ungárischen Sozialdemokraten mit ihren auslöndisctien Kollegen in Verbindung treten köninen...

\subsection{Uhr}

In.der Anwaltskammer von Budapest fand eine stürmišche Sitzung statt. Die mehreren Hundert Mitglieder der Kammer kamen zusarnmen, um mit der bisherigen kriminellen Leitung abzüurechnen...

\subsection{Uhr}

Auslandsnachrichten:

New York:-In seiner Television- und Rundfunkansprache erklärte Prösident Eisenhower im Hinblick auf Osteuropa, daß dort "eln neuer Tag anbricht. Uber Ungarn sagte er, daß die ganze Welt mit Bewunderung auf das tapfere ungarische Voik blicke, dessen Söhne ihr Lében opjerten, um sich von ihren frëmden Herren junabhöngig zu machen...

\subsection{Uhr}

Achtung! Eine wichtlge Mitteilung:

Heute vormittag um 11.00 Uhr trafen sich zu elner Sitzung im 
Parlamentsgebaude de Großbétriebe, dás revolutionàre studentenkomitee der'Budapester Universität, dos Revolutionskomitè der ungarischen Intellektuelien, der vorstand des Verwaltungskomitees des Landesverbandes der Freien Ungarischen Gewerkschaften und Vertieter der Nationalregierung. Sie besprachen die politische und wirtschaftliche Situation der nationalen Revolution...

\subsection{Uni, "Hier ist der Frele Sendér Petöfl!}

Der Rat des Komitats Veszprém hat mit der Organisierung der Burgerwacht begonnen, welche sich hauptsạnlich aús Studenten "und Schülern zusammensetzt."

\subsection{Uhr, "Hier ist der Frele Sender Petófi, Györ!}

Sie hören uns duf den Wellenlängen 344,$5 ; 188 ; 5$ und 223,8 so. wie auf $43 \mathrm{~m}$ Kurzwelle.

Liebe Hörer, in wenigen Minuten ertönen die Glocken zur Ehrung unserer Toten! Anschließend gedenken wir in einer Minute der Stille unserer Gefallenen!

(Pausenzeichen) Glockenläuten (eine Minute Stille).

"Meine lieben ungarischen Brüder Heute ist Allerseelen... Auch diejenigen leben, die "von uns gegangen sind Neue Gräber wölben sich auf unseren Friedhöfen, die Graber derer, die vor ein paar Tagen ih Leben in heldenhaftem. Entschlus für ihr Heimatiand gegeben haben "...Wir sind érfullt von dem heiligen Glauben, daß ihr Opfer nicht umsonst war; sondern die voliständige Auferștehung der Freiheit Ungarris bringen wird! - Wir danken euch fü das Opter. Wir werden eure Saat sorgfältig behüten. "Gebe Gott euch, ihr seelen, das ewige Licht und euren Leibern friedliche Ruhe in der freien ungarischen Erde: Amen."

(Musik: Ave Maria von Schubert, Violine, Danach Trauermùsik.

\subsection{0 Ühr, Freier Sender Kóssuth}

Aufruf des Revolutionskomitees ungarischer filmschaffender und Theaterschauspieler:

". In Zukunft aber darf im neven Theaterleben Ungarns das politische verdienst nie höher gewertet werden áls dje Be: gabung $\therefore$ lu $^{4}$

\section{5:35:Uhr}

Das Komitee der Universitätsstudenten nat unter anderem ouch an den verband ungarischer filmkunstler enen lakw voll 
Lebensmittel geleltet, die von dén Ungarn aus Bátaşzék geschickt wurden ...

\subsection{Uhr}

$\because$ Gestern konstitujerte sich der provisorische. Revolutionsrat der Ungarischén Okonomischen Universität und übernahm die

\subsection{Uhr} Leitung der Universität...

Alle Pädagogen, die ihr Gehalt nicht abholen konnten, weil sie' sich nicht bei ihren Dienststellen befinden, wenden sich. bitte, an die Unterrichtsbehörde ihres, gegenwärtigen Aufenthaltsortes wegen eines Vorschusses. Wir ersuchen die Unterrichtșbehörden, Schritte zụr Erfüllung solcher Wünsche żu ynternehmen. géz.: das Nationale Revolutionskomitee des Unterricht́sministeriums.

\subsection{Uhr}

Aus Drebrecen teilt uns das Ehepaar Tóth, Fiäs-Straße 19; mit, daß es von den im Verlaufe des Freiheitskampfes verwaisten Kindern ein Mädchen $z$ wischen 5 und 1,3 Jahren adaptieren möchte.

\subsection{Uhr, Freier Sender Kossuth, Budapest}

"Neberó dem Radio", Gedicht von Károly Jobbágy.

Mán spricht vọn uns in allen Spracheri.

Im Ather kreischt und pfeift es voll Bewunderung.

Für den Kampi Davids mit dem Goliath.

- Wir wollten nicht berühmt werden!

Erst recht niemals um diesen Preis ...

Denn unser schmerz ist ohnehin unendich.

Seit jeher war uns vom. Schicksal bestimmt,

Bewundernd angestarrt zu werden - -

Die Leiber unserer Söhne aber werden zerfétzt!

Europa ist wieder ruhig.

Nur uns durchbohrt die Lanze dessen,

Der uns auch vor hundert Jahren trafl

So laßt uns denn - während die Welt in Deckung liegt

Und nur die Radios gellen -

Das Leben für Freiheit tauscheni 
Will uns das Schicksál zuchtigen?

Weil wir zehn Jahre geduldet haben?

Wir heben das blutig geschlagene Haupt

Und wissen: es wird uns verzeihn!

\subsection{Uhr}

Die an der Nachrichtentechnischen Akademie von Leningrad studierenden ungarischen Offiziere erklärten heute in einem Telegramm; daßsie sich einmütig hinter die neve nationale Regierung und den Militörischen Revolutionsiat stellen. Sie erklären sich mit den berechtigten Forderungen der revolu-. tionären Arbeiterschaft, der Jugend sowie der Bauernschaft solidărisch. Sie ersuchen die Nationalregierung und den revolutionären Militärrat, sie sofort nach Ungarn zurückzuberufen.

\subsection{Uhr}

Die Fraüenorganisation der Unabhängigen Kleinbavernpartei eriäßt folgenden Aufruf:

"Ungarn! Sucht alle kleinen Waisen und Halbwaisen auf, bis zum Alter von 3 Jahren, deren Eltern den Kämpfen zum Opfer gefallen sind. Soweit sie kein Zutiause haben, meldet es bitte sơtort der Sozialen Abteilung der Fravenorganisation der Unabhängigen Kleinbavernpartei. Der, kalte Winter ist nahe, bis dahin soll jedes verwaiste ungarische Kindrein Dach über dem .Kopf haben und in einem warmen Zimmer sein.".

\subsection{Uhr}

László Németh (Schriftsteller): "Die Erhebung der Nation" "Als ich vór 13 Jahren zum letztenmal mit der jungen Intelligenz Ungarns zusamméntráf, ging eine Epoche zu Ende. Vielleicht, dachte ich, wirst 'du nie mehr zu ihr sprechen können ... Jetzt aber kam ich mit dem erstèn Fahrzeug, auf dem sich ein. Platz für miich befand, nach Budapest, schloB mich in mein Zimmer ein und setzte mich hinter die Schreibmaschine wie hinter eine Waffe, um sie klappern zu lassen, solangẹ meine Kraft noch reicht. An der Schreibmaschine sitzendidenke ich an jenes junge Mädchen auf dem Dach des Gebäúdes am Kalvin-Platz. Als die Männer einer nach dem anderen heruntergeschossen wurden, handhabte sie das Maschinengewehr weiter, bis auch itir junger Kopf zur Seite sank: Ich weiß nicht, ob es sich genau so zugetragen hat, aber in meinem Herzen ist dieses Mädel jetzt die Muse. Sie winkt mir vôm Dach zu: 
Los, alter Todeskandidat! Wenn ich mein junges Leben weggeworfen habe, warum solltest du armer Greis deinen Teil nicht tun!"

\subsection{Uhr, Freier Sender Petöfi, Györ}

"Demonstration in München", - Kommentar von Ernö Rácz.

"ich drehe am Knopf meines Emptängers. Kurzwelle. Paris, New York, Australien. Und zwischendurch die entschwindende und wiederauftauchende Stimme: "Hier ist der Sender Freies Europa, die Stimmie des Freien Ungarn.' - Ich höre eine Ubertragung von der Großversammlung der Münchner Universitätsstudenten. Professor Graf Stauffenberg spricht. Jener Ștauffenberg, dessén Bruder dem mißglückten Attentat auf Hitler zum Opfer gefallen ist. Ich höre ihn gern, denn was er sagt ist meine eigene Stimme. Das wunderbar junge, heiße Herz, mit dem er damals wie heute die Seele der deutschen Jugend bebaut. Jetzt spricht er von uns, von unseren heldenhaften Jugendichen. Ungarn hätte auch dann Weltgesçhichte gemacht, wenn der Kampf erfolglos geendet hötte. Und, daß dieser Kampf darum gelang, weil dieses Stück Geschichte von dem ganzen Volk geschrieben wurde. - Schade, daß viele hundert Kilometer zwischen uns sind. So kann ich Professor Stauffenbergs Hand nicht drücken, und nicht die Hände der tausend' deutschen Studenten, die ihre Mützen hochwerfen und an unserer Seite demonstrieren.

.. die Stauffenbergs, für die des Volkes freiheit keine Handelsware ist, die man kauft und verkauft, drücken wir an. unsere "Herzen!" -

\subsection{Uhr, Freier Sender Kossuth, Budapest}

Imre Nagy, Präsident des Ministerrates und amtierendèr AuBenminister; hat heute vormittag Herrn Andropov, Botschafter der Sowjetunion in Ungarn, zu sich gebeten. Er teilte ihm mit, daß die Regierung der Ungárischen Volksrepublik verläßliche Informationen hobe, wonach neue sowjetische Militärverbände nach Ungarn einmarschieren. Er forderte die unverzügliche Abziehung dieser Truppen. Er teilte dem sowjetischen Botschafter mit, daß die ungarische Regierung den War- . 'schauer Vertrag mit sofortiger Wirkung kündige, gleichzeitig die Neutralität Ungarns erkläre und sich an die Vereinten Nationen wende mit der Bitte um Schutz der Neutralität dẹs 
Lâades durch die vler Großmächtel $\therefore$ Zuglelch verständigte er defi Generalsekretär der UNO telegrafisch uber die Ereigmisse in Ungarn und von dem EntschluB dér ungarischen Rëgierung Er érsuchte die UNO, diese Frage auBer der Reihe auf ihre Tagesordnung zu setzen!

\section{$19.50 \mathrm{Uhp}$}

Imre Nagy, Ministerpräsident und amitierender AuBenminișter der Ungarischen Volks'republik, spricht zum ungarischén Volk: "Bevoôlkerüng von Ungarn! - Von tiefem Verántwortungs"; bewüßtsein durchdrungen dem ungarischen volk als auch der - Geschichte gegenüber, sowie dem einmütigen wunsch der. Millionen des ungarischen Volkes entsprechend, erklärt die Ungarische Nationalregierung die Neutralität de ungarischén Volksrepublik. Im Sinné der Statuten der Vereinten Nâtionen möchte das ungarische volk au der Bạsis vôn Unabhängig ? keit und Gleichberechtigung mit seinen Nächbarn, der Sowjetunion und allen Völkern der Welt in wahrer Freundschaft lëben. Es würischt die Festigung und Weiterentwicklung der" Errungenschaften únserer nationalen Revolution; ohne daß es sich irgendeiner Machtgruppe anschließt. Damit wird ein jahr hundertealter Traum des ungarischen volkes verwirklicht (Nátionalhymne)

\subsection{Uhì}

\section{Chorwerke von Kodály.}

\subsection{Uhr}

Liebe Hörer, Sie hörén jetzt die Botsctieft von Furstprimas József Mindszenty:

„Nach langer Gefangenschaft spreche ich jetzt zư allen Kindern unserer ungarischen Heimat. In meinem: Herzen verbirgt: sich hiemandem gegenüber Haß. Eine bewundernswerte $\mathrm{Hel}$ denhaftigkeit befreit jetzt unser Land. In der Weltgeschichte: íst dieser Freiheits kamptelnžigartig Unsere Júgendichen verdienen jëdèn Ruhm. . Das Land befindet sich in einer auBer"Oordentilich schweren Lage. . . Ich werde mich jetzt informiereh und innerhalb von zwel Tagen in einér persönlichen Botschaft an die Nation den Weg zur Entfaltüng dariegen

\subsection{Uhr :}

Es spricht Dr.. Endre Várga, Präsident der Katholișchen Volkspartei: 


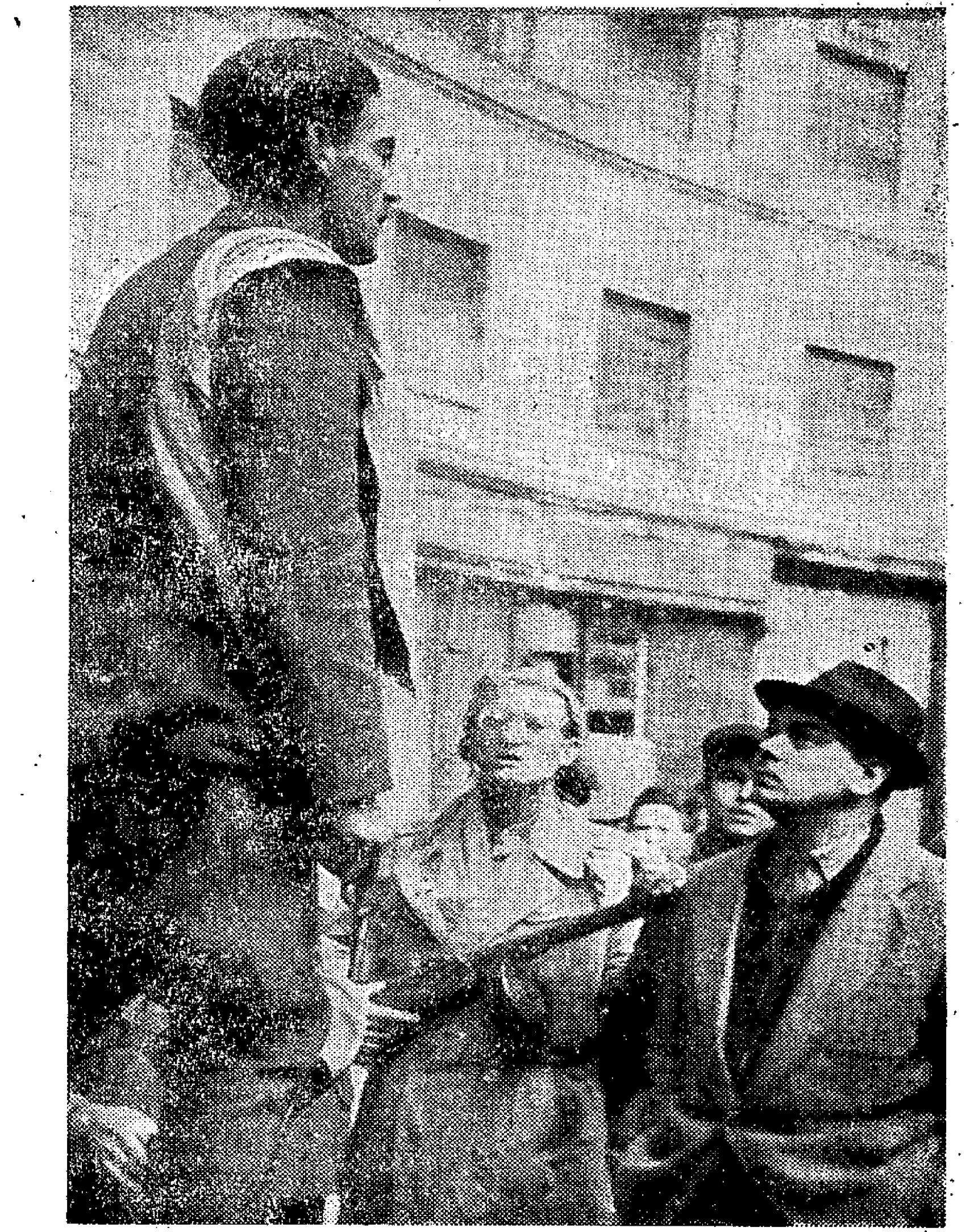


"Nach acht Jahren erbltterter Untergrúndkämpfe 'gruBt, dle Katholische Volkspartel das ganze ungarische Volk über den Freien, Sender Kossuthl... Das Feuer der Freiheit, welches in dèn Kämpien der vergangenen'Jahré nur in der 'Tiefe der Seelen glühte, hat den ungerecht Unterdiujckten und Leldenden die Erlösung gebracht. Unser Volk hat bewiesen, daß es ein Löwe seln kann; aber es wird sich in ein "Lamm verwandeln, sobald es einen guten Hirten hat. Auch dafur haben wir gesorgt. Der gute Hirte, unser Fürstprimas József Mindszenty, ist frel. . $\therefore$

\subsection{Uhr}

Seit-Monaten erregt die Frage des ungarischen Urans die öffentliche Meinung. Unser Reporter hat nun Professor Lajos Jánosi, den welṭberühmten Atomwissenschaftler; aufgesucht und um ein Interview gebeten:

Jónosi: „Die sowjetischen Behörden haben alles, was mit dem Uran zusammenhing, streng bewacht. Nicht nür, daß sie keine - Fórscher einbezogen, nicht einmal fachleute haben sie einbezogen; deshalb war es auch unmöglich, wirtschaftliche Autschlüsse zu erhalten; die Ungarn 'tappten völlig' im Dunkeln: So habe ich als Vizeprösident der Atomenergiekommission keinerlei Informationen Uber die Uranvorkommen erhalten und erfuhr von den Funden erst durch die Zeltung ..."

\subsection{Uhr}

Unsere Reporter sprechen mit Freiheitskämpfern:

„.... Erlauben Sie, daß ich zuerst den Jüngsten vơrstelle: józsl ist 16 Jahre alt und der Held des Krankenhauses am BakóchPlatz: Er gehört dem, Corvin'-Regiment dèr-Freiheitskämpfer an. Noch ist sein Gesicht von den tiefen Spuren der Verwündung entstellt ..."

"Zuerst kämpften wir in der RákóczíStraße. Dort waren sowjetische Panzer, die schossen... Fréitog "früh h-bis 5 Uhr hielten wir Haus Nr. 1 in der Mester-Straße. Die Rússion schossen mit Panzerabwehrkanonen hinein und ich wurde verwundet. Splitter in beide Beine und ins Gesicht. Unter Lebensgefahr brächten mich die Jungs hierher ins Hospital."

.Und warum bist du zu den Freiheitskämpfern gégangen?"

-1848 sind unsere Frelheltskämpfer gegen die Unterdrückung 
aufigestanden. Auch "wir wollen das Treiben der fremden Unterdrücker in unserem Heimatland nicht duldén."

\subsection{Uhr}

Wir übertragen jetzt die Ansprache von János Kadar:

"Ungarische Arbeiter, Bauern und Intellektuellel - Ich spreche. zu euch in schicksalhafter Stunde. Es war die blinde und kriminelle Politik der Vertreter des Stalinismus, nämlich Rákosi und Gerö, welche unsere. Partel zum Wérkzeug der Willkür und Versklavung der Nation degradierte!...

Jene Kommunisten, die auch bisher zum Kampt gegen die Tyrannei Rákosis aufgerufén haben, haben die Gründung 1 einer neven Partei beschlọssen. Die neve Partéi bricht ein für alle mal mit den Sünden der Vérgangenheit. Unsere Partei heißt jẹtzt: Ungarische Sozialistische Volkspartei ..."

\subsection{Uhr}

Wie die Sowjetische Botschaft in Budapest mittelit, haben sowjetische Panzereinheiten die ungarischen 'Flugplätze darum umzingelt, damit die Evakuierung auf dem Luftwege von den Familienangehörigen sowie Verwundeten der sowjetischén Truppen gewährleistet wird. Die gesamte ungarische Luftwaffe war bereit, den Kampl. gegen die Ubermacht auf* zunehmen. In verantwortungsvoller Weise hat 'die Regierung jedoch das Eröffnen des Feuers verboten. So stehen die ungarischen Luftwaffenangehörigen in größter Disziplin den sowjetischen Einheiten gegenüber. Ohne daß auch nur ein Schuß fällt, warten sie auf den Abzug der: sowjetischèn Truppèn.

\subsection{Uhr}

Am. Donnerstag konstitulerte, sich die Ungarlsche Sozlaldemokratische Jugendbewegung ...

\section{Freltag, 2. November 1956}

\subsection{Uhr, „Hier ist der Freie Sender Szombathelyl}

"Menschen im Sturm“. Liebè Hörer, wir lesen thnen; jetzt einen Bericht aus der Zeitung MAGYAR FUGGETLENSÉ (, Ungarische Unabhöngigkeit ") vor:

Dle Ruhe wurde nur durch das gewohnte Klappern der 
Möschnengewehre unterbiochen. Von Zeit zu Zeit setzte die Exploston einer Mine den Pulikt an das Endé der langatmigen Kugeisutze Ausgebrannte, gewátige .52-tonnen-Panzerungeneuer sind stumme Zeugen für die Wunder, die Patriotismus und der. Wunsch nach freiheit und Unobhangigkeit bewirken können. Ein éinfacher, roher Holzşarg würde von eifien schluchizenden älteren Ehepaar begieitet. Siébegruben ihren enzigen Sohn. Er war in den Kümplen in Vlil. Bezirk gefállen ble aufgehende Some der. Freiheit hat er nicht mehr erlebeli dürten . Voran eine Krankenschweșter mit einep riesigen Rot-Kreuz-Fahne, so zogen die beiden Sanitäter mit der Tragbahre los, um auf dem Platz die verwundeten Freiheitskämpter zu bergen. Und da geschah das Urifoßbare, was selbst: in den Weitkriegen zwischen erbitierten Feinden nicht vorkam. Die Mörder des Staatssicherheitsdienstes schossen au sie ; Blutüberströmt brach die vorangehende Krankentsçnvester zusammen! l'ch bin ein Mann der Feder, nicht dér Waffert, und habe bisher alles Blutvergießen zutiefst gehaßt. Aber jenem Moment schwor ich, zusammen mit den FreiKeitskämptern zu stürmen: Ich habe es getan ... Seine Leiche haben sie mit den FüBen nack oben an einen Baum gehängt, und der dicke Kadaver hing dort, blutversctimiert, wie ein für alle Zeiten warnendes Ausrufezeichen..."

\subsection{Uhr. Freier Sender Kossuth, Budapest}

In der villa von Mátyás Rákosi $\therefore$. Auf dem Schireibtisch ein Chäo's von Schriftstücken. Man sieht, es. war nicht viel Zeit zum Verlassen des Hauses. "Wer sein Parteibuch vergißt oder verliert mu aus dèr Partei ausgeschlossen werden!" - hatte Rékoșipefohlen Und nun liegt, zu unserer Uberraschung, das Párteibuch Mátyás Rákosis vor uns! Daneben das seiner Frau. So Wiehtig haben sie die Partel genommen... Dafur haber sle slch auch mit den. Mitgliedsbeiträgen nicht ruiniert. Ganze 160 Forints, bel einem Monatsgehalt von $40000^{\prime}$ Forint. Von diesem "Mámmuteinkommen konnten wir" uns "mit. eigenen Augen überzeugen, denn die perfekte Administration hat auch dofur Gehaltsstreifen verfertigt...

16.25 Uhr, "Hier ist der Rundfunk des Arbeiterrates von Bốród, Miskole!

"Aufruf in Ungarisch, Deutsch und Engtiseth), 
Achtung! Der Revolutionäre Arbelterrat von Mátészalka richtet folgenden Aufruf an alle Hilfsorganisationen:

- In unserer engeren Umgebung erkrankter innerhalb der letzten sechs Wochen 150 Personen an kinderlähmung. "30 Kranke sind gestorben. Die Epidemie breitet sich aus Wir bitten diringend um ein Gegenserum. Wenn ihr unsitielfen konnt, benachrichtigt bitte den Sender des Arbeiterrates von Borsod.".

"Attention, Attention! This is an appeal by the Workers' council of Mátészálka..."

\subsection{Uhr, Freier Sender Kossuth, Budapest}

Die ungarischen Juden, welche ihre.:Religionsfreiheit zurückerlangt haben, begrüßen begeistert diëerrungenschaften dèr Revölution: Wir gedenken der Gefallenen mit Hochachtungund Pietät: Wir fühlén, uns eins mit dem unabliängigen, freien. Heimatland. Wir bitten die jǘdischen Organisationen im Aus. land, dem heldenhaften ungarischen Volk, das so viel gelitten hat, schnelle und wirksame Hilfe zuteil weriden zu lassen.

gez.: Oberrabbiner von Budapest .

Landeszentrale der Ungarischen Israeliten

Das provisorische Revolutionskomitee der Ílsaelitlschen Glau-

\subsection{Uhr} bensgemeinśchaft von Budapest

An dén Generalsekretär der Vereinten Nationen, Herrn Dag Hammarskjöld, New York:

"Exzellerizl Der Präsident des Ministerrates der Ungarischen Volksrepublik möchte als beauftragter AuBenminister folgende Informátionen zur. Kenntnis Eurer Exzellenz bringen:

In meiner Botschaft vom 1. November erwähnte ich bereits, daß neve sowjetische Militäreinheiten nach Ungarn einmarschiert sind; daß die ungarische Regierung den sowjetischen Botschafter hiervon unterrichtet; den Warschaver Vertrag gekündigt, Ungárns Neutrałtiät prọklamiert und sich wëgen Garantlerung der Neutralität Ungarns an die Vereinten Nationen gèwaridt hat:

Am 2. November hat die ungarische-Regierung weitere genaue Informationen erhalteri, wonach bedeutende sowjetische Verbä̀nde die Landesgrenze überschritten haberi und in Richtung Budapest ziehen, unterwegs, die; Elsenbahninien, Bahnstationen ... ete. in Besitz nehmend: 
Ich ersuche Eure Exzellenz, die Großnọ̈chte zur Anerkenmung der Neutralitat Ungarns aufzutordern und durch den Sicherheitsral die Regierungen der sowjetunion und ungarns zur Aufnahme sofortiger Verharidungen anzuweisen

gez lmre Nagy, Ministerpräsident und bevollmachigter

\subsection{Uhir}

AuBenminister der Ungarischen Volksiepublik

Den Meldungen über die Voliversammlung der UNo nach wird die Logge Ungarns, heute oder mörgen vor den Sicherheitsrat gebracht. Der amerikanische AuBenminister Duilles erklärte, dá der Débatte über die Neutralitätse rklàrungüngans große Wichtigkeit beigemessen werden muB. Hoffen wir, daB noch heute die für unser Land so brennend wichtige frage einigermảßen geklärt wird.

22.30 Uhr, Frẹier Sender Kossuth, Budapest, und Freies Radio Pẹtöf, Györ :

¿Liebe Hörer, wir haben bereits am Nachmitiag mitgeteilt. daß wir am Abend die Radioansprache des Bưndestagsabgeordneten der Freien Demokratischen Partei "der. Deutschen Bundesrepublik, Dr. h. c. Hubertus Prinz zu Löwenstein, übertragen werden. Jetzt ist Herr Dr. Hubertus Prinzzu Löwenstein. am Mikrofon.

"Meine lieben Hörerinnen und Hörer Ich spreche dus dém: provisorischen 'Studio von Radio Budopest. Es ist im Parlamentsgebäude untergebracht. Die eigentliche Rundfunikstation Budapest ist in den schweren Kämpfen vom 23 und 24 oktober schwer beschädigt worden. Es ist, eine eigenartige Stimmung, in der ich zu Ihnen spreche. Im Novembernebel, wnd wenn ich aus dem Fenster hinausschaue erkennt man den Ring von Panzern, die um das Parlamentsgebaude aufgestelkt sind Einige Panzer stehen auf den. Donaubrücken, das ist eine Vorsichtșmaßnahme der ungarischen Regierung denn die Gerüchte haben sich verstärkt, nach denen sowjetische Truppen immer näher an die: Stadt herankommen Aber Panik gibt es in Budapest nicht. Alles ist rutig $\therefore$ Das Bemerkenswerte an dieser ungarischen Revolution ist gewesen, da $B$ sie nicht organisiert war. sie kam spontan, wirkilch aus dem Witlen desivolkes. Es war keine verschworing dahinter, und es wor 

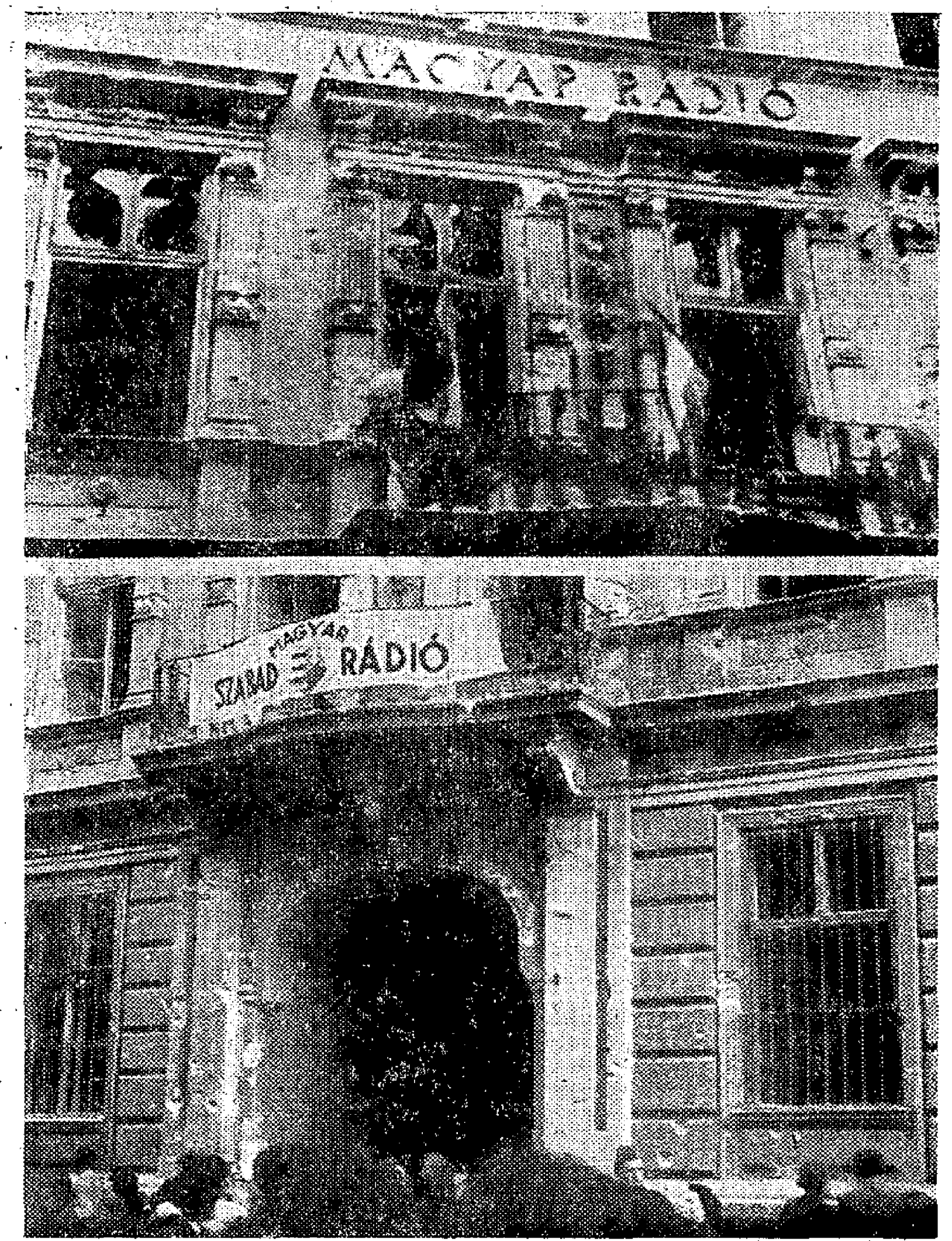

. . Das Studiogebäude von Radio Kossuth, Budapest, nach der Eri. ștürmung; , unten mit , der, Aufschrift "Freier Ungarischer Sender". 
eigeñtlich so, daß̉ die Führer des geistigen Widerstandés selbst überrascht waren, daß das valk diese große innere Kraft aufbringen konnte. Besonders schön und bemerkenswert ist, daß die ungarische Jugend die Führung dieser Revolution hatte: Vor allem die Studenten der Universität Budapest, aber auch viel jüngere, $15-16$ jährige Jungen und Mödchen Gerade jene jugend, die in kommunistischen schulèn erzogén worden war, die kêneswegs, wie man of angeñommen hat, nun damit indoktriniert war . . Auf diesem Land" lastete ein jahrelanger Druck, mlt einer großen Armut in Urigarn, dos doch einimal: Brot für ganz Europa verschaffte. Eine große seelische "Not wa" auch da. Vielleicht war die seelische Not noch"schlimmer $\therefore$.Wir in Deutschiand düfen nicht vergessen daß Ungárn für uns gekämpft hat, tür die Freiheit aller, undi ch meine, dáß die. Wiedervereinigung in Freiheit einen wesentlichen "Schritt" nähergekommen ist sèit den Ereignissén in Ungarn. Einige meiner Freunde haben mir erzöhlt, wie flief gerührt siewaren, hier in Budapest; als sie hörten, daß in aljen Fenstern von West-Berlin Lichter angezündet wurden im Gedenken der Toten des ungarischen Freiheitskamptes $\therefore$ Maine Frounde in Budapest-ságen mir, daß sle Bücher aus der Bundesrepư blik überhaupt nicht bekommen können. Sie möchten wissen, was hier bel uns geschrieben wird, welche größen Schriftsteller jetzt besonders bekannt sind, whe das deutsche Geistesleben aussieht ... Und ein weiteres Anliegenr; das ich mit vlelen Studenten hier besprochen habe, dle. ja in der allerersten Front des Freiheiltskamples standen. Wir geben in der Bundesrepublik záhlreiche Stipendien für auslähdische-Studenten. Aber diesé stipendién, wié és ja ganž logisch ist, waren auf Studenten beschrankt aus Lândern westlich, oder Jedenfalls außerhalb des Élsernen Vorhangs. "Ich möchte vor: schilagen; und zwar möchte ich das in der allernöchsten Zeit bereits im Bundestag vorschlagen, do $B$ unsere stipendien $\mathrm{mlt}$ sofortiger Wirkung ungarischen Studenten zur Verfugung gestellt werden. Das junge geistige Üngarn; das auf das tief́sté doch mit der abendländischen Kultur verbunden jist, soll dadurch wieger AnschluB bekommen. Und das ist der Wille der Nation und das ist die sehnsucht der akádemischen Jugend. dieses Landes. 
Meine Damen und Herien, noch ist dieser, Kampt nicht zu Ende. Ich tühle das sehr stark, daß wir mitten drin sind bir wissen nicht, was die, nächsten Tage bingen werden, wị wisser nicht einmal, was die nächsten. Stunden bringen werdẹn. Ich kann nur zum AbschluB sagen, daßB ich mich dem Appell anschließe meiner Freunde in Budapest, deir Appell an das Gewissen der Welt. Daß dieses Gewissen der Welt dem ungarisciien Volke, das für uns alle gekcimṕf hat, die Entwicklung seines eigenen freien, seines eigenen demokratischen Staates ermöglicht ... Und wenn, wir als Devische da etwas, beitragen können durch unsere moralis dhe und umșere materielle Hilie, dann meine ich, solltén wir es tun und zwar "gieich."

\section{Samstag, 3. November 1956}

7.00 Uhr, Freier Sender Kossuth, Budapest, und Freies Radio Petöl, Györ:

Liébe Hörer, eine der eríreulichsten Erscheinüngen der letzten Tage ist, daß die Zeitungskioske bunter geworden sind. So qus dem köpf kann ich gar nicht sagen, wie viele neue Zeitungen diese Woche, erschienen' sind. Die eine oder andere ist den Lesern nicht unbekannt. Mit großer Freude kaufén die Menschèn die seit Jahiren zum Schweigen gebrachiten und nun wiederauferstandenen Blätter ...

\subsection{Uhr}

Das Herz der Weit hat sich uns aufgetan, öffinen jetzt, auch wir der Welt unser Herz. Laßt die Ungarn.sehen, wie der indische Baver arbeitet, wie sich das Altagsleben des'britischen Bürgers, des amerikanischen Farmers, des deutschién Beamten, des finnischen Holzfällers, des bulgarischen Gärtners oder'des chinesischen Fabrikarbeiters abspielt ..

\subsection{Uhr, "Hier ist der Freie Sender Szombathely!}

- Bei der Unterzeichnung des österreichischen Staatsvertroges haben wir uns von Herzen gefreut, aber - geben wir es offen zu - ein wenig waren wir auch neidisch. Warum können wir das nicht tun? - sagten oder dachten wir, und siehe da, der uratte Traum des ungarischen. Vólkes ist verwirklicht worden, denn an der Seite des benachbarten Osterreich gehört unsere Heimat in die Reihé der neutralen Länder ..." 
. Generalmajor Pál Maléter hat erklärt, daß Mikojan am vergangenen Mittwoch mit Staatsminister Kis vereinbart habe, daB alle auf Grund des Warschaver Vertrages in Ungarn stationierten sowjetischen Einheiten abgezogen würden. Im Gegensatż dazu teilt Radio Budapest heute mit, Mikojan hätte zuletzt erklärt; daß alle Truppen abgezogen würden, a u ś$g$ en $\mathrm{mm}$ men die auf Grund des. Warschauer Vertrags in Ungarn stationiertenl Vorläufig.äber kriegen , die Truppen lediglich mëhr und mehr Verștärkung! Die österreichisch-ungarische Grenze ist hermetisch abgeriegelt worden. Alle Fahrzeuge, welche nach Wien unterwegs waren, wurden gestoppt, daruntér auch die von 20 Journalisten. Bei Magyaróvár ist ein improvisiertes Lager errichtet worden, in dem die aufgehaltenen Personen von Sowjetsoldaten bewächt werden. Dlér Vereinigten Staaten haben bei der Sowjetunion Protest eingelegt, well sich unter den festgehaltenen.Personen auch amerikanische Diplomaten befinden. Der Sprecher drückte seine Vérwunderung darüber aus, daß an der österreichischungarischen Grenze so starke: Sowjettruppen stehen.

\subsection{Uhr, Freler Sender Kossuth, Budapest, und Freies Radio'Petöfl, Györ}

(ganz am Schiub der Presseschau - Inlandpresse - wird auch der Leitartikel des KP-Blattes zitiert:)

Abschließend verlesen wir den heutigen Leitartikel der. Ungarischen Sozialistischén Arbeiterpartei-Zeitung "Népszabadsóg". (Volksfreiheit):

$\because$ Wir werden keine Millionenpartel sein, wir werden im bescheideneren Rahmen, mit bescheideneren Mitteln als bisher arbeiten. Wer Mitglied der Ungarischen Sozialistischen Arbeiterpartel sein will, der rechne damit; dọ die Parteimitgliedșchaft keinen glänzenden Posten, eine vornehme Position oder Irgendwelche Privilegien einbringt. Harte, schwere Wochentagsarbeit wartet aut unsere Mitglieder. Ein puritanisches arbeltsames Leben wartet auf uns, keln Glitzern und An-der-Sṕltze-Marschieren, keine verlogene Uberheblichkeit, welche slch ouf Bojonetté stützt ..." 


\subsection{Uhy, Freler Sender Szombathely}

. . Freitag vormittag kamen zwel Panzerzüge uber die Grenze, abwohl 'das Signal auf Rot gestellt war ... Wie wir von der MÁV (Ungarische, Staatseisenbahn) erfahren, hat eine große Anzahl sowjetischer Eisenbahner die Eisenbahnllnie von Zahony nach Nylregyháza überniommen.

In den Nachrichten des Universitätsrundfunks' von Miskole wurde gemeldet, daß in der vergangenen Nacht ein größerer Panzerverband über Kisvárda ins Land hereingerollt ist...

\subsection{Uhr}

\section{Schüler; Achtung!}

Das Revolutionskomitee des Unterrichtsmińisteriums teilt mit: ". . . Sämítliche Geschichtșbücher der Allgerieinen. und Mittelschulen werden eingezogen."

"Fur den Unterricht in ungarischer Literatur an den Allgemeinen Schulen sollen die Studieriräte nur diejenigen Abschnitte behandeln, die sich mit der ungarischen Literatu' befassen. Die, Kapitel über russische Literatur sind auszulassen."

"Im Erakundeunterricht an den Allgemeinen Schulen ist die Geographie der Sowjetunion in dem Maße zu behandeln wie die anderen "Stäaten.":

"Sämtliché Erdkundebücher der Alìgemeinen Sctiulen werden eingèzogen."

„In der vierten Klasse der Mittelschulen werden die Biologlebücher aus dem Gebrauch gezogen." :

"In der áchten Klasse der Allgemeinen schule fällt die Ver"fassungslehre fort."

"An ollen. Allgemeinen und Mittelschulen muB" der" frele Rellgionsunterrịcht gewährleistet werden. Die Sondereinschreibungen zum Religionsunterricht werden hiermit'abgeschafft." "In sämtlichen Schulen des Landes wird Russisch als Pflichtfach abgeschafft.".

"Die nach russischem Muster aufgebauten Allgemeinen Schulen werden abgeschafft . . ."

12.00 Uhr, Freier Sendèr Kossuth, Budapẹst, und Freles Radio Petöfl, Györ

Wir bringen Nachrichten:

Der Komponist Zoltán Kodaly hat sich in einem Telegramm an die sowjetischen Komponisten gewandi mit dèr Bitte, bel 
Ihrer Reglerung daraut hinzuwirken, das die sowjetischèn Truppen sotort aus Ungarn abgezogen werden.

- Vór den Véreinten Nationen erklärte der Delegierte Perus in seiner Rede, er würde jede Bestrebung unterstützen, die ermögliditi. daß Ungarn von seinem selbstbestimmungsiecht praktischen Gebrauch machen kann. Er führté. weiter aus: der Rat laabe unbedingt das Recht, die Sowjetunion zưr sofortigen Zurǘkziehung ihrer Truppen aufzufordern . .

Der sowjetische Delegierte Soboljew sagte, Imre Nagys Erklärungen, wonach neue bewaffnete sowjetische Truppen in das tond marschiert seien, entbehrten jeder Grundlage $\therefore$ Der vertreter des Vereinigten Königreichs spiach als nächster: er erkläte, daß die Lage im Nahen Osten die ungarischen Ereignisse nicht vergessen lassen könne. Dann gab ei seiner Hoffriung: Ausdruck, die Regierung der Sowjetunion würde éndlich einsehen, daß ihre Politik der bewaffneten interven: tion zusammengebrochen sei. . .

\subsection{Uhr}

Achtưng! Eine wichtige Mitteilung:

Der gemeinsame AusschuB des Kommandos der ungarischen und sow.jetischen Stréitkräfte hat sich heute. Mittag zusammengesetzt, und beide Teile haben lihren Standpunkt bezuglieth der technischen Fragen des Abzúges der sowjetischen Trüppen dargelegt, Nach Prüfung der gegenseitig' gemachten Vorschläge wird sich der gemeinsame Ausschuß heute abeind um 22 Uhtr wieder zusammensetzen. Bis dahin hat die, sowjêtia sche Belegation folgendes versprechen gegeben: Weitere. sowítische Truppentransporte werden die Landesgrenze nicht uberschreiten!

16.10 Uhr, Unidentifizierter Freier Sender (Szombathely oder Pécs)

$\therefore$ Oberstleutnant. úber die sowjetischen Truppenbewegungen: "Sựwestlich von Békéscsaba und südich von Szarvas biwakiert je eine motorisierte Sowjeteinheit. Ich sehe, wie sie" die stadt einkreisen wollen. Später trat ich mit ihnen durch parlamentare in verbindung und erkundigte mich nach, ihren Absichten. Der sowjetische Kommandant war sehri erstaunt, als. er gebeten wurde, die bewohnten Gebiete zu meiden, weil die Bevolkerung in sehr erregter Stimmung sei Der sowjetische Koinmandeur ekklörte, sie seien hergeschickt worden, 
um gegen Faschisten zu kömpfen, welche die taschistlsche ordnung wiederherstellen wollten! Die Parlamentäre widerlegten dies. Dagegen wolle das ungarische volk seine volle . Freiheit und ein unabhängiges Lebent... . Nach diesen Erklärüngen vérspractien díe sowjetischen offiziere, daß sio. niemáls auf das ungarische volk schießen lassen, würden!"

14.00 Uhr, H. Hier ist der Freie Sender des Nationalkomitees vón Dunapentelel.

Aufrut an alle freien ungarischen Radiostationen:

Wir sind in den Besitz von Informationen gelangt, die beweisen, daß die, den sowjetischen Sendern und Soldaten ausgehändigten Propagandaschriften 'von : faschistischem Blutvergießen in Ungarn berichten. Da zu befứrchten. ist, daB sehr viele Sowjetsoldaten diesen verleumdungèn Glauben sctienken .... bitten wir alle freien ungarischen sender, 'durch regelmäßige Sendungen In russischer und ungarischer Sproche diese böswilligen Gerüchte zu widerlegen $\therefore \ldots$

19.35 Uhr, „Hier ist der Freie Sender Pécs!

Einheiten der sowjetischen Armee nähern sich unserer Stadt. Die Delegation des Arbeiterrates vom Komitat Baronya ging ihnen entgegen und teilte ihnen mit, dả wir friedicher Absicht sind und keine Elnmischung in die Angelegenteiten der Stadt

- wünschen. Wir rufen die Einwohner dèr Stadt mit großem Ernst auf, die Ruhe zu bewahren und sich nicht-auf der Straße autzuhglten. Ein einziger. Schuß kann die Vernichtung der Stadt bedeuten!"

20.00 Uhr, Freler Sender Kossuth, Budapest, angeschlossen Radle Petöll

Kardinal Jozsef Mindszenty, Erzbischof von Esztergom, Fürstprimas von Unigarn, spricht jetzt zur Welt und zum ungarlschen Volk:

"Heutzutage wird sehr oft betont, dả derjenige, der eine Rede hält, milt der Vergangenheit brechend, offén, spricht. Ich konn dies nicht behaupten. Ich brauche mit meiner Vergangenheit nicht brechen, denn durch Goltes Ginade bin ich derselbe; wie vor meiner Einkerkerung. Mit der gleichen körperlichen und gelstigen Integrität stehe ich auch heute - wie vor acht Jahiren - für meine Uberzeugung ein, obwohil mich die Gefangenschatt mitgenommen hớt. 
$1:$

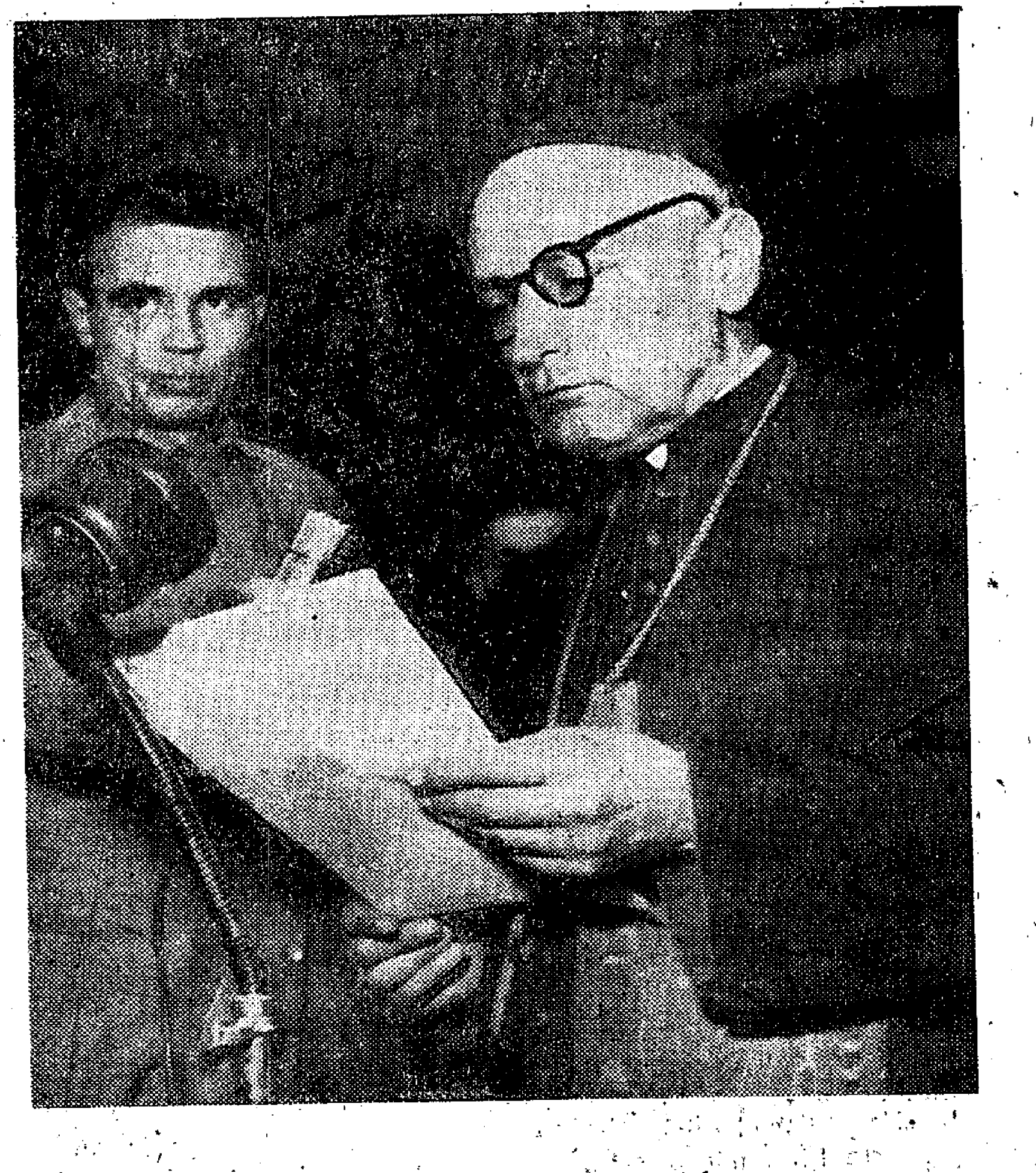

3

Fürstprimas József Kọrdinal Mingaşenty 
Es ist heute dós érste Máf; daß, lah in lebendèn Worten dem Áusland für das agnken kann, was es uns darreicht vor allem mönte ich dem Heiligen vater, Seiner theiligkeit papst Pius Xll, meifen pergontichen-Dank dafür ausúducken, daßer sich so oft des Hauptes der ungarischen Katholischèn Kirche erinnert hat. Zugleich grüße ich in tiefer: Dankbarkeit alle jene Staătsoberhoupter, führer der Katholișchen Kirche, Regierungen," Parlamente sowie Pesönlichkeiten des offentlichen und privaten Lebens, die wăhrend der Zeit die ich im Géângnis - verbracht habé meinem Vaterland und meinem schicksal gegenüber Mitgefüh und Hilfsbereitschaft zeigten, Gott möge es ihren lohnen. Mit der gleichen Dankbarkeit denke ich an die Vertreter der Weltpresse und an das weltumspannende Netz der Rundfunkstationen, deren elëktrische wellen die einzige Großmacht des Humanum billén lch freve mich, dies endlich frei aussprechen zu k̈önnen. Andererseits möchte ich davon sprechen, daß die gesamite Kulturwelt, das Aussland sich sozusagen ungetelit neben uns stell und hilft. Für uns bedeutet dies nömlich eine viel größere Kraft als wir selbst besitzen. Wir sind eine kleine Nation. Ein kleines Land auf deir Erakugel. In einer-Hinsicht jedoch stehen wir an "erster Stelle. Es gibt keine Nation, die im Laufe seiner tausendjährigen-Geschichte mehr gelitten hätte "Nach der 'Reglerung unseres ersten Königs, Stephan dèm Heiligen, entwickélten wir uns zu einer großen Nation. Nach dem sieg von Năndor-

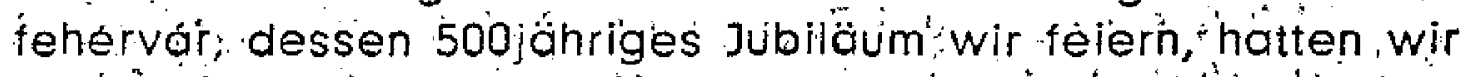

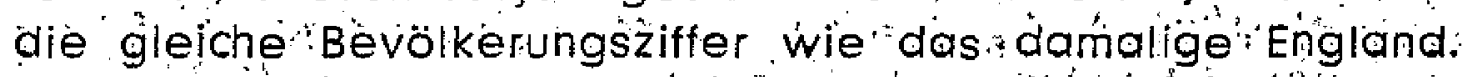
Aber.wir mußten davernd Freineitskriege füren. Meistehs zur Vèrteidigung der westhchen Länder, Bas hat unsere Nation. behinért, wir mußten? uns' stets aus eigener Kraft Wieder emporarbeitèn. Jetzt geschieht és zum erstën Mal in der Geschichte, daß Ungarn -das wirklich wirksame Mitgéfühl der anderen Kulturvölker genießt. Wir alle sind deswegen tiefgerührt. Jedes einzelne 'Mitglied dieser kleinen Nation freut isich von Herzen; daß wegén seiner Freiheitsliebe die anderen. Völker sich seiner Sache annehmen. Wir sehen darin die göttliche fürsorge, die sich durch die Solidarität- des Auslands so offenbart wie es in unserer Nationalhymne heißt: Gott, segre den Ungar - halte Deine schützende Hand über 
Ihn! Und unsere Nationalhymne fährt fort: Wenn er mit dem Feind kämpt!l Aber auch in unserer außerordentlich schwierigen Lage hoffen wir, daß wir keinen Feiñd:haben! Darum, weil auch wir niemandes feind sind. Wir wollen mit-jedem Volk Und Land in Freundschaft leben . .

Von 1945 ab, nach einem vertorenen und für uns sinnlosen Krieg, wurde das hiesige Regime gewaltsam errichtet, dessen Erben itim nun das glühende Schandmal der verieúgnung, Vercchtung und verurtellung aufariucken. Das Regime wurde durch dos gesamte ungarische volk hinweggefegt wirbrauchen neve, saubere Wählen mit der Beteiligung jeder Partei. Die: Wahlen sollen unter internationaler Kontrolle stattfinäen ... Aber ich muß auch die materielle Fassung der Aufgäben betonen, denn wir leben in einem Rechtsstaat, einer kiassenlosen Gesellschaft, wir entwickeln :demokratische Errungen-" schaften, stehen auf der Grundiage des von sozialen Interessen richtig und gerecht eingeschränkten Privatbesitzes, und wollen ein ausschließlich von kulturnationalistischem Geist durchărungenes Volk und Land'sein.

$\therefore$ Mit Recht erwarten wir die sofortige Wiedereinfuhrung der Freiheit des christlichen Religiónsunter schts sowie die Rückgabe der Einrichtungen und Gesellschaften der Katholischen Kirche, darunter ihrer Presse"... (Orgelmusik)

\section{2:02 Uhr}

Es spericht Professor Sándor Szalai:

"Ich habe nahezu 6 Jahre im Gefängnis zugebracht 1... Die Autgabe, vor der wir ungarischen Wissenschaftler jetzt stehen, ist in erster Linie nicht unsere eigene Rehabilitieriving, sondern die Rehabilitierung unserer "Wissenscháft: und die Aufnahme der verbindungen mit dén Wišsenschaltlern der Welt. In einem freien Ungarn freie Wissenschaften - dies ist die Forderung. Wir sind um ein Jahrzehnt" já, ưm mehr als ein Jahtzehnt zurückgeblieben ... . Ich habe die: Tage und zum Téil auch die Nächte der Revolution bel unserer kämpfenden Jugend verbracht. Ich hasse alle Schlägwórte, ich habe sie hassen gelernt, aber jetzt möchte ich trotzdem sagen: es lebe das frele, unabhängige und neutrale ungarnil . . . In meinem eigenen, engeren Fachgebiet, der Philosophie und Soizialwissenschaft und - was die Soziologie betrift, mịt 
ihren Begleitfächerm, der Sozlalpsychologie und einer Reihe von anderen, unterdrujckten Wissensgebieten; ferner - was die spezialgebiete meiner eigenen wissenschaftichen 'Arbeit betrifft: die formale und symbolische Logik, die philosophische_Anthtopologie, die Psychoanalyse und einiges mehr auch hier ist die einzige Forderung nach völligei wissenschaftlicher Freiheit: Dies schließt ein nicht nür die freie Verkündung der wissenschaftlichen Uberzeugung in Wort und Schrift, quf der Universität und dem gesamten Forum der Óffentlichkeit, der Akademie, sondern auch die Freiheit des Kontakts mit den Wissenschaftlern der Welt ..."

\section{Sonntag, 4. November 1956}

\subsection{Uhr, Freier Sender Kossuth, Budapest, und Freies Radio'Petöfl, Györ}

Guten Morgen, liebe Hörer. Heute ist Sonntag, der 4. November 1956. Im Kalender steht der Name Karl.

\subsection{Uhr}

Auslandsnachrichten:

Paris: gestern haben die Regierungen Frankreichs und Großbritanniens folgendes gemeinsame Kommunique herausgegeben: Die Regierungen Frankreichs und Großbritanniens haben

- die von der UN-Generalversammlung am 2. November angenommene Resolution geprüft. Die beiden Regierungen sind der Meinung, daß die Polizeiaktion im Nahen oșten weitergeführt werden müsse. . .

\subsection{Uhr}

Achtung, Achtung, Achtung, Achtung!' ..

"Hier spricht Imre Nagy, Prösident des Ministerrates der Ungarischen Volksrepublik. Heute im: Morgengrauen haben die sowjetischen Truppen gegen unsere Hauptstadt den Angriff eröffnet, mit dem offensichtlichen Zièl, die gesetzmäßige ungarische demokratische Regierung zu sturzen!

Unsere Truppen stehen im Kampf. Die Regierung ist auf. inrem Platz! Dies teile ich der. Bevölkerung des Landes'sowie der Weltöfentlichkeit mit!"

(Nationalhymne)

(Die Mitteilung wird um 5.35 in Englisch wiederholt. Von do 
ab wird sle alle 2 Minuten auf Engllsch, Französisch, Deutsch, Ungarisch und in einer slawischen Sprache wiederholt.),

\subsection{Uhr}

Achtung; Achtung, Achtung!

Imrè Nagy, Ministerpräsident der Nationalregièrung, rưft Verteidigungsminister Pal Maléter, Generaistaḅschẹf István Kovács sowie alle Mitglieder der Mititádelégation welche gestein abend um 10 Uhr auf Einladung des sowjetischen Armeebefehlshabers zur Verhandiung gegangen und noch nicht zurückgekómmen sind, quf, sofort zurückzukehren und dié Leitung ihrer Amter zu übernehmen! Ich wiederhole: . .

\section{$6.45 \mathrm{Uhr}$}

Um 6.24 gab uns Associated Press eine Soniderdurchsage; datiert bei der UNO-Zentrale, wonach die Regierung der USA ám frühien Sonntagmorgen den Sicherheitsrat der.UNO ersucht hat, eine duBerordentliche Sonntagssitzung abzuhalten und sich mit: dem sowjetischen Angriff auf Üngaín zu befaśsen.

\subsection{Uhr}

Achtung, Achtung! Wir verlesen einè wichtige Mitteilung:

"Die ungarische Regierung ersucht die Offiziere und Soldaten dér sowjetischen Armee, nicht zu, schießen! Vermeiden wir das Blưtvergießen! Die Russen sind unsere Freunde und werden es"auch bleiben." (Wiederholung in russischer sprache.)

\subsection{Uhr}

\subsection{Uhr:}

(Schubert: "Ave Maria“).

-Achtung, Achtung! Liebe Hörer, wir verleseñ den Aufruf des Verbandes Ungarischer Schriftsteller:

"An älle Schriftstellér der Welt, ân alle Wissenschaftler, an alle Schriftstellerverbände, Akademien, wissenschaftlichen Vereinigungen und an alle Führer des Geisteslebens: Helft uns! Die Zeit ist knapp / Die Tatsachen'sind euch bekannt, wir brauchen sie euch nicht zu erklären. Helft Ungarn! Helft dem ungarischen VolkI Helft den ungarischen Schriftstéliern,' Wis: senschaftlern, Arbeitern, Bavern und geistig, Schaffenden. Helftl Helft I Helft!"

(Der Aưfruf wird in Englisch, Deutsch und Russisch wiederholt.) (Der Frele Sender Dunapentele strahilt jetżt dás gleiche Programm wie der Freie Sender Kossuthi) 


\subsection{Uhr}

(Mitten in der Sendung fältt der Frele Sender Kossuth Budapest aus.)

8.15 Uhr, Unidentifizierter Sender der kommunistischen Gegenregierung aụ $1187 \mathbf{~ k H z ' ~ ( m o ̈ g l i c h e r w e i s e ~ v o n ~ a u ß e r h a l b ~ U n g a r n s ~}$ sendend) „Achtung, hier spricht Dr. Ferenc Münnich:

Offener Brief an das werktätige Volk Ungarns I - Patrioten, Arbeiter- und Bauernbrüderl Die Unterzelchneten; die Staatsminister Antal Apró, János Kádar; István Kósa und Ferenc Münnich, ehemalige Mitglieder der R'egierung Imre Nagy, tellen mit, daß wir am 1. November sämtliche Bezlehungen zu jener Reglerung abgebrochen haben, aus der Regierung ausgetreten sind und die Initiative zur Gründung der Regiérung der ungarischen revolutionären Arbeiter- und Bauernschaft ergriffen haben.

Zu diesem verantwortungsvollen Schritt trieb uns die Erkenntnis, dab die unter den Druck der Reaktion geratene und hilflos gewordene Regierung Imre Nagy uns keinerlel Gelegenheit mehr gab, gegen dle immer mächtiger werdende konterrevolutionäre Gefahr zu handeln; die unsere Volksrepubllk und die sozialistischen Errungenschaften unserer Arbelterund Bauernmacht zu vernichten drohte ..."

10.03 Uhr, „Hier Ist Radlo Szombathelyl (Nicht mehr in den Händen der Freiheltskämpfer).

Achtung, Achtungl Wir verlesen den Befehl des Militärkom-' mandanten:

"In letzter Zeit erweisen sich die örtlichen Behörden von Stadt und Landkreis als unföhig, für Ordnung und Sicherheit zu sorgen. Kriminelle Elemente; Provokateure stören den Friéden der ungarischen Bevölkerung . . . Auf bestlalische Art miBhandeln und morden sie die sowjetischen Soldatenl ... Ich befehle deshalb:

Alle im Besitz von Waffen befindlichen Personen haben diese sofort auf der sowjetischen Mllitärkommandantur abzuliefern. Wer diesen. Befehl nicht ausführt, werden. wlr streng bestrafenl . . . Dle Werktatlgen der Betriebe ... haben die Arbelt aufzunehmen ... Dlesen Befehl haben alle: Burgèr und Be- 


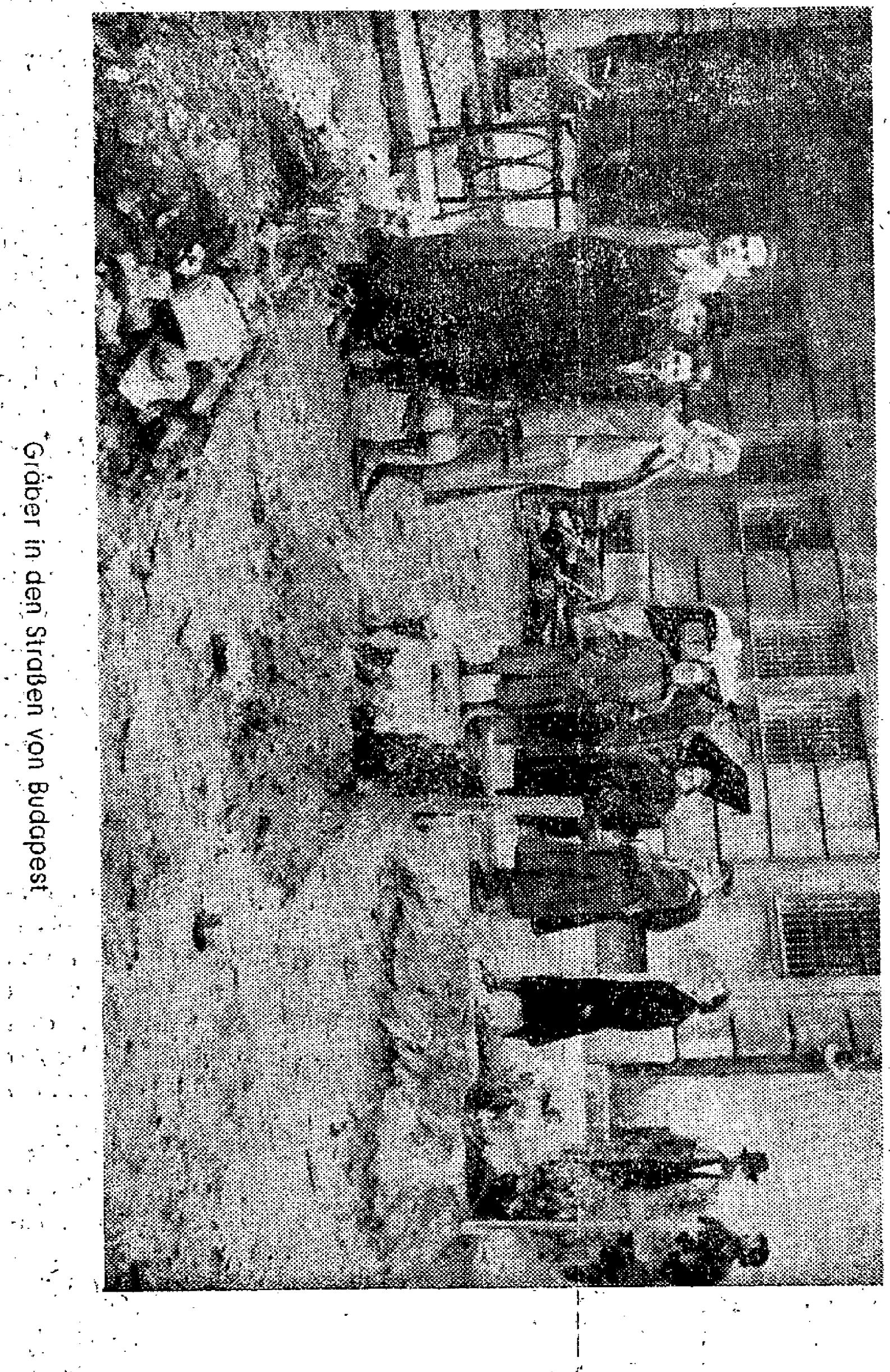


hörden zu befolgen, bls Ordnung und slcherhelt wlederhergestellt sind!"

(Nach kurzer Pause folgt der Rákóczi-Marsch.)

10.10 Uhr (Trompetensignal), "Hier ist Radio Szombathely!?

Liebe Hörer, um 11 Uhr bringen wir Nachrichten, Bis dahin ubertragen wir schallplattenmusik."

\section{$11.00 \mathrm{Uhr}$}

(Wiederholung des Befehis des Militârkommandanten, dann): „Der konterrevolutionäre faschistische Putsch ist infolge der kráftvollen Erhebung dés Völkes zusammengebrochèn . . . Dio Macht des volkes hat endgültig und unwiderruflich gesiegt ...." -

12:23 Uhr, Unbekannter ungarischer Sender auf $7285 \mathrm{kHz}$ (Kurzwelle) Achitung, Achtungl An alle! Wir erb́tten Euré Hilfé für die ungarische Revolution! Hunderte sowjetischer Panzer greifen die ungarische. Hauptstadt an! Wir appellieren an die ganze Welt: helft uns!...

13.03 Uhr, Unbekannter Sender cuf dem 29-m-Band; $10005 \mathrm{kHz}$ “... wenden wir uns immer wieder an das Gewissen der Welt! Die Kulturwelt kann nicht mitarisehen $\therefore$ furchtbare Vernichtung und 'das Töten .. . eine kleine Nation ... friedliche Köexistenz ... Weltmacht . . Sowjetunion : . in die neue Sklaverel. Brüder, die Máske Ist gếfallen. Nách 12 Jahiren unsere letzte bittere Lektion ... "(Schlechter Emptang)"

\subsection{Uhr, Auf $8300 \mathrm{kHz}$, unidentifizierter Sender}

- Achtung! Appell an die Vereinten Nationen! Heute früh um 02.30 Uhr haben die sowjetlschen Truppen mit dem Generalangriff auf das ungarische Volk.begonnen. Wir bitten die UNO um. sofortige Hilfe für Ungarn! ... Wir wenden uns an die. Millionen anständigér Menschen in der Welt: Helft unsl Helft uns! . : .

\subsection{Uhr, Nichtldentifizierter Sendef auf der Wellenlange von}

\section{Dunapentelé}

"Ungarische Fraven, ungarische Mädchén und Mütter! Achtung! Wer in Erster Hilfe ausgebildet Ist; melde sich bitte bel den Krankenhoöusern! Achtung, Achtung! la wiederhole: ... " 
Attention attention, ce matin a 2 heures 30 minutes les soldats russes ont attaque le peuple hongrois.

This is Hungary calling, the last remaining station

Message to the United Nation! Early this morning the Soviet troopsiaunched a general attack on Hungary. We request you to send us immediate aid in the form of parachute, troops over the Travisdanubian provinces..."

(In deutscher Sprache:) „Achtung, Achtung! Aufruf an die UNO. Heute morgen um $2.30 \mathrm{Uhr}$ machten die russischen Truppen eirien Generalangriff auf das ungarische Volk. Wir bitten sofortige militärische Hilfe von den Vereinten Nationen. "Dies ist die letzte ubriggebliebene ungarische Sendestation ..."

\subsection{Uhr}

"Wir bitten Fallschirmtruppen nach Transdanübien. Auçh unsere Stunden werden bald gezählt sein, wie die der anderen Serider. Wir wissen nicht wie lange :wir weitersenden können . : "

16.20 Uhr, „Hier spricht der Frele Ungarische Rundfunk! Hier ist der Sender Csokonal!

„... An alle UNO-Delegierteni Delegierte der völker! in den kommenden Stunden entscheidet ihr über Leben und Tód unseres Volkes. Während eure Söhne glücklich und in Frieden leben können, fallen die Söhne des ungarischen Volkes im mörderischen Fever der sowjetischen Panzer. und Bomber. Uriser Land ist von auBen mit Waffengewalt angegriffen,worden. Ihr seid die letzte Zuflucht! $\because$ Zeigt, daB. die UNO ihren willen verwirklichen kann, daß sie durch inre Be schiusse erreicht, daß unser Land wieder frei wird! 'An euer Gewissen appellierend bitten wir euch: handelt rascht.

Die'sowjetischen Militärbehörden haben angekündigt, daß sie Bưdapest in Kürze bombardieren werdénl

\subsection{Uthr, Radio. Kossuth, Budapest}

Wir verlesen jetzt den Brief der Ungarischen Revolutionären. Arbeiter- und Bavern-Regierung an den Generalsekrétär der UNO: 


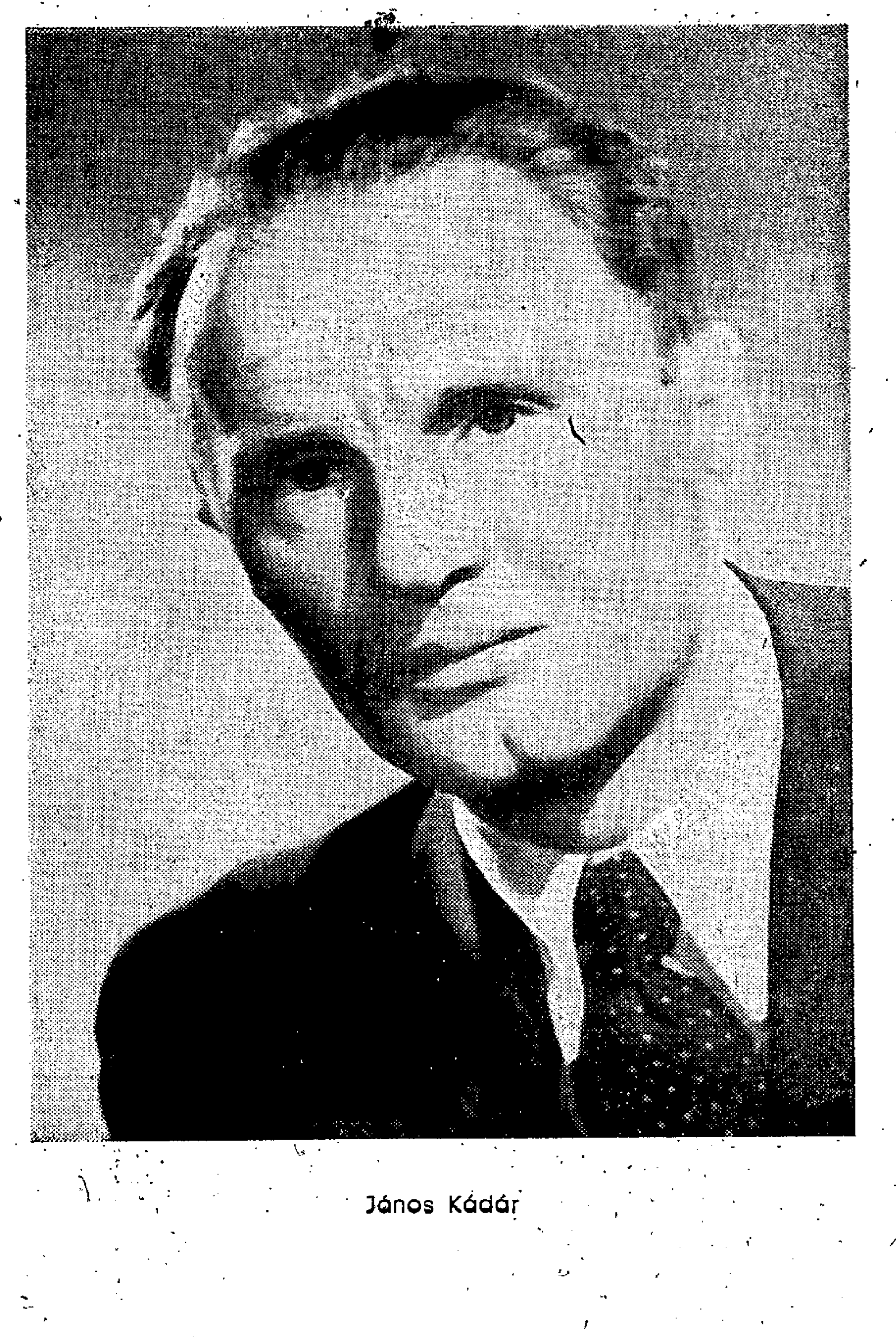


An den Generalsékretär der Wo, Herrn Dag Hammarsjkjölal

$\because$ Budapest am:4 November 1956.

Im Namen der ungarischen Regierung . ersuchen wir sie, der UNO mitzuteilen, daß Imre Nagys Gesuch an "die UNO bezüglich der ungarischen Frage seine Rechtsgrundlage verloren that Es is t ungültig, weildie Regierung lmre Nagy nicht mehri im Amt ist. Die Revolutionẩre Arbetter Buuern-Regie rung protestiert dagegen, daß diese fráge dem isicherheitsrat bzw der UNO-Generalversammlung unterbreltet wird weil sle eine rein interne Angelegentheit der unganischen volksrepublik ist gez: Janos Kadár; Prásident der Revolutionàren Arbelter-Bauern'Regierung, Imre Horvath, AuBenminister."

\section{Montag, 5 . November 1956}

6.36 Uhr, "Hler ist Rádio Kossuth, Budapestl

Guten Morgen, Jiebe Hörer."Wir bringen Untertaltungsilusik."

15.10. Uhr ,Hier let der Sender Rakoczl, Ungarn! Wit bringen Nachrichten:

In der Hauptștadt wird gekämpft Dle auf die Hauptstadt marschierenden russischen Tuppeneinheitentaben wir an vieilen Stellên eingekreist. Díe russischen Panzer wagén sicht nur méh in geschlơssenen verbănden zubewegen An mehreren Stellen wurden vor innen auf den Sträßen Barikaden errichtet: Hier finden erbitterte Kömpfe statt $\ldots$

17. 30.Uhy, ,Hler Ist der Sender Rakoczl, Ungarñ!

Aus drej Richtungen bereiten die sowjetischen Truppen ihren Angriffout Dunapentele vor...".

\subsection{Uhi, Radlo Kossuth.}

Wir bringen Nachirichten:

"Genosse Wilhelm Plëck hat der Kadar-Reglerung eiñ GruB telegramm geschickt."

"Die französische KP hat ein Bulletin veröfentlicht, das sich mit der Lage in Ungarn befaßt. Unter anderem wird darin gesagt daß Imre Nagy auf landesver äterische Welse faschistiscte Elemente in die Regierung eingeschmuggelt hat. Aufr dás Ersuchen der vôm Gehossen Kódar geletéten Règierung 


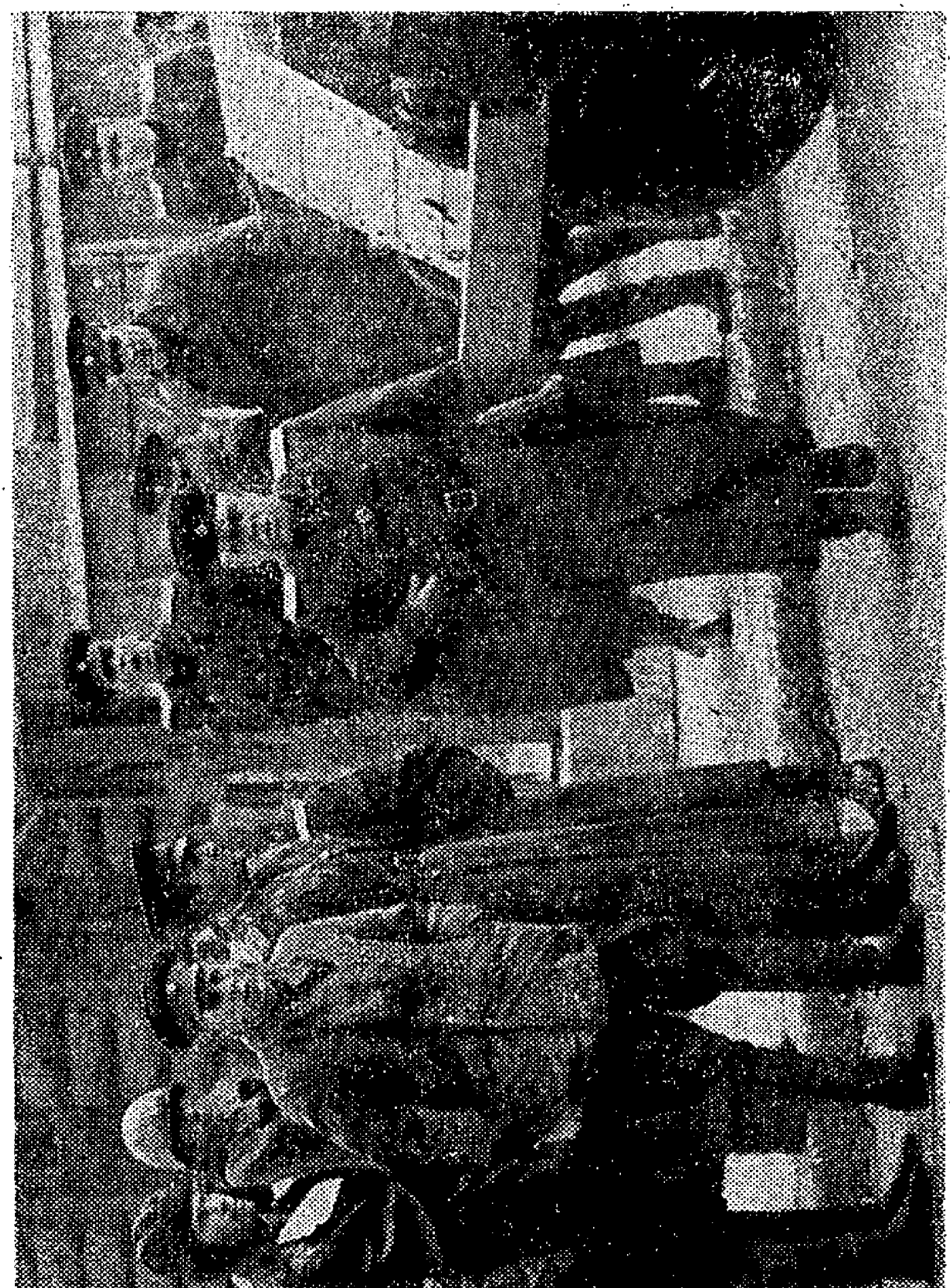

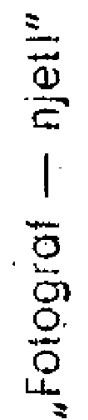

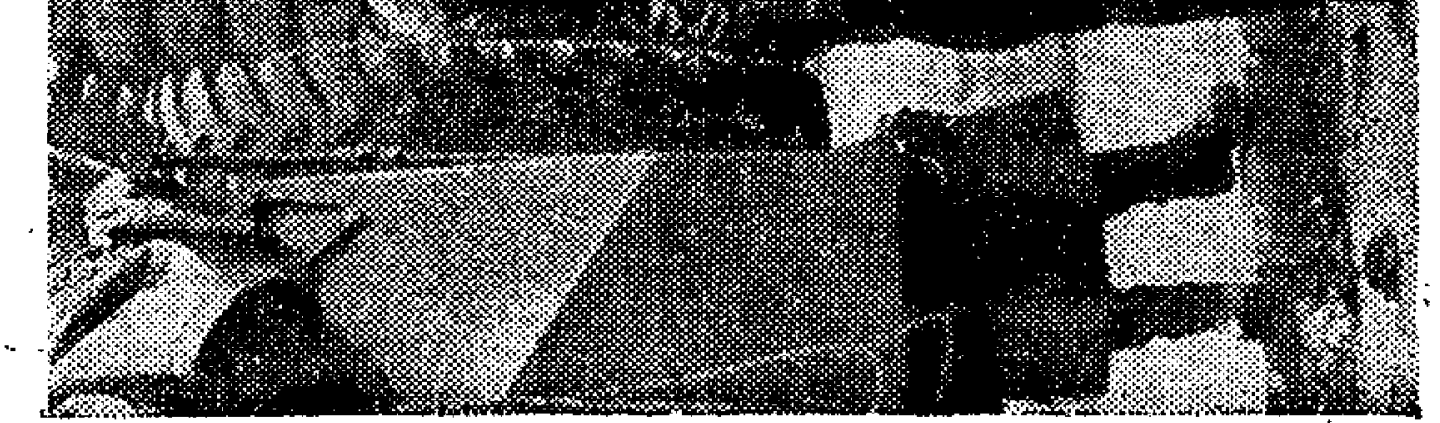


konnte die Sowjetunion die Handlungen "der faschistischen Elemente nicht länger, tatenlos mitansehen . ..$"$

"Die chinesische KP schreibt: ... konnte die Sowjetunion nicht. tatenlos zusehen, wie Ungarn auf den Weg des Faschișmus hinuntersank ..."

23.15 Uhr, Amateurfunker In Budapest (in deutscher Sprache) "Viel Artillerie schießt in die Stadt. Der Widerstand geht weiter. . . Wir bitten keine worte mehr, aber viel und schnell Waffen und Munitiont....".

\section{Dienstag, 6. November 1956}

10.35 Uhr, „Hier Ist der Sender Rákóczi, Ungarn (in deutscher Sprache)!

Hier spricht Ungarn, Rákóczi-Sender! - Aufruf an das Internationale Rote Kreuz in Genf. Trotz dem Aúfruf 'der Vereinten Nationen, der Angriff gegen unbewaffnete Leụte; Fraüen und Kinder durch die sowjetische Armee ist noch im. Gange.

- Sie werfen Bomben auf diè Rote-Kreuz-Institutionen, Spitäler 'und Hilfsplätze. Sle verhindern dié Ausgabe der Medizin uñ Verbönde..."

\section{$\$ . \dot{5} 2 \mathrm{Uhr}$}

“. . . unter diesen Umstönden appellieren -wir an das Gewissen der Welt. Der eventuelle Verlust des Suezkanals ist

w für England. und Frankreich nicht gleichgültig, derin dorthin haben sie sofort Polizeitruppen vor der UNO erbeten. Aber ein kleines Land, welches seine Freiheit tausend Jahre hindurch mit vielen Blutopfern erkauft hat - darf das seine Frelheit verlieren? Warum sind nur die Interessen der Großmächte wichtig, warum nicht auch unsere Krankenhauser, Schulen und nationalen Schätze? "Warum dürfen diese den Bomben und defí Feuer zum Opfer fallen? Warum hört ihr nicht den. Hilfeschrei unserer ermordeten Frauen und Kinder? Völker der Welt Vernehmt doch den Hilferuf veines kleinen Volkes! ... . Wir sind keine Faschistenl Wir wollen das gern einem:-unabhänglgen internationalen Ausschü $B_{1}$ beweisen, aber nicht jenen, die uns mit Phosphorbomben antworten Helft uns, denn. mit dem Schlagwort der. Verwirklichung der 
Demokratie nehmen sie uns die letzte Möglichkeit zur Demokratie!"

'15.12 Uhr

„Wiè der. Sender Róka um 14 Uhr meldete, haben unsere Freiheitskämpfer gestern das. Parlamentsgebäude zürückerobert. Auch dieStraßen nach Székesfehérvár und Kecskemét sind in unserer Hand. LaBt keine weiteren Sowjettruppen in die. Hauptstadtl Einen großen Tell der eingebrochenen Sowjettruppen haben wir vërnichtet. Wir brauchen Lebensmittel, Medikamente und bewaffnete Hilfe! . .."

\subsection{Uhr}

"Achtungl Handelt schnelll Die Bedenkfríst; die sie uns gegeben haben, läuft bald ab. Dann werden sie angreifen. Wir sind vorbereitet. Wir warten auf den Angriff . . . Werft Waffen und Munition per Fallschirm ab. Beellt euchl Handelt rasch ..."

\section{Mittwoch, 7. November 1956}

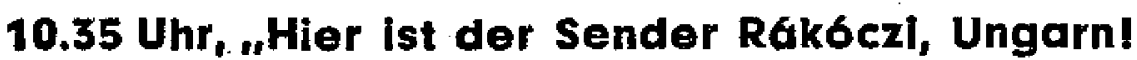

". . . auf unsere Autrufe keinerlei Antwort bzw. Hilfe. Laßt uns deshalb unseren Hilferuf wiederholen. Ist euch die Freiheit tever? Uns ist sie es auch! Habt ihr Fraven und Kinder? Wir auchl Habt ihr Kranke? Auch wir haben aus hundert Wunden blutende Verwundete, die ihr Blut für die heilige Sache der Freiheit haben fließen lassen. Aber wir hảben keine Verbandsstoffe, um ihre Wunden zu verbinden, und keine Medikamente, um ihre Schmerzen zu lindern! Und was sollen wir unseren Kindern geben, die um Brot bitten, denn auch unser letztes Stück Brot ist verzehrt. "Bei allèm, was euch lieb ist, bitten wir: helft uns: Denkt ihr nicht, daB die Herzen unserer für die Freiheit gefallenen Lieben, die aufgehört haben zu schlagen, alle diejenigen anklagen, denen es möglich gewesen wäre, uns zu helfen, und die nicht geholfen haben? ... die UNO ... sie hat die Möglichkeit ... Wir senden diese Botschaft heute, da unseres Wissens die UNO zur auBerordentlichen sitzung zusammentritt. Wir senden diese Botschaft Präsident Eisenhower anläßlich seiner heutigen Wiederwahl ..." 


\subsection{Uhr}

Seit Morgengrauen tobt der Kampf im Gebiet. vón Dunapentele mit unverminderter Heftigkeit . .

In Kecskemét und Kalocsa sind nun Partisanenkämpfe gegen die sowjetischen Truppen aufgeflammt . . .

\section{4:05 Uhr}

Wir bitten um bewaffnete Hilfe für Ungarn! . . Wir kämpfen gegen eine erdriuckende Ubermacht! Vielleicht werden sie bald auch unseren Sender vernichten. Aber wir werden als Partisan'en' weiterkämpten! Vielleicht werdet ihr-unsere Nachrichitèn nicht ‘mehr hören...

\subsection{Uhr}

Bleibt cuf unserer Wellenlänge. Sobald wir etwas Zelt haben, um aus der Feverstellung zum Radio zurückzukommen, melden wir uns wieder. -

\subsection{Uhr}

Achtung, Achtung! Hier "ist der Sender Rákócżi, Ungarn! Sowjetische Panzer und Flugzeuge greifen Dunappentele an! Der Kampf geht mit unverminderter Heftigkeit weiterl Wir unterbrechen jetzt unsere. Sendung für unbestimmite Zeit $\ldots$

(Per Sender Rakoszi meldete sich nicht wieder.)

\section{ENDE}




\section{Stlchwortverzolchnis}

APRO ANTAL, neben GERO das einzigo seit 1945 ständige Mitglled des Politburos der ungarischen KP, 1953 Mitglied des Prösidialrats, November 1953 stellvertretender Ministerprasident, 1956 Prasident der "Vaterländischen Volksfront.

DERY TIBOR; Universitötsprofessor, Schriftsteller. 1948 Mitglled des Nationalkomitees der Ungarischen Intellektuellen, 1955 nach der Schriftstellerrevolte ous der Partel ausgeschlossen, 1956 rehabllitiert:

Disz, "Dolgozó lfjuság Szóvetsége" = Verband der Werktätigen Jugend.

Dunapentele, (vorher Sztalinváros = Stalinstadt) vom kommunistischen Regime gegrundet, solite die. Musterstadt der Schwerindustrie werden.

RREIE JUGENo, ("Szabad Ifjuság") offizielles Presseorgan des DISZ.

PREJES VOLK, ("Szabad Nép) offizlelles Presseorgan der ungarischen KP, wahrend der Revolution in VOLKSFREIHEIT ("Népszabadsóg"). umbenannt.

OERO ERNO, seit 18: Juli 1956 1. Sekretär der Partel, hat selt 1945 als Reglerungsmitglied stets eine wichtige Rolle in der ungarischen Politik gesplelt. Finanzfachmann. Ging am 31. Oktober In die Sowjetunion.

GROSZ JOZSEF, Erzbischof von Kalocsa, nach der Einkerkerung Kardinat MINDSZENTYS Führer des katholiscien Lebens in Ungarn, sputer selber zu 15 Jahren Zuchthaus verurteilt, begnadigt und freigelassen. Verfocht Noiwendigkeit eines Kompromisses zwischen Kirche und Staat.

haY orula, schriftsteller, führende Pérsönlichkelt im Pętófi-Krels.

HORVATH IMRE, AUBenminlster, b/s Jull 1956 Botschafter in (Ost-)8erlin, London und Prag.

KADAR JANOS, von Jugend an Kommunist, 1945 stellvertretender Befehlshaber der Polizeikrafte in Budapest, 1948-1950 innenmInister, 1951 verhaftet, gefoltert, 1954 freigelassen, 1955 Erster Sekretăr des Partelkomitees des Komltats Pest, am 18. Jull Mitglied des ZK, am 19. Jull Sekretär des ZK, am 25. Oktober Erster Sekretär der Partei.

KLEINE Zeitung („Kis Ujsag"), Tagblatt der unabhängigen Partel der kleinen Landwirte und der Burgerpartei.

Komitat, ungarische Provinzen, mit verhältnismäßig weitreichender, historisch bedingter Selbstverwaltung, am ehesten mit den französischen Departements vergleichbar. Ungarn besteht houte aus 19 Komitaten.

KOssa IstVAN, vor dem Krieg Mitglied der Sozlaldemokratischen Partel, 1948 Generalsekretär des Gewerkschaftsrats, 1952/53 Minister fur dle SchwerIndustrie, 1955 Vizeprásident des Plonungsbüros, finanzminlster der Regierung IMRE NAGY.

Kossuth-Wappon (nach dem Staatsmann des ungarischen Freiheltskrieges 1848/ 49 - Lajos Kossuth), das ungarische Nationalwappen ohne die daruber befindlicie Stephanskrone, seit 1848/49 Symbol der demokratischen Republik.

Kovacs BÉlA, nach dem Krieg Sekretär der unabhängigen Partel der kleinen Landwirte, bis 1947 Landwirtschaftsminister, 1947 verhaftet und nach der UdSSR deportiert, konnte im Juni 1956 wieder nach Ungarn zurudkkohren. 
WKACS GYORGY, 1919 Volkskommissar, zwischen den beiden Weltkriegen wissenschaftliche und literarische Tätigkeit in Osterreich, Deutschland und der Sowjetunion, bedeutender Vertreter des Neomarxismus, Verfasser bekannter Werke, wie "Goethe und das bürgerliche Zeitalter", "Krise der burgerlichen Philosophie", 1946 Universitätsprofessor, 1949. wegen "Rechtsabweichung" von der Partelleltung angegriffen, 1956 wurden seine literarischen und wissenschaftlichen Ansichten rehabilitiert.

MALETER PAL, genannt der Held von Budapest, geboren 1920, 1942 Leutnant, 1944 als Partisan an der Seite der Sowjets, 1947 Oberstleutnant, Kommandeur der Lelbwache, selt 1949 im Verteidigungsminlsterium.

MDP, "Magyar Dolgozók Partja - Ungarische Arbeiterpartel, die KP Ungaras.

15. Marz, Nationalfeiertag zum Gedächtnis an die von der akademischen Jugend und intellektuellen begonnenen Revolution von 1848 , mlt dem Namen Petöfis verknupft.

MEFEsz, Föderation ungarischer Universitäts- und Hochschulstudenten, gegründet im Oktober 1956.

MUNNICH FERENC, 1945-1949 Polizeipräsident von 8udapest, 1950-1954 Im diplomatischen Dienst, 1954-1956 Botschafter in der Sowjetunion, im September 1956 Botschafter in Jugoslawien, innenminister der Regierung IMRE NAGY.

NAGY IMRE, alter Kommunist, 1946 Landwirtschaftsminister, 1953 bis April 1955 Ministerpräsident ("Never Kurs"), Im Dezember 1955 wegen "Rechtsabweichung" aus der MDP ausgeschlossen, am 14. Oktober 1956 rehabilitiert.

NEMETH LAsZLO, Essayist, bekannter Schriftsteller, in letzter Zeit Mitglied der Direktion des ungarischen Schriftstelierverbandes.

6. Oktober, Nationalfeiertag, Gedenktag der Hinrichtung von 13 Freiheltohelden von 1849.

PETOFI SANDOR (1823-1849), einer der gröBten Dichter; fürende Persönlichkeit im Freiheitskampf von. 1848/49, fiel als Major im Kampl gegen russische Truppen, welche die Freiheitserhebung niederschlagen halfen.

Petsfl-Krels, literarischer Kreis innerhalb des DISZ.

PIROS LAszLO, seit 1954 Innenminister, Generalmajor des Staatssicherheitsdienstes.

SOTER ISTVAN, Universitätsprofessor, Rektor der Universităt Budapest, später stellvertretender Unterrichtsminister.

SzOVVosz, "Szövetkezetek Országos Szövetsége” = Landesverband der Gonossenschaften.

vas zolTAN, Mitglied des ZK und Präsident der Direktion des szovosz.

volksstimme ("Népszava”), Tageszeitung der Sozialdemokratischen Partel Ungarns.

ILoy Zoltań, vor dem Krieg Prösident der Kieinen-Landwirte-Partel, 1945 Ministerprösident, 1946 Präsident der Volksrepublik, 1948 RỤcktritt und Hausarrest, 1956 rehabilitiert.

ZakK ZOLTAN, Dichter, 1951 mit dem "J6zsef-Attila-Preis" ausgezelchnet, 1952 Mitglled des Prösidiums des ungarischen Schriftstellerverbarides. 


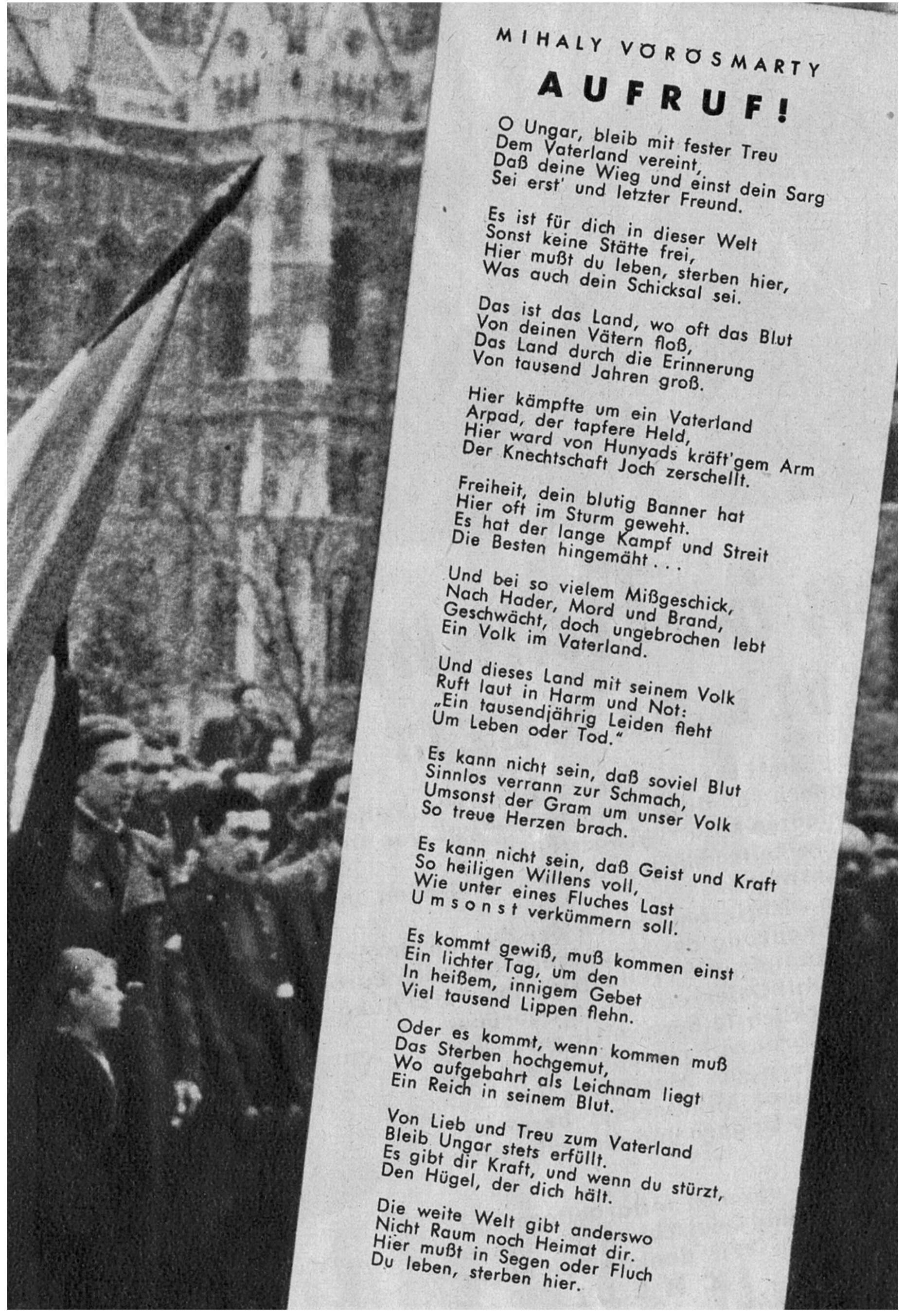


Time, New York, 7. 1. 1957

\section{ER WAHLTE DIE FREIHEIT}

Die Welt begann das Jahr 1956 mit einer Fülle großer Männer: Volksführer, Staatsmänner, Philosophen, Künstler und Wissenschaftler, von denen viele unvergessen bleiben werden als die Bedeutendsten unserer Zeit. Doch der Mann, der diesem Jahr seinen Stempel aufdrückte - der Mann des Jahres war nicht unter den Großen dieser Welt als das Jahr begann. Bei Jahresende aber hatte er die größte Gewaltherrschaft der Geschichte in ihren Grundfesten erschüttert ...

Der Mann des Jahres hatte viele Gesichter, aber er war nicht ohne Gesicht; er trug viele Namen, aber er war nicht namenlos. Die Geschichte würde ihn am Gesichtsausdruck erkennen, gespannt, unerbittlich, verzweifelt und entschlossen, den er am Abend des 23. Oktober in den Straßen von Budapest gehabt hat; die Geschichte würde ihn an dem Namen erkennen, den er sich während seines furchtlosen Kampfes mit sowjetischen Panzern wählte: der ungarische Freiheitskämpfer. 


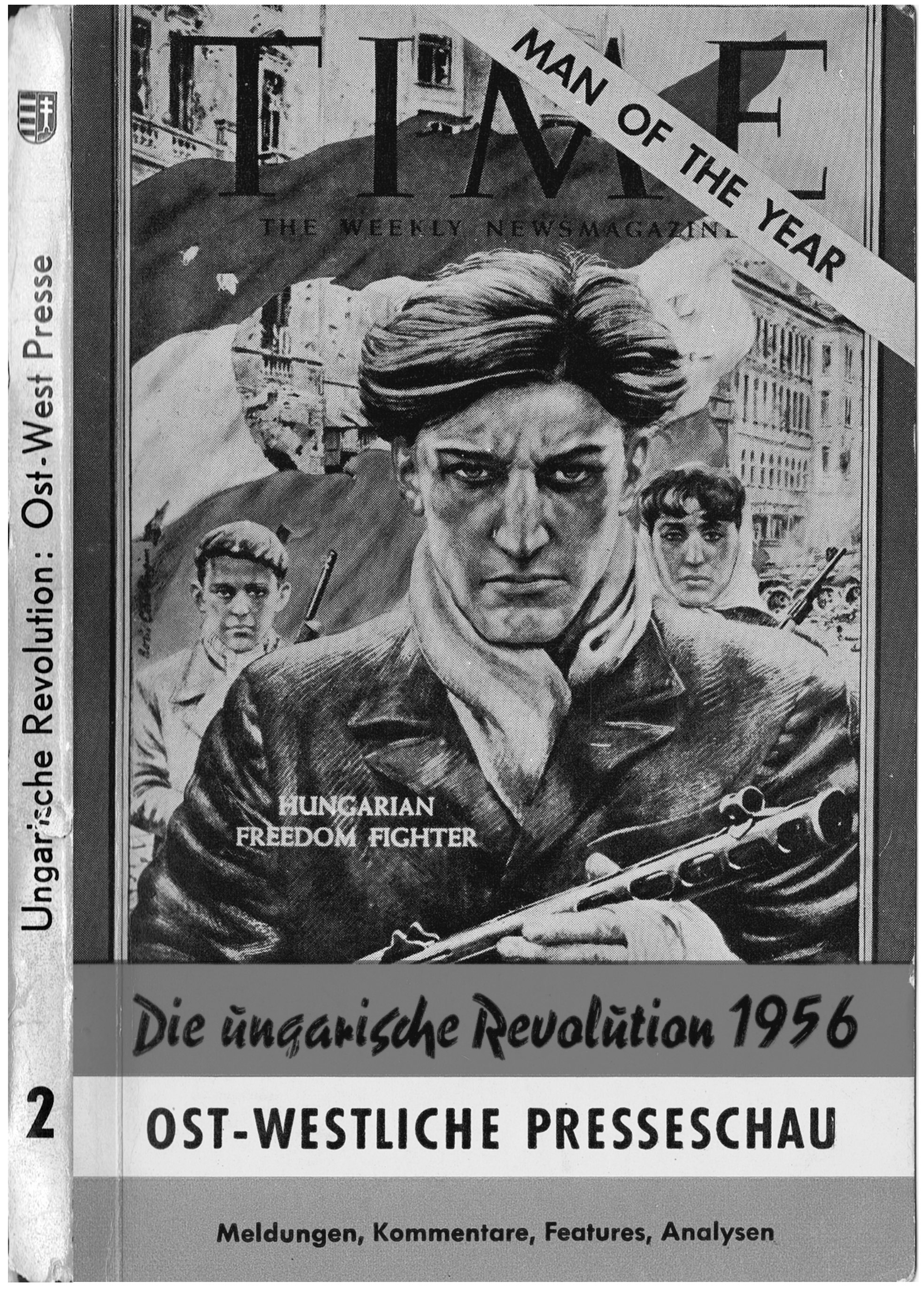




\section{E \\ U N G A R I S C HE \\ REV OLUTION \\ 1956 \\ Ost-westliche Presseschau}

Zusammengestellt und übersetzt von József Gert Farkas Druck: Buchdrudkerei Dr. Johann Herp, München

Heraugegeben im Selbstrerlag von J. G. Farkas, München 


\section{VOR W O R T}

In Zeiten revolutionärer Bewegungen kommt 'der Presse eine besondere Bedeutung zu, gleich welcher Parteirichtung sie dient, und es ist daher zur Klärung der Lage und zur Beurteilung für den Historiker wichtig, daß die Stimmen der Presse auf beiden Seiten nach objektiven, wissenschaftlichen Gesichtspunkten gesammelt und gesichtet werden.

Es hat sich in den Tagen der ungarischen Revolution, wie schon so oft in ähnlichen politischen Kämpfen, gezeigt, daß einer freien Presse auch neben Rundfunk, Film und Fernsehen eine wichtige Aufgabe zufällt.

In diesem Sinne ist das Erscheinen des vorliegenden Buches "Die ungarische Revolution 1956 im ost-westlichen Pressespiegel“ schon vom Standpunkt der Zeitungswissenschaft zu begrüßen.

München, den 12. Oktober 1957.

$$
\text { Professor Dr. Karl d'Ester }
$$


Die russische Einmischung hat den Unwillen der ganzen Welt herausgefordert... Idh bin überzeugt, dab wohl kaum je im Lauf der Geschichte der Freiheitskampf einer Nation mehr Sympathien geweckt hat als unser. Im Kampf waren wir auf uns allein gestellt, abgeschnitten von der Welt.

LAJOS KOSSUTH (1849)

Dieser 'Auswahl aus der enormen Zahl von Artikeln, die in der. Presse verschiedener Länder zwischen Herbst 1956 und Sommer 1957 mit Bezug auf die Ereignisse in Ungarn erschienen sind, ist kein eigener Kommentar beigefügtt. Um die Objektivität nicht $\mathrm{zu}$ beeinträchtigen, ist die chronologische Anordnung auch wegen interessanter. Gegenüberstellungen nicht unterbrochen worden (z. B. S. 32 und S. 74). Wo Kürzungen unvermeidlich waren, , wurde sorgfältig darauf geachtet, daß die Aussage des Verfassers nicht verfälscht werde. Die Streichungen sind durch Punkte angedeutet. Bei der Ubersetzung ging es in erster Linie um eine wörtlich genaue Ubertragung, nicht um flūssigen Stil. Da diese Publikation Teil einer umfassenderen Arbeit über die ungarische Revolution 1956 ist, fehlen meist Presseveröffentlichungen und Reden, die bereits in der Broschüre "Ungarische Rundfunkdokumente" oder den folgenden enthalten sind.

Bei der.Arbeit an dieser Broschüre wurden viele tausend Zeitungs- und Zeitschriftenexemplare aus verschiedenen Ländern durchgesehen; wenn nun bei dieser Zusammenstellung der Akzent auf'der bundesrepublikanischen und ostzonalen Presse ist, drückt das die Erkenntnis des Herausgebers aus, daß im Großen und. Ganzen die Pressestimmen des geteilten Deutschland als stellvertretend für die beider ideologischen Hemisphären gewertet werden können. Die Zitate aus Zeitungen anderer Länder sollen diese Ansicht begründen. Eine besondere Stellung nimmt die ungarische Presse jener Tage ein, während der sie keiner Zensur unterlag. - Die Liste der verwendeten Zeitungen und Zeitschriften sowie ein Stichwortverzeichnis befinden sich am SchluB des Buches.

Allen Zeitungs- 'und Zeitschriftenverlagen, Schriftleitungen und Journalisten, deren freundliche Genehmigung zum kostenlosen Abdruck von Artikeln das Erscheinen dieser Broschüre ermöglicht hat, sei hier nochmals herzlichst gedankt.

József Gert Farkas 
Münchner Merkur, 15. 10.56

WIRD RAKOSI VERHAFTET?

i. m. - Das Schauspiel im kommunistischen Ungarn wird immer makabrer. Hatte man am vergangenen Wochenende die bisher im Gefängnishof verscharrten Leichen des hingerichteten früheren Außenministers László Rajk und seiner Genossen ausgegraben und in einer Massendemonstration ehrenvoll beigesetzt, so fand diesmal eine ähnlich gespenstische Zeremonie für fünf Generale statt. Mehr.noch: der frühere Ministerpräsident Imre Nagy wurde rehabilitiert und endgültig wieder in die Partei aufgenommen, während Mihály Farkas, einst Verteidigungsminister, Parteisekretär und Mitglied des Politbüros, verhaftet wurde und vor Gericht gestellt werden soll ...

...Vorerst gilt es, die Einsicht nicht außer Acht zu lassen, daß in Budapest lediglich ein großes Schlachten zwischen Kommunisten der verschiedenen Flügel beginnt; daß Machtkämpfe dahinter stehen und daß weiten Kreisen; die nach Herkunft, Bildung und Gesinnung dem Westen in ihrem Freiheitsstreben verbunden sind, noch immer keine Bresche für eine Mitwirkung an der Gestaltung des politischen Schicksals ihres Landes geöffnet worden ist.)

Frankfurter Allgemeine Zeitung, 16. 10! 56

MIT WIDERSTANDEN

... In Polen rechnet man damit, daß das Zentralkomitee der dortigen Kommunistischen Partei seinem früheren Ersten Sekretär, Wladislaw Gomulka, einem „Titoisten“, die Rückkehr in höchste Amter endgültig freimacht.

In Ungarn dagegen scheinen die gegensätzlichen Kräfte unter der Oberfläche erbittert miteinander zu ringen. Bei ihnen ist die Entstalinisierung noch so unklar, daß sogar. ein alter Stalinist, der Parteisekretär Gerö, die ungarische Delegation leitet, welche die parteikommunistischen wie die zwischenstaatlichen und wirtschaftlichen Fragen in Belgrad erörtern soll... Diese Umstände erklären, daß 
Tito selbst sich diesen Gesprächen fernhält und sie dem jugoslawischen Vizepräsidenten Alexander Rankiovic überläßt. Das Schwimmende der ungarischen Verhältnisse ist: auch durch die Vermutung charakterisiert; daß der populärste Politiker des Landes, der rehabilitierte Imre Nagy, nicht darauf ausgeht, den Posten des Ministérpräsidenten, der bald frei werden dürfte, zu übernehmen...

Szabad Ifjuság, Budapest, 19. 10. 56

WIR EROOFFNEN DIE DISKUSSION:

Um die Reform des "DISZ“

...Vor der 'Befreiung wohnte ich in einem kleinen Dorf wo nie jemand die Jugend organisierte, und doch haben wir uns instinktiv in freundschaftliche Kollektiven, Gruppen zusammengeschlossen, denn in uns lebte das Verlangen nach Gemeinschaft, der sogenannte "Kollektivgeist". Heute dagegen, wo wir organisieren, Versprechungen machen (und manchmal auch etwas geben), mit allen Mitteln den Kollektivgeist in die Jugendlichen "hineinerziehen" möchten, will dies gar nicht gelingen...

\section{Die langweiligen politischen Versammlungen}

Es melde sich derjenige Jugendführer, der nicht sèlber die mit Phrasen gespickten, stotternd vorgeleșenen Reden satt hat. lch will nicht sagen, daß man in der Jugendorganisation nicht politisieren soll: Aber nicht mit diesen unerträglich groben Methoden...

\section{Der Arbeitswettbewerb}

Hand aufs Herz, Jugendführer, wenn jemand euch andauernd ins Ohr flüsterte: Veranstaltet Wettbewerbe, würdet ihr den Betreffenden nicht irgendwohin schikken?... Und ob! .. Ich wünschte, unșere Jugendführer (und auch die Parteiführer) würden verstehen, daB man vor allen Dingen Lust und Fröhlichkeit in die Herzen der Jugendlichen zaubern muB, dadurch daß wir für sie Unterhaltung und ein besseres Leben schaffen, dann braucht man sie nicht immer zur Arbeit anhalten, sie werden von selbst um die Wette arbeiten. Für gute Arbeit aber verschaffen wir ihnen den verdienten Lohn. 
Denn bisher haben wir uns herzlich wenig darumi gekümmert...

Szabad Ifjuság, Budapest, 19. 10. 56

DIE GEFAHR DES ZYNISMUS

Subjektive Bemerkungen zum Brief von András Tábori

Von András Sándor

Es. gibt keine Jugend ohne Glauben.

In meiner Jugend habe auch ich geglaubt, flammend, hingebungsvoll... Anfangs an die christliche.Moral, dann an das Volkstum, später an den Sozialismus, die kommunistische Bewegung und die neue Welt. Ich glaubte an die Berufung der Ungarn, an das Bauerntum, die Arbeiterklasse, an philosophische Systeme, Religionen, große Führer, Idealbilder und Ideen...

Wenn mich mein Glaube enttäuschte, hatte ich immer einen neuen, denn ich brauchte den Glauben wie die Luft, - den Glauben der Galeerensklaven, der Märtyrer von Eperjes, den Glauben der von der Inquisition Gefolterten, diesen. weisen, in die Zukunft blickenden Predigerglauben an die wahre Sache, diesen von Weihrauch und Mysterien freien, klaren und rationalen Glauben.

Wie gut verstehe ich meinen unbekannten Freund Timári der jetzt die große Krise seines jungen Lebens durchmacht! Er glaubte... an einen zum Mythos vergröBerten Mann... und jetzt stellt sich heraus, daß dieser olympische Gott ein nur allzu irdischer Mensch war, kein Riese, nur ein trauriger Zwerg... Wie konnte es aber auch geschehen, daB man den Menschen, welche nach langem Elend ein Obdach ersehnten, ein Haus gebaut hat, von dem man genau wußte, daß es eines Tages über ihnen zusammenstürzen würde? ...

.... GroB ist dies Dunkel, wir haben die Welt in Brand gesteckt und sehen keinen Schritt weit...!" Die Kuruzzen-Verse von Ady klingen in unseren Ohren, dumpf, wie Trommelwirbel beim großen Begräbnis, das zugleich die endgültige Beerdigung des modernen Baal-Kultes ist, des neuen Menschenopfers und des bösen Zaubers der neuen Barbarei, welche den Namen und die Gestalt des Humanismus miBbrauchte... 
IB und trink, genieBe so viel du nur kannst und lach, über die Welt, den Schwachen, den Gefallenen, über dein Opfer, das dumm genug war, dir auf den Leim zu gehen, - dies ist das LebensgefühI, welches leicht in jungen Seelen Wurzel, schlagen kann, denn es ist das Erbe, welches ein Mihály Farkas und ein Mátyás Rákosi hin. terlassen haben... Die heutige Jugend hat kein festes 'Fundament... WeiB denn die heutige Jugend, was der Sozialismus ist? Kennt sie das Endziel, dais menschliche Glück? WeiB șie was Liebe ist...? Ist es denn nicht'so, daß sie nur zwischen Potemkinschen Kulissen herumirrt, statt wirkliche geistige Werte kennenzulernen?

Und überhaupt: Kennt diese Jugend den. Weg, ihr eigenes Ziel, weiB sie wohin sie will? - Man muB diese Fragen stellen und die Antwort kann nur sein: Der Jugend schnellstens einen Glauben zu geben. Doch diesen. Glauben können nur Glaubende geben...

\section{Szabad Ifjuság, Budapest, 19. 10. 56}

500 DELEGIERTE, 50 INTERPELLANTEN, AUF SITZUNG DES SCHULERPARLAMENTS

Im großen Saal des "Hauses der Parteierzieher" sitzen 500 Schüler, die Delegierten der Budapester Oberschulen. Nacheinander bitten sie ums Wort und stellen Fragen an die anwesenden Vertreter des DIŚ und des Unterrichtsministeriums sowie an unsere ganze Gesellschaft. Sie sagen ihre Meinung. In eigener Sache und in Angelegenheiten des Landes. Die viele Jahre lang unterdrückte Meinungsfreiheit und das gekränkte. Gerechtigkeitsgefühl brechen hervor... Die meisten Fragesteller sprechen über die Möglichkeit von Auslandsreisen. Verständnislos stehen sie vor der geplanten Verordnung des Innenministeriums, welche Reisen nach dem. Ausland erschwert. Statt dessen bitten sie um Erleichterung und Hilfe...

Die Schüler bitten und verlangen Unterricht in Kunstgeschichte sowie der ges a m t e $n$ ungarischen Literatur, und sie möchten die g a $\mathrm{nz}$ e Weltiteratur kennenlernen - endlich einmal nicht nach engstirnigen, "politischen" 
und aktualisierten Gesichtspunkten. Es wäre nicht schade wenn wir dies alles !statt des Luftschutzunterrichts kriegLen, - das lernt sowieso niemand - Lehrern und Schülern hängt es gleichermaBen zum Hals heraus - sagen sie...

György Kertész berichtete, daß die Schüler in so mancher politischer Frage nicht klar sehen. Und zwar deshalb nicht, weil meistens ihre Lehrer - als Folge der vergangenen Jahre — auch heute noch keine ehrliche Meinung sagen, keinen Standpunkt zu vertreten wagen...

\section{Szabad Ifjuság, Budápest, 19. 10. 56}

DIE STUDENTEN BATEN UMS WORT!

Von András Török

... Wir stehen an der Schwelle von Umwälzungen, die wir schon lange ersehnt haben, und die nun keine Macht mehr aufhalten kann. Wie bei allen gröBeren Umformungen ist auch für diese charakteristisch, daß sie auch die. jugendlichen Massen immer mehr in Bewegung bringt.

In diesen Tagen hallen die Universitäten von scharfen politischen Kämpfen wider. Die Budapester Volkswirtschaftler haben den Széchenyi-Kreis gegründet, die Juristen den Hajnóczy-Kreis, an der:Hochschule für Theaterwissenschaften und bildende Künste haben "reinigende. Gewitter"... stattgefunden, an der philosophischen Fakultät von Budapest schlagen die Wellen der berechtigten studentischen Forderungen immer höher, die Studierenden von Szeged versammeln sich und die Studenten von. Debrecen haben eine Delegation nach Budapest geschickt - mil einem Wort: es tut sich was...

Worum geht es...? Um die Abschaffung der törichten Bindungen, welche (in der Atmosphäre des Dogmatismus geboren wurden... Abér unter den studentischen Forderungen gibt es auch solche, mit denen wir durchaus nicht einverstanden sein können. Zweifellos sind diese Forderungen so entstanden, daß der revolutionäre Strom, welcher jetzt durch unsere Universitäten tost, auch die Schlagworte solcher Elemente mitführt, die unserem Volk fernstehen. Wie kann man sich dagegen wehren? Nur 
e in Mittel gibt es! Man muB die berechtigten Forderungen erfüllen... so werden innerhalb von Tagen all diejenigen den Boden unter den FüBen verlieren, die in dem jetzigen revolutionären Strom nicht an die Oberfläche geIangen dürfen.

Die Kämpfe, welche jetzt an unseren Universitätén stattinden, erinnern an die glorreichen Tage von 1848..

Szabad Ifjuság, Budapest, 20. 10. 56 .

OFFENTLICHE DISKUSSION DER WOHNUNGSFRAGE AUF SITZUNG DES BUDAPESTER "DISZ"-KOMITEES

Wie sollen die Jugendlichen $\mathrm{zu}$ Wohnungsbauminister Szijárto Vertrauen haben? - Die jungen Delegierten fordern die Ernennung eines Regierungsbeauftragten. Wie verschwanden 5000 . Wohnungen im Labyrint der Bürokratie?

„... Heute werden in Budapest 137000 Wohnungen benötigt. Nach den veröffentlichten Ziffern sollen im Laufe des gànzen Fünfjahresplanes 60000 . Wohnungen gebaut werdén. Aus diesen beiden Zahlen geht hervor, daB die Wohnungssorgen der Budapester auch zum Ende des Fünljahresplanes nicht verschwinden werden... Im Fünfjahresplan ist die Ubergabe von jährlich 12000 Wohnungen vorgesehen. Heuer werden aber nur 9145 Wohnungen aufgebaut. Also erhält die Bevölkerung nicht einmal jene geringe Anzahl von Wohnungen, für die die. Regierung die materiellen Möglichkeiten garantiert. hat ..."

Szabad Ifjuság, Budapest, 20. 10. 56

Sturm in Szeged. Ein Sturm, der Dienstagabend unter den Hörern der Philosophischen Fakultät ausgebrochen ist und noch heute anhält...

Betrachten wir jetzt auch die politischen Forderungen, welche źwar über die Universitätssphäre hinauswachsen, aber mit dem Leben der Studierenden eng verknüpft sind: Völlige Pressefreiheit, Abschaffung der Todesstrafe, Festsetzung der obersten Grenze des vom Staat bezogenen Einkommens und beschleunigte Erhöhung der niedri- 
gen Löhne. Die Jugiendlichen von Szeged,sind der Meinung, daß auch einige personelle Veränderungen nötig sind und $d a \beta$ die Schuldigen bestraft werden. Sie fordern, dạ $B$ der.15. März Nationalfeiertag sei...

Szabad Ifjuság, Budapest, 20.10. 56

Zum erstenmal im Leben unseres Jugendbundes ist es geschehen, daß 3000 Studenten unseren Verband verlassen und eine neue Organisation gegründet haben. Diesen Schritt einfach zu verurteilen, wäre Blindheit und Engstirnigkeit.

Warum kam es in Szeged zu dem Bruch?

Wie dié. Hörer im Verlaufe der Diskussionen berịchteten, haben sie die Erfahrung gemacht, daß der DISZ sich nicht an die Spitze ihrer Bewegung zu stellen vermochte und nicht konsequent für die Erfüllung ihrer berechtigten Forderungen eingetreten ist. Sie konnten die Langsamkeit, das Hin und Her, sowie die lauwarmen Beschlüsse nicht länger ertragen...

Szabad Ifjuság, Budapest, 21. 10. 56

WOHIN MARSCHIERT DIE UNIVERSITATSJUGEND?

Im ganzen Land finden Diskussionen statt.

An der Buda"pester Technischen Universität wurde Samstag eine außerordentliche Versammlung abgehalten.... Wir wissen wohl, daß in letzter Zeit bedeutende Anderungen im politischen, und wirtschaftlichen Leben unseres Landes eingetreten sind. Herzerquickende Reden über das Aufdecken begangener Fehler wurden gehalten, doch wurden bis heute nur wenige Maßnahmen zur Beseitigung dieser Fehler getroffen..."

Die Versammlung faBte den BeschluB, daß - sofern die Forderungen nicht innerhalb von zwei Wochen verwirklicht werden - Demanstrationen als Ausdruck der Unzufriedenheit durchgeführt würden.

Szabad Ifjuság, Budapest, 21. 10. 56

Die in dem Memorandum enthaltenen Forderungen halten, wir für wichtig und wesentlich... Aber obgleich 
sie brennende Probleme im Leben unserer akademischen Jugend berühren, sind sie wohl doch nicht vergleichbar mit den Hauptragen der Reform unseres Lebens, der völligen und restlosen Erringüng der sozialistischen Demokratie. Es gab (und fügen wir das gleich hinzù: es gibt auch heute) viel schwerwiegendere und gröBere Probleme. Und doch wurden sie auch ohne StraBendemonstrationen gelöst.

Wir möchten jetzt an einiges erinnern dürfen. Hat sich denn-Mátyás Rákosi leicht von der Spitze der Führung getrennt - ist etwa die Juliresolution unserer Partei leicht zustande gekommen - ging denn die pietätvolle Rehabilitierung von László Rajk und seiner Märtyrerkameraden glatt - und hat etwa der Brief von Imre Nagy genügt, ihm seine Parteimitgliedschaft wiederzugeben?

Nein, gewiB nicht. Und doch ist all dieses geschehen obgleich manchmal erst im allerletzten Moment - auch ohne die Straße.

Nicht Furcht, sondern Besorgnis leitet uns beim Schreiben dieser Zeilen... Die Straße — würde unweigerlich auch solche Elemente mit sich reiBen und vielleicht sogar an die Oberfläche spülen, die wir alle verurteilen und für schädlich halten.

Szabad Ifjuság, Budapest, 21. 10. 56

VERSAMMLUNG'AN DER UNIVERSITAT FUR ARCHITEKTUR UND VERKEHRSTECHNIK

,Wir schlièBen uns den Vorschlägen der Studenten von Szeged an und haben auch an unserer Universität die MEFESZ gegründet... Die politischen Forderungen der Universitätsjugend sind:

1. Sofortige Einberufung des Zentralkomitees der Ungarischen Arbeiterpartei.

2. Umbildung der Regierung unter der Führung des Genossen Imre Nagy.

3. Reform der Beziehungen zwischen Ungarn und der Sowjetunion sowie zwischen Ungarn und Jugoslawien auf der Basis völliger wirtschaftlicher und politischer Gleichberechtigung. 
4. AlIgemeine gleichberechtigte und geheime Wahlen mit der Teilnahme aller in der Volksfront zusammengefaßten Partelen sowie die Wahl neuer Parlamentsabgeordneter.

5. Reorganisation des ungarischen Wirtschaftslebens unter Einbeziehung von Fachleuten, und im Rahmen, dessen die wirtschaftliche Nutzung des ungarischen Uranèrzes. Veröffentlichung der AuBenhandelsverträge und Revision des auf Planwirtschaft eingestellten ungarischen Wirtschattselbens.

6. Revisión der Normen für Industriearbeiter und Einführung der Arbeiterautonomie in den Betrieben.

7. Revision des AbIjeferungssystems und Unterstützung der selbständig arbeitenden Bauern.

8. Revision sämtlicher politischer und wirtschaftlicher Prozesse, Amnestierung der politischen Gefangenen, Rehabilitierung der unschuldig Verurteilten. Offentliche Verhandlungen gegen Mihály Farkas.

9. Wiedereinführung des Kossuth-Wappens an Stelle des bisherigen. Der 15. März und 6. Oktober sollen zu Nationalfeiertagen und arbeitsfreien Tagen erklärt werden.

10. Die Verwirklichung völliger Meinungs- und Pressefreiheit (auch beim Rundfunk!) und in diesem Rahmen eine eigene Tageszeitung für die MEFESZ-Organisation, Veröffentlichung und Vernichtung des alten KaderMaterials.

Szabad Ifjuság, Budapest, 23. 10. 56

AUFRUF DER „DISZ“-MITGLIEDER DER BUDAPESTER MEDIZINISCHEN UNIVERSITAT

„.. Die Einheit und Massenbasis der Jugend muB bewahrt werden, weil nur der Jugendeinheitsverband konsequent und kraftvoll für die Interessen aller Jugendlichen unseres Landes eintreten kann... Die Delegiertenkonferenz des ,DISZ' an der Budapester Medizinischen' Universität setzt sich folgende Ziele: .․ Wir.fordern freie internationale Berichterstattung, Wissenschafts- und Mejnungsaustausch. - Wir fordern die Verwirklichung der Parlamentarischen Demokratie, die Ausarbeitung einer 
neuen, demokratischen Wahlordnung und ihrer Anwendung. - Befreiüng der weiblichen Studierenden von der militärischen Ausbildung und dem MiIitärdienst sowie Revision des Unterrichts für männliche Studierende und deren Ausbildung."

\section{Szabad Ifjuság, Budapest, 23. 10. 56}

Gestern haben auch die Bewohnerinnen des Studentinnenheimes der Budapester Medizinischen. Universität eine auBerordentliche Versammlung abgehalten...

Sonntag nachmittag hat die Studentenschaft der Universität Sopron (Odenburg) beschlossen, sich voll und ganz den Forderungen der Studenten der Technischen Universität anzuschließen. Sonntag abend haben die Studierenden der drei Fakultäten: Bergbau, Forstwirtschaft und Geologie vorbereitende Versammlungen abgehalten und ihre Forderungen in Punkte zusammenyefaßt... Die Professoren erschienen in großer Zahl. Nach dem Singen der Nationalhymne und dem Rezitieren von ,"Erhebe dich, Ungar!" wurden die Forderungen verlesen und besprochen... Das wichtigste Diskussionsthema war der Austritt aus dem "DISZ* und die Gründung des MEFESZ ...

Hèiß war gestern abend auch die Stimmung in Gödöllö, an der Agrarwissenschaftlichen Universität ... Während der Sitzung traf der MEFESZ-Delegierte von Szeged èin, dem die Anwesenden eine begeisterte Ovation brachten.

Bei RedaktionsschluB trafen noch immer Nachrichten von unseren Universitäten ein sowie Delegationen mit den Forderungen der akademischen Jugen"a. Mit dem gröBten T'eil der Beschlüsse und Forderungen der Jugendlicheñ sind wir einverstanden und unterstützen diese. Aber einzelne Punkte der Beschlüsse (Fragen der Struktur des ungarischen Wirtschaftslebens, Probleme des AuBenhandels usw.) können lediglich als Diskussionsgrundlage dienen. Diese Fragen, welche wir auf Grund der Prinzipien kommunistischer Pressefreiheit mitteilen, werden sicherlich von dem Zentralkomitee unserer Partei sówie von unserem Parlament mit unserem ganzen Volk erörtert werden. 
ES KNISTERT IM GEBALK.

von Werner Friedmann

$\because$. Moskau, das sich in der arabischen Welt als Nutznießer des Kampfes der erwachenden Kolonialvölker um ihre Selbständigkeit wähnen durfte, steht plötzlich in seinem eigenen Wirkungskreis vor einer recht dynamischen ",antikolonialistischen" Bewegung - vor dem wachsenden Widerstand seiner Satelliten gegen diè zentrale Bevormundung...W Wenn der Kreml Gewalt anwendete, was am-Freitag der vergangenen Woche, als Chruschtschow wutschnaubend im unbotmäßigen Warschau eintraf; einige Stunden lang drohte, wäre der Eindruck auf der ganzen Welt katastrophäl únd für das Prestige der neuen sowjetischen Politik niederschmetternd. Die Sowjetunion kann sich ein. blutiges Schauspiel solcher -Art nicht leisten. Läßt der in die Zwickmühle geratene Chruschtschow den Dingen aber ihren Lauf, so wird der Geist des Widerstandes allenthalben gestärkt und Moskaus Blockpolitik könnte einen schweren Schlag erleiden.

Süddeutsche Zeitung, München, 24.10. 1956

AUCH UNGARN SCHLAGT NEUE WEGE EIN. WEITGEHENDE FORDERUNGEN DER.STUDENTEN. SOWJETTRUPPEN ZUM ABZUG AUFGEFORDERT

Budapest . (UP) ...

In eịner öffentlichen Diskussion in Raab verlangten mehrere Redner nach dortigen Presseberichtèn den Abzug der Sowjettruppen aus Ungarn und die Freilassung des inhaftierten Kardinals Mindszenty. Als Leiter der Diskussion, die als die „erste freie öffentliche Debatte seit 1948“ bezeichnet wurde, erklärte der mit dem Kossuth-Preis ausgezeichnete Schriftsteller Gyula ". Háy, die Anwesenheit militärischer Formationen sei nicht mehr nötig. Háy wies darauf hin, daß Jugoslawien seine völlige Unabhängigkeit erfolgreich verteidigt habe, währènd Polen und China auf dem Wege seien, ihren eigenen Weg zum Sozialismus zu gehen. „Wïr müssen uns bemühen, diese Praxis auch in unserem Lande zu entwickeln." 
Hannoversche Presse, 25.10. 1956

DIE BLUTNACHT VON BUDAPEST. CHAOS IN DER STADT. „RAUS MIT . DEN SOWJETS!" SCHUSSE. MISCHEN SICH IN DIE TANZMUSIK DES RUNDFUNKS. RUSSISCHE PANZER FEUERN AUF DEMONSTRIERENDE MASSEN. DUSENJAGER GREIFEN EIN

Budapest. Schüsse peitschen durch Budapest. Ihr Knall unterbricht die Musiksendungen des ungarischen Rundfunks. Ein ganzes Volk hört diese Schüsse. Es sitzt vor den Lautsprechern und hungert nach Nachrichten - nach Nachrichten aus Budapest. Dort. stehen ein paar zehntausend Studenten und Arbeiter auf den Barrikaden...

Es begann am späten Nachmittag des Dienstags: Uber zehntausend Studenten ziehen durch die Straßen der ungarischen Hauptstadt. Sie wollen für größere Freiheit, bessere Lebensbedingungen unạ den Abzug der sowjetischen Truppen demonstrieren. Innenminister László Piros verbietet die Kundgebung. Unter dem Druck der Studenten muß er dieses Verbot aufheben. Und $\mathrm{zu}$ den. Studenten auf dem Bemplatz vor dem Gebäude der polnischen Botschaft gesellen sich Arbeiter, Angestellte und dienstfreie Soldaten. Sie vereinen sich in dem Ruf: "Hinaus mit. den russischen Truppen" und "Wir wollen eine neue Regierung unter Imre Nagy."

Aus den Fenstern des ungarischen AuB̉enministeriúms blicken hohe Parteifunktionäre auf die brodelnde Menschenmasse. Die ungarische Nationalhymne tönt auf, und der Appell des Dichters Koelcsey mit dem Refrain: ${ }_{\text {IN Nie }}$ wieder Knecht sein, heißt unser Schwur."

Aus einer-am Bemplatz gelegenen Kaserne fährt ein Lastkraftwagen mit ungarischen Soldaten. Die Studenten drücken den Uniformierten Flugblätter mit ihrěn Forderungen in die Hand. Die Soldaten rufen: "Ihr wollt dasselbe wie wir - die Russen sollen hinaus aus Ungarn."

\section{Signal zum Aufruhr}

Unter den Parteispitzen herrscht Unruhe. Der erste KPSekretär, Ernö Gerö, wird vorgeschickt. Er soll zu den Demonstranten sprechen. Seine Worte: „Wir lehnen eine 
Lockerung der Beziehungen" zur Sowjttunion $a b^{\prime \prime}$, sind das Signal zum offenen Aufruhr.

"Nieder mit Gerö", hallt es durch Straßen, die der Zug der Demonstranten auf dem Weg zum Funkhaus passiert. Von allen Seiten strömen immer mehr Ungarn der Demonstration zu. Ungarische Flaggen wehen über dem Zug. Auch die polnischen Nationalfarben führen die Demonstranten bei sich.

\section{Die ersten Schüsse}

Gerö, der sich noch im Funkhaus aufhält, erklärt sich bereit, eine Delegation zu empfangen; als die Spitze des Zuges eintrifft. Aber die Masse der .Demonstranten ist. ungeduldig und drängt. In den Türen des Funkhauses stehen Geheimpolizisten. Sie versuchen, sich ihrer Haut zu wehren. Tränengas. Die. Demonstranten versuchen, in das Gebäưde einzudringen - - durch Fenster und Türen. Da fallen die ersten Schüsse. Das Feuer wird erwidert. A.uch die Demonstranten haben Waffen. Das Gefecht vor dem Funkhaus leitet die Blutnacht von Budapest ein.

\section{Schweißbrenner gegen Stalin}

Indessen versuchen andere, eine acht Meter hohe Stalinstatue zu stürzen. Mit. Stahltrossen und Schweißbrennern gehen sie dem Ungetüm zu Leibe. Vom Dach eines Gebäudes der ungarischen Gewerkschaften wird ein roter Stern heruntergerissen...

In dieser Atmosphäre beschließt das Politbüro: Imre Nagy wird Ministerpräsident. Wird er den Aufstand abwenden, die Ordnung in Budapest wiederherstellen können? Die Ereignisse haben diese Hoffnung schon überrollt. Vor dem Parlamentsgebäude Ungarns fließt Blut. Eine Viertelmillion Menschen stehen dort zusammengepfercht - einig in dem. Drang: „Es muß anders werden." Ernö Gerö, zur Beruhigung herbeigeeilt, wird niedergeschrien. Panzer sollen die empörte Menschenmenge zerstreuen. Die Demonstranten versuchen, sie zu ștürmen ... 150 Menschen kommen ums Leben.

... Radio Budapest sendet ununterbrochen Tanzmusik. 
Der Nachrichtendienst um Mitternacht . bringt nur Auslandsberichte. Imre Nagy unterzeichnet seine erste Amtshandlung: Das Standrecht wird verhängt.

Neues Deutschland, Ost-Berlin, 25. 10: 1956

VOLKSDEMOKRATISCHE ORDNUNG UNANTASTBAR.

( $A D N)$ Der Erste Sekretär des Zentralkomitees der Partei der ungarischen Werktätigen, Ernö.Gerö, nahm am Dienstagabend - nachdem es in Budapest zu Demonstrationen gekommen war - in einer Rundfunkansprache zur: politischen und wirtschaftichen Situation dés Landes Stellung, wabei er das ungarische Volk vor den Umtrieben der Feinde der ungarischen Volksdemokratie warnte ... Die Führung unserer Partei-ist fest entschlossen, die Fortsetzung des Aufbaus des Sozialismus im Geiste dër.Juli-Beschlüsse durchzuführen, wabei sie sich immer stärker auf die Arbeiterklasse, auf unsere ganze werktätige Bauernschaft, auf unsere Intellektuellen, auf unser ganzes Volk stützt."

Osterreichische Neue Tageszeitung, Wien, 25.101956 ZUGVERKEHR NACH UNGARN EINGESTELLT BLUTIGE STRASSENKAMPFE IN BUDAPEST - NEUERNANNTER MINISTERPRASIDENT NAGY RUFT SOWJETTRUPPEN ZUं HILFE - VERLANGERTES AMNE-. STIEANGEBOT VON AÜFSTANDISC̈HEN NICHT BEACHTET: - ARBEITER . VERSCHANZEN SICH IN DEN FABRIKEN"

Neues Deutschland, Ost-Berlin, 25. 10. 1956

UNGARN SCHLAGT KONTERREVOLUTION NIEDER. SIEG DER SOZIALISTISCHEN VOLKSMACHT.

ARBEITER VERTEIDIGEN IHRE BETRIEBBE

Budapest ( $A D N / N D)$. Im Laufe des Mittwoch wurde in der ungarischen. Hauptstadt ein Putsch konterrevolutionärer Elemente niedergeschlagen. Nachdem bewaffnete faschistische Banden schon in der Nacht von Dienstag zu Mittwoch damit begonnen hatten, gegen die Volksmacht 
aufzuwiegeln und Blutvergießën anzuzetteln, nahmen die Arbeiter selbst. Waffen in die Hand, um zusammen mit den Streitkräften die volksdemokratischen Errungenschaften vor den konterrevolutionären Anschlägen zu bewahren...

\section{Süddeútsche Zeitung, München, 25. 10.1956}

\section{UNGARNS KOMMUNISTENFUHRER}

(SZ) Der neue Ministerpräsident Imre Nagy, ein Mann von 61 Jahren, stammt aus einer Kleinbauernfamilie. Er war anfangs Sozialdemokrat, machte aber in der Budapester Räterepublik von 1919 mit, schloß sich den Kom* munisten an und mußte schon vor über 30 Jahren in die Sowjetunion flüchten. Von Beruf Nationalökonom, wurde er 1944 nach Ungarn zurückgeschickt. Der Reihe nach war er dann Landwirtschaftsminister, Innenminister und stellvertretender Ministerpräsident. Innerhalb der kommunistischen Partei vertràt er den bauernfreundlichen Kurs. 1953 wurde Nagy für kurze Zeit Ministerpräsident, aber 1955 wieder abgesetzt und seiner Parteiämter enthoben. Seit Mittwoch ist er wieder. Ministerpräsident und Mitglied.des kommunistischen Politbüros.

Nagys starker Gegenspieler war bis vor kurzem Mátyás. Rákosi, der jetzt 64 jährige radikale Kommunist, der vor $40 \mathrm{Jahren}$ wegen seiner politischen Betätigung zum Tode verurteilt und später begnadigt wurde. Dieser hartnäckige Vertreter des Stalinismus suchte als Parteiführer und Ministerpräsident das russische. Beispiel ohne Einschränkung auch auf Ungarn. anzuwenden. Rákosi ist erst: 1956 wegen seiner Gegnerschaft zu Tito vom-Kreml fallengelassen worden. Er lebt jetzt wieder als Emigrant in der Sowjetunion.

Rákosis Nachfolger als Parteiführer.wurde der 58jährige Ernö Gerö, der den stalinistischen Kurs als. Wirtschaftsminister mitmachte, aber dabei in einem gewissen persönlichen. Gegensatz zu dem älteren Parteisekretär blieb. 
Times, London, 25. 10. 1956

.....Ungarn lliegt zu Füßen Eurer Majestät", schrieb der siegreiche General Paskievitsch dem Zar, nachdem die Kossuth-Revolution 1849 niedergeschlagen war. Ob sich die Geschichte wiederholen wird, hängt von vielen Dingen $a b$, die noch unbekannt sind...

\section{New York Times, 25. 10. 1956}

\section{DIE MARTYRER VON BUDAPEST}

Ost-Berlin im Juni 1953, Tiflis im März 1956, Posen im vergangenen Juni, Budapest gestern, das ist die tragische Ehrenliste großer Städte, in denen sich unterdrückte Menschen gegen die Sklaverei Rußlánds erhoben. Die heroischen Märtyrer, die gestern in Budapest starben, waren Ungarn, die in der Hauptstadt ihres eigenen Landes durcti russische Panzer. und russische Gewehrkugeln getötet wurden. Sie sind tot, aber ihr Kampfruf: "Russen geht heim" schallt ohne Unterlaß durch die Welt...

\section{Abendzeitung München, 25. 10. 56}

Wien (UP) Die Kämpfe in Budapest und Umgebung halten an. Nach Meldungen des Budapester. Rundfunks haben die aufständischen Arbeiter und Studenten auch das zweite Ultimatum der Regierung zur Niederlegung der Waffen mißachtet. .

New York Times, 25. 10, 1956

PRAWDA ERKLART: UNGARISCHER AUFSTAND IST NIEDERGESCHLAGEN

Von William J. Jorden

(Spezialbericht der N.Y.T.) Moskau, 25. Oktober: die "Prawda", das kommunistische Parteiblatt, brachte heute eine TASS-Meldung aus Budapest, die besagt, daß ein "konterrevolútionärer Aufstand" ausgebrochen ist und mit Hilfe von Sowjettruppen niedergeschlagen wurde.

Dieser Bericht war der erste, den die Sowjetbürger über die blutigen Demonstrationen gegen das kommunistische Regime in Ungarn zu Ohren bekamen: 
Der Sowjetbericht schob die Schuld auf "Rebellenbanden" die, wie es hieB, "zu den Waffen gegriffen und in einigen Fällen Blutvergießen verursacht hatten".

Der Bericht gibt an, daß seit" letzten Mittwoch die "feindlichen Abenteurer" niedergeschlagen sind...

\section{Abendzeitung, München, 25. 10. 56 Gerö abgesetzt}

Wien (AP). Der Erste Sekretär der ungarischen KंP, Ernö Gerö, ist seines Postens enthoben worden, gab Radio Budapest, am Donnerstag bekannt. Zum neuen Ersten Sekretär wurde János Kádár ernannt...

Neues Deutschland, Berlin, 25. 10. 56

DIE KRAFTE DES SOZIALISMUS SIND STARKER

(H. A.) Der Imperialismus hat eine neue schwere Niederlage erlitten. Der Versuch der internationalen Reaktion, wirtschaftliche Schwierigkeiten und politische Auseinandersetzungen in Polen und Ungarn auszunutzen, um durch eine wüste nationalistische Propaganda und antisowjetische Aktionen, und wie in Ungarn durch Putsch, diese beiden Bruderländer aus dem sozialistischen Lager herauszubrechen, hat ein schmähliches Fiasko erlitten...

Warum muBte der konterrevolutionäre Putsch in Ungarn scheitern? Weil heute die Lage in der Welt und auch in Ungarn völlig verschieden ist von der im Jahre 1919, als die junge ungarische Räterepublik von den weiBgardistischen Horthy-Banden und der internationalen Reaktion erwürgt wurde. Heute hat der Sozialismus tiefe Wurzeln in Ungarn gefaßt. Das Volk liebt und verteidigt seinen volksdemokratischen Staat, der bei allen MängeIn tausendmal-besser ist als das verfluchte Regime der Magnaten und Kapitalisten. Heute existiert ein einheitliches, festes sozialistisches Lager, das auf keinen Fall schwächer ist als das Lager des Imperialismus. Volksungarn hat gute, zuverlässige Freunde und Verbündete. Erneut hat die sowjetische Armee sich ehrenvoll ins Blatt der Geschichte eingeschrieben. Einige ihrer Truppen 
haben Schulter an Schulter mit-den Soldaten der ungarischen Volksarmee gegen die konterrevolutionären Banditen gekämpft.

Frankfurter Allgemeine Zeitung, 26. 10. 1956 MOSKAUER EINGRIFF

J. T. . . Einstweilen sind die sowjetischen Truppen: Sieger in den Budapester Straßenkämpfen. Die Moskauer Marxisten aber werden sich erinnern, daß Karl Liebknecht einmal meinte: Es gibt Siege, die Niederlagen, und Niederlagen, die Siege sind.

\section{Neue Zürcher Zeitung, 26. 10. 56}

wg. Wien, 25. Okt, ... Die "Times" macht darauf aufmerksam, daß ausgerechnet die Lieblingskinder der Sowjetpropaganda, Studenten und Industriearbeiter, heute zuvorderst auf den antirussischen und- antikommunistischen Barrikaden stehen. Der "Daily Worker" schreibt dagegen, das ungarische Proletariat habe sich schützend um seine Regierung geschart, um einen konterrevolutionären Angriff abzuwehren.

Die nächsten Ereignisse werden von den meisten Londoner Beobachtern in Moskau erwartet, wo unter den Rivalen.im Kreml eine wilde Debatte über die Sowjetstrategie in Ost- und Mitteleuropa entbrannt sein muß.

Münchner Merkur, 26. 10. 1956

\section{DIE EMPORER}

Von Walther Kiaulehn

...Die Hurtigkeit, mit der Kommentatoren uns zu beweisen versuchen, daß dies alles uns nichts angehe, weil Ulbricht doch stärker sei, die Eilfertigkeit des Kleinmuts, dér sofort die Vokabel "Kossuth-Stimmung" aus dem Zettelkasten fischt, um die romantische Aussichtslosigkeit des Unternehmens der Kadetten und Studenten anzudeuten, das überwuchern der Klugheit, die Bereitschaft zur Resignation sind die Kennzeichen des westlichen Menschen. Mit. dieser Bemerkung soll die Vernunft nicht herabgesetzt werden. Sie bleibt unsere beste Warnerin. 
Doch vergessen wir allzuleicht und allzugern, daß einer unserer Vorfahren jener Prometheus war, der genau wußte, daß man ihn an der Leber strafen würde, und der. dennoch wußte, was er tun wollte'...

Neue Zürcher Zeitung, 26. 10. 56

\section{AUFRUF DER UNGARN IM EXIL}

Paul A u e r, ehemaliger Präsident der Außenpolitischen Kommission des ungarischen Parlaments; : hat im Namen der "Vereinigung versklavter Völker "Europas" den folgenden Aufruf erlassen:

„Der Westen hat bisher eine erstaunlich große Gleichgültigkeit gegenüber den Leiden der Völker hinter dem Eisernen Vorhang an den Tag gelegt. Nach den Vorgängen in Posen und Budapest sollte er sich endlich Rechenschaft darüber geben, daß in Europa weder von Friede noch von friedlicher Koexistenz gesprochen werden kann, solange die zentraleuropäischen und osteuropäischen Fragen nicht eine Lösung gemäß den Wünschen der betroffenen Völker gefunden haben. Es wäre ein großer Irrtum, zu glauben, daß eine Lösung in einer gewissen Liberalisierung und in einigen Konzessionen bestehen könnte."

Abendzeitung, München, 26. 10. 56

GENERALSTREIK IN UNGARN - BLUTIGE KAMPFE

Wien (AP). Radio Budapest kündigte an, daß sowjetische Truppen zu einem Großangriff angetreten sind, um die "völlige Niederschlagung" des Aufstandes, der nach Berichten der ungarischen Nachrichtenagentur MTI nicht nur in Budapest, sondern auch in zahlreichen anderen Städten tobṫ, zu erreichen...

Osterreichische Eisenbahnbeamte, die am Freitag aus Hegyeshalom zurüdkkehrten, berichten, daß die Arbeiterschaft Ungarns in einen Generalstreik getreten sei. Der Streik habe am Freitagmorgen begonnen.

...Zum ersten Male hat sich am .Freitagmorgen eịn allerdings nur schwacher Sendèr der Aufständischen gẹ- 
meldet, der "Freiheitssender des ungarischen Volkes". Er rief zum Generalstreik auf und forderte die Freilassung von Kardinal Mindszenty.

In Budapest wurden am Donnerstagabend und Freitagmorgen Flugblätter verteilt, die vom "Verteidigungsausschuß der neuen vorläufigen Revolutionsregierung " unterzeichnet waren. Die Flugblätter-forderten den sofortigen Austritt Ungarns aus dem Warschauer Pakt und die Ubernahme der vollziehenden Gewalt durch die ungarische Armee.

Die Flugblätter wurden in der Druckerei der Parteizeitung "Szapad Nép“ gedruckt, die von der Armee besetzt ist und von Offizieren und Soldaten der ungarischen Armee verteilt.

Mit Sicherheit steht fest, daß am Mittwoch und vor allem am Donnerstag in Budapest ein regelrechter Krieg geführt wurde, der in den ersten Morgenstunden des Freitag noch immer weiterging ...

Geschäftsreisende berichten bei ihrer Ankunft in Osterreich, die Budapester Aufständischen hätten sie gebeten, Photographien von den Demonstrationen zu machen, "um dem Westen von unserem Kampf zu berichten."

Süddeutsche Zeitung, München, 27. 10, 1956

TRUMMER UND TOTE IN DEN STRASSEN VON BUDAPEST. EIN DEUTSCHER BERICHTET: DIE RUSSEN SCHOSSEN AUS DEN FENSTERN MEINES HOTELS

(SZ) Im Zentrum der Stadt, vom Astoria-Hotel aus hat der Kunsthändler Hans Heinz Müller-Rusicka aus Frankfurt am Main die Ereignisse am Mittwoch erlebt.

...A Am Mittwoch wurde Müller-Rusicka in seinem Hotelzimmer um 4.30 Uhr morgens durch das Rasseln von Panzerketten geweckt. Es waren russische Panzer. Als Müller-Rusicka zum Fenster hinaussah, riefen ihm die Russen $\mathrm{zu}$, er solle vom Fenster weggehen.

Die aufgeschreckten Gäste versammelten sich in der Hotelhalle. Uberall in der Stadt war Gewehrfeuer zu hören. Plötzlich betraten Russen das. Hotel und hielten 
es fortan besetzt. Die Gäste bekamen kein Frühstück."Sie mußten zusehen, wie etwa 30 Ungarn, die sich während der Nacht in das Hotel geflüchtet hatten, von den Russen aufgestöbert und als Gefangené aus dem Hotel geführt wurden. Die Gäste fanden dann in den Zimmern, in die sich die Ungarn geflüchtet hatten, Patronen und Flugzettel unter den Teppichen.

Dann begann der Feuerwechsel zwischen den Russen aus den Hotelfenstern und den Aufständischen auf den Straßen... Gegen 14 Uhr erhielt-das Hotel den ersten Treffer aus einem Granatwerfer, kurz darauf einen zweiten ...

Die Hotelgäste befanden sich bis etwa 20 Uhr im Keller. Es wurde berichtet, daß eine Reihe von Schwerverletzten in der Hotelhalle aufgebahrt waren. Der Speisesaal lag in Trümmern. Gegen 21 Uhr wurden die Ausländer wieder auf ihre Zimmer geführt. In der Nacht waren noch mindestens drei schwere Gefechte zu hören.

Müller-Rusicka begab sich, am Donnerstagmorgen zu seinem Wagen, der schwer beschädigt, aber noch fahrbereit war. Ein russischer Offizier stellte Benzin zur.Verfügung, - Müller-Rusickas Tank war fast leer - und wollte ihm sogar die Hotelrechnung begleichen, da der Deutsche nur Schecks bei sich hatte, er lehnte jedoch ab und verkaufte seine Uhr an einen Ungarn, um die Rechnung bezahlen zu können.

Süddeutsche Zeitung, München, 27./28. 10. 1956.

\section{DIE FESSELN LOSEN SICH}

Von Immanuel Birnbaum

"Du fällst, doch tröste dich, Magyar.. / Wir andre haben schlimm're Schmach genossen." So rief vor 107 Jahren Heinrich Heine den ungarischen Freiheitskämpfern zu, die von einmarschierten russischen Truppen unter ein autoritäres Regime zurückgezwungen wurden. So fühlen wir auch heute für die Freiheitskämpfer von Budapest. Sie können nicht vergeblich gefallen sein, ihr Aufstand war das Flammenzeichen einer Bewegung, die weiter- 
geht, an der Donau wie an der Weichșel, in Europa wie in Asien.

Es ist die.Bewegung der Völker, die der.Kommunismus unter russische Vorherrschaft gebracht hat, die aber jetzt von dieser Hegemonie wieder fortstreben. Große Militärmächte háben von jeher die Tendenz gehabt, ihre Verbündetén in Untergebene zu verwandeln, und so ist es auch den Gefolgsiändern Rußlands ergangen. Weltweite Imperien sind aber auch immer wieder in Teilstaaten zerfallen. Sind wir schon so weit, daß auch das Riesenreich Stalins sich zu zersetzen beginnt? Ist der Versuch, den die Nachfolger des Georgiers jetzt, mehr-öder weniger freiwillig, mit der Lockerung der Ketten für ihre Satelliten machen, ein Anfang. zur Umbildung des gewaltigen Kolonialreiches zwischen Ëlbe und Gelbem Meer?

Als vor fast vierzig Jahren die rusissche Revolution das zusammengebrochene Zarenreich übernahm, war es zunächst der geistige Einfluß ihrer Zukunftsvisionen, der ihr Sympathien in der Arbeiterbewegung des Westens und bei den Kolonialvölkern des Ostens verschuf. Damals sah es aus, als ob die Führung in der sozialen Neụordnung der Welt für unsere Epoche den Russen zugefallen wäre, auch 'wenn man ihr Experiment nicht ohne weiteres auf aüdere Länder übertragen konnte. Aber es erging der kommunistischen Revolution Rußlands wie-einst der großen bürgerlichen Revolution in Frankreich. Zwei Jahrziehnte nach der. Erstürmung der Bastille säh ganz Europa die "große Nation" nicht mehr als die Befreiern der anderen 'Völker an, sondern Napoleon als den Zwingherrn des Kontinents, gegen den man Freiheitskriege führen mußte. Tatsächlich blieb dann auch nicht Frankreich der politische Nutznießer der neuen Zeit des Bürgertums, sondern England regulierte das nächste Jahrhundert hindurch dạs europäische Gleichgewicht und einen guten Teill der Weltpolitik... 
Mittelbayerische Zeitung, Regensburg, 27:/28, 10. 1956 EUROPAISCHES TRAUERSPIEL

Von Ios. Ludw. Hämmerle

... Es waren Arbeiter und Studenten, die am 17. Juni 1953 in der. Sowjetzone einen Aufstand versucht haben. Es waren Arbeiter in. Posen, es waren Arbeiter und Studenten, die in Warschau zum gleichen Einsatz bereit waren. Es scheinen in unseren Tagen nur noch diese zwei Schichten zu sein, die notfalls für die persönliche Freiheit und die nationale Existenz ihr Leben zu wagen bereit sind: die Arbeiterschaft, auf die der technisierte moderne Staat vor allem angewiesen ist, und die noch nicht verbeamtete oder saturierte Intelligenz. Daß diese Kräfte, die gegen ein kommunistisches Zwangssystem angehen, äber keineswegs bereit sind, für ein "kapitalisti"sches" oder bürgerliches Ideal ihr Leben in die Schanze zu schlagen, dürfte wohl klar sein...

Frankfurter Allgemeine Zeitungr. 27. 10.1956

Die Aufșăndischen sind keine Faschisten

Belgrad,.. 26. Okt. (Eigener Bericht.) Die beiden Belgrader Tageszeitungen "Borba" und "Politika" veröffentlichten am Freitag die ersten Berichte ihrer nach Ungarn entsandten Sonderkorrespondenten ...

....Eïn Korrespondent berichtet wörțlich:“" "Obwohl an den Kämpfen auch faschistisctie Elemente teilgenommen haben, war es doch keine Konterrevolution, sondern ein Protest gegen' die Fronde, die die-Bemühungen der Arbeiterschaft um die Entwicklung der sozialistischen Demokratie vereiteilten. "...

Aus den Schilderungen der jugoslawischen Korrespondenten kann man deutlich das Dilemma ersehen ${ }^{\prime}$ in dem sie sich befinden. Obwohl sie von dem entscheidenden Eingreifen der sowjetischen Truppen nicht schweigen, versuchen sie den Gang der Ereignisse so darzustellen, als sei er- weder direkt noch indirekt durch die sowjetischen Panzer beeinflußt worden... 
Neues Deutschland, Ost-Berlin, 28. 10, 1956

SOLIDARITAT DER ARBEITER DER DDR

Berlin (ND) Żahlreiche Werktätige und Betriebsbelegschaften richten spontan brüderliche Kampfesgrüße an die Verteidiger der ungarischen Arbeiter- und Bauernmacht, die unter Führung der.Ungarischen Werktätigen heldenhaft den imperialistischen Putsch konterrevolutionärer Elemente niedergeschlagen haben.

Die Werkstätten des Stahl- und Walzwerkes Brandenburg haben an die Arbeiter, Angestellten und Ingenieure des Eisen- und Stahlwerkes Csepel in Ungarn ein Solida-. ritätstelegramm gesandt.

$\because$ Die Imperialisten versuchten auch bei uns am 17. Juni 1953, mit den gemeinsten Mitleln ihre Macht wiederherzustellen", heißt es in der GruBbotschaft: "Wir Stahl- und Walzwerker Brandenburgs haben damals den faschistischen Provokatèren, die ihre schmutzigen Hände nach unserem Werk ausstreckten, eine kräftige Abfuhr erteilt . . ."

Aus dem Phänomen-Werk, Zittau, sandten die Genossen und Kollegen ein Solidaritätsschreiben an das $Z K$ der Partei der Ungarischen Werktätigen, in dem es heiBt:

"Die Genossen der Betriebsparteiorganisation der Sozialistischen Einheitspartei Deutschlands im Kraftfahrzeugwerk Phänomen, Zittau, übermitteln Euch in diesen Tagen die brüderlichsten Kampfesgrüße. ... Unser Kraftfahrzeugbetrieb in Zittau betrachtete es bisher schon als eine große Ehre, Euren Werktätigen unsere Erzeugnisse liefern zu können. 'Bis 25. Oktober 1956 haben wir bereits den Export an Kraftfahrzeugen nach Ungarn mit 108\% übererfüllt. Am 26. Oktober 1956 beschlossen die Kollegen der Fahrgestellmontage, die Belegschaft aufzurufen, die weiteren vörgesehenen Lieferungen nach Ungarn vorfristig, und zwar bis zum 30. November 1956 zu erfüllen, darüber hinaus bis. 31. Deezmber 195640 weitere Fahrzeuge $\bar{z} u$ produzieren und nach Ungarn zu senden, die erst in der Produktion für 1957 vorgesehen sind. Damit ergeht unsererseits im 'Phänomen' der Aufruf an alle Zulieferbetriebe, die gleichen Solidaritätsmaßnahmen zu be- 
schließen, damit unser $\ddot{K}$ räftfahrzeug-Betrieb die Verpflichtung einhalten kann. Auch die anderen Betriebe der $D D R$ werden aufgerufen, unserem Beispiel Folge zu leisten. Betrachtet bitte diese Bereitschaft unserer Kollegen als Antwort an die westlichen Provokateure und ihre Helferstëlfer."

Neue Zürcher Zeitung, 28.10.1956

ZURUCKHALTUNG IN WASHINGTON

Tel. unseres Korrespondenten.

W. I. Washington, 27. Oktober. - Das Staatsdepartement nahm-am Freitag. Konsultationen mit Großbritannien, Frankreich und andern befreundeten Regierungen über die Frage einer eventuellen Behandlung der Sowjetintervention in Ungarn durch die Vereinigten Nationen auf ...

Natürlich erhebt sich da und dort der Ruf, die Administration sollte "etwas tun.., was: begreiflich aber kaum sehr realistisch ist. Im Staatsdepartement ist man überzeugt, daß größte Vorsicht am Platze ist, weil eine gefährliche Lage entstehen könnte, wenn Moskau sich in seiner Sicherheit bedroht fühlen sollte, von dem Schicksal ganz zu schweigen, das die nach Unabhängigkeit und Freiheit strebenden Völker des Sowjetimperiums ereilen würde.

Es mag überraschend klingen, aber es ist eine Tatsache, daß man hier deshalb hofft, die osteuropäische Entwicklung "los von Moskau" möge, im Augenblick wenigstens, nicht zu weit gehen, sondern gewissermaßen an 'der Zwischenstation des "Titoismus" vorläufig Halt machen. Walter Lippmann vertritt diese These mit der Begründung, die militärische Gefahr für Westeuropa werde radikal vermindert, wenn der Titoismus sich inOsteuropa ausbreite... 
Neue Zürcher Zeitungr 28. 10. 1956.

\section{TIEFER EINDRUCK IN LONDON}

\section{Berichte-des britischen Gesandten in Budapest}

Tel. unseres Korrespondenten.

E. M. London, 26. Oktober: - . . Wie heute an der Pressekonferenz des Foreign Office bestätigt wurde, strömten gestern etwa 2000 Demonstranten, welche: die ungarische Nationalhymne sangen und blutbefleckte Trikoloren schwenkten, vor der britischen Gesandtschaft in Budapest zusammen. Ungefähr 50 davon erhielten.Einlaß und beschworen den britischen Gesandten, ihre Sache vor die Vereinigten Nationen zu bringen... Der britische Minister versprach, über die Ereignisse in Budapest so wahrheitsgetreu und vollständig wiè-möglich nach London zu-berichten. Sie begaben sich daraufhin zur amerikanischen Botschaft.

National Zeitung, Ost-Berlin, 28. 10. 1956.

SCHMUTZIGE HANDE

(nz) Ungeheuerliches ist in Budapest geschehen. An den Händen der Aufrührer klebt nicht nür das Blut der von ihnen gemordeten Verteidiger der Volksmacht. Sie haben sich auch mit einer Kulturschandë beschmutzt, die ihresgleichen nur noch in der barbarischen. Vernichtung hat, als anglo-amerikanische Bomberverbände weritvoll. sten deutschen Kulturbesitz in Flammen aufgehen oder in Schutt und. Asche sinken ließen.

Schmutzige Hände haben das. Budapester Nationalmuseum, diesen koștbaren Hort weltberühmter europäischër Kunst mit Werken von Raffael bis Dürer. und Goya sowie mit. Gipfelleistungen der ungarischen. Kunst in Brand gesteckt und die sofort einsetzenden Rettungsmaßnahmen aus feigem Hinterhalt unmöglich gemacht. Noch einmal wütete hier der Haß des Faschismus gegen alles, was dem kulturliebenden ungarischen Volk wie der ganzen Menschheit kostbar und heilig ist. Und noch einmal müssen wir schaudernd erleben, wie eine verwilderte Dollarpresse sich als Herold und Beschützer dieser Kulturbarberei aufspielt und nicht ein einziges kritisches 


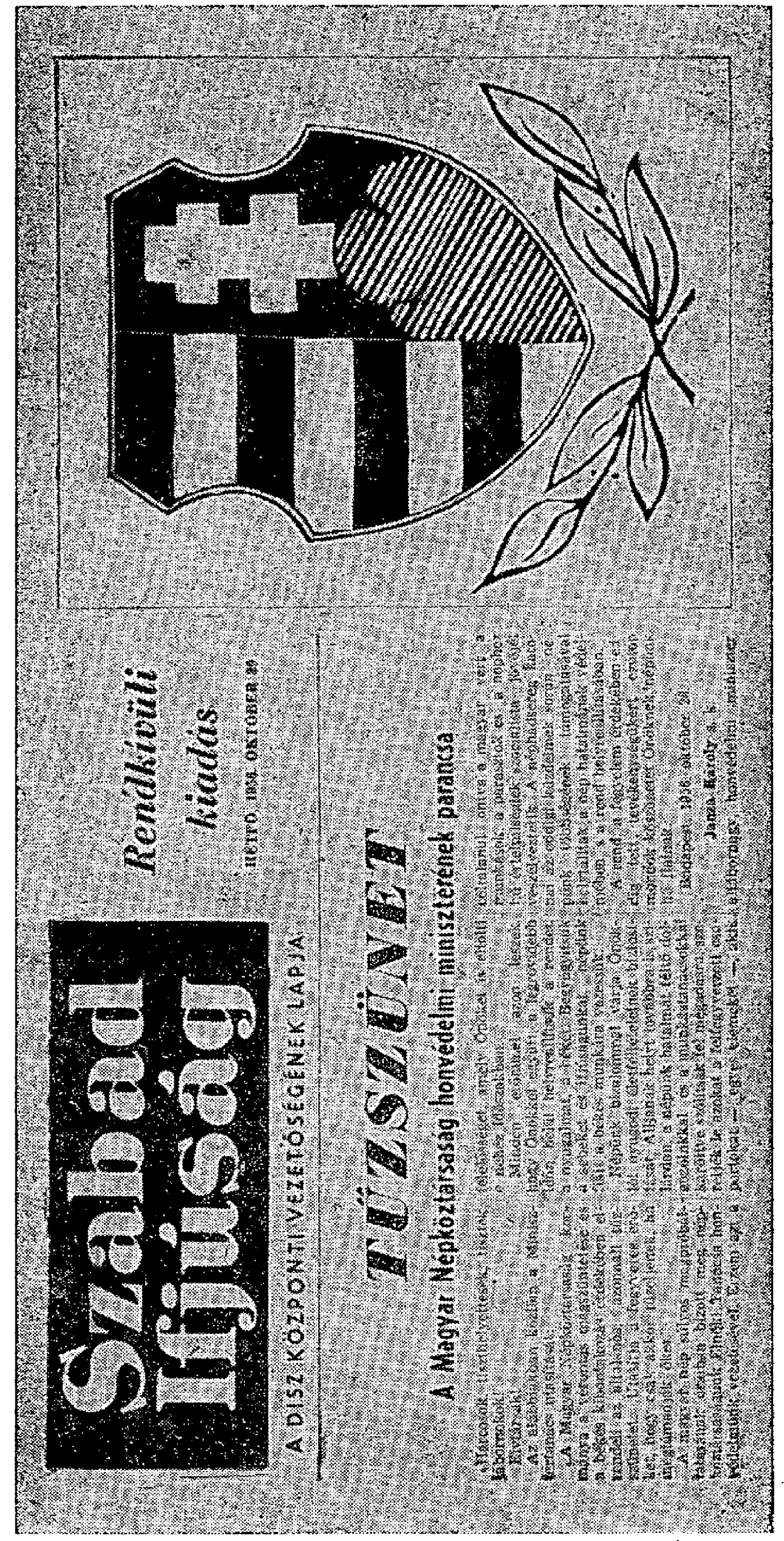

$\stackrel{g}{g} \frac{0}{\square}$

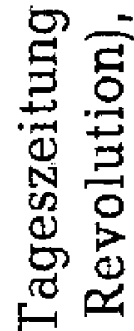

岁守

क्षे

证

豆。年

-

잉 은 응

응

$N \stackrel{0}{\leftrightarrows}$

혀

$=$ 丞

데 N

워요

$\rightarrow \mathscr{O}$

躳怘

ब

\&

$=$ 吾

엉 홍

6 㝋

की

-

넝 옹

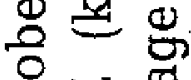

Nㅛㅇ

$\circ \stackrel{\infty}{\circ}$

ภ n

뎡유

8 炙

(2)

号苛

S. 0

哇 엉

\%

点豈

다 $\mathrm{N}$ 
Wort über èin solches Verbrechén verliert, Dafür speit sie Gift und Galle gegen alle, jene Kräfte, die die Ehre und Würde der Menschheit und die Errungenschaften des Sozialismus verteidigen.

Ihre wildeste. Wut richtet sich gegen die Sowjetarmee, die heute; wie einst im Hitlerkrieg, in selbstlosem Einsatz, ja unter Verzicht auf taktische Erfolge bei ihren Operationen, 'unersetzliche Kulturwerte schonte und schützte ... Dankbar erinnern wir uns ihrer umsichtigen und behutsamen Maßnahmen.zur Rettung der Schlösser und Gärten von Sanssouci wie ihrè unverzüglichen Aktion zur Bergung der dem Untergang überantworteten Dresdner Gemälde... ein Hohelied auf die humanistische Verantwortung und das. KulturbewuBtsein der Sowjetunion und seiner Armee!...

Frankfurter Allgemeine Zeitung, 29. 10.1956

REVOLUTIONARE OHNE ORGANISIERTE FUHRUNG. Augenzeugenberichte aus Ungarn / Mit Handgranaten gegen Frauen und Kinder

Eigene Berichte unserer Korrespondenten. - Ko. Wien, 28. 0ktobér.

Ein Student berichtet über das grauenvolle Blutbad in Ungarisch-Altenburg (Magyaróvár). Dort hatte šich am Freitagmittag ein unbewaffneter "Demonstrationszug formiert und war mit Frauen, Kindern und Studenten voran durch die Straßen zur Kaserne der Grenzpolizei gezogen. In Sprechchören forderten sie, die Soldaten sollten den Sowjetstern von der Kaserne herunterreißen. Völlig unmotiviert. befahl plötzlich der Kommandant der Staatspolizisten Feuer aus Maschinenpistolen. Er selbst warf Handgranaten. Binnen einer halben Minute gab es auf dem Platz 14 Tote und Hunderte von Verletzten. Die Opfer waren meist.Kinder, Jugendliche und Frauen.

Die maßlos erbitterte Bevölkerung holte nun aus Raab Waffen und Verstärkung und erstürmte die-Kaserne. Die fünf aus der Gruppe der Staatspolizisten, die den Angriff überlebten, wurden von der Menge zu Tode getrampelt. Zwei Offiziere; die sich zuerst in Sicherheit 
bringen konnten, wurden am Samstag öfentlich auf dem Hauptplatz gehenkt. Insgesamt hat das kleine Städtchen 91 Tote und zweihundert Schwerverletzte zu beklagen. In den Spitälern liegen zahlreiche furchtbar zugerichtete Kinder und Frauen. 'Einer der Arzte von UngarischAltenburg erzählte, daß sie keine Medikamente, keine ausreichenden chirurgischen Instrumente, nicht einmal Morphium und Verbandszeug für die Schwerverletzten gehabt hätten und der Verzweiflung nahe gewesen seien...

In Osterreich werden Vorbereitungen getroffen, um notfalls Flüchtlinge in großer Zạhl aúfnehmen zu können.

Budapest, 28. Okt. (dpa). . . Die Fráge stellt sich, wer kämpft gegen wen. Auf alle Fälle Ungarn gegen Sowjets. Die aufständischen Soldaten fordern: Provisorische revolutionäre nationale Regierùng unter Beteiligung' der Führer der rebellierenden Jugend, sofortige Trennung vom Warschauer Pakt, allgemeine Amnestie und sofortiger friedlicher Abzug der Sowjettruppen ...

Ich sprach mit einigen Führern der Aufständischen. Es sind Kommunisten. Ihnen schwebt eine Art Volksfront vor. Sie wollen keine Rückkehr zu den alten feudalen Verhältnissen. Sie wollén den ungarischen. Weg zum Sozialismus ...

Neue Zürcher Zeitung, 29.10.1956

STURM AUF DIE SOWJETISCHE BOTSCHAFT IN BUENOS AIRES

Buenos Aires, 28. Okt. ag (Reuter). In Buenos Aires wohnhafte Ungaren versuchten am Samstag, die sowjetische Botschaft in Argentinien zu stürmen ... (und) richteten an dem Gebäude bedeutenden Schaden an.

Abéndzeitung, München, 29. 10. 1956

MUNCHNER BLUT·FUR - UNGARN

München .(Eigener Bericht). München hat einen humanen .Beitrag für den Freiheitskampf der Ungarn geliefert: Am Wochenende gingen mit einem Flugzeug 100 Blutkonserven nach Wien. Von dort fahren sie-ungarische Ambulanzwagen über die Grenze. 
Durch diese Spende ist der Bedarf an Blutkonserven in München keineswegs knapp geworden. Die Blutspenderzentrale verfügt noch über einige hundert Konserven, die für den Notfall jederzeit bereitstehen.

Außerdem haben sich die ungarischen Emigranten verpflichtet, innerhalb der nächsten Tage das kostenlos bereitgestellte Blut durch eigene Blutspenden wieder zu ersetzen.

\section{Ungarisches Flugzeug holte Medikamente}

Wien (dpa). Uberraschend landete am Sonntagabend ein ungarisches Flugzeug in Wien, um Medikamente für Budapest abzuholen. Das Flugzeug trug als Hoheitszeichen die Farben Grün-Weiß-Rot, jedoch ohne roten Stern; der, wie ein Besatzungsmitglied erklärte, erst am Sonntag entfernt worden war...

\section{The 'Times, London, 29. 10. 1956}

\section{AUFERSTEHUNG}

Das ungarische Volk gewinnt den Kampf: Es hat seine Gefängnistiore aufgebrochen... Noch jetzt kann man diese Neuigkeit kaum glauben... Aber im Moment sieht es so aus, als ob das Volk, das. sich gegen die Tyrannei erhob und trotz allem, was dagegen sprach und mit wenig mehr als Verzweiflung, Mut und gemeinsamer Entschlossenheit gewappnet, eine Veränderung zuwege brachte, die weit mehr als das Schicksal Ungarns wandeln wird ...

Süddeutsche Zeitung, München, 29.10.1956

"WARUM HELFT İHR UNS NICHT?"

Von Werner Friedmann

"Warum helft ihr uns nicht?" haben die für die Freiheit demonstrierenden Menschen vor den Gesandtschaften der Westmächte in Budapest gerufen. Und die tapferen Unabhängigkeitskämpfer, die eine schier hoffnungslose Sache nicht aufgeben wollen und lieber im Feuer der sowjetischen Panzer sterben als kapitulieren, mögen dasselbe murmeIn, wenn sie hinter ihren Barrikaden keine 
Zeit finden; ihre niedergemähten Kameraden zú begraben. Es greift einem ans Herz, dieses Wort, wenn man, im Bewußtsein der eigenen Ohnmacht, am warmen westlichen Ofen sitzt und zum untätigen Ohrenzeugen einer blutigen. Tragödie zu werden gezwungen ist.

Wie oft hat die freie Welt derlei schon erlebt: als Hitler die Demokraten in Deutschland in den Kerker warf und die Juden abzuschlachten begann - als die Tschechen von Moskaus Sendboten vergewaltigt würden -- als am 17. Juni $1953^{\circ}$ die revoltierenden Arbeiter in der Sowjetzone vor den russischen Panzern weichen mußten. Und doch ist das ungarische Drama ohne Beispiel und, ein historisches Ereignis von größerer Bedeutung, als wir es, nur wenige Stunden vom Schauplatz entfernt, und gleichwohl nur Zuseher (mitunter zu satt, um tieferer Anteilnahme fähig zu sein) heute ahnen...

- Was ist das für eine Welt, in der sich unter den Augen aller freiheitsliebenden Menschen ein ganzes Volk zu verbluten droht? Kann man. wirklich nicht mehr tun; als für die Freiheitskämpfer zu beten und ihnen Verbandsmaterial zu schicken, da doch die Charta der UN so eindeutig das Recht der Nationen auf Selbstbestimmung verkündet? Eben dieses Recht ist es doch, von dem die unglücklichen Ungarn Gebrauch machen wollen... .

Süddeutsche Zeitung, München, 29.10. 1956

UNGARN NICHT IN MELBOURNE

Wien (AP). - Wie der ungarische Rundfunk am Sonntag meldete, wird Ungarn nicht an den Olympischen Spielen in Melbourne teilnehmen. Die Meldung wurde zurückgezogen, weil das Training der $\dot{ }$ - Mannschaftsmitglieder durch den Aufstand unterbrochen worden ist.

Süddeutsche Zeitung, München, 29. 10.1956

FERENC PUSKAS GEFALLEN ?

Wien (dpa). Der ungarische Major Ferenc Puskás, einer der besten Fußballspieler der Welt, soll am Freitagnachmittag bei den Kämpfen in Budapest erschossen worden sein ... 
London (UP). Aus diplomatischen Kreisen in London wurde äm Sonntág bekannt, daß József. Csermák, der Hammerwurf-Olympiasieger von 1952, und der Olympiazweite im Modernen Fünfkampf, Gábor Benedek, bei den Kämpfen gëgen die russischen Truppen ums Leben gekommen sein sollen.

\section{VIELE WOLLEN HELFEN}

IM. München (Eig: Bericht). Bei Sturm und Regen verließ heute in den frühen Morgenstunden dér große Hilfszug des Deutschen Roten Kreuzes München in Richtung Ungărn.' Tịefer 'Ernst' lag auf den Gesichtern der fünfzig Männer und Frauen, die dem Ruf Ungarns nach. Hilfe folgten. Sie wissen: was sie erwartet, unterscheidet sich in nichts vom Krieg, und manche yon ihnen - der Arzt, Sanitäter 'und Schwestern - haben den Krieg, die Not der Verwundeten und Flüchtlinge noch allzu gut in Erinnerung...

\section{Abendzeitung, München, 29. 10. 1956}

ROTKREUZHILFE -FUR - UNGARN

\section{Aufruf der Liga in Genf}

Genf, den 28. Okt. ag. Die Liga der Rotkrëuzgesellschaften hat"am Samstag auf Ersuchen des Ungarisctien Roten Kreuzes einen internationalen Appell erlassën, ùm dringliche Sendungen von :Medikamenten und Lebensmitteln fụ̈r 10000 bis 50000 Personen in Ungarn zuu bewirken.

Abendzeitung, München, 29. 10. 1956 . Eine Stimme aus dem Vatikan

Rom (KNA). Der "Osservatore Romano", das offiziöse Organ des.Vatikans, veröffentlichte einèn Aufruf zur Einstellung des Massenmordens in Ungarn:

„Das Massenmörden muß aufhören. Maǹ höre den verżweifelten Schrei jener, die unter dem Feuer der Kanonen nach Brot,. Freiheit und Achtung dèr menschlichen Person rufen, die im Namen eines Fortschritts geschlagen wurden, der von Tränen und Blut trieft." . 
Nicht die Macht der Waffen könne eine umgestürzte natürliche Ordnung wiederhestellen, betont der "Osservatore", sondern nur. die wahre Achtung des Menschen, seiner Würde und seines unveräußerlichen Lebensrechtes. „Möge dies die Lehre des vergossenen Blutes sein. Wer sie weiter hartnäckig ignorieren will, kann vielleicht noch einmal mit. Waffenterror die Ruhe im Volk herstellen, aber niemals den Frieden, der sich aus Gerechtigkeit ergibt.".

\section{Abendzeitung, München, 29, 10: 1956}

RUSSEN VERLASSEN BUDAPEST; 'ABER SIE BL̈EIBEN' IM LAND - EIN AUGENZEUGENBERICHT

Von Anthony Cavendish

Die sowjetischen Streitkräfté verlassen am heutigen Montag unter Mitnahme ihrer Panzer und aller Waffen sowie ihrer Toten, die durch den Volksaufstand schwer mitgenommene ungarische Haúptstadt. Sie lassen eine stark zerstörte Stadt hinter sich; in deren rauchenden Ruinen noch ungezählte Tote liegen. .

Schon kurz vor Budapest begegnetèn wir dem ersten Konvoi sowjetischer Truppen, der sich in südlicher Richtung bewegte und der von Panzern angeführt wurde...

Die russischen Soldaten starrten düster und erbittert vor sich hin. Sie befinden sich auf dem Rückzug - dem èrsten Rückzug, seit sie gegen Ende des zweiten Weltkriegs bis ins Herz Mitteleuropas vorgestoßen sind.

Am Straßenrand standen Ungarn, die schweigend den Abmarsch der sowjetischën Truppen beobachteten.: Ein ungarischer Bauer spuckte einen der an ihm vorüberfahrenden sowjetischen Panzer an. Die sowjetischen Soldaten taten șo, als'sahen sie dies nicht. Es war ihnen jedoch anzumerken, daß sie nervös sind...

Wir 'begegneten immer mehr Konvois, unter ihnen zahllose ungarische Lastkraftwagen, die von den Sowjets beschlagnahmt und für Zwecke der Verwundetentransporte verwendet wurden. Die Lastkraftwagen wàren mit Verwundeten übersät, deren Wunden nur notdürftig verbunden waren. Das die Verwundeten begleitende Sanitätspersonal war über und über mit Blut beschmiert. 
Schließlich kamen Wagen mit Hinweisschildern, daß sie Leichen befördern. Je näher wir dem Zentrum der Stadt kamen, desto erschütternder wurde das Bild. Immer gröBer wurde gleichzeitig die Zahl der sowjetischen:Truppeneinheiten, die in südlicher Richtung, aus der Stadt abzogen. In einem einzigen Konvoi zählte ich wenigstens 60 Panzer, die alle starke Spuren des Kampfes aufwiesen.

Neues Deutschland, Ost-Berlin, 30. 10. 1956

AUGENZEUGENBERICHT AUS BUDAPEST. DEUTSCHE ANTIFASCHISTEN: ALS ZEUGEN DER EREIGNISSE IN DER UNGARISCHEN HAUPTSTADT

Mit ejner Delegation der Deutschen Demokratischen Republik weilten aus AnlaB der Feierlichkeiten zum 20. Jahrestag der Internationalen Brigaden zum spanischen Freiheitskampf die ehemaligen Spanienkämpfer Heinz Wieland und Herbert Grünstein vom 18. bis 23. Oktober in der ungarischen Hauptstadt. Einern Vertreter der ADN gaben sie ihre Eindrücke von den Ereignissen in Budapest wieder.

„... Sicher ist, das die Ereignisse in Ungarn von der Konterrevolution ausgenutzt wurden, ihre Ziele zu verwirklichen. Ihre Verbrechen in Spanien und Deutschland und 1919 in Ungārn hat die Reaktion um neue Bestialitäten vermehrt..."

Abendzeitung, München, 30.10.1956

TROSTLOSES STRASSENBILD IN BUDAPEST. BERICHT EINES AUGENZEUGEN

Budapest (dpa). Einen Bericht über das Aussehen der schwer umkämpften ungarischen Hauptstadt konnte der Journalist Noel Barber gestern, Montag, nach Wien weiterleiten. Dieser Bericht ist am Sonntag geschrieben worden, als in Budapest noch Kämpfe im Gange waren. Unmittelbar danach wurde Barber von sowjetischen Truppen angeschossen. Er liegt mit einer Kopfverletzung in der britischen Botschaft in Budapest. Sein Zustand soll nicht besorgniserregend sein. Noel Barber berichtet: 
...Gestern wurde den ganzen Tag lang in Buda (Ofen) jenseits der Margaretenbrücke, gekämṕft. Die Aufständischen schlugen sich von Straße zu Straße.

Es ist jetzt klar, daß die Sowjets die- Kampfkraft der Freiheitskämpfer weit unterschätzt haben ...

Uberall fragen mich die Leute das eine: "Wann kommt Hilfe?" ...Mir ist elend zumute, ich bin unfähig zu antworten. Uberall gibt es Tränen... Ich habe wirklich einiges vom Kriege gesehen, aber dies hier ist furchtbar,. Kinder mit blutigen Verbänden an Armen, Köpfen kämpfen mit Maschinenpistolen und selbștgemachten Handgranaten gegen Panzer und Artillerie.

Magyar Szabadság, Budapest, 30.10.:1956 AKADEMISCHE FREIHEIT !

Erklärung der ELTE-Leitung und der Professoren.

Rektor, Dekan und Professaren der Eötvös-Loránd Wissenschaftlichen Universität waren von Anfang an mit den Forderungen der akademischen Jugend einverstanden, haben die nationale, demokratische revolutionäre Initiative der Jugend begrüßt und an ihrer Bewegung mit ganzer Kraft teilgenommen. Bei der Vorbereitung der Demonstration, die den Auftakt zur Revolution darstellte, habën sie der Jugend ihre Hilfe zuteil werden lassen. Bei der Demonstration waren die Leiter und Professoren der Universität in großer Zahl anwesend. Den Heldentod starb Zoltán I.Tóth, Dekan der Geschichtlichen Fakultät, der als Mitglied jener Delegation gefallen ist, die am zweiten Tag der Revolution die Forderungen der Jugend dem $\mathrm{ZK}$ zur Kenntnis brachte, die Ablösung der kriminellen Führer und den Abzug der sowjetischen Truppen forderte.Damit die Arbeit an der Universität dem internationalen wissenschaftlichen Niveàu angeglichen werden kann... fordern wir nun, da die Revolution gesiegt hat:

1. Die Tore der Universität sollen allen offenstehen, deren Ausbildung zum Besuch einer Universität befähigt und die studieren wollen. 
2. Freiheit des Lehrens, d.h. jeder Professor soll seiner demokratischen Uberzeugung entsprechend .. seinen wissenschaftlichen Standpunkt in. Wort und Schrift frei vertreten dürfen.

3. Freiheit des Lernens, d.h. jeder Studierende soll im Rahmen der Prüfungsordnung diejenigen Vorlesungen hören dürfen die ër möchte...

4. Autonomie der Universitäten, d. h. in Fragen der Wissenschaft, der Lehre und der Beśetzung von LehrstühIen soll die Universität entscheiden...

5. . . Unverzügliche Wiederberufung der zu Unrecht entfernten Professoren.

6. Die Verleihung akademischer Grade soll ausschlieBliches Recht'der Universitäten seiñ...

7. Wegen der antiwissenschaftlichen Politik der letzten Jahre ist die materielle Lage der Universitäten unhaltbai geworden. Unsere Bibliotheken sind zusammengeschrumpft, die Laboratorien unmodern...

8. Revision des Stipendien-Systems, bei deren Gewährung in erster Linie Studienerfolg und Befähigung maßgebend sein sollen.

9. Freier Jugendverband...

10. Die materielle Lage der akademischen .Jugend muß sofort gebessert werden...

11. Wir sprechen Albert Kónya, dem jetzigen Kultusminister, und István Sötér, dem Ministerialbeauftragten für Hochschulerziehung, unser MiBtrauen aus $\cdots$ Budapest, den 29. Oktober 1956.

gez.: Miklós Világhy - Rektor, Györgỳ Székely - Vizerektor; die Dekane: Gusztáv Mödlinger, László.Fuchs, Tibor Kardos; die Vizedekane: József Herman und János Varga; die Lehrstuhlinhaber:...; die Professoren: ...; die Dozenten und Lektoren:...

Magyar Szabadság, Budapest, 30. 10. 1956

Wir haben nur wenig Papier! Lies die Zeitung und gib sie weiter! 
Neues Deutschland, Ost-Berlin, 30.10.1956:

WIE KONNTE ES DAZU KOMMEN?

Fine Zuschrift an die Redaktion des " ND"

Von Maria Reichmann

Werte Genossen!

. Der Aufbau des Sozialismus ist, wie wir aus eigener Erfahrung in Deutschland wissen, -keine einfache Sache. Jedes Land hat seine besonderen.. Schwierigkeiten zu überwinden, sowohi auf materiellem als auch auf ideologischem Gebiet...

Eine besondere Schwierigkeit in Ungarn sind diè Nachwirkungen der $25^{\prime}$ Jahre Herrschaft des Horthyfaschissmus...

Beachten muß man aùch diẹ besonderèn klerikálen. Einflüsse, die in Ungarn wirksam werden...

Ich. habe mich in Ungarn manchmal sehr darüber geärgèrt, mit welcher Hemimungslosigkeit, ja Böswilligkeit manche Leute, die angeblich für den Sozialismus waren, Mißständè und Mängel kritisierten. Nicht unerwähnt bleiben-darf auch die Tätigkeit der ausländischen Spionage- und Sabotageagenturen, die von einigen diplomatischen Vertretungen der imperialistischen Mächte in Ungarn direkt unterstützt wuirden, ohne daß die Regie-. rung sich $z u$ entschiedenen. Maßnahmen hiergegen entschließen konnte...

Süddeutsche Zeitung, München, 30. 10.1956

GEFAHRLICHE FAHRT ZUM PLATTENSEE

Ein Reporter streift durch West-Ungarn / ${ }_{n}$ Plötzlich schieBt ein russischer Soldat auf unseren Wagen".

(SZ) Als Sonderkorrespondent der britischen Nachrichtenagentur Reuter ist der englische Journalist Peter Howard am Sonntag achtzehn Stunden lang-durch die Teile West-Ungarns gefahren, die in den Händen der Aufständischen sind. Howard gab darüber folgenden $\mathrm{Be}$ richt: ... Als der Leutnant für einen Augenblick verschwand, schmuggelte mich Zoli in einen der ungarischen Autobusse, mit denen Rot-Kreuz-Lieferungen herübergebracht wurden... 
Während der holperigen Fahrt debattierten alle miteinander. Was hatte die Revolution erreichit? Nichts? Alles? Kann der Kommunist Nagy Ministerpräsident bleiben, oder sollten alle, die während der letzten elf Jahre mit dem Regime verbunden waren, einer provisorischen Regierung den Weg frei machen, die nur so lange bestehen würde, bis freie Wahlen abgehalten werden können? Sollten alle politischen Gefangenen freigelassen werden? Sollte die Kommunistische Partei geächtet werden? Oder würde sie an der Macht bleiben, áber Ex: ponent eines nationalen ungarischen Sozialismus werden? Und die beherrschende Frage: Sollten die russischen Soldaten - von denen es schätzungsweise 80000 in Ungarn gibt - mit jeder Waffe, die gerade-zur Hand ist, mit Sensen oder Panzern, angegriffen werden oder sollte man sie in Ruhe lassen? Diese Ungarn waren über jede Frage grundsätzlich verschiedener Ansicht.

Als wir viel später durch Györ (Ráab) kamen, stand ich vor dem Stadthaus, als eine Gruppe junger Studenten keiner konnte älter' sein als 20 - auf den "Balkon hinaustrat. Einer von ihnen rief zu den etwa 10000 Menschen, die sich auf dem Platz angesammelt hatten, hinunter: "Was immer die Nationalen Ausschüsse entscheiden mögen - wir, die Jugend von Ungarn, wèrden kämpfen, bis unser geliebtes Land frei ist vom sowjetischen. Joch, bis die kommunistische Partei nicht. länger die despotische Herrin des Landes ist, bis all jene gegangen sind, die an unserem Elend in den vergangenen elf Jahren schuld haben, bis wirklich freie und geheime Wahlen unter Aufsicht der Vereinten Nationen eine Regierung ermöglichen, die vom Volke und für das Volk gewählt wurde." Auf die Worte des jungen Studenten folgte langanhaltender Beifall.

Als wir uns Veszprém - nördlich des Plattensees näherten, kamen uns zwei Lastkraftwagen mit sowjetischen Truppen entgegen. ... Einige Kilometer weiter sahen wir plötzlich Panzer, Artillerie und Soldaten in vorbereiteten Stellungen beiderseits der Straße. Die Panzer waren eingegraben, nur die Geschütztürme ragten heraus. Ein sowjetischer Offizier hielt uns auf. Er kam 
in den Bus, sah die Rot-Kreuz-Lieferungen und winkte uns, weiterzufahren. Drei Minuten später stießen wir auf ungarische Stellungen. Hier hielten wir an und fragten nach dem verantwortlichen Offizier. Er erklärte uns, die Ungarn hätten hier mit den Russen vereinbart: "Schießt ihr nicht, schießen wir nicht." Aber das seien unsichere Abmachungen ...

In der Universität von Veszprém haben Studenten und Professoren eine Telephonzentrale für ganz. West-Ungarn eingerichtet. Sie dient auch als Informationszentrum. Im anschließenden Gebäude ist der Sender der Revolutionäre. Ich kam gerade hinein, als der Ansager ein Ultimatum an den Ministerpräsidenten in Budapest verl̄às.

\section{Nur zwei Kugeln trafen}

Wir verließen Veszprém. Der Fahrer, der sich in der Gegend gut auskannte, schlug einen Abkürzungsweg ein. Als wir fast querfeldein fuhren, machte uns ein sowjetischer Kradschütze auf seinem Motorrad fast zur gleichen Zeit aus, wie wir ihn entdeckten. Der Russe sprang ab und eröffnete mit seiner Maschinenpistole das Feuer auf unseren Wagen. Er muß ein schlechter Schütze gewesen sein. Nur zwei Kugeln trafen den Wagen. Plötzlich verstummte seine Maschinenpistole. Mein Fahrer senkte das Gewehr in der Hand. Ich hatte ihn über dem Rattern der Maschinenpistole nicht schießen hören, aber ich sah, wie der Russe sich zusammenkrümmte und zu Boden sank. Wir kletterten wieder in den Wagen und jagten mit höchster Geschwindigkeit davon...

Neues Deutschland, Ost-Berlin, 30. 10. 1956 WELTGEWERKSCHAFTSBUND AN UNGARNS ARBEITER

( $A D N)$ Der Weltgewerkschaftsbund hat am Sonntag in Prag eine Botschaft an den Zentralrat der ungarischen Gewerkschaften und an die Werktätigen Ungarns veröffentlicht..., das vom Generalsekretär des WGB, Louis Saillant, unterzeichnet ist:

..."Das volksdemokratische Regime Eurer Republik hat heute eine schwere Prüfung zu bestehen. In ihrem 
verzweifelten Versuch, dàs kapitalistische Regime wieder "zu errichten, schrecken die ärgsten Feinde der ungarischen Werktätigen vor keinem Mittel zurück. Wir haben ihre blutige Intervention auch vor den Werktätigen der ganzen Welt und vor dem Sicherheitsrat der Vereintén. Nationen angeprangert, um gegen die Konterrevolution Anklage zu erheben, und den faschistischen Putsch zu brandmarkten.

In diesem. schweren Augenblick reichen wir Euch unsere Bruderhand und versichern Euch unserer bedingungslosen Unterstützung... Es lebe die internationale Arbeitersolidarität!"

In einer Erklärung, die der Weltgewerkschaftsbund an den UNO-Sicherheitsrat abgab, heiBt es:

„Um ihre Privilegien zurückzuerobern, mißbrauchten konterrevolutionäre, dem. Sozialismus feindlich gegenüberslehende Gruppen die demokratischen Freiheiten in Ungarn und nützten gewisse Fehler und Mängel wirtschaftlicher Natur aus, um einen blutigen Putsch anzustitten. Sie benutzten dabei gerade jenen Zeitpunkt, da die Regierung, unterstützt von den Gewerkschaften; daranging, eine Verbesserung der Lage zugunsten der werktätigen Massen herbeizuführen, denn es kam ihnen darauf an, diese. Verbesserung zu verhindern...

Der Weltgewerkschattsbund wünscht dem.Sicherheilsrat gegenüber zu betonen, daß die ungarischen Arbeiter und ihre Gewerkschatten zusammen mit dem ganzen ungarischen Volk allein imstande sein werden, die pläne der. nationalen und internationalen Reaktion zu zerstören...

Neue. Zürcher Zeitung, 30.10. 1956

DIE SOWJETISCHE INTERVENTION IN UNGARN. VOR DEM SICHERHEITSRAT

\section{Isolierte-Stellung der Sowjetunion}

Eigener telegraphischer Bericht

M. B. New York, 28. Oktober. - Der Sicherheitsrat hat gestèrn nachmittag über die Lage in Ungarn debattiert. 
Als er sich um $10 \mathrm{Uhr}$ nachts vertagte, ließen sich drei Ergebnisse feststellen: 1. Die Sowjetunion war völlig isoliert und in die Defensive gedrängt: 2 . Ihr militärisches Vorgehen gegen das ungarische Volk war von allen Ratsmitgliedern, die das Wort ergriffen - den Vertretern der Vereinigten Staaten, Englands, Frankreichs, Kubàs, Perus, Australiens, Nationalchinas und Belgiens -, auf das schärfste verurteilt worden, selbst der Vertreter. Jugosla: wiens, der nur in der Prozedurdebatte das. Wort ergriff und dabei zwar die Befassung des Rates mit der ungarischen ${ }^{\star}$ Frage bedauerte, sprach sich gegen das Eingreifen fremder Truppen in Úngarn aus, was auch bereits der Delegierte Irans getan hatte, der im übrigen noch Instruktionen seiner Regierung abwartete. 3. Man hofft, daß, bevor der französische Ratspräsident Cornut-Gentille den Rat wieder einberuft, die Sowjetunion unter dem Eindruck der heutigen überwältigenden Kundgebung ihre Truppen aus Ungarn zurückzieht und auf jeden Fall keine Kampfaktionen mehr unternimmt...

Die Atmosphäre im Ratssaal, der mit Diplomaten und Publikum überfüllt war, während auf der Straße patriotische ungarische Demonstrationen stattfanden, war plötzlich nach einer Periode der "Koexistenz" wieder die des Kalten Krieges, wozu vor allem der Rückfall des Sowjetvertreters in wilde antiamerikanische und antikoloniale Redensarten und seine Beschuldigung beitrug, daß es sich für die Vereinigten Staaten um ein propagandistisches Wahlmanöver handle...

\section{Neue Zürcher Zeitung, 30. 10. 1956}

... Dèr Ministerpräsident teilte mit, das Zentralkommitee der Kommunistenpartei sei angesichts der neuen Lage am. Sonntag zusammengetreten. Es habe ein aus sechs Mitgliedern bestehendes Komitee bestellt, das die Parteiangelegenheiten in die Hand nehmen soll, bis zum Zusammentritt des vierten Parteikongresses in naher $\mathrm{Zu}-$ kunft. Zum Vorsitzenden dieses neven Komitees wurde János Kádár, der Erste Parteisekretär, gewählt. Die weiteren Mitglieder sind: Antal Apró, Károly Kiss, Ferenc 
Muennich, Imre Nagy und Zoltán Szántó. Nagy führte dann aus:

"Es ist nicht wahr, daß das, was sich in Ungarn ereignet, eine "Konterrevolution' ist. Es ist eine demokratische Béwegung, die unsere ganze Nation erfaßt hat, um unsere Unabhängigkeit zu sichern, die die eirzige Grundlage einer sozialistischen Demokratie ist. Obwohl sich einige reaktionäre Elemente dieser nationalen Bewegung angeschlossen haben, kann nicht geleugnet werden, daß im Verlauf dieses Kampfes unsere demokratische Einheit geboren wurde. Ich muß zugeben, daß schwere, von unserem alten Regime begangene Verbrechen die Explosion ausgelöst haben, nachdem die alte Führung gezögert hat, die Konséquenzen zu ziehen.".

Nagy kündigte anschließend das neue Regierungsprogramm an, welches $u$. a. einschließen soll: Lohn- und Rentenerhöhungen, ein privates, von der Regierung unterstütztes - Wohnungsbauprogramm, Reorganisation des Landwirtschaftssystems, Ermutigung privater Unternehmungen. Nagy sicherte außerdem den Studenten eine sofortige Verbesșerung ihrer Lebensbedingungen zu ... .

Süddeutsche Zeitung, München, 30, 10. 1956

BONN ERWAGT KONTAKTAUFNAFME

Bonn (SZ). - Nach Konsolidierung der Verh̆ältnisse in Ungarn und Polen wird die Bundesregierung voraussichtlich prüfen, ob sie zu beiden Ländern diplomatische Beziehungen aufnehmen kann...

Neues Osterreich, Wien, 30.10.1956

Die Ungarn vom Erfolg ihres Freiheitskampfes überzeugt: "ICH GLAUBE, WIR HABEN BEREITS GEWONNEN" Verwundete Aufständische von österreichischen Soldaten ientwaffinet / Jeeps mit schußbereiten Maschinengewèhren patrouillieren entlang der Grenze / Ruhe an der gesamten Grenze / Nickelsdorf Hauptquartier der internationalen Pnesse

An der österreichisch-ungarischen Grenze herrschte auch über das Wochenende vollständige Ruhe. In Nik- 
kelsdorf und Klingenbach ging es allerdings'zu wie in einer Frontstadt. Pausenlos wurden Sendungen des Roten Kreuzes von österreichischen Lastautos auf ungarische LKW verladen.

... In Nickelsdorf trafen Sonntag vormittag in einem PKW mit der Flagge des Roten Kreuzes drei verwundete Freiheitskämpfer und eine Krankenschwester ein. Nachdem Soldaten des Bundesheeres den Jugendlichen die Waffen - Maschinenpistolen und Handgranaten - sowie die Munition abgenommen hatten, wurden sie vom Roten Kreuz bewirtet und versorgt....

Für die Begeisterung, mit der die Ungarn den Kampf gegen die kommunistische Herrschaft führen, zeugt wohl am deutlichsten die Tatsache, daß keiner der Aufständischen die günstige Gelegenheit wahrnimmt, um das Asylrecht in Osterreich anzusuchen... Was vielleicht am meisten überrascht: die Anteilnahme der Jugend am Freiheitskampf, obwohl sie vielfach die Freiheit in ihrem ganzen Leben noch nicht kennengelernt hat.

.... Einer ganzen Reihe von Osterreichern gelang es im Laufe des Sonntags, bis nach Ungarisch-Altenburg und Raab vorzustoßen. Ungarn erzählten ihnen mit Begeisterung, wie es den Freiheitskämpfern gelang, die 600 sowjetischen Soldaten in Raab außer Gefecht zu setzen.

Da die Russen unter Lebensmittelmangel litten, sandten sie Patrouillen auf die Kolchosen aus, um Fleisch, Brot und Gemüse zu requirieren. Die Bauern verständigten sofort die Aufständiscchen und die ungarischen Soldaten: Diese umstellten die Gehöfte, und die sowjetischen Soldaten durften erst abziehen, nachdem sie ihre Waffen abgeliefert hatten.

Bald darauf bot eine Delegation dem Kommandanten in der Kaserne Lebensmittel, sofern er sich bereit erkläre, den Freiheitskämpfern Waffen zur Verfügung zu stellen. Nach kurzer Beratung. gingen die Russen auf dieses Angebot ein. Sie folgten einen Teil ihrer Waffen aus und steckten sich selbst rot-weiß-grüne Kokarden auf die Mützen. Daraufhin erhielten sie Lebensmittel in ausreichender Menge. Auch als sich die Einheit Montag in. 
östlicher Richtung absetzte, gab iḥ̣ die Bevölkerung "Marschverpflegung" mit auf den Weg.

\section{Abendzeitung, München, 31.10.1956 \\ DIE FREIHEIT HATTE KEINEN GENERAL}

Ich erlebte am Rundfunk die ungarische Revolution . von Hans Habe

Hier in den österreichischen Bergen hört man, ich weiß nicht weshalb, Radio Budapest besonders deutlich. Tageund nächtelang wich ich nicht vom Apparat. Ich verstehe Ungarisch. Ich verstehe vielleicht auch Ungarn ...

Als nach einem vollständigen Chaos von. 48 Stunden Ministerpräsident Imre Nagy zum ersten Male wieder ohne zu drohen odér zu flehen sprach, da hörte ich: „Der 15. März, ich verspreche es euch, wird wieder als Natio-" nalfeiertag "würdig bègangen werden."

Wagte sich der Ministerpräsident des blutenden Landes mit diesem "Programm" an die Offentlichkeit?... Um es zu deuten, muß ich etwas weiter ausholen. Zuweilen schien es mir am Radioapparat, als wäre der Regierungssender in die Hände der Aufständischen gefallen - doch nein, es war nur so, daß der Regierungssprecher die Revolutionären als "junge Helden “ ansprach. Dann wieder versuchte ich, dem Freiheitssender zu entnehmen, ob die Aufständischen Titoisten waren oder Demokraten oder Patrioten oder Nationalisten - , doch auch das war nicht festzustellen, denn die Aufständischen priesen Nagy, for'derten seinen Rücktritt, bezeugten ihm. Vertrauen; stellten ihm Ultimaten.

Und deutlich war am Ende nur dies: daß alle die Freiheit wollten, und da $B^{\prime}$ die Freiheit keinen General hatte ... Daß unter dem Wort Freiheit jeder etwas anderes verstand, denn Freiheit heißt Recht, auf tausendfältiges Verstehen, Freiheit ist endlos wie die ungarische Puszta und reich wie die schwarze Erde des Alföld und mannigfach wie die Obstgärten bei Kecskemét, und Freiheit gehört keiner Partei und keiner Organisation - und Freiheit hat keinen General. 
Deshalb, so meinte ich in der Nacht am blinden Gerät, war die Ankündigung des Ministerpräsidenten vielleicht teuflisch, doch war, sie auch ein Symbol der Stunde. Der 15. März, den die neuen Herren "abgeschafft" hatten, war der Tag der Freiheit. Und in dem großen Chaos war nichts verständlich als dieses einzige Wort.

"Mir aber, mir hat die Tugend eignen Wert", sagt Marquis Posa, der Ungar hätte sein können. Für die Ungarn hatte die-Tugend der Freiheit, von der der Spanier spricht, immer "eigenen Wert"... Wenn'die Ungarn an den März 1848 zurückdenken, taucht vor ihnen das Bild Sándor Petöfis auf, der auf den Stufen des Pester Museums seine Befreiungshymne deklarierte, dann denken sie an Mihály Vörösmarthy, der seinen "Aufruf an die Nation", an Mihály Tompa, der das unsterbliche Revolutionslied "Der Vogel an seine Söhne" dichtete.

- Diese Gedichte deklamierten in den Revolutionstàgen des Oktober 1956 Männer und Frauen 'mit bebender Stimme über die ungarischen Sender, diese Hymnen ertönten aus dem Äther. "Vor den Fenstern des Funkhauses wird gekämpft", sagte einmal ein Ansager, und aus dem. Lautsprecher kam Gesang. Singend starben Tausende. Es war die Revolution eines Volkes, dem die "Tugend eigenen Wert" hat. Die Revolution eines Volkes, das immer von Dichtern angeführt wurde, das nicht immer ein Programm, aber immer eine Fahne besaß, und das nie nach dem unmittelbaren Sinn des Todes fragte, weil der Sinn des Tódes nicht unmittelbar ist... Das zynische Wort: "... und dann kommt die Moral". hat hier seine Geltung verloren.

Es gab einen Eindruck, der war stärker als alle anderen. Nur zögernd schreibe' ich das 'Wort nieder, denn es könnte frivol klingen: Die ungarische Oktoberrevolution von 1956 war eine altmodische Revolution.

Die blassen Stimmen, die ich auffing aus dem Ather, schienen aus den vergilbenden Büchern längst vergangener Gèschichte vorgelesen. Auch die erschreckende Totenzahl änderte nichts an diesem Eindruck: wir wissen ja, daß die Schlachten des ersten Weltkrieges mehr Opfer 
forderten als die des zweiten. Wenn durch die wohlverschlossenen Fenster des Kossuth oder Petöfi-Studios von der Straße immer wieder Gesang auftönte, wenn es hieß, auf diesem oder jenem Gebäude sei die rotweißgrüne Flagge gehißt worden, wenn der Rundfunk meldete, die Soldaten rissen sich den Sowjetstern von den Mützen und schmückten sich mit Bändern in den nationalen Farben, wenn in Raab schon die Heldengräber geschmückt wurden, während man noch auf der Budapester Lánczbrücke kämpfte - dann war es, als tauchte hinter dem Rundfunkgerät nicht die Photographie der revolutionären Stadt aus dem Jahre 1956, sondern ein Kupferstich aus den Revolutionstagen von 1848 auf.

Das Wichtigste aber scheint zu sein, daß der ganze Begriff, der Revolution, den wir schon für altmodisch, gestrig und 'geschichtlich hielten, aus dem Kupferstich von. Budapest wieder als lebendige und pulsierende Wirklichkeit hervorgetreten ist. In jeder Sekunde an meinem Rundfunkgerät glaubte ich, das Ende dieser "altmodischen" Revolution wäre gekommen, denn wie könnte es eine Revolution von barhändigen Menschen geben - im Zeitalter der Panzer, Düsenjäger und Atombomben! Aber die Revolution ist ausgebrochen, und in diesem Ausbruch liegt ihre Größe - nicht in ihrem unmittelbaren Erfolg.

Süddeutsche Zeitung, München, 31.10.1956

DIE GANZE WELT WILL DEN . UNGARN HELFEN. BUNDESREGIERUNG SPENDET EINE MILLION MARK. ERSTE . TRANSPORTE VON LEBENSMITTELN UND MEDIKAMENTEN :

Das. Bundeskabinett hat beschlossén, eine Million Mark zur Linderung der Not in Ungarn bereitzustellen, eine Anzahl weiterer Hilfsmaßnahmen wurde in Aussicht gestellt. Seine besondere Anteilnahme drückte das Kabinett dem ungarischen Volk aus, das „den Kampf gegen Willkür, für die Menschenrechte und für die Wiederherstellung seiner Freiheit aufgenommen" habe. 
...Der Berliner FDP-Abgeordnete Ullmann hat über den Berliner Sender Freies Berlin die Bevölkerung aufyefordert, einen Tagesverdienst für die Ungarn-Hilfe zu spenden.

Abendżeilung, München, 31. 10. 1956 KUNDGEBUNG FUR UNGARN

Zi. München (Eig. Ber.). Der Allgemeine StudentenAusschuß an: der Universität München hat einen Aufruf erlassen, in dem es heißt:

„In Lingarn kämpft das Volk um seine Freiheit. Dieser Kampf geht auch uns an. Wir dürfen nicht untätig zusehen, wie die gerechten Forderungen des ungarischen Volkes mit Gewalt und Terrormaßnahmen unterdrückt werden. Ihr Kampf; ist auch unser Kampf."

Die Münchner Studentenschaft ruft daher die gesamte Münchner Bevölkerung, insbesondere die Jugend, zu einer Kundgebung heute abend um $18 \mathrm{Uhr}$ in der Aula der Universität auf. Es spricht Professor Alexander Graf Schenk von Stauffenberg.

Frankfurter Allgemeine Zeitung, 31. 10:1956 BUDAPESTER TAGEBUCH

Aus den Aufzeichnungen eines Augenzeugen der ungarischen Revolution

Endre Márton, Korrespondent der amerikanischen Nachrichtenagentur Associated Press in Budapest, Ungar von Geburt, hat den Aufstand in Budapest von Anfang an miterlebt:

... Sonnabend, den. 27. Oktober. Heute treffe ich die erste Streife der ungarischen Armee. Ein Hauptmann und zwei Soldaten mit Maschinenpistolen. Sie haben keinen Sowjetstern mehr auf den Mützen. Sie stehen vor einem Haustor und diskutieren mit einem Dutzend Zivilisten. Der Hauptmann fragt sie: "Wie sollen wir die' Ordnung wiederherstellen, wenn ihr den Befehlen nicht folgt und trotz des Verbotes immer auf die Straße geht?" Eine Frau 
gibt bissig zurück: „Und wo sollen wir. Brot hernehmen für die Kinder, die vor Hunger :weinen?" Der Offizier sagt immer wieder, die Russen könnten nicht abziehen, solange die Ordnung nicht wiederhergestellt sei. "Die Regierung hat sie gerufen, und sie würden das Gesicht verlieren, wenn sie jetzt abzögen. ". Und schließlich: „Wer garantiert dafür, daß die Kämpfe aufhören, wenn siè abziehen, daß ihr dann nicht auf uns schießt?" Die Antwort. "Das wißt ihr ganz genau. Keiner hăt auf ungarische. Soldaten geschossen, sie wurden überall jubelnd begrüßt, wenn sie auftauchten. Traurig ist nur, daß ihr nicht auf unserer Seite kämpft." Das ganze Gespräch wird ohne jede Aufregung geführt, ganz höflich, beide Seiten

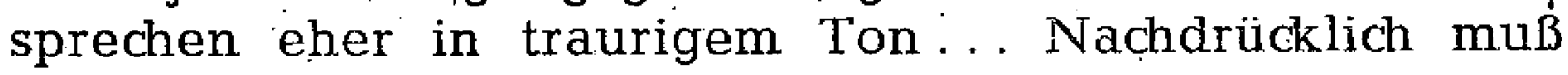
ich feststellen, daß. nach meinem, Wissen kein einziger Aufständischer vor ein Standgericht gestellt oder hin'gerichtet wurde. Die Regierung scheint ihre' wiederholten Ultimaten nicht ernstgenommen zu haben. .

Die heutigen Berichte aus den Provinzen 'deuten an, daß 'praktisch ganz Ungarn in der. Hand von "Revolutionsausschüssen" ist. Kollegen bei den Zeitungen sagten mir, sie hätten noch nie so lebhaft geschriebene Bérichte von ihren Provinzkorrespondenten bekommen. „Die Kerle müssen übergeschnappt sein vor Freude, daß sie zum ersten Mále in ihrem Leben nicht über die Ubererfüllungen des. Solls und über Neuerer-Methoden bei der: Schweinezucht berichten müssen "...

\section{Süddeutschè Zeitung, München, 31.10.1956}

\section{TITO BEGRUSST UNGARNS NEUEN KURS}

Belgrad (dpa) … Das politische Porgramm der neuen ungarischen Führung sèi ein Beweis dafür, daß die Politik dieser Führung und die ,echten sozialistischen, demokrâtischen Bestrebungen der ungarischen / Werktätigen" ein Ganzes geworden sind. Tito nannte dabei als Programmpunkte die Arbeiter-Selbstverwaltung nach jugoslawischem Muster, die Entwicklung der Beziehungen sozialistischer Länder auf der Grundlage der Gleichheit 
und die „Initiative für Verhandlungen über den Rückzug der sowjetischen Truppen".

\section{Albanien: Impérialistisches Abenteuer}

Tirana (dpa). In einem ersten Kommentar bezeichnete die albanesische kommunistische Arbeiterpartei den Aufstand in Ungarn als "imperialistisches Abenteuer" und als ,blutige Aktionen der imperialistischen und faschistischen Konterrevolutionäre". Sie schloß sich damit vorbehaltlos den in der Sowjetpresse geäußerten. Ansichten an.

Abendzeitung, München, 31.10. 1956

IN UNGARN: VOLLER SIEG --

IN AGYPTEN: DER KRIEG

Abendzeitung, München, 31.10.1956

HINTER MIR LAG EIN UNGLUCKLICHES LAND

Ein Amerikaner kam aus Budapest

Hermann Blumenfeld, der Direktor der "Fox-Wochenschau" für Deutschland, ist gestern, Dienstagabend, von seiner zweiten Fahrt nach Budapest zurückgekehrt und gegen 19. Uhr in Wien eingetroffen.

.. In der Nähe von Budapest stand praktisch ein russischer Panzer neben dem anderen. Hundèrte von Panzern auch in der Innenstadt. Ich kam kaum mit meinem Wagen durch die verstopften Straßen.

Noch niemals habe ich so viele Panzer in meinem ganzen Leben gesehen. Es wäre Massenschlächterei, wenn die Freiheitsarmee den Versuch unternehmen würde, gegen diese Panzermassen vorzugehen...

Münchner Merkur, 31.10. 1956

IM ŹEICHEN DER FREIHEIT von Aifons Dalma, z. Z. Wien

... Vorsicht bleibt jedoch mehr denn je geboten. Denn die Kommunisten sind Meister der Verstellung, der Dop- 
pelzüngigkeit und des Vorgehens unter falscher Flăgge... Es kann das Ziel des Regimes sein, den Aufstand durch Scheinkonzessionen zu betäuben, den aus den Tiefen des leidenden. Volkes herausgebrochenen revolutionären Schwung lahmzulegen, um dann allmählich seine Machtpositionen wiederherzustellen und seine Versprechen. zurüdkzuziehen . . .

Frankfurter Allgemeine Zeitung, 31. 10. 1956

MEHR FLUCHTLINGE AUS UNGARN. OSTERREICH GEWAHRT JEDEM HILFESUCHENDEN ASYL

Eigener Bericht unseres Korrespondenten

Ko. Wien, 30. Oktober. Seit Beginn dieser Woche ist die Zahl der aus Ungarn nach Osterreich kommenden Flüchtlinge, stark angewachsen. Allerdings kann. man noch nicht von einem Flüchtlingsstrom sprechen...

In einem Gespräch an der Grenze bei Odenburg (Sopron) im südlichen Burgenland mit einigen. Studenten der dortigen Technischen Hochschule, die in diesem Gebiet zusammen mit einer Gruppe von Jungarbeitern, die Macht in der Hand halten, äußerten sich die jungen Ungarn sehr besorgt über die mögliche zukünftige Entwicklung. Gerade Sopron ist eines der Beispiele dafür, wie sehr es den Freiheitskämpfern an geschulten Leuten mangelt, weil die antikommunistisch eingestellte Intelligenz entweder ausgerottet wurde oder aber so eingeschüchtert ist, daß sie es nicht wagt, sich bei der derzeitig ungeklärten Situation schon $z u$ exponieren. So führt ein 21 Jahre alter Student heute das ganze Komitat Sopron. Drei Hochschulprofessoren sitzen an der Grenze. und übernehmen die aus Osterreich eintreffenden Hilfslieferungen zum weiteren Transport ins Landesinnere ...

Die Studenten erkennen zwar die große karitative Hilfsaktion Osterréichs und der europäischen Staaten für Ungarn dankbar an, sind aber bitter enttäuscht, daß der Westen ihnen nicht auch in anderer Form, vor allem durch die Lieferung von Waffen, unter die Arme greift. 
Süddeutsche Zeitung, München, 1.11.1956

KARDINAL MINDSZENTY IN FREIHEIT '

Feierlicher Einzug des jahrelang eingekerkerten Kirchenfürsten in Budapest

Budapest (dpa). Nach achtjähriger Gefängnishaft und Internierung kehrte der Fürstprimas der katholischen Kirche Ungarns, Kardinal Mindszenty, am, Mittwochmorgen wieder̈ nach Budapest zurück. Wenige Stunden später empfing er in seiner Residenz in der ehemaligen königlichen Burg eine kleine Gruppe von Pressekorrespondenten. Mindszenty trug an seinem Bischofsgewand die rotweißgrüne Kokarde des freien Ungarns...

Mindszenty, 1892 geboren, wurde 1915 zum Priester geweiht. 1945 ernannte ihn der Papst zum Erzbischof von Esztergóm (Gran) und verlieh ihm ein Jahr später die Kardinalswürde. Der Konflikt der Kirche mit der ungarischen Regierung erreichte im Frühjahr 1948 seinen Höhepunkt, als der Kardinal sich in einem Hirtenbrief scharf gegen die Verstaatlichung der konfessionellen Schulen wandte. Die kommunistische Regierung verhängte über ihn ein Rede- und Predigtverbot und ließ ihn wegen "Spionage, Verbrechen gegen die Sicherheit Ungarns und Devisenschmuggel verhaften. Im Dezember 1949 wurde Mindszenty zu lebenslänglicher Haft verurteilt und durch zahlreiche Gefängnisse geschleppt. Im Juli 1955 entließ man ihn zwar aus der Haft, wies ihm aber einen Zwangsaufenthalt zu.

Népszava, Budapest, 1.11.1956

UNGARN MITTELPUNKT DES WELTINTERESSES

Trotz des Konflikts um den Suezkanal widmet die Weltpresse den ungarischen Ereignissen und ihren voraussichtlichen Auswirkungen große Aufmerksamkeit...

\section{Chaos unter Frankreichs Kommunisten}

Die französische Presse befaßt sich noch immer an führender Stelle mit den ungarischen Ereignissen: Die „Populaire" stellt fest, daß die französische Arbeiterklasse die Vorgänge in Ungarn mit großem Interesse verfolgt 
hat. Das sozialistische Blatt richtet einen scharfen. Angriff gegen die kommunistische "Humanite" und "Liberation", weil sie die Verleumdungen der "Prawda". wiederholt haben obgleich diese sowohl von dem offiziellen Organ der ungarischen Kommunisten als auch von der polnischen Presse zurückgewiesen wurden. "In den Reihen der tranzösischen Kommunisten", schreibt die "Populaire", "ist ein neues Chaos zu bemerken." Als Beweis dafür gilt auch das Schweigen von Pierre Courtade.: Jene, die in der KP Frankreichs Anhänger der, starken Hand" sind, haben angefangen, in den Betrieben um Paris Flugblätter zu verbreiten, welche die Verleumdungen der. "Humanité" wiederholen. "Wir müssen die politische Entwicklung des polnischen und ungarischen Volkes mit gröBter Wachsamkeit und. Aufmerksamkeit verfolgen", schrieb die "Populaire"; "denn diese Länder können jetzt den Weg dèr sozialistischen und demokratischen Erfahrung wählen."

"Figaro" weist darauf hin, daB die Sowjetunion ihre Beziehungen zu den Volksdemokratien weitgehend revidiert. "Aurore" meint, daB in Moskau die Ansichten der Führer geteilt sind. Schepilow sei. für eine Intervention, Mikojan dagégen.

Die polnische Presse erachtet die offizielle sowjetische Erklärung übèr den Abżug,ihrer Truppen ausiden Volksdemokraten für besonders wichtig. "Zycie "Warszawy" drückt' ihre große Freùde darüber aus, daß jetzt "der Albdruck verschwindet, der bisher, über dem ganzen sozialistischen Lager gelastet hat"...

\section{Süddeutsche Zeitung, München, 1. 11.1956}

. . Ministerpräsident Nagy scheint sich klar zụ werden, daß die Entwicklung über sein Konzept des 'volksdemokratischen Parlamentarismus hinweggegangen ist. $\because$ Angesichts der Stimmung in der Bevölkerung. hat er sich mit der Zulassung der alten Parteien einverstanden erklärt, die sich zur Zeit zu konstituieren beginńner... Von den sieben Mitgliedern der geschäftsführenden. Regierung Nagy sind vier Kommunisten, zwei Ministerposten hat 
die Partei der Kleinen Landwirte, inne. Den siebten Ministerposten hat Nagy der Sozialdemokratischën Partei angeboten, die unter dem Vorsitz der 67 jährigen, jahrelang von den Kommunisten eingekerkerten Kéthly ihre Tätigkeit wieder aufgenommen hat...

Népszava, Búdapest, 1.11.1956

Das provisorische Aktionskomitee des Landesverbandes Freier Ungarischer Gewerkschaften teilt mit:

Auf seiner außerordentlichen Sitzung am Dienstag hat das Präsidium des SZOT (Landesrat der Gewerkschaftèn) abgedankt. Die Leitung hat das provisorische Aktionskomitee des Landesverbandes Freier Ungarischer Gewerkschaften übernommen. Mitglieder des provisorischen Aktionskomitees sind die ehemaligen, bisher beiseilegestellten und eingekerkerten Gewerkschaftsführer sowie auch neue, revolutionäre Gewerkschaftsführer...

Népszava; Budapest, 1.11.1956

MOSKAUER REGIERUNGSERKLARUNG

UBER ABZUG DER SOWJETTRUPPEN

Moskau,. 30. Oktober. Die offizielle Nachrichtenagen-" tur der Sowjetunion, TASS, hat' folgende Erklärung veröffentlicht:

\section{Die Völker sind gleichberechtigt}

...Der XX. KongreB der KPSU hat sich die Aufgabe gestellt, in den zwischen der Sowjetunion und den anderen sozialistischen Ländern unterhaltenen gegenseitigen Beziehungen das Leninsche Prinzip über die Gleichberechtigung der Völker konsequent zu verwirklichen. Der $X X$. KongreB hat ausgesprochen, daB die geschichtliche. Vergangenheit und die Eigenarten jedes einzelnen Lan-. des, welches den Weg'zum Aufbau eines neuen Lebens eingeschlagen hat, voll beachtet zu werden haben... Die sowjetische Regierung ist bereit, mit den Regierungen der anderen sozialistischen Ländern jene Maßnahmen zu erörtern, welche die Weiterentwicklung und Stärkung der wirtschaftlichen Beziehungen der sozialistischen Länder. 
garantieren, damit alle Möglicilleiten der Verletzung de's Prinzips von nationaler Souveränität, gegenseitigen Vorteilen und Gleichberechtigung in den wirtschaftlichen Beziehungen ausgemerzt werden... Die sowjetische Regierung hält es für notwendig, genieinsam mit anderen sozialistischen Staaten die Frage zu prüfen, ob der weitere Aufenthalt von sowjetischen Beratern in diesen Ländern zweckmäßig ist ...

\section{Die Sowjetregierung will überprüfen ...}

...Im Interese der Sicherung der Sicherheit der sozialistischen Länder ist die sowjetische Regierung bereit; mit den anderen sozialistischen Ländern dos Warschauer Paktes die Frage der Stationierung, sowjetischer Truppen auf dem Gebiet der betreffenden Länder zu überpiüfen. In, dieser Hinsicht geht die sowjetische Regierung von dem allgemeinen Prinzip aus. daß die 'Verlegung von Truppen des einen oder anderen am Warschauer Pakt beteiligten Staates auf das Gebiet eines anderen "Warschauer-Pakt-Staates auf Grund der von sämllichen Paktmitgliedern getroffenen Vereinbarung geschieht, und nur mit Zustimmung jenes Staates, auf dessen Gebiet - auf Ersuchen des betreffenden Staates - sich die Truppen befinden.

\section{Sowjetregierung zu Truppenabzug bereit}

... Die sowjetische Regierung ist bereit,'mit der Regierung der Ungarischen Volksrepublik sowie den Regie-. rungen der anderen am Warschauer Pakt beteiligten Staaten Verhandlungen über die Stationierung der sowjetischen Truppen in Ungarn aufzunehmen...

\section{Népszava, Budapest, 1.11.1956}

\section{KEINE ABLIEFERUNGSPFLICHT MEHR}

Am 30. Oktober 1956 hat die Nationalregierung die $A b$ lieferungspflicht abgeschaft. Das gemeinsame Interesse der Arbeiterschaft und der Bauern ist mit der BeibehaItung der Ablieferungspflicht unvereinbar; welche in den vergangenen Jahren die Rentabilität der Iandwirtschaftlichen Produktion und die Sicherheit der Produktion 
untergraben hat, und manchmal soy:lT dazu führte, daß ein Teil der Bauern von der Ernte nicht einmal den eigenen Bedarf décken konnten...

Népszava, Budapest, 1.11.1956

WIR SIND SOZIALDEMOKRATIN!

von Anna Kéthly

... Mit gesenktem Haupt müssen wir jenen tiefe Enrfurcht zollen, dlie es érmöglicht halen, daß wir wieder aulrecht stehen können - den vielen tausend intellektuellen und werktätigen Jugendlichen, die hungrig und zerlumpt, beseelt allein von der Idee eines unabhängigen und freien Ungarn gekämpft haben. In tiefer Ehrfurcht verneigen wir uns vor denen, die das Meiste gegeben haben; ihr. junges Leben, damit die Ubriggebliebenen erhobenen Hauptes und ohne Demütigung in diesem Lande Jeben können. Ihr Andenken wird neben dem der gröBten Helden der ungarischen Nation stehen, und auf ihre Gräber legen wir außer unseren Kränzen auch die Anerkennung und Bewunderung der gunzen Welt.

Aber das. Gedenken an den Kampf und die Opfer ist zugleich eine Verpflichtung für die Lebenden: die Gefahı, welche die Idee und die Ziele der Revolution bedrohl, ist noch nicht vorbei. Wir müssen... auch darauf achten, daß die, gèwaltige Kraft der Revolution nicht von jenen für ihre eigenen Ziele miBbraucht wird, denen schon die unter: Teilnahme der Sozialdenokratischen Partei gs. leistete Arbeit zum Aufbau des Landes zuviel war. Wir wissen, daß zu der Zeit, als die Sozialdemokratische Paltei zum Schweigen gebracht wurde, sich ungeheure Bittt:1keit in den Herzen angestaut hat. Aber es nützt weder dem Land und der Partei im allgemeinen, noch den sozialdemokratischen Massen im besonderen, wenn die Konterrevolution diese Bitterkeit für ihre Zwecke nutzbar machen. kann...Die Fabriken, Bergwerke und Felder müssen in der Hand des Volkes bleiben... In diesem Sinne wollen wir ein neues Leben beginnen, vertrauerit unserer eigenen Kraft und der wiedergeborenen Partei, vertrauend dem neuen; demokratischen, unabhängigen 
Ungarn, dessen Konturen wir heute bereits klarer sehen als vor einer Woche.

\section{Sozialdemokraten! Freundschaft!}

Mittelbayerische Zeitung, Regensburg, 2. 11,1956

BUDAPEST, DIE HAUPSTADT EINES FREIEN LANDES. DIE DRAMATISCHEN - STUNDEN :DER GESCHICHTLICHEN WENDE IN UNGARN.

Von dpa-Sonderkorrespondent Eugen Géza Pogány

Budapest, 30. Oktober 1956. ... Die Sowjets'verlassen die Stadt. Während ich diese Zeilen schreibe, ziehen die Sowjets draußen vorbei und aus ider Stadt hinaus. Die Einheiten machen den Eindruck ejner geschlagenen. Armee:.. Vor zwei Stunden war ich dabei; als die seit' 1948: praktisch nicht mehr existierende: Kleinlandwirtepartei, jene Partei, die bei den ersten freien geheimen Wahlen im Oktober 1945 vom ungarischen Volk die absolute Majorität erhielt, wieder unter unbeschreiblichem Jubel der Menschënmassen ihr, einstiges Hauptquartier in der Semmelweißucca beziehen konnte.

Das bisherige KP-Zentralorgan "Szabad Nép". hat sein Erscheinen eingestellt. Angehörige des Druckhauses rissen von der. Fassade àm Dienstag das ..Wort "Szabad" (ungarisch: frei) nieder. In Budapest verlautet, daß die ungarische 'KP in Kürze eine neue Zeitung herausgeben : wird ...

\section{„Hinter dem Eisernen Vorhạng“, München, Sept. 1957}

DIE WANDIUNGEN DER UNGARISCHEN PRESSE

Genau wie in den übrigen Satellitenstaaten unterschied sich die Presse auch in Ungarn bis zum Tode Stalins im .Tahre, 1953 nur, wenig von der Presse in Sowjetrußland selbst. Sie hielt sich politisch streng an die Moskatier Glaubenslehre. Die unansehnlich aufgemachten Zeitungen und Zeitschriften dientẹn ohne Unterschied der kommuniștischen Schulung ihrer Leser. Im großen und ganzen eintönige Berichte, deren Länge in umgekehrtem Verhältnis zu ihrer Bedeutung stand, füllten ihre Spalten. Dazu kamen nicht, weniger langweilige und langatmige soge- 


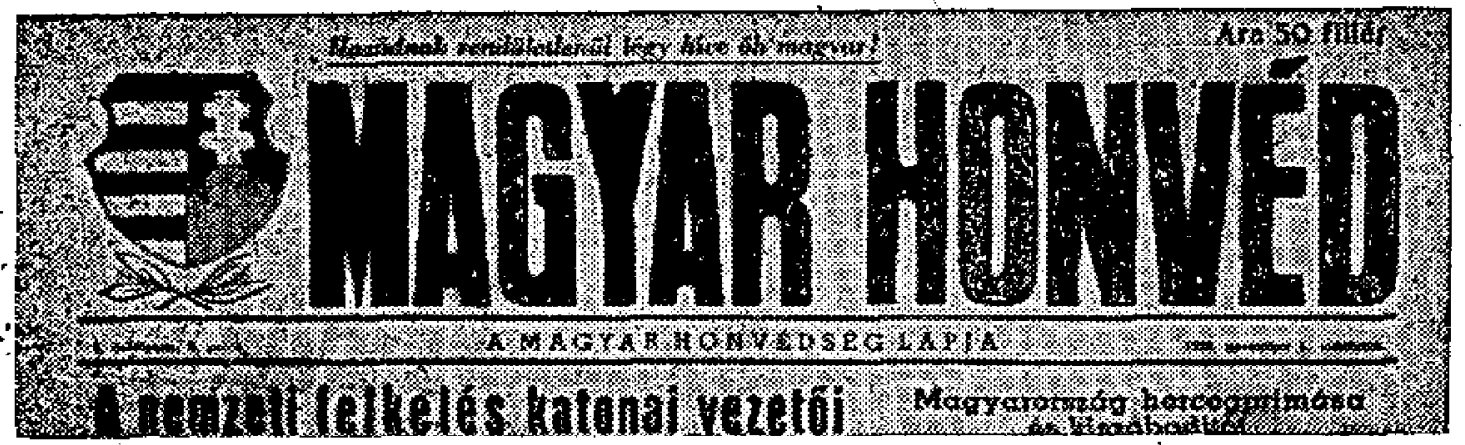

Kopf der (ungarischen Soldatenzeitüng "Magyar Honvéd: (Ungarischer Soldat) vom 1. Nov. 1956. it

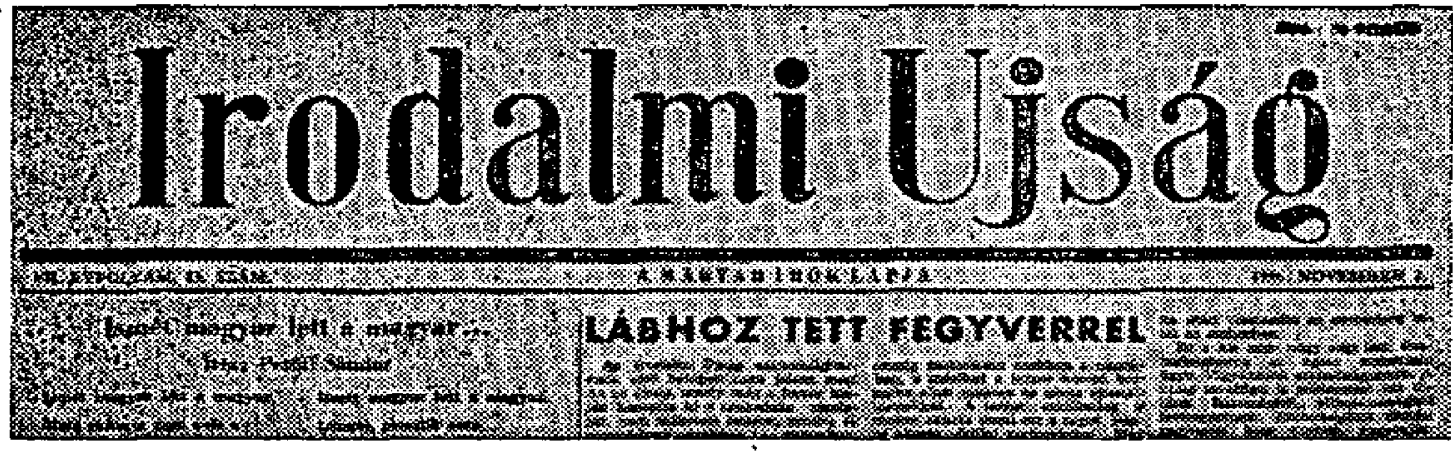

Die letzte Nummer der in Budapest am 2. Nov. 1956 erschienenen Zeitung des ungarischen Schriftstellerverbandeș "Irodalmi Ujság” (Literạrische Zeitung).

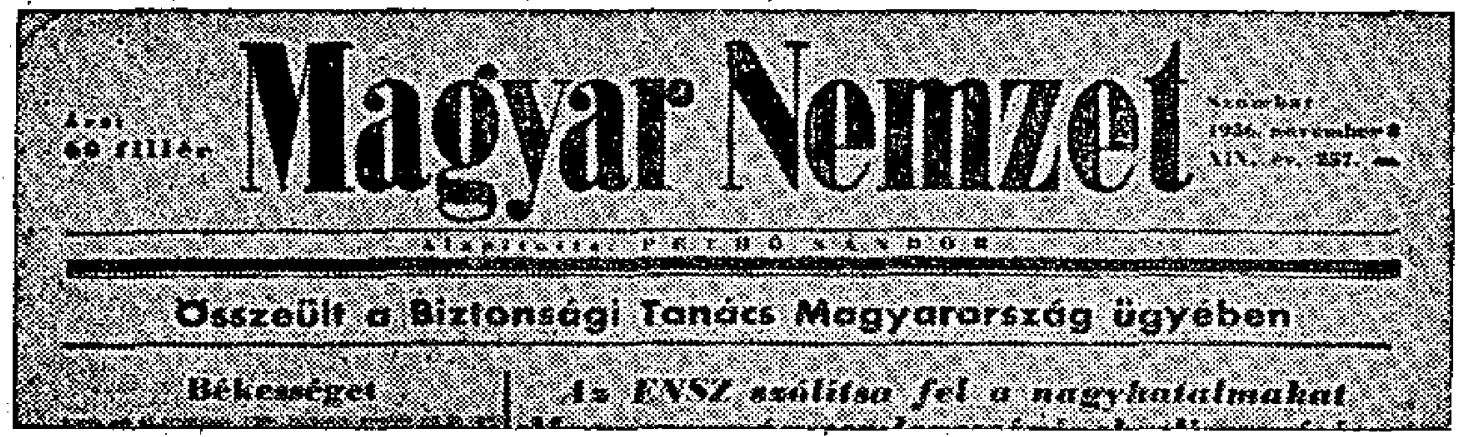

Der Kopf der letzten Nummer von „Magyar Nemzet" (Ungarische Nation) vom 3. November 1956. 
nannte theoretische Abhandlungen und aus der Sowjetunion fix und fertig gelieferte Nachrichten. Die Kommentatoren verhimmelten alles Sowjetische und machten alles Westliche schlecht, wobei sie auch vor groben Entstellungen nicht zurückschreckten ...

Mit der Ernennung Imre Nagys zum Ministerpräsidenten im Sommer 1953 schwenkte auch die ungärische Presse auf den neuen Kurs ein. Sie ging zum erstenmal nach vielen Jahren dazu über, kritische Beiträge über die Zustände unter dem kommunistischen Regime zu veröffentlichen; die an Schärfe und Deutlichkeit nichts zu wünschen übrig ließen. Hierbei taten sich besonders die literárischen Zeitschriften, vor allem das Organ des unga" rischen Schriftstellerverbandes, die Wochenzeitung "Irodalmi Ujság" (Literatur-Zeitung) sowie die Zeitschrift des Schriftstellerverbands, der monatlich erscheinende ."CsilJag" (Stern) hervor . . Damit hatte die: ungarische Presse begonnen, die bisherige Linie der Uniformität $z u$ verlassen und unterschiedliche, ja gegensätzliche Meinungen zu Wort kommen zu lassen ...

Im. Frühjahr 1955 wurde Nagy wegen Rechtsabweichung verurteilt, aus der Partei ausgestoßen und seine Politik aufs schärfste angegriffen. Strengste Linientreue wurde erneut zum obersten Gesetz. Die Intellektuellen fuhren auch weiterhin fort, aufrührerische Artikel, Gedichte und Erzählungen in ihrem Organ "Irodalmi Ujșág" zu veröffentlichen, und es gelang ihnen auch, ihren abweichenden Anschauungen auf indirekte Weise in anderen Zeitschriften Eingang zu verschaffen. Diese vermieden zwar offene Angriffe auf die Partei selbst, aber durch mutige Darlegungen der tatsächlichen Situation trugen sie dạu bei, deren Politik zu erschüttern.

\section{Die Presse während der Revolution}

Der Triumph der "Liberalen" in der revolutionären Periode zwischen dem 23. Oktober und dem 4. November leitete für die ungarische Presse eine völlig neue Epoche ein. Die Wandlung war so tiefgreifend, daß trotz der verzweifelten Versuche mancher Redaktionen, . wenigstens den Anschein einer Kontinuität aufrechtzuerhalten, kaum 
noch Merkmale der Presse der Rákosi-Ära erhalten blie: ben...Gleichzeitig mit den neuen Vereinigungen und Parteien, die in der kurzen Spanne verhältnismäßiger Freiheit gegründet wurden, entstand auch eine "Reihe" neuer Publikationen. Die Stalinisten, die Rákosi unterstützten, wurden aus den Redaktionen der altetablierten Zeitungen ebenso hinausgeworfen wie aus ihren sonstigen führenden Stellungen im Lande...

Sowohl die neuen wie die alten Zeitungen unterschieden sich in Format und. Inhalt gănz wesentlich von den bisherigen Presseprodukten. Eine langweilige, blutarme und unter Zensur stehende Presse verwandelte sich fast über Nacht 'in hochinteressante und wirklich anregende journalistische Erzeugnisse, die eine aufregende Lektüre boten.

Während in den Straßen von Budapest die Kämpfe tobten, widmeten sich Dutzende von. Ungarns besten Schriftstellern - viele von ihnen Kommunisten - mit einem Mut und einer Leidenschaft der Sache der Nation, wie es in der Geschichte fast beispiellos dasteht. Diese Schriftsteller mißachteten angesichts der überwältigenden sowjetischen Streitkräfte jede persönliche Gefahr; ihr Ziel wạr offenbar, den Kampf um Befreiung, auch wenn er mißlingen sollte, gleichwohl zu wagen, um-künftige Generationen zu inspirieren... Es war die Presse, die durchgreifende Programme aufstellte und veröffentlichte und an das Volk in seiner eigenen Sprache appellierte. Und es war wiederum die Presse, die in Ausgaben von -nur zwei oder allerhöchstens vier Seiten der Selbstaufopferung des Volkes Sinn und Ausdruck verlieh.

\section{"Magyar Nemzet"}

Nach Aussagen vieler Flüchtlinge war „Magyar -Nemzet" die meistgelesene und einflußreichste Zeitung der Volkserhebung...A Am 25. Oktober veröffentlichte "Magyar Nemzet" die Erklärungen Zoltán Tildys (ehemaliger Staatspräsident und einer der führenden Köpfe der Partei der Kleingrundbesitzer, erst im Sommer 1956 aus dem Gefängnis entlassen) sowie eine Erklärung Imre Nagys, dessen Berufung auf den Posten des Ministerpräsidenten 
das Blatt in einem Leitartikel mit Begeisterung begrüßte.

Am darauffolgenden Tage brachte das Blatt einen ergreifenden Artikel unter der Uberschrift „Weht, ungarische Banner!". und eine Proklamation, in der die unverzügliche Entlassung aller politischen Gefangenen gefordert wurde. Am 30. Oktober publizierte die Zeitung in einer erweiterten Ausgabe einen Leitartikel mit der Uberschrift „Wir dürfen die Existenz des Vaterlandes nicht gefährden". Darin' wurde zur Zurückhaltụng gemahnt, um eine Provozierung der Sowjets zu vermeiden. Aber in der gleichen Aušgabe antwortete "Magyar Nemzet" auf einen in der Moskauer "Prawda ". veröffentlichten Angriff gegen die.. revolutionäre : Bewegung. Am 31. Oktober faßte das Blatt seine Haltung zu den Ereignissen in einem Leitartikel unter der Uberschrift "Wir machen Weltgeschichte" zusammen." In einem mit "Verrat wird an den Pranger gestellt" überschriebenen Artikel griff der (auf Weisung Kádárs eingekerkerte) dramatische Schriftsteller Gyula Háy, eine der markantesten Gestaltè untèr den kommunistischen Rebellen, in mutiger: Offenheit ein System an, das angeblich im Namen des "Sozialismus", aber offenbar zu dem Zwecke errichtet worden war, die Wahrheit zu verdrehen...

$\mathrm{Ab}$ 1. November führte die Zeitung unter ihrem Titel noch den Zusatz: „Gegründet von Sándor Pethö:“" (Pethö, ein Monarchist und überzeugter Antinazi, hatte in der ungarischen Presse vor dem Kriege eine führende Rolle gespielt.) Der bedeutsamste Artikel dieser Nummer "Das ungarische Volk wünscht die Neutralität des Landes" hatte Béla Kovács zum Verfasser, den früheren Generalsekretär der Partei der Kleinlandwirte, einen alten Feind der Kommunisten. Kovács war seinerzeit von den Sowjets ver̂schleppt worden und..wurde 1956 wieder freigelassen. Imre Nagy berief ihn am 27. Oktober zum Landwirtschaftsminister. Und als wollte das Blatt seine Stellung in der Frontlinie des Kampfes um größere Freiheit noch besonders unterstreichen, veröffentlichte es als Leitartikel einen in einer englischen Zeitung erschienenen-Artikel, der die Uberschrift "Heldenmut in Ungarn endlich belohnt!" trug. In der gleichen Ausgabe erschien 
ein Interview mit dem gerade erst aus dem Gefängnis befreiten Kardinal Mindszenty.

Die am 3. November erschienene Nummer der Zeitung ist voll dunkler. Vorahnungen kommender Dinge - Vorahnungen des tragischen Endes, das bereits der nächste Tag bringen sollte. Sie enthielt Berichte über verdächtige Truppenbewegungen der Sowjets und erklärte sich von neuem für Ungarns Neutralität.' Zur gleichen Zeit wies das Blatt die Behauptung der Sowjets zurück, die Freiheitskämpfer seien gemeines Gesindel. Eines der eindrucksvollsten Dokumentè der Revolution stellt der Hilfe: ruf der. ungarischen Schriftsteller an iher Kollegen in der freien Welt dar, der ebenfalls in dieser Nummer publiziert wurde.

\section{"Szabad Nép" und "Népszava"}

Das zum Sprachrohr der Nagy-Régierung gewordene "Szabad Nép" spiegelte den ganzen Mángel an Entschlußkraft des neuen Regierungsoberhauptes wieder. Am 28. Oktober . wandte sich "Szabad. Nép" gegen ...jene, welche die Sache Ungarns in Verruf bringen". In der folgenden Nummer versuchte das Blatt, den Freiheitskämpfern einzureden, daß sie bereits alle ihre Ziele erreicht hätten und die Waffen niederlegen könnten.

"Népszava", das offizielle "Zentralorgan der Ungarischen Gewerkschaften", wurde am 1. November zum "Zentralorgan der Sozialdemokratischen Part̄ei“ erklärț, die während der Revolutionstage wieder gegründet worden war. Der Leitartikel dieser ersten Nummer stammte von der bekannten Sozialistin Anna Kéthly...

\section{Zeitungen für die Jugend}

Für die Jugend gab es vor Ausbruch der Revolte nur eine einzige Zeitung: "Szabad Ifjuság" (Freie Jugend). Sie hielt sich im ganzen streng an die üblichen didaktischen Richtlinien der Partei, die auch für die übrgen Blätter galten. Im Sommer und Herbst 1956 aber nahm sie mit der zunehmenden Gärung im Lande eine weniger starre Haltung ein. Dieser verspätete Versuch, sich mit den' wirklich aktuellen.Problemen zu befassen, konnte jedoch das Blatt nicht vor dem Untergang retten: mit ihrer Num- 
mer vom 23: Oktober stellte die Zeitung ihr Erscheinen gänzlich ein. An ihre Stelle traten vier neue. Tageszeitungen: "Magyar Ifjuság". (Ungarische Jugend), "Magyar Jövö.. (Ungarische Zukunft), "Egyetemi Ifjușág" (Universitäts-Jugend) und "Igazság" (Wahrheit).

\section{"Magyar Honvéd" und "Irodalmi Ujság"}

Eine der interessantesten Zeitungen, die der Aufstand hervorbrachte, $:$ war "Magyar Honvéd". (Ungarischer Soldat), das Organ der bewaffneten Macht der Revolutionäre. Daß dieses Blatt die-Sache der Freiheitskämpfer unterstützte; wurde durch das unter seinem Titel stehende Motto noch besonders unterstrichen: „Ungar, steh treu zu deinem Vaterland" - ein Zitat aus einem "Gedicht: von Mihály Vörösmarthy, dem berühmten Dichter des vorigen Jahrhunderts. Am 1. November brachte das Blatt dann auf seiner Titelseite ein Bild des Kardinals Mindszenty inmitten einer Gruppe von Freiheitskämpfern, die ihn aus dem Gefängnis herausgeholt hatten, sowie einen Artikel mit der Uberschrift: "Wir fordern Aufklärung über die von der. Rákosi-Gerö-Clique begangenen Verbrechen. "Dieser Artikel verlangte-ferner von der Sowjetunion die Auslieferung des ehemaligen Diktators, damit er sich "für seine Verbrechen vor Gericht verantworten könne". Das Blatt wandte sich - wie es auch "Magyar. Ifjuság" getan hatte - scharf gegen die "unwürdige Haltung Rumạniens und der Tschechoslowakei gegenüber der ungarischen Revolution." und veröffentlichte weiter einen Artikel mit der Uberschrift: "Die Welt blickt mit Bewunderung auf das mutige ungarische Volk.".

Das ergreifendste Dokument der ganzen Revolution war indessen die Nummer der "Irodalmi Ujság" vom 2. November, die -Beiträge der bedeutendsten lebenden Aưtoren Ungarns - viele von ihnen heute im Gefägnis - enthielt.

\section{Nach der Revolution}

Nach der zweiten Intervention der sowjetischen Streitkräfte am 4. November wurden alle während der Revolution gegründeten Blätter sofort unterdrückt $\therefore$. 
Die Freiheitskämpfer mußten heimlich:Flügblätter drukken und verbreiten, um ihre Pröklamationen und Aufrufe an die Offentlichkeit gelangen zu lassen.

Fast während des ganzen Monats November herrschte im Land völliges Chaos. Die einzigen beiden Tageszeitungen, die regelmäßig erschienen, waren "Népszabad: ság" (das offizielle Parteiorgan) und "Népakarat" (Volksstimme - das Sprachrohr der vom Regime beherrschten Gewerkschaften) .....

Die Revolution bezeichnete man immer noch als Revolution, und die Freiheitskämpfer wurden noch Freiheitskämpfer genannt; die Streiks wurden żwàr als ungesetzlich, waber immerhin als psychologisch" verständilich". bezeichnet. .Es 'wurde auch noch zugegeben, daß es die ganze ungarische Nation. war, die auf den Barrikaden stand, ..und daß die Mehrheit dès Völkès das Regime, unter dem es zehn Jahre lang zu leben gezwungen war, verabscheute...

Die kommende Entwicklung begann aber bereits ihre Schatten vorauszuwerfen. Drohungen lösten allmählich die Ermahnungen ab. Einige der "Tagesbefehle".,.die in der Presse veröffentlicht wurden, stammten, offensichtlich von Kommandeuren der in Ungarn stationierten sowjetischen Einheiten. Einen bis dahin unbekannter Zynișmus legte_Ferenc Münnich, der Chef der Streitkräfte und nach Kádár mächtigste Mann des Regimes, an den.Tag, der ausgèrechnet in dem Augenblick, als Tausende von Freiheitskämpfer verhaftet und deportiert w' wurden, sich in einem Zeitungsartikel über die neue "Gesetzlichkeit" verbreitete.

In diesem Zeitabschnitt mußten die Zeitungen versuchen, mit lügen und Verdrehungen Kádárs Handlungsweise zu rechtfertigen und die "brüderliche Hilfe". der Sowjets „ins rechte Licht.. zu stellen...

Während der Revolutionstage erschienen schätzungsweise etwa 50 neue Zeitungen -ùnd Zeitschriften;-darunter einige Parteiblätter, die alle wieder eingestellt wurden. Die wichtigsten davon waren: 1. "Magyar Jövö" (Ungarische Zukunft) - von Universitätsstudenten herausgegeben, wandte sich an die intellektuelle Jugend 
und trat für einen "revisionistischen Kommunismus" ein. 2. "Igazság (Wahrheit) - wurde von jungen Revolutionären herausgegeben, zeigte eine nichtkommunistische Haltung. 3. "Valóság" (Wirklichkeit) - von einer-demokratischen, nichtkommunistischen Gruppe herausgegeben. 4. "Magyar Világ" (Ungarische Welt) — nannte sich "Unabhängige politische Tageszeitung ", war antikommunistisch, betont demokratischer Einstellung. 5. "Magyar Függetlenség“ (Ungarische Unabhängigkeit) — vom Nationalen Revolutionsrat herausgegeben, betont demokratisch. "Kis Ujság“ (Kleines Blatt) — heraúsgegeben von der Partei der Kleinlandwirte, demokratisch, nichtkommunistische Einstellung. 7, Die nationale Bauernpartei veröffentlichte das Blatt "Szabad Szó". - Welche Auflagenziffern diese Blätter erreichten, ist nicht bekannt.

\section{Csepeli U.jság, Csepel, 2.,10́. 1956}

\section{GEDANKEN IN DER DRUCKEREI}

Von. József Kiss

Ich stehe hier in der Setzerei der ehemaligen SzikraDruckerei, wie ein Kind das,sich ins Märchenland verirrt hat. Die Setzer arbeiten schon seit 16 Stunden durchgehend. . Die Hauptstadt schläft. Die Nacht breitet gnädige Dunkelheit über die zahllosen Wunden von Budapest.

Hier aber pulsiert quirlendes Leben. Die Setzer reihen tote Buchstaben aneinander und gieBen das Blei, damit es bis zum Morgen eine lebendige Zeitung werde... weil ohne Zeitungen das Leben, der soziale Fortschritt ebenso stehen bleiben würden als hätten wir kèine Elektrizität.

Kis Ujság, Budapest, 2.'11. 1956

„UNGARN NEUTRAL!" ERKLART NAGY SOWJETBOTSCHATER. "WIR ERBITTEN HILFE DER GROSSEN VIER"

(MTI) - . . Der Ministerpräsident hat über seine Unterredung mit dem sowjetischen Botschafter der Leitern aller in Budapest akkreditierten diplomatischen "Vertretungen mündlich Mitteilung gemacht. Gleichzeitig hat er den 
Generalsekretär der Vereinigten Nationen telegrafisch über die Ereignisse unterrichtet...

\section{Kis Ujság, Budapest, 2.11. 1956}

\section{JANOS KÁDAR VERKUNDET AUFLOSUNG DER MDP} Gründung einer neuen Partei

Der Erste Sekretär des $Z K$ der Ungarischen Arbeiterpartei, János Kádár, gab die Auflösung der Ungarischen Arbeiterpartei bekannt. Innerhalb einer Woche wird unter der Bezeichnung "Ungarische Sozialistische Arbeiterpartei" eine neue Partei gegründet.

\section{Egyetemi Ifjuság, Budapest, 2. 11. 1956}

\section{EINE NEUE UNGARISCHE AUSSENPOLITIK!}

...Folgen wir dem Beispiel unserer finnischen Brüder, die - wenn möglich - mit Diplomatie und - wenn nötig - mit der Waffe die Unabhängigkeit ihres Landes wahren. Das Bündnis mit dem neutralen und befreundeten Osterreich sowie dem uns blutsverwandten finnischen Volk ist von erstrangiger Wichtigkeit, doch vergessen wir daneben nicht die italienischen und französischen Beziehungen, durch die unsere nationale Kultur so sehr bereichert wurde, und auch nicht die Verbindung zu dem für seine Freiheit kämpfenden Brudervolk der Polen und dem neutralen Jugoslawien. Im Geiste des Zusammenschlusses aller Kleinstaaten wollen wir unsere Bruderschaft mit den skandinavischen Ländern, den BeneluxLändern, den Mitgliedern des Balkan-Paktes ausbauen, und auch mit dem Vatikan...

Das Rückgrat unserer ganzen nationalen Außenpolitik soll der Europa-Gedanke sein! Wir müssen an der Arbeit des Europarates teilnehmen und endlich in der geistigen Vorbereitung des vereinten Europa eine Rolle übernehnten, die unserer großen geschichtlichen Tradition würdig ist.

Heute, wo unser Land und die KuIturwelt der glorreichen Heldeñ von Nándorfehérvár gedenkt, am 500. Jahrestag des gewaltigen Sieges János Hunyadis, geloben wir, 
das mit dem Blut unserer Ahnen zurückeroberte heilige Erbe treu zu bewahren: das freie unabhängige Ungarn. Daran mögen uns die Mittagsglocken erinnern, die jetzt. auch wieder im Ungarischen Rundfunk ertönen!

\section{Ost-Dienst, Hamburg, 2. $11 \div 1956$}

\section{TSCHECHOSLOWAKEI. REAKTION: AUF UNGARN}

(OD). - "Wie Ratten", hat "Rudé Právo" (25. "10.) erklärt, seien in Ungarn bürgerliche Elemente aus ihren unterirdischen Löchern hervorgekrochen. Diese Linie -der Berichterstattung wurde eine ganze Woche beibehaltèn und mehrfach eine "Liquidierung" der Rebellen gemeldet. .Millionen Dollars", so behauptete Radio Prag (28. 10.), seien von den USA für Zersetzungstätigkeit in den Volkssdemokrätien ausgegeben wordèn... "Der "Weizen wird in der CSR für ähnliche Ideen (wie in Ungarn) nicht blühen ", sagte der Sénder... . .

\section{Süddeutsche-Zeitung, München; 2.11.1956}

$\therefore$ Der österreichische Kronprätendent Otto von Habsburg wünscht, daß-die "freizuwählenden Vertreter der ungarischen . Nation unser höchstes nationales Symbol, die "Krone des Heiligen Stephan" zurückerhalten. Diese Bitte äußerte er in einem an den amerikanischen Präsidẹnten Eisenhower gerichteten Telegramm. Die Krone wird gegenwärtig von amerikanischen Behörden an einem streng geheim gehaltenen Ort verwahrt.

Englische Rundschau, 2.11. 1956

DER FREIHEITSKAMPF IN UNGARN: WENDEPUNKT DER . GESCHICHTE

News Chronicle, 29. Okt. 1956. ... Die Politik der westlichen. Welt muß den Wandlungen, die sich : vollziehen, Rechnung trạgen... Das ganze weltpolitischè Gefüge hat sich geändert.. Selbst wenn die Russen zu ihrer Politik erbarmungsiloser Unterdrückung zurückkehren, wird die starre Scheidung zwischen Ost- und Westeuropa unreal. sein ... 
Neués Deutschland, Ost-Berlin, 2, 11.1956

UNNGARN UND WIR

Es ist höchst. seltsam, wie sich sämtliche Publikationsorgane des westdeutschen und sonstigen Imperialismus plötzlich für die Revolution begeistern.:. Unter Revolution ist die Umwälzung żu verstehen, die die Machtverhältnisse-in der Richtung des" geselIschaftlichen Fortschritts ändert. Da wir in der Periode des Ubergangs vom Kapitalismus zum. Sozialismus leben, kann eine. Revolution nur eine Umwälzung sein, die zum Sozialismus führt... Wenn aber Leute, die sich Revolutionäre nennen; die Regierung Nagy stürzen wollen und eine Regie-. rüng des Kardinal Mindszenty fordern..., dann ist klar: in Ungarn hat in den letzten Tagen nicht die Revolution, sondern die Konterrevolution Fortschritte gemacht...

\section{Abendzeitung, München, 2. 11. 1956}

SOWJETS UMZINGELN ALLE FLUGPLATZE:

\section{IN UNGARN}

Wien (UP). Radio Budapest gab in den späten Abendstunden des Donnerstag bekannt, daß alle Flugplätze Ungarns von sowjetischen Streitkräften umzingelt worden seien.

Der Sender teilte gleichzeitig mit,.daß die ungarischen Luftstreitkräfte zum Widèrstand gegen die sowjetischen Truppen bereit seien. Die ungarische Regierung̈ habe jedoch befölèn, das Feuer'nicht zu eröffnen ...

Wie Radio Budapest im Zusammenhang mit den neuen Maßnahmen der Sowjettruppen in Ungarn weiter mitteilte, habe die sowjetische Botschaft in Budapest die ungarische Regierung davon in Kenntnis gesetzt, daB Sowjettruppen die Flugplätze umzingelt hätten, " um die Rückführung sowjetischer. Truppen und verwundeter sowjetischer Soldaten zu schützen"... 
Valóságr Budapest, 3. 11. 1956

UNSERE ...NATIONAL"

(Gy. K.) - . . ein Augenzeuge, der Museumsangestellte Mihály. Tavasz, berichtet:

"Am Dreiundzwanzigsten, Dienstag, deklamierten junge Menschen von den Stufen des Museums das, Erhebe dich, Ungar!' Zu Beginn der Kämpfe am Funkhaus kamen dann ein paar Jungen ins Museum und schossen aus dem Fenster, - wohl auf die AVO's, - gingen aber nachts wieder fort. Mittwoch kamen Soldaten, angeblich waren es ÃVO-Leute in Armeeuniformen, durchsuchten das ganze Gebäude und fanden niemand. Trotzdem begannen kurz darauf russische Einheiten das Gebäude aus 15,5 er Geschützen zu beschießen. An der Ecke Museumstraße und anderen Stellen schlugen Phosphorgranaten ein und Feuer brach aus. Jemand aus der Nachbarschaft holte die Feuerwehr... aber die wurde nicht herangelassen, ein Löschwagen erhielt sogar einen Treffer und fiel aus. Am selben Tag noch versuchten ein Löschzug aus. Kecskemét sowie Kadetten einer Offizierschule den Brand zu löschen, durften aber ebenfalls nicht ran. Da sie wuBten, welche Werte hier vernichtet werden, versuchten sie es Donnerstag bei Tagesanbruch nochmal, dabei sețten sie ihr Leben aufs Spiel, weil ringsum stark gekämpft wurde. Eine sowjetische Abteilung unter dem Kommando eines Oberleutnants durchsuchte wieder das Museum und befahl den Feuerwehrmännern, das Löschen sofort einzustellen, weil aus dem Gebäude noch geschossen würde. Wer geschossen haben sollte sagten sie aber nicht. Umsonst versicherten die Museumsangestellten, daß kein Kämpfer im Museumsgebäude sei - und es war auch wirklich keiner drin - umsonst baten sie um Feuereinstellung und Verschonung der unersetzlichen Schätze..." 
Süddeutsche Zeitung, München, 3.11. 1956

DIE UNGARN SAGEN: ES GIBT KEIN ZURUCK MEHR Gestern in Budapest: SZ-Gespräch mit Oberst Maletta (*) vom ungarischen Verteldigungsministerium

Von Raymund Hörhager, z. Zt. Budapest.

‥Maletta (") sagte, ungarische Luftaufklärung stelle zur Zeit fest, um was für Einheiten es sich bei den anrückenden russischen Truppen handele. Die ungarische Armee sei von den Sowjets völlig neu und mit modernstem Gerät bewaffnet worden. Sie könne als die beste Streitkraft der Satellitenstaaten gelten. Erst vor einem Vierteljahr habe die Luftwaffe eine große Anzahl neuester sowjetischer Düsenjäger bekommen.

Maletta, der sein Ministeramt seit.Samstagabend ausübt, betonte, die Armee stehe völlig hinter Nagy. Sie habe auch die Kontrolle über die verschiedenen Gruppen der Freiheitskämpfer. Die Armee billige das Programm des Ministerpräsidenten, das den Austritt Úngarns aus dem Warschauer Pakt sowie die Neutralisierung des Landes und die Annahme westlicher Hilfe vorsehe. Maletta sagte, es sei nicht Nagy gewesen, der die Sowjets zu Hilfe gerufen habe. Aus diesem Grund könne der Ministerpräsident jetzt auch auf die Unterstützung der Armee rechnen ...

Maletta hatte am vergangenen Mittwoch vom Kriegsministerium den Befehl bekommen, gegen die KilianKaserne, in der sich Abteilungen der Freiheitskämpfèr verschanzt hatten, vorzugehen. "Als ich aber sah, daß, diese Revolutionäre keine Banditen "waren, sondern wirkliche Kämpfer für die Sache des ungarischen Volkes, stellte ich mich auf ihre Seite. Ich verlasse den Posten als stellvertretender Kriegsminister nicht eher, als bis wir den Endsieg errungen haben.

Valóság, Budapest, 3. 11. 1956

WIR MUSSEN DEM BEISPIEL DANEMARKS FOLGEN

Im Parlamentsgebäude warten mehrere Abordnungen auf Minister Ferenc Erdei...

("k) Maléter 
„...Wir wollen alles daran setzen, aús Ungain ein zweites Dänemark zu machen." —. Vorläufig sieht der Plan so aus, daß wir unter Beibehaltung des ungarischen Charakters das dänische Landwirtschaftssystemannehmen wollen: weitgehende Unterstützung und Mechanisierung der. selbständig arbeitenden bäuerlichen Betriebe, Errichtung eines Kreditinstituts, Förderung landwirtschaftlicher Genossenschafien usw....

\section{Kis Ujság, Budapest; 3. 11.1956}

KEINE LYNCHJUSTIZ ! RICHTET IM GERICHTSSAAL!

\section{Aufruf des ungarischen Schriftstellerverbands}

Wir fôrdern die. Bevölkerung aúf, die Schuldigen unbeschädigt den Streifén dèr. Nationalgarde oder Honvédàmee zu üb̈ergeben. Persönliche, Rache ist unser unwürdig! $\therefore$ Die Welt bewundert"die. Reinheit unserer Revolution. Es sall kein Makel an ihr haften!

gez.: László Benjámin, Tibor Déry, Pál Ignótus, Gyula Illyés, László Németh, Lörinc Szabó, Áron Tamási, Péter Veres, Zoltán Zẹik.

Mittelbayerische Zeitung, Regensburg, 3./4. 11. 1956 AGGRESSION UND SCHEINHEHLIGE

Von. Jos. 'Lụdw. Hämmerle

... Die britisch-französische Aktion ist um so verantwortungsloser, als sie zu einem Zeitpunkt érfolgt, da mitten in Europa das ungarische Volk um seine Freiheit und Unabhängigkeit ringț. Der Mann auf der Straße wird , zwischen der Freiheit Ungarns und der Freiheit Agyptens keinen Unterschied erkennen. Es erscheint wie ein blutiger Hohn der Geschichte, daß in dem gleichen Augenblick, da: die.Sowjets Miene mạchen, ihren Machtgriff um. die osteuropäischen Länder zu lockern, zwei sogenannte abendländische Mächte mit Bomben und Granaten gegen ein kleines Land vorgehen. Es muß den. Żeitgenossen höchst traurig und nachdenklich stimmen, wenn er sieht, daß auch demokratisch regierte Völker nicht in der Lage sind, etwaigen haß- und giftgeladenen Politikern in den Arm zu fallen"... 
Neues Deutschland, Ost-Berlin, 3.11. 1956

VERRAT AM BUNDNIS DER SOZIALISTISCHEN

STAATEN

Die Budapester Regierung hat erklärt, daß sie den Warschauer Vertrag über Freundschaft, Zusammenarbeit und gegenseitigen Beistand zwischen den europäischen Ländern der ${ }^{-}$Volksdemokratie kündigt. . .

Der Plan Nagys ist Verrat an der Sache des Sozialismus, an der Sache der nationalen Unabhängigkeit seines Staates, der sich auf dem Wege des Sozialismus befánd. Wir hoffen, daß die sozialistischen Kräfte Ungarns einer solchen. Politik noch rechtzeitig entschieden entgegentreten und zu verhindern wissen, daß den imperialistschen Kräften neue Möglichkeitèn zuí Störung des euro. päischen Friedens eröffnet werden...

Münchner Merkur, 3./4. 11. 1956

BUDAPEST HẠLT WIEDER DEN ATEM AN

Lichtermeer in Ungarns Kirchen: Das Land Gedenkt der in grausamen Kämpfen Géfallènen

Von unserem Wiener Korrespondenten Hans Georg Rambousek

... Wilde AlarmmeIdungen jağen einänder. Die allgemeine Aufbruchsstimmung breitet. sich aus. Vor der Hotelkasse balgen sich die Leute, um ihre Zimmer- und Telephonrechnungen zu bezahlen. Kọffer werden geschleppt, Autotüren fallen ḳnallend zu. Konvois werden gebildet. Nur wenige Mutige wollen bis Freitag früh noch ausharren - oder haben sie vielleicht vor der Nachtfahrt an die Grenze, 200 Kilometer über dunkle Straßen, vorbei an sowjetischen Stützpunkten, Angst? Id folge dem Rate meines ungarischen Freundes und nehme die Einladung zur Fahrt in einem Volkswagen an.

Um neun Uhr kommen wir noch einmal ins Hotel "Düna". Die Stadt, in der eineinhalb Hundert Journalisten tagelang einen gigantischen Redaktionsbetrieb und eine Nachrichtenbörse eingerichtet hatten, ist völlig verwandelt. Die meisten Autos sind schon fort. Im Rund- 
funk hört man wieder aufgeregte ungarische Ansagen, dann die Staatshymne, ihre weihevollen Klänge verhallen gerade, da brausen auch wir los.

\section{Magyar Nemzet, Budapest, 3. 11. 1956}

\section{TELEGRAMM UNSERER STUDENTEN IN MOSKAU}

Die in Moskau studierenden ungarischen Universitätshörer ließen dem Revolutionskomitee der Budapester Akademischen Jugend eine Erklärung zukommen, in der sie sich dem Aufruf dès Komitees anschlièßën und mitteilen, 'daß sie gemeinsam mit den Kommilitonen 'in der Heimat für das unabhängige Ungarn kämpfen wollen.

Népakarat, Budapest, 3.11.1956

\section{ZWEI STUNDEN AM RAND DES UMZINGELTEN BUDAPEST}

\section{Von Ferenc Baktai und Gábor. Nógrádi}

- Wo stehen die russischen Panzer?

Der junge Nationalgardist wischt sich die Stirn. Seine Bekleidung ist völlig durchnäBt, er steht wohl schon seit Stunden im Regen. Er gibt unsere Ausweise zurück, dankt höflich, dann erklärt er uns die Lage. In Richtung Mátyásföld sieht man durch den Regenschleier graubraune Flecke in dichtem Nebeneinander. Man könnte sie für Büsche halten, aber die langen Geschützrohre verraten es: ein starker Panzerring ist um den Flugplatz gezogen. Panzer stehen auch am Waldrand - und was sich im Wald selbst befindet, kann man von hier aus nicht feststellen.

- Es sind viele, aber wir passen auf.

Vis-à-vis auf der Landstraße nähert sich ein ungarischer Armeetransport, am Straßenrand steht eine Panzerabwehrkanone, sorgfältig eingeschanzt: Ein Stückchen weiter ein anderes Geschütz, unter der Zeltplane frierende junge Artilleristen. Sie beobachten den Waldrand und verfolgen jede Bewegung der sowjetischen Panzer...

Inzwischen ist die Nacht hereingebrochen, der Scheinwerfer unseres Wagens glitzert über den nassen Beton 
des Flugplatzes - ringsum Panzer, Panzer, Panzer. Zwischen und neben ihnen, an kleinen Feuern, sich wärmende sowjetische Soldaten. Die Besatzer! Das Volk hat sie nicht gerufen - wer sie angefordert hat. ist bereits auBer Landes und versucht nur noch von dort, den heiligen nationalen Aufstand des Volkes als Konterrevolution zu schmähen.

Wir weriden uns wieder der Stadt zu. Die beiden jungen Männer von Rákoshegy, unșere freiwilligen Begleiter, weisen auf die abgerissene Straßenbahnoberleitung und die auch im Dunkel klaffenden Löcher in den Hauswänden.

- Es wird 'ne Menge Arbeit geben! sagt der eine.

Und der andere, jüngere, der Siebzehnjährige, der. in einem Betrieb in Buda als Schlosser beschäftigt ist, fügt leise hinzu:

- Es wäre gut, wieder zu'schaffen.

Valóság, Budapest, 3. 11. 1956

\section{DIE KRAFT DES HUNGERS}

\section{Von Kóti}

Feinkostgeschäft am Museumring. Glitzerndes, glän-. zendes Schaufenster. Feine, verlockende Happen. Vor der Auslage ein junger Mann im schäbigen Anzug. Er ist hungrig. Seine Bewegungen, seine Augen und ganze Halturig verraten, daß er am liebsten durchs Glas langen und alles verschlingen würde...

Neben uns lautes Klirren. Ein Querschläger hat die Scheibe zertrümmert... Mein Freund schaut hin. Leises Flattern der Augenlider... Er blickt auf mich. Ich ermuntere ihn...

"Nein, das nicht! Wir sind keine Räuberbande und kein Pöbel!" Er winkt mir zu und rennt weg. - Vaterlandsliebe, ungarisches SelbstbewuBtsein und Ehrgefühl haben den Hunger besiegt. Damit auf ungarischem Boden keiner mehr Hunger leide. 
Süddeutsche Zeitung, Mün̈chen, 3.11.1956

"KREUZZUG DES GEBETES" FUR OSTEUROPA

Kirchliches und weltliches Rom im Banne der Vorgănge

in Ungarn und Polen

Valóság, Budapest, 3. 11.1956

AUF DEN STRASSEN VON BUDAPEST.

(Gy.) - Wer heutzutage bei uns viele Menschen bei: sammen sieht, weib gleich, daß entweder Zeitungen ver-. kauft oder Lebensmittel verteilt werden, oder ein Augenzeuge Neuigkeiten aus der Provinz erzählt. Doch der Menschenauflauf an der Ecke des "Hotel Astoria" hat einen anderen Grund. Dort steht, unbewacht, eine offene Kiste und die Leute füllen sie mit dem Inhalt ihrer Geldbeutel. Der Schriftstellerverband hat die Kiste mit"folgender Aufschrift dort hingestellt: "Die Reinheit unserer. Revolution erlaubt, daß. wir auf diese Weise sammeIn. Das Geld ist für die Hinterbliebenen gefallener Freiheitskämpfer bèstimmt." - Gestern bis Einbruch der Dunkelheit mußte" die Kiste zweimal geleert werden: 20.000 Forint wurden dort gespendet.

Mittelbayerische Zeitung, Regensburg, 3.11. 1956

UNSER AUS UNGARN ZURUCKGEKEHRTER BERICHTERSTATTER BRACHTE AUCH GRUSSE FÜR REGENSBURG

Eine weitere Ungarnfahrt ist geplant. Unser Berichterstatter und Landwirt Elias Lang lieferten ërste Spenden persönlich ab

... Die Welt ist klein. Die Bestätigung dafür erhielten wir in Budapest. Im Hofe des Rókus-Krankenhauses waren wir von einer Menge Menschen. umringt....,Woher kommt ihr?" Als wir sagten: aus Regensburg, drängte sich eine Frau durch die Menge: "Mein Gott - aus Regensburg", rief sie, "meine Schwester lebt in Regensburg." Es war Frau Somogyi, Budapest VIII, Stahli u. 5. Ihrer Schwester Margarethe Angerholzer - vom Stadt- 
theater bekannt - möchten wir ausrichten, daß alles gesund und die Wohnung in Ordnung sei...

In Budapest hatte man uns die Brücke zur Margareten-: Insel freigekämpft, damit wij unser Ziel, das Rókưs Kórház (Krankenhaus) errẹichen * konnten ... Manchmal flackerte in unserer Nähe ein kurzes Gefecht auf, Schüsse peitschten durch die Dämmerung. Wir waren im achten Bezirk der ungarischen Hauptstadt, in dem noch heiß gekämpft wurde; denn im achten und neunten liegen die Nester der AVO's, der Sicherheitspolizei.

\section{Zwei Augen für das Vaterland}

Eine bildhübsche ungarische Studentin - die zurückliegendèn Tage ununterbrochener Einsatzbereitschaft als Schwester im Krankenhaus hatten an ihr gezehrt, der einstmals weiße Mantel war schmutzig grau und rot vom Blut - führte mich in die Abteilung für Augenverletzungen und kam nach kurzer Zeit mit einer anderen Schwester wieder, die fließend deutsch sprach:' In dem Raume lagen die Jungens, die ihre-Augen der ungarischen Freiheit geopfert hatten. Vielen fehlten beide Augen, manche hatten nur eines verloren. In einer Edke lag ein etwa $17 \mathrm{jähriger} \mathrm{Junge,} \mathrm{eine} \mathrm{Binde} \mathrm{über} \mathrm{dem} \mathrm{Kopf:} \mathrm{blind!} \mathrm{Er}$ hatte gehört, daß wir aus Deutschland gekommen waren. Ich mußte $\mathrm{zu}$ ihm ans Bett treten und dann suchte er mich mit seinen tastenden Händen, und als er meinen Kopf spürte, da drückte er mich nieder zu sich, umarmte mich und aus seinen leeren Augenhöhlen (die Binde hatte sich etwas verschoben) flossen Tränen. Inzwischen war der Chefarzt gekommen und übersetzte mir, was der $17 \mathrm{j}$ ährige mir ungarisch zu sagen hatte: daß er den Dank der gesamten ungarischen Jugend ausdrücken möchte, daß man es gar nicht fassen könnte, daß sich die Welt so für sie interessiert, und daß man weiterkämpfen. werde, bis wieder die Freiheit für Ungarn gekommen sei. Es gab niemanden im Raume, der nicht geweint hätte!-Neben mir stand ein 15jähriger, dem vor wenigen Tagen ein Auge entfernt werden mußte. "Das ist der Stolz unserer Nation. Wir haben nicht gewußt, daß wir so eine Jugend haben", sagte mir der Chefarzt, und legte dem Jungen 
die Hand auf die Schulter, dabei unaufhörlich weinend ...

In meiner Tasche hatte ich mir einige Orangen für die Rückfahrt aufgehoben. Sie brannten darin wie Feuer, und ich gab sie dem Jungen, der sie hilflos in den Händen hielt und nicht. wußte, was damit anzufangen ist. Erst der A.rżt zeigte es ihm. Er kannte keine Orange. Inzwischen war ein vierzehnjähriges Mädchen, blond und mit einer Mützè auf dem Kopfe, mit Brandwunden an den Händen eingeliefert worden. Sie hatte eben einen Panzer erledigt und sich dabei verletzt....

- Gerade die Generation war es, die von den Russen erzogen wurde, der in den Schulen schion jene Kampftheorien beigebracht worden sind, mit denen sie jetzt ihre "Lehrmeister" mit deren eigenen Waffen bekämpft und besiegt.

\section{Valóság, Budapest, 3. 11. 1956}

\section{UNO-TRUPPEN AN UNGARNS GRENZEN!}

....Ein junger Budapester Freiheitskämpfer konnte in der Nacht vom Donnerstag auf Freitag mit einem Pkw bis zur österreichisch-ungarischen Grenze fahren. Dort sprach er mit den UNO-Truppen, die sich bereits an der Grenze befinden. Wie ihm mehrere englische und amerikanische Soldaten erzählten, stehen die UNO-Truppen in Bereitschaft, werden aber ohne ausdrückliche Aufforderung Nagys ungarischen Boden nicht betreten . .

\section{Süddeutsche Zeitung, München, 3. 11. 1956}

\section{UNGARNS KAMPF UM DIE FREIHEIT}

\section{Briefe an die Süddeutsche Zeitung}

Verantwortlich an dem Blutbad in Ungarn ist nicht nự die Sowjetunion, sondern auch die freie Welt. Nach der Evakuierung Osterreichs war die Sowjetunion laut-Friedensvertrag verpflichtet, auch Ungarn und Rumänien zu verlassen. Wenn die Sowjetunion diese Länder damals verlassen hätte, wäre es zum jetzigen Aufstand in Ungarn nicht gekommen ...

Die Regierungen der freien Welt, die Vereinten Nationen müssen die Sowjetunion auffordern, ihre Truppe von 
der Sowjetzone Deutschlands und vön den anderen Ostländern Europas zurückzuziehen bis übër die Ostgrenze Pólens und Rumäniens von 1938. Gleichzeitig müssen die Alliierten Westdeutschland verlassen. Internationale Kommissionen sollen freie Wahlen in den Ostländern beaufsichtigen und zur Erhaltung des Friedens dort bleiben, bis der Friede gefestigt ist.

Hermann Sitte, Ludenhausen (Obb.).

\section{Der neue Kurs in Warschau}

Es ist.m. E. völlig verkehrt, etwa zu hoffen; Rußland werde seinen. Einfluß auf Polen weitgehend verlieren. Ändern wird sich nur die Art... - an Stelle einer Hörig-keit tritt eine freiwillige Mitarbeit... Ein solcher gewandelter Kommünismus wird jedoch anders als bisher imstande sein, auch westlich denkende Menschen für sich zu gewinnen, die bisher wegen der Grausamkeit gewisser. Revolutionsnachwehen abgeschreckt wurden. Nachdem die Revolution ihre Kinder gefressen hat, schicken die. Enkel sich an, die Früchte der Revolution zu ernten. Und es wird für den. Westen sehr schwierig sein, gegen diesen neuen Kurs erfolgreich anzukämpfen.

Gerhard Doehring, München, Zaunweg. 14:-

Mittelbayerische Zeitung, Regensburg, 3./4.11. 1956 GEISTIGE NEUORDNUNG DER WESTLICHEN WELT

Regensburg (ea). Als Professor. Köhler (Berlin) seine Vorträge: "Die andere Welt" im Rahmen des Ostsemi-. nars vorbereitete, mag er kaum geahnt haben, welche erschreckenden praktischen Beweise seiner. Interpretation der sowjetischen Ideologie die jüngsten Ereignisse für ihn bereithalten würden. Die Politik im sowjetischen Herrschaftsbereich erhebt den Anspruch; aus einer Weltanschauung heraus gestaltet $\mathrm{zu}$ werden, eine Ideologisierung der Pólitik also, die unter dem Schlagwort: "Einheit von Theorie und Praxis" läuft...

$\therefore$ Verbindlich für das praktische Handeln ist einzig und allein das Ziel. Dazu wird die Ideologie mit allen Mitteln im Bewußtsein der schon beherrschten Menschen 
verankert. Von ihr werden die Lebensbedingungen und -verhältnisse geformt. Der wunderbare Eintritt des Zustandes der klassenlosen Gesellschaft wird einen allgemeinen Frieden realisieren, da die bisher durch den ständigen Klassenkampf antagonistische Geschichte ihr Ende erreicht haben wird. Die klassenlose "Gesellschaft ist eine Erwartung entgegen allen Erfahrungen der bisherigen Geschichte. Daß diese Paradoxie Glauben finden konnte, liegt einerseits in ihrer emotionalen Verwurzelung, andererseits trat sie zu einem Zeitpunkt hervor, der durch die Unsicherheit des Menschen gekennzeichnet war. Der Mensch hatte Gott als seine tragende Mitte verloren. Um dem Menschen in dieser Situation die Flucht in die $\mathrm{Zu}-$ kunft noch glaubwürdiger anbieten zu können, mußte der Schrecken in der Gegenwart zum letzten gesteigert werden, eine Rechtfertigung des sowjetischen Terrors übrigens, die schon in der Ideologie verankert ist...

Györi Munkás, Györ (Ráab), 4.11.1956

RUSSISCHE TRUPPEN VERHINDERN TRANSPORT AUSLANDISCHER HILFSSENDUNGEN

Neues Deutschland, Ost-Berlin, 4.11.1956.

FASCHISTEN WERDEN NACH UNGARN GESCHLEUST Westen schickt Verstärkung für Konterrevolution.

Bonner Flugzeuge im Einsatz. Appell an die Werktätigen Ungarns

Wien (ND). Wie die "Osterreichische Volksstimme" meldet, wird für die konterrevolutionären Gruppen in Ungarn ständig Verstärkung. über die österreichische Grenzé géschleust...

Frankfurter Allgemeine Zeitung, 5.11.1956 MINDSZENTY: DIE RUSSEN ENTSCHEIDEN Der letzte Appell des Kardinals. Hilferuf an Amerika

"Unser Kampf ist keine Revolution gewesen, sondern ein Befreiungskampf. 1945 ... ist das Regime gewaltsam aufgebaut worden... Dieses Regime ist vom gesamten 
ungarischen Volk beiseitegefegt worden ... Der Unabhängigkeitskampf wurde geführt, weil die. Nation ihre Lebensform selbst bestimmen will ... Es müssen neue Wahlen unter Beteiligung aller Parteien und ohne jedes Mißtrauen organisiert werden. Diese Wahlen mögen unter internationaler Kontrolle abgewickelt werden.

Politik ist jetzt eine sekundäre Angelegenheit. Unser Anliegen ist es 'gegenwärtig, die Existenz der Nation und unser täglich Brot zu sichern... Wir wollen eine Gesellschaft ohne Klassen und einen legalen Rechtsstaat, ein Land, das die demokratischen Errungenschaften auf der Grundlage des durch die Interessen der Gesellschaft und des Rechts eingeschränkten Privateigentums weiter entwickelt"...

Mittelbayerische Zeitung, Regensburg, 5. 11.1956

EIN ABGEKARTETES SPIEL: KOMMUNISTISCHE . GEGENREGIERUNG" BITTET RUSSISCHE TRUPPEN 'UM WIEDERHERSTELLUNG VON "RUHE UND ORDNUNG”. Sowjetpanzer walzen Ungarns Freiheitstraum nieder. Moskau schlägt erbarmungslos $2 u$, um seinen Herrschaftsbereich $2 u$ sichern. Die Regierung Nagy auseinandergefallen. Kardinal Mindszenty in die USA-Botschaft.geflüchtet. Radio Budapest schweigt. Amateur-Sender flehen: Helft uns - schickt Truppen! UN-Generalversammlung einberufen

Neue Zürcher Zeitung, 5.-11. 1956

"KRIEGSLIST" UND BRUTALE GEWALT

Die Verhandlungen über den Rückzug waren eîn russisches Täuschungsmanöver

...Mit einer verblüffenden Genauigkeit wiederholte sich Samstagnacht das gleiche zynische Spiel, wie es im Frühjahr 1945 gegenüber den Vertretern. der polnischen rechtmäßigen Führung und der polnischen Widerstandsbewegung angewandt wurde. Damals luden die Vertreter Marschall Schukows 15 polnische Führer der antinazistischen Widerstandsbewegung mit General Okulicki an der Spitze am 28. März 1945 in eine Villa in Pruszkow in der Nähe von Warschau zu, angeblichen Verhandlun- 
gen ein und nahmen sie dort in Haft. Die meisten von ihnen sind bis zum heutigen Tage nicht zurückgekehrt, mehrere starben in den sowjetrussischen Gefängnissen ...

\section{Süddeutsche Zeitüng, München, 5.11.1956}

\section{"UNSER V VOLK FURCHTET DEN TOD NICHT"}

Der letzte Mann am Fernschreiber in Budapest schildert die Tragödie im Morgengrauen. "Unsere Jungen stehen auf den Barrikaden und rufen nach Munition." Radio Budapests letzte Sendung: Die Nationalhymne

Um 8.30 Uhr gab der "Fernschreiber der Zeitung "Szabad Nép" folgende Meldung: ,.... Die Mensichen springen auf die Panzer, werfen Handgranaten und verschmieren die Sehschlitze. Das Volk fürchtet den. Tod nicht. Es ist nur schade, daß wir nicht lange Widerstand leisten können." Nach einer kurzen Pause hieß es: ,Jetzt schießen sie wiederl Wir erhalten Treffer. Die Panzer kommen näher, das schwere Artilleriefeuer hält an... Seid nicht böse über meinen Berichtstil. Ich bin aufgeregt. Ich möchte wissen, wie das ausgeht. Ich möchte schießenn, aber ich finde bis jetzt kein Ziel. Ich werde solange wie möglich weiter berichten. Was tun die . Vereinten Nationen. . .?"

Als der Szabàd-Nép-Rédakteur von AP."Wien später informiert wurde, daß Kardinal Mindszenty in der amerikanischen Gesandtschaft Zuflucht gefunden hat, fragte er erbittert: "Ist das alles, was die Amerikaner erreicht haben?"

Er.berichtet weiter: „Sowjetische Flugzeuge schießen mit Bordkanonen. Wir wissen aber nicht wo, wir hören -und sehen es. Es werden weiter 'Barrikaden gebaut. Das Parlament. hier in unserer Nähe ist von Panzern umringt. Uber uns fliegen Flugzeuge, man kann sie nicht zählen, es sind zu viele. Jetzt kommen die Panzer in großen Rudeln. Sie schießen auf unser Gebäude. Sie heulen und rasseln so laut, daß man sich kaum noch verständigen kann."

„Hier wird gerade das Gerücht verbreitet, daß die amerikanischen Truppen in zwei Stunden bei uns sein 
werden ... Grüßt meine Verwandten in England, grüßt sie herzlich. Wir sind wohlauf und kämpfen. Es ist jetzt $9.20 \ldots$.

Um 10 .Uhr melden die österreichischen Telephonzentralen, daß alle Telephonverbindungen mit. Ungarn unterbrochen sind...

\section{Abendzeitung, München, 5.11. 1956 \\ DER SCHULDIGE \\ von Rudolf Heizler}

Das Herz krampft sich zusammen, wénn wir an Ungarn denken. $\therefore$ Ein Nervenkrieg ohnegleichen. wird gegen uns neben dem heißen Krieg geführt. Da verkündet eine Nachrichtenagentur den Rücktritt Nassers. Wenige. Stunden später entpuppt sich die Meldung als ein übles Börsenmanöver, gemacht, um einigen Hyänen Millionengewinne zu bringen, während Tausende für die Freiheit sterben müssen. Eine andere Nachrichtenagentur berichtet von einer "amtlichen Moskauer . Erklärung", dié Groß̣britannien und die Bundesrepublik beschuldigt $_{i}$ "Hunderte von Militärpersónen nach Ungarn geflogen zu. haben". Am nächsten Tag, zwanzig Stunden später, entpuppt sich diese beunruhigende Nachricht als .Hörfehler" des britischen Rundfunks. In Wahrheit war diese amtliche Erklärung ein Zitat aus einer Wiener kommunistischen Zeitung. Und noch ein drittes.Beispièl für diesen Nervenkrieg. Der Staạtssekretär im britischen Versorgungsministerium sagte am Freitagabend in einer öffentlichen Redé, man werde in wenigen Stunden am Suezkanal landen. Der Samstag und Sonntag vergeht ohne Landung. Der Herr Staatssekretär erklärt daraufhin,. das sei nur so eine Redewendung von ihm gewesen.

Börsenmanöver - Redewendungen - Hörfehler? Nein! Nervenkrieg, um uns in Angst und Schrecken zu versetzen. Wir müssen uns damit abfinden, wir leben mitten im Krieg. Aber wir müssen unsere Ruhe bewahren. Wir werden eines. Tages, vielleicht schon bald, von den Schuldigen Rechenschaft fordern. 
Mittelbayerische Zeitung, Regensburg, 5. 11. 1956 .

\section{BLUT, TRANEN UND. RUINEN}

von Jos. Ludw. Hämmerle

Jedem Menschen dreht sich das Herz.im Leibe um vor Entsetzen und Kummer ... Die neu an die Oberfläche geschwemmten politischen Repräsentanten, ganz gleich welcher Farbe, mußten sich klar darüber sein, daß eine Weltmacht wie Moskau gewisse Beleidigungen-und Ängriffe gegebenenfalls schlucken kann, daß sie sich aber nicht wie ein mịliebig gewordener Hausknecht vor den Augen der schadenfrohen Welt mit Fußtritten aus dem Hause werfen lassen kann. Jeder Vertrag, und sei er noch so penetrant durch Gewalt erzwungen gewesen, hat seine Kündigungsfrist und ist mit der Notwendigkeit maßvoller. Verhandlungsbereitschaft gekoppelt. Es sei denn; der kündigende Partner sei stark genug und verfügte über so gewaltige Bündnismächte, daß er sich einen schroffen Bruch leisten kann. In der heutigen Welt kann dies außer den beiden großen Weltmächten keine andere Macht auf der Welt.

Politik ist und bleibt die Kunst des Möglichen. Imre Nagy und seine Leute waren entweder unfähig, den blinden Freiheitssturm ihrer Landsleute vor einem Amoklauf in den Tod zurückzuhalten, oder sie waren zu feig und gewissenlos, sich dem Druck der Erregung entgegenzustellen... Wie dumm oder zynisch dieser Nagy sein muß, beweist nebenbei die Tatsache, daß er sich mit seinen Hilferufen auch an - Großbritannien, und Frankkreich gewendet hat, zwei Mächte, die in den vergangenen Tagen die ganze westliche Welt durch ihren Uberfall auf Ägypten unheilbar kompromittiert haben ...

Ein klein bißchen Hirn für weltpolitische Zusammenhänge hätte den Budapester Regierungsleuten sagen müssen: in einem Augenblick, da durch den LondonPariser Agyptenskandal die Weltenuhr bedrohlich anfängt zu schlagen, den Russen zuzumuten, von einer .Stunde zur andern überstürzt ihr wichtigstes europäisches Vorfeld kampf- und preislos zu räumen, ist doch wohl ein Gipfel von Naivität... 
Mittelbayerische Zeitung, Regensburg, 7.11. 1956

-Wien (up/lb) . . . Der Budapester Rundfunk bewahrte sein Schweigen über die tatsächlichen Vorgänge auch am Dienstag. Während die letzten. Widerstandszentren von den sowjetischen Truppen niedergekämpft wurden, brachte der Sender vorwiegend Tanz- und Jazzmusik sowie Operetten- und Zigeunerweisen. Die wenigen Nachrichtensendungen beschränkten sich im wesentlichen auf die Verlesung von Glückwünschen an die von den Sowjets eingesetzte Regierung Kádár, die von dem Sowjetzonenpräsidenten Wilhelm Pieck, dem französischen KPChef Maurice Thorez und führenden Kommunisten anderer Länder nach Budapest gesandt wurden...

Die Welt, Hamburg, 7.11.1956

DAS DRAMA DES VERLORENEN GESICHTES von Hans Zehrer

Auf allen Straßen der Welt demonstrieren die Menschen, Bürger, Arbeiter und Studenten. Vor allem *die Jugend ${ }_{r}$ die damit öffentlich zum Ausdruck bringen will: dies ist keine Welt, in der wir leben wollen, dies ist eine verruchte Welt...

Mittelbayerische Zeitung, Regensburg, 7.11.1956

PAPST PIUS: UNGARNS BLUT SCHREIT ZUM HERRN Neue Enzyklika an das gesamte katholische Episkopat. Aufforderung zum Gebet

Vatikanstadt (dpa). Zum dritten Male innerhalb von zehn Tagen wandte sich Papst Pius XII. mit einem Rundschreiben an das gesamte katholische Episkopat... "Die Worte, die Gott an Kain richtete: Laut schreit aus der Erde zu mir das Blut deines Bruders (Gen. 4, 10), haben auch heute ihren vollen Wert; und so schreit das Blut des ungarischen Volkes zum Herrn. Während er als gerechter Richter die Sünden der einzelnen oft. erst nach dem Tode bestraft, trifft er, wie die Geschichte lehrt, die Regierenden und die Nationen wegen ihrer Ungerechtigkeit manchmal schon in diesem Leben"... 
Mittelbayerische Zeitung, Regensburg, 7.11.1956

\section{DEPRESSION UND .VERZWEIFLUNG IN DER ZONE} vön unšerem Berliner Büro

Berlin (pvh). Die blutige Niederschlagung der unga-rischen. Freiheitsbewegung und die Machtlosigkeit der UN haben in der Zone tiefe Depression und Verzweiflung ausgelöst. Der Flüchtlingsstróm; der in den vergan-. genen Wochen angesichts der beginnenden Liberalisierung im Ostblock merklich zurückgegangen wàr, ist seit gestern wieder sprunghaft angeschwollen. In West-Berlin werden die inzwischen stillgelegten :Auffanglager wieder hergerichtet... .

Süddeutsche Zeitung, München, 8.11.1956. SOLIDARITAT INNERHALB DER NATO GEFORDERT

In der Sendung Politik aus erster Hand des Bayerischen Rundfunks sagte Strauß am Mittwochabend, niemand könne garantieren, daß die von der Sowjetunion eingesetzten gewaltsamen Mittel nicht eines Tages auch außerhalb des derzeitigen sowjetischen Machtbereiches eingesetzt würden. Die erschütternden Vorgänge in. Ungarn sollten jedermann in der Bundesrepublik Veranlassung geben, ernsthaft seine Einstellung zur Frage der Verteidigung zu prüfen :...

Nationalzeitung, Basel, 8. 11.1956 TITOS DILEMMA

W. B. Marschall Tito hat sich mit seinen. engsten politischen und militärischen Mitarbeitern auf seine Adriainsel Brioni zurüdkgezogen, um in vollkommener Weltabgeschiedenheit darüber zu beraten; was die jüngsten Vorgänge in 'Ungarn für Jugoslawien bedeuten und welche Konsequenzen aus ihnen gezogen werden müssen ...

Die Grausamkeit dieses Dilemmas besteht darin, daß Tito weder die russische Intervention noch den Aufstand des ungarischen Volkes billigen kann, ohne sich selbst zum Tode zu verurteilen... 
Süddeutsche Zeitung, München, 8. 11: 1956

VERZWEIFELTER WIDERSTAND IN UNGARN

\section{Heftige Schlacht um die Industriestadt Dúnapentele. 200000 Sowjets mit 4600 Panzern im Einsatz}

Wien (UP). Trotz ihrer gewaltigen Ubermacht ist es den sowjetischen Truppen noch nicht gelungen, den letzten Widerstand der ungarischen Freiheitskämpfer zu brechen- Seit den frühen Morgenstunden des Mittwoch tobt eine heftige Schlacht um die Industriestadt Dunapentele südlich von Budapest....

In höchster Verzweiflung richteten die Verteidiger vonDunapentele abermals dèn Aufruf $:$ an die freie Welt, ihnen żú hélfen. Sie hätten bisher auf ihre Bitten weder Antwort noch Hilfe erhalten. Wörtlich appellierte der. Sprechẹ "im Namen aller aufrechten Ungarn" an die Welt: "Ist Euch die Freiheit heilig? Uns ist sie heilig. Habt Ihr Frauen und Kinder? Wir haben sie auch. Habt Ihr Verletzte? Wir auch. Sie bluten aus hundert Wunden und wir haben kein Verbandsmaterial und keine Medikamente... Was sollen wir unseren Kindern geben, wenn das letzte Stück Brot gegessen ist? Bei allem, was Euch heilig ișt, helft uns. Hört Ihr nicht die "Toten klagen? Glaubt Ihr nịcht, daß sie diejenigen anklagen, die die Macht gehabt hätten, zu helfen und die nichts getan haben? Wir hören, daß in Ägypten die Feuereinstellung befohlen ist, daß eine UN-Polizeitruppe dorthin kommt. Warum kann nicht das Gleiche für Ungarn geschehen? ....Wollt Ihr, daß unser Glaube an das Gewissen der Welt ausgelöscht wird? Dies ist unsere Botsschaft an den wiedergewählten Präsidenten der USA: Falls.er in seiner neuen Präsidentschaft die Partei der Unterdrückten ergreift, soll jeder seiner Schritte gesegnet sein. 'Wir haben noch keine Antwort auf unseren Aufruf an die UN, daß Dunapentele zur offenen Stadt und Zentrale -des Internationalen Roten Kreuzes erklärt werden soll. Warum antwortet uns die Welt nicht?"

Aus Berichten von Flüchtlingen und diplomatischen Gewährsleuten geht hervor, daß die Sowjetunion Truppen in Stärke von 2.00000 Mann und 4600 Panzern zur 
Niederwerfung des Aufstandes nach Ungarn geschickt hat...

Neues Deutschland, Ost-Berlin, 8. 11.1956

UNGÄRN FASST FESTEN TRITT

Leben kommt in normale Bahnen. Produktion läuft an. "Szabad Nép“ erscheint wieder. Große Hilfe Chinas

Budapest ( $A D N$ ND) ... Die Zeitung "Szabad Nép" ist am Dienstag als Zentralorgan der Ungarischen Sozialistischen Arbeiterpartei erschienen. Sie veröffentlicht die Dokumente der neuen Regierung und den: Appell des Weltgewerkschaftsbundes. Bedeutenden Platz räumt die Zeitung den Ereignissen in Agypten ein. In einem über Radio Budapest verlesenen Leitartikel der Zeitung zum 39. Jahrestag der Großen Sozialistischen, Oktoberrevolution heißt es: "In schweren Stunden gedenken wir des 17. November 1917, der ruhmreichen Tage der Großen Sozialistischen Oktoberrevolution. Dieser Sieg des Proletariats hat vom Standpunkt der Arbeiterklasse der ganzen Welt gewaltige Bedeutung. Darum ist den Arbeitern nichts teurer als der Staat, der aus der Großen SoziaIistischen Oktoberrevolution entstanden ist ${ }^{\prime \prime}$...

Neue Zürcher Zeitung, 8. 11.1956

TOD EINES FRANZOSISCHEN REPORTERS

Paris, 7. November. ag (AFP). In Paris starb am Mittwoch der-Reporter und Photograph der Zeitschrift "ParisMatch ${ }^{\prime}$ Jean-Pierre Pedrazzini an den Folgen einer Verwundung, die er in Ausübung seiner Berichterstatterpflicht in den ersten Tagen der Freiheitsbewegung in Budapest erlitten hatte.

Neues Deutschland, Ost-Berlin, 9. 11. 1956.

DIE VERTEIDIGUNG VON FREIHEIT UND FRIEDEN Palmiro Togliatti

... Und das, was geschehen muBte, war die logische Folge des Klassenkampfes. Es trat ein Augenblick ein, wo man, meines Erachtens, die Sowjetunion hätte ver- 
urteilen können, und zwar in dem Falle, wenn sie sich übrigens zum zweitenmal zu Hilfe gerufen - nicht eingemischt und diesmal die ganze Kraft eingesetzt hätte...

\section{Arbeiterzeitung, Wien, 10.11.1956}

- SARTRE WASCHT SICH DIE HANDE

Paris. Der in den letzten Jahren eng mit den Kommusten verbundene Schriftsteller und Philosoph Sartre, Verfasser des Stückes "Die schmutzigen Hände", hat in einem Interview mit der Wochenzeitung "L'Express" festgestellt, er müsse das sowjetische Vorgehen in Ungarn rückhaltlos verurteilen. Sartre erklärte weiter, er würde seine Verbindung mit sowjetischen Schriftstellern und der französischen Kommunistischen Partei abbrechen.

Die gegenwärtige sowjetische Regierung habe ein Verbrechen begangen, und der Kampf zwischen den einzelnen Gruppen der führenden Kreise habe einer Fraktion die Macht gegeben, die heute den Stalinismus noch übértrifft, den sie eben angeklagt hat.

"Ich breche also meine Verbindungen mit meinen Freunden, den sowjetischen Schriftstellern, die das Massaker in Ungarn nicht verdammen oder nicht verdammen können, bedauernd, aber vollständig ab. Man kann nicht länger Freundschaft für die führende Clique der sowjetischen Bürokratie fühlen: dort herrscht der. Terror."

Von den Parteiführern der französischen Kommunisten erklärte Sartre: "Jeder ihrer Sätze, jeder ihrer Gesten ist das Ergebnis von dreißig Jahren Lüge und Arterienverkalkung. Ihre Reaktionen sind die von unverantwortlichen Menschen."

Vertriebenen-Anzeiger, München, 10. 11. 1956 ANKLAGE AUF MORD!

(NYT) Wir klagen die Sowjetregierung des Mordes an ...

Der Tag der Schande ist vorbei. Die niederträchtige Tat ist getan. Die meisten heldenhaften Freiheitskämpfer sind tot. Aber die Sache der Freiheit lebt, und ist stärker als je zuvor, getränkt mit dem Blute jener, die als Märtyrer für die Freiheit fielen. Das ungarische Volk wird 
niemals vergëssen. Wir werden nicht vergessen. Und aus. Haß und Tränen steigt unser Schwur, den Kampf vorwärtszutragen, bis die Freiheit triumphiert.

Mittelbàýerische Zeitung, Regensburg, 10/11.11:1956 DOMSPATZEN . SANGEN IN WESEL EINEN BITTGOTTESDIENST · FUR UNGARN

\section{"Ihr schönes Singen dringt. in die Herzen und hinterläßt einen bleibenden Eindruck"}

abr. In der Martinikirche von Wesel sangen -unsere "Domspatzen" auf ihrer Herbstreise am Donnerstag einen Bittgottesdienst für das leidende Ungarn. 'Teile aus der Messe "Lauda Sion", "Kompositionen von Bruckner, Mozart und anderen Meistern trugen sie dabei vor. Nach dem Gottesdienst blockierten Hunderte- von begeisterten Weseler Zuhörer den weißblauen Omnibus der Regensburger .Sänger, um ihrer Freude Ausdruck zu geben. Es fiel dem Fahrer des Omnibusses inmitten der Menschenmenge schwer, Gas zu geben für die Weiterfahrt nach Borken...

Süddeutşche Zeitung, München, 10.11.1956

DIE WELTLAGE IM. MILCHLADL

Im Auditorium maximum endet gerade eine Vorlesung. über Staatsrecht. Wir sprechen einen Studenten an. Sofort ist eine lebhafte Diskussion im Gange. Die Freiheitskämpfer in Ungarn seien durch den Angriff auf Agypten verraten worden, das ist die Ansicht fast aller Umstehenden . . .

Kaum einer der Befragten wollte seinen Namen nennen. Ein Taxichauffeur weigerte sich, auch nur seine Meinung bekanntzugeben. .Geh laßts ma doch mei Ruah. Wenn i Eahna heut mei Meinung sag und morgn kummit da Ruß, nacha häd as schwarz auf weiß.".

In der Hofbräuhausśchwemme sitzt ein 62jähriger Dachdecker. Er schiebt seinen Maßkrug beiseite und zieht bedächtig an seiner- Virginia. Dann sagt er: ,So lang's bloß de andern d'Köpf dahaun, laßt mi des koid. D'Hauptsach, i hob mein Leberkas, mei Bier und an Rauch." 
Der Zeitungsverkäufer in der Neuhauser Straße erkiärt, er habe noch keine rechte Meinung, außer der, daß - er ein so gutes Geschäft wie, in den letzten Tagen sein Leben lang noch nicht gemacht habe. Vier von fünf be-

- fragten Hausfrauen . versichern: "Seit dem Aufstand in Ungarn und dem . Uberfall auf Agypten lesen wir jede politische Meldung in der Zeitung, sogar die Leitartikel.,"

"Ham 'S as in der Żeitung net gsehn, wia beim' Aufstand in Budapest russische: Soldaten tot auf der Straßn glegn san? Daß sich des de Russn net gfảlln lassen; . kann. ma verstehn", sagt eine Milchfrau am Wiener Platz:

"Richtig Angst". hatte das neunzehnjährige Fräulein an der Kasse eines Selbstbedienungsladens. „Wie unsere Warenregale immer leerer worden sind, hab ich gwußt, daß ein Krieg droht." In dieser Meinung. daß nämlich eine Katastrophe drohte, waren sich alle Befragten einig.

\section{New York Times, 12.11.1956}

\section{KOEXISTENZ IN BUDAPEST}

Auf dem XX. Kongreß der KPSU in Moskau, im Februar, sagte Vizepremier Anastas I. Mikojan: "Unsere Feinde behaupten, daß wir lletztlich doch für den Krieg sind, weil wir den Kommunismus mit gewaltsamen Mitteln über die Wèlt ausbreiten wollen. Sie argumentieren, daß wir zur Zeit noch nicht gerüstet sind und so lange eine friedliche Koexistenz wünschen, bis wir ihnen den Kommunismus mit Waffengewalt aufzwingen können... Das ist eine Verleumdung unserer Politik. Der Kommunismus ist nicht ạuf Krieg angewiesen. Er ist' ein Gegner des'Krieges. Die kommunistische Idee wird auch ohne Krieg siegen."

In einer offiziellen sowjetischen Erklärung aus Moskau vom vergangenen Samstag heißt es: "... Das sowjetische Volk sympathisiert mit jenen Völkern, die das béschämende Joch des Kolonialismus abschütteln und ihre Unabhängigkeit erringen wollen." 
Süddeutsche Zeitung, München, 12.11.1956

DEMOKRATIE LASST SICH NICHT ERZWINGEN, SAGT NEHRU

Indiens Ministerpräsident zu den Vorgängen in. Ungarn

(SZ) Indiens Ministerpräsident Nehru, dessen Delegierter in der UN-Vollversammlung zusammen mit der Sowjetunion gegen die amerikanische Forderung nach freien Wahlen in Ungarn stimmte, erklärte die indische Haltung mit seiner Ansicht, eine demokratische Staatsform könne man nicht erzwingen, weil dies undemokratisch sei...

\section{Süddeutsche Zeitung, München, 13.11. 1956.}

\section{RADIO FREIES EUROPA ERHEBT PROTEST}

München (dpa). Gegen die in den letzten Tagen wiederholt aufgestellten Behauptungen, die ungarischen Freiheitskämpfer seien durch die Sendungen von Radio Freies Europa immer wieder aufgeputscht worden, legte der Leiter der ungarischen Abteilung des Senders, Andor Gellért, scharfen Protest ein. Gellért und der Leiter der Presseabteilung, Ernest Langendorf, erklärten übereinstimmend, daß sie einer Uberprüfung der Sendungen durch die Bundesregierung mit Ruhe entgegensähen. Radio Freies Europa habe in dreistündigen Sendungen, die sechsmal am Tage nach Ungarn ausgestrahlt wurden, lediglicti Nachrichten verbreitet und auf alle Kommentare verzichtet. Man habe die Sympathiekundgebungen der ganzen Welt und die Pressestimmen der westlichen Welt dem kämpfenden ungarischen Volk wohl zur Kenntnis. gebracht, habe aber niemals Aufrufe wie "Erhebt euch, wir helfen euch!" gesendet.

Neue Zürcher Zeitung, 14.11.1956

DIE REGIERUNG KADAR GEGEN INTERNATIONALE BEOBACHTER

New York, 13. Nov. (United Press). Die kommunistische ungarische Regierùng unter Kádár hat am Montag die Entsendung von Beobachtern der Vereinigten Nationen nach Ungarn abgelehnt... 
Der Spiegel; Hamburg, 14.11. 1956

DIE UNGARISCHE TRAGODIE

Von Jens Daniel

... Die Aufständischen haben der Regierung Nagy keine Chance gegeben, den Sowjets als Regierung gegenüberzutreten. Sie hatten ihrerseits auch keinen Mann, den sie an die Stelle von Nagy hätten setzen können oder wollen - es sei denn, den Märtyrer-Kardinal Mindszenty, der für die Sowjets die Verkörperung der ihnen feindlichen Mächte darstellt. Dieser einflußreiche Kirchenfürst hat noch neun Stunden vor dem russischen Uberfall die Regierung Nagy, die flehend um Autorität bat, über den Budapester Rundfunk für illegetim erklärt - wahrlich ein Schulbeispiel schwerer politischer Schuld...

Mittelbayerische Zeitung, Regensburg; 14. 11. 1956

IM DIENST DER UNGARN-HILFE

München (lb). Ubèr 30 -Filmprominente; darunter die Schauspielerinnen Cornell Borchers und Lieselotte Pulver, und die Schauspieler Bernhard Wicki und Hans Richter, sammelten bei einer Nachtvorstellung in einem großen Münchner Kino zugunsten der Ungarn-Hilfe. Die Sammlung ergab 1816 D-Mark.

Neue Zürcher Zeitung, 16. 11. 1956

AUSWIRKUNGEN DER UNGARISCHEN REVOLTE IN SIEBENBURGEN

Wien, 14. Nov. ag (Reuter). Aus gewöhnlich zuverlässigen Quellen verlautete am Mittwoch in Wien, in Siebenbürgen, das einen starken ungarischen Bevöikerungsteil hat, sei es zu Unruhen, Verhaftungen und antisowjetischen Demonstrationen gekommen...

Hamburger Abendblatt, 17. 11. 1956

DANK FUR UNGARN

Von Ernst Friedländer

... Von so mancher Seite bekommt jetzt Ġomulka das beste Zeugnis ausgestellt. Er habe es sehr viel klüger, 
sehr viel geschickter angestellt: als die. Ungarn... Erst einmal Titoismus, dann sehr-viel später vielleicht Demokratie, das sei die logische Reihenfolge. Dies alles ist recht klug. Es mag sogar, im Sinne der politischen Erwägung "richtig" sein. Aber kann man, darf man dem ungarischen Volke jetzt, gleichsam mit erhobenen Zeigefinger, das Zeugnis ausstellen: Ihr habt alles falsch gemacht, ihr hättet es besser machen müssen? ...

Ungarn hat der Welt gezeigt, was es wirklich will: nicht den nationalen Kommunismus, sondern die ganze Freiheit. Es hat dies stellvertretend mitgezeigt für.alle seine Nachbarvölker in Osteuropa. Und das ist eine Tat, die weiterwirken wird in der Weltpolitik ...

\section{Abendzeitung, Münchẹn, 17./18. 11: 56}

\section{OFFENER BRIEF AN EISENHOWER}

"Sprechen Sie endilich das erlösende Wortı"

Von Hans Habe

Sehr geehrter Herr Präsidentl

... Uber drei Wochen seit dem Beginn des ungarischen Aufstandes sind-vergangen, zwei. Wochen beinahe, seit der Freiheitskampf der ungarischen Nation in Blut ertränkkt wurde.

Millionen Europäer bringen Ihnen, Herr Präsident, das gleiche Vertraüen entgegen, das Ihnen Ihr eigenes Volk am 6. November mit so überwältigender Mehrheit bekun:dete. Millionen Europäer haben von Ihnen das erlösende Wort erwartet...

Das große kleine Land an der Donau und Theiß. ist das Land der Freiheit. Für die Geschichte der. Freiheit ist die ungarische Revolution von 1848 nicht weniger bedeutsam als die Französische Revolution von 1789. Auf einem stillen Platz vón New York steht das Denkmal des Franzosen Lafayette, der für die Unabhängigkeit der Vereinig:ten Staaten gekämpft hat. Auf einem stillen Platz von New. York steht auch das Denkmal :von Lajos Kossuth, der für die Unabhängigkeit Ungarns gekämpit hat . . . Es ist nicht wahr, Herr Präsident, daß es nur Knechtschaft gibt oder Atomkrieg. Ich habe mit Dutzenden von Men- 
schen gesprochen, die aus Ungarn kamen. Freiheitskämpfer waren es, Arbeiter, Arzte, Soldaten, Frauen und halbe Kinder, Proletarier und Professoren, Ungarn ûnd auch andere. Jeder von ihnen hatte einen Vorschlag. Warum ist der. Generalsekretär der Vereinten Nationen nicht mit einem Sonderflugzeug nach Budapest gekommen? fragten die einen. Warum hat Präsident Eisenhower nicht seinen Freund Marschall Schukow, den Blutgewaltigen von Budapest, ans Telephon gerufen? fragten die :anderen. Warum geschieht-nichts? fragten alle.

Die Vorschläge mögen Ihnen rührend und rührend-naiv erscheinen. Doch ist die Frage nicht naiv, warum nichïts geschieht.

Dies, Herr Präsident, könnte geschehen:

$\dot{D} a ß$ die freie Welt ihren Abscheu vor der blutigen Knechtung eines Volkes einmütig bekundet, indem alle diplomatischen Vertreter der freien Welt, von Norwegen bis Athiopien, von Italien bis Amerika, aus Moskau abberufen werden. Schon am 39. Jahrestag der bolschewistischen Oktoberrevolution haben sich viele westliche Minister geweigert, "an den Feiern in den sowjetischen Botschaften teilzunehmen.

Daß die freie Welt aufhört, so zu tun, als wäre die Barbarei salonfähig — daß keine Fußballmannschaft eines demokratischen Staates mehr gegen ein sowjetisches Team antritt, daß keine.Monarchin mehr einer sowjetischen Ballerina applaudiert, daß kein künstlerischer oder wissenschaftlicher KongreB mehr in. Anwesenheit von sowjetischen Vertretern stattfindet. "Ein Anfang wurde schon gemacht:

Daß die freie Welt sofort und ohne Verzug alle wirtschaftlichen Bindungen zur Sowjetunion löst, keine neuen mehr knüpft und sowohl die Einfuhr nach wie die Ausfuhr aus der Sowjetunion unterbindet. Das und manches andere bedeutet keinen Krieg. Es bedeutet nicht einmal -das Ende der Ko-Existenż, wenn sie so verstanden wird; wie sie immer hätte verstanden werden müssen: als ein Nebeneinander-Leben, nicht als ein Zúsammen-Leben ...

(Dieser Brief von Hans Habe wurde an Präsident Eisenhower in englischer Ubersetzung abgeschickt.) 
Neue Zürcher Zettung, 17.11.1956

FORTSETZUNG DES GENERALSTREIKS

Budapest, 15. Nov, ag (Reuter). Das einzige Organ der kommunistischen Partei Kádárs. "Népszabadság" mußte am Donnerstag sein Erscheinen einstellen, da die Drukker sich dem Generalstreik angeschlossen haben. Die ein. zige offizielle. Nachrichtenquelle war somit das Radio.

Népakarat, Budapest, 18.11. 1956

... Wir stellen fest, daß die am 17. November 1956 erschienene Ausgabe von "Népszabadság" von Personen herausgegeben wurde, die unsèrer Gewerkschaft fernstehen und mit denen die Freie Industriegewerkschaft Druck und Papier nichts gemein hat.

Der provisorische Arbeiterrat

der Freien Industriegewerkschaft Druck und Papier.

Süddeutsche Zeitung, München, 20.11.1956 KEINE DEPORTATION, SAGT SCHEPILOW Moskaus Außenminister bestreitet vor den UN die Verschleppung von Ungarn

New York (UP) .....Der amerikanische Delegierte Lodge erklärte, den USA lägen authentische Berichte darüber vor, $\mathrm{da} \beta$ die Sowjets mindestens 16000 Ungarn deportierten. Er appellierte an die Sowjetunion, Achtưng für die öffentliche Meinung der Welt zu haben und die Deportation_einzustellen. Lodge teilte mit, er habe in den letzten 24 Stunden Informationen erhalten, nach denen die Verschleppungen weitergehen. Eine große Anzahl der Deportierten werde in offenen Güterwagen befördert und sei dem sicheren Tod im eisigen russischen Winter preisgegeben.

Süddeutsche Zeitung, München, 20.11.1956

Ungarns Freiheitsflagge mit dem alten Kossuth-Wappen wurde im Olympischen Dorf in Melbourne feierlich gehißt, nachdem auf Verlangen der ungarischen Teilneh- 
mer an den Olympischen Spielen und mit Zustimmung des Mannschaftsführers Julius Hegyi die Flagge des kommunistischen Ungarn mit dem Sowjetstern niedergeholt worden war. An ihrer Sportkleidung entfernten die Ungarn ebenfalls die kommunistischen Abzeichen und ersetzten'sie durch einen Trauerflor.

Studdeutsche Zeitung, München, 26.11.1956

EMPORUNG UBER DIE ENTFUHRUNG NAGYS

Der ehemalige ungarische Ministerpräsident seit seiner Verschleppung durch Russen spurlos verschwunden. Jugoslawien protestiert in Budapest und Moskau gegen den flagranten Bruch diplomatischer Vereinbarungen

Neues Deutschland, Ost-Berlin, 28.11, 1956

NACHSCHUB FUR FREMDENLEGION UND BORDELLE West-Berliner ${ }_{n} B Z^{*}$ enthüllt grauenhafte Lage der Ungarnfluchtlinge

Colloquium, Berlin, Dezember-Heft 1956 GEDANKEN AN GRABBERN

(W.H.) - ...Ein so merkwürdiges Fazit scheint uns nichts anderes zu beweisen als die Richtigkeit des schon aus den Zèiten des Völkerbundes überkommenen Verdachts, daß der Einsatz internationaler Sanktionstruppen von der Schwäche des Landes abhängt, daß Anlaß zu Sanktionen gegeben hat. Den gefährlichen Luxus derart unzulänglicher Sicherheitsvorkehrungen kaṇn sich die Welt nicht länger leisten. Trotzdem, noch immer tragen die Vereinten Nationen als einzige Institution 'die Hoffnung der ganzen Menschheit auf die Bewahrung des Friedens, daran kann auch ihr Versagen im Falle Ungarn nichts ändern...

Mittelbayerische Zeitung, Regensburg; 5: 12.1956 "UNGARN-PATENSCHAFT" ERFOLGREICH

München (lb). Dè am Wochenende in München gegründete Vèrein "Ungarn-Patenschaft der freien Welt" 
konnte schon am Montag von schönen Erfolgen berichten. Acht Ehepaare erklärten sich bereit, elternlose-ungarische Kinder zu adoptieren, die Bauern der Gemeinde Moorenweis im Landkreis Fürstenfeldbruck schickten eine Delegation, um erklären zu lassen, daß rund $20 \mathrm{Un}$ garn in Familien in Moorenweis aufgenommen werden können. Ein Polizist Iud eine.Ungarin oder einen Ungarn eine Woche lang ein als Gast uiber Weihnachten.- Die Hilfsbereitschaft zeigte sich auch auf andere Weise: So stellten. viele Firmen zu Weihnachten Geschenke zur Verfügung. Die "Üngarn-Patenschaft der freien Welt", deren Beirat der bayerische Arbeitsminister Walter Stain; Professor. Dr. Marchionini, der Schauspieler Hans Albers, der Schriftsteller Dr. E. Kästner und zahleiche andere Pro-. minente ängehören, ist unter der Anschrift München 13, Daimlerstraße 5, zu erreichen.

\section{Arbeiterzeitung, Wien, 6. 12.1956}

\section{DIE ROTTERDAMER DOCKARBEITER ENTLADEN} KEINE SOWJETSCHIFFE

Rotterdam. In Rotterdam weigerten sich Montag die Dockarbeiter aus Protest gegen das russische Eingreifen in Ungarn. zwei sowjetische Schiffe zu entladen.

Süddeutsche Zeitung, München, 6.12.1956 UNGARISCHE FLUCHTLINGE IM HUNGERSTREIK Studenten und Soldaten protestieren gegen Internierung in. Osterreich

ki. Salzburg (Eigener Bericht). Unter ungarischen Studenten und Soldaten, die im ehemaligen amerikanischen Kasernengelände von Siezenheim bei Salzburg interniert sind, ist es zu Uniuhen und zu einem Hungerstreik gekommen. Der Grund dafür ist, dảß die Ungarn das Lager nicht verlassen dürfen. In Siezenheim sind rund 1000 ungarische Studenten und Soldaten untergebracht, die bewaffnet aus Ungarn geflüchtet waren und sich unter den Schutz der österreichischen Republik gestellt hatten.

180. ungarische Studenten versuchten sich durch tagelange Essensverweigerung gegen ihre Festhaltung zu 
wehren, nachdem sie erfahren hatten, daß viele ihrer Kommilitonen, - die 'Ungarn unbewaffnet verlassen hatten', ihr Studium in den Gastländern fortsetzen können: Die Unruhen unter den Studenten griffen auch: auf die ungarischen Soldaten über. 28 Internierte brachen aus dem Lager aus, auch Wasserwerfer konnten sie nicht an der Flucht hindern; „Wir hatten mit. einer regelrechten Gefangennahme, nicht gerechnet", sagt ein : ungarischer Offizier dazu. Ungarische Zivilisten in nahegelegenen andẹren. Lagern beteiligten sich an den Unruhen.

Das Schicksal dieser ungarischen Soldaten und Studenten wird von der Genfer Konvention bestimmt: Die Internierten dürfen nur entlassen werden, wenn entweder ein entsprechendes Abkommen zwischen der Wiener und dèr Budapester Regierung erzielt 'worden ist oder wenn die österreichische Regierung offiziell feststellen kann, daß die Kampfhandlungen in Ungarn beendet sind und somit kein Grund mehr für die Festhaltung der. Soldaten gegeben ist $\therefore$..

\section{Népakarat, Budapest, 6. 12.1956}

UNTER 14JAHRIGEN "AUSWANDERER-ASPIRANTEN"

$\therefore$ "Was ist mit dir passiert, mein Junge?".

"Das selbe wie mit den anderen" auch. Sie haben uns geschnappt"; sagt der Büb gleichmütig. Die Frau Hauptmann mischt sich ebenfalls ins Gespräch.

"Warum wolltest du fort aus Ungarn?"

Der Junge schaut sie an: "Weil ich hier keinen Beruf erlernen konnte. Als ich die 8 . Klasse beendet hatte, wollten meine Eltern gerade nach Budapest übersiedeln und gaben mich darum nicht in die Lehre. Außerdem wollte ich Dreher werden und das konnte ich in Szekszárd nicht lernen. Ich dachte, wir würden bald nach Budapest kommen, aber dann bekamen meine Eltern die Zuzugsgenehmigung nicht, und als wir sie schlieblich doch kriegten, war ich schon über das Alter-hinaus und wurde nicht mehr als Gewerbelehrling angenommen. Für die Umschulung war ich aber noch zu jung. So bin ich seit meinem 14. Lebensjahr Hilfsarbeiter; Ich arbeite wie die Er- 
wachsenen. Für 650-700 Forint. Kann man denn davon ordentlich. leben? Ich konnte mir keinen Mantel kaufen, nicht mal eine billige Theaterkarte. Was sind das für Aussichten, daB ich mein Leben. lang Hilfsarbeiter sein soll? Seit anderthalb Jahren arbeite ich bei einem Elektroinstallateur. Den Beruf habe ich beinah schon ausgelernt, aber Facharbeiter werde ich nie sein können!"

Die-Worte stürzen aus seinem Mund, der Bub macht seiner Verbitterung Luft. Die Frau Hauptmann seufzt...

Ich frage ihn: "Und wenn es dir gelänge, einen Beruf zu $u$ erlernen, würdest du dann geŕn daheim bleiben?"

Seine Augen leuchten auf: "Wenn ich Elektriker sein. könnte, würde ich nicht fart wollen:...".

Süddeutsche Zeitung, München, 7. 12.1956.

WEISSBUCH KADARS MIT FALSCHUNGEN

... Wie die Fälschung des Weißbuches zustande kam; geht aus den Aussagen der beiden .Flüchtlinge József Vanek und Tibor Bérczy hervor; die in der von den Sowjets beschlagnahmten ungarischen Armeedruckerei Vörös Csillag in Budapest beschäftigt gewesen sind. Nach ihren Aussagen mußten sie am Montag, dem 3. Dezember, mit zehn anderen Kollegen Flugblätter drucken, nachdem die übrige Belegschaft bereits nach Hause geschickt war. Diese Flugblätter lauten folgendermaßen: " Der Westen läßt Euch nicht im Stich. Kämpft weiter, haltet aus! Die Hilfe kommt! Die Kommunisten werden alle ver: nichtet. Das christliche Ungarn wird auferstehen. Kardinal Mindszenty betet für Euch. 'Es lebe Ferenc Nagy, der Ministerpräsident der einzigen legalen ungarischen Regierung." Als Impressum wurde links unten auf dem Flugblatt angegeben: "Neue Freie Druckerei. Salzburg, 66.743-II ${ }^{u} \ldots$ 
Suiddeutsche Zeltung, München, 8./9.12.1956

OI_YMPISCHE - EHRENTAFEL

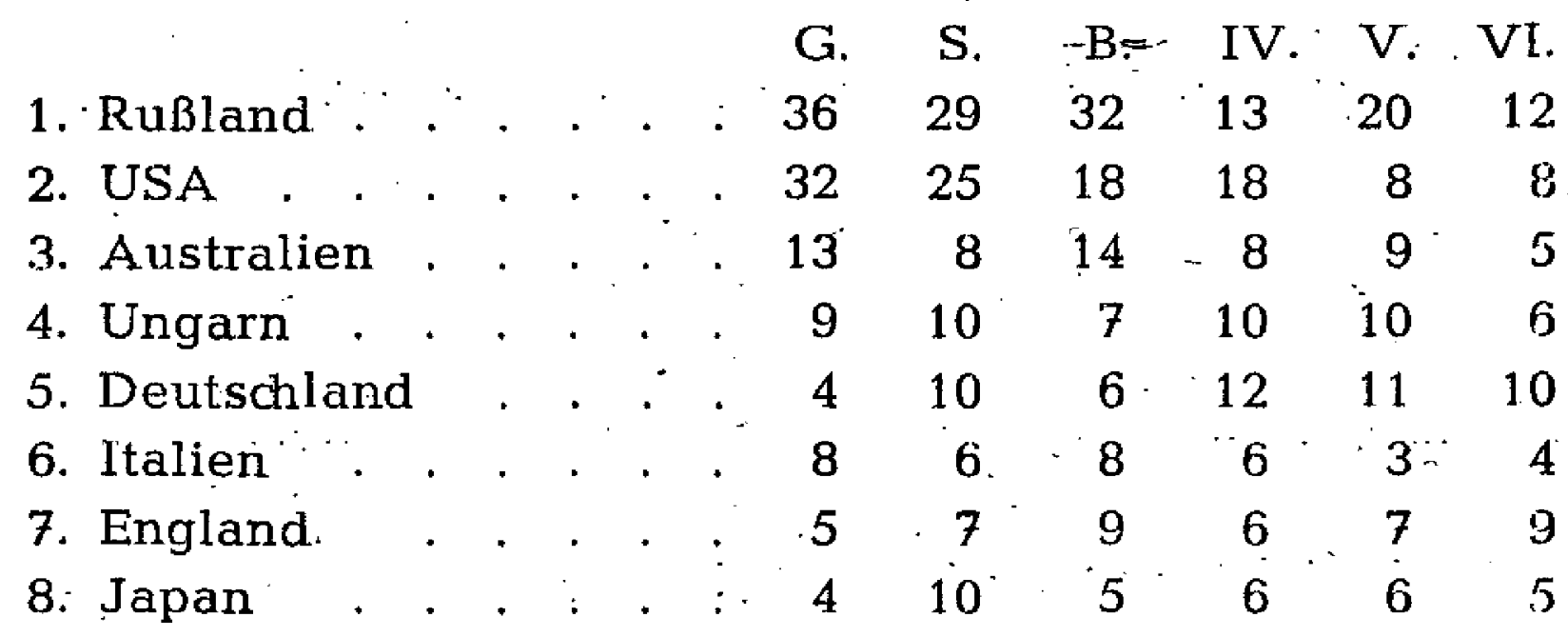

Népakarat, Budapest, 9.12.1956

VERTEILUNG VON MILCHPULVER HAT BEGONNEN

Die Leitung des Ungarischen Roten Kreuzes 'teilt mit, $d a B$ in allen Bezirken GroB-Budapests mit der.Verteilung von Milchpulver begonnen wurde. Bezugsberechtigt sind werdende Mütter vom 7. Monat an und Kleinkinder bis zum Alter von 4 Jahren...

Neues Deutschland, Ost-Berlin, 14.12. 1956

FASCHISTEN ERNEUT GESCHLAGEN

Volksmacht in. Ungarn bestand Kraftprobe. Rädelsfuhrer verhaftẹt

Von unserem Sonderkorrespondenten Werner Kolmár

Budapest, 13. Dez. In Budapest nahm das Leben heute nach dem Scheitern des Versuches des "Zentralen Arbeiterrates" durch Streiks und bewaffnete Provokationen die Regierung Kádár zu śtürzen, wieder seinen gewohnten Gang...

Die Faschisten und ihre Washingtoner Auftraggeber haben sich also verrechnet. Sie konnten zwar der Volkswirtschaft großen Schaden zufügen, aber ihre politischen. Ziele nicht erreichen... 
Stiddeutsche Zeitung, München, 15. 12. 1956

DER AUFSTAND DER DICHTER :

\section{Lyrik der ungärischen Revolution}

Von Clemiens Podewils

An den Westen:

Ihr wollt noch kommen? Kommt zu spät.

Wir sind gefallen wie das Korn,

Geschnitten und gemäht.

(Ungarischer Student $\mp$ in Budapest am 3.11.1956)

$\because$ Zu unserém nicht endenden Staunen gehört. abei auch die Entdeckung, daß die Sprache dieser Erhebung dichterisch ist. Nicht in pathetischer. Steigerung, sondern weil es sich zeigt; daß dies die einzige: Sprache ist, in der ein ganzes Volk zu reden vermag, wenn es, durchdrungen von dem Schicksal, von der Sendung, die ihm erwuchs, vor die Welt tritt, brüderlich, mahnend, beschwörend oder mit dem letzten Hilferuf:

„Völker der Erde! Auf den Wachttürmen-des tausendjährịgen Ungarn erlöschen die letzten Feuer. Völker Europas, hört das Sturmgeläut der ungarischen Glocken! Im Namen der Gerechtigkeit und Freiheit, helftl Das Schiff sinkt; das Iicht schwindet, die Schatten werden von Stunde zu -Stunde dunkler über der Erde Ungarns. Hilfe, SOS, rettet uns! Gott mit Euch und mit uns..." So scholl. der letzte Freiheitssender des Landes:

Du, mein zum Himmel strebendes Volk,

Juwel an der Brust der Mutter Gottes!

Heute schwelgt, in Sünden taumelnd,

Eine Welt im Duft deines Blutes,

Der Christus unter den Völkern, Dul...

In Ungarn werdet ihr uns nicht mehr finden;

Könnt nur noch staunend blicken ins Grab,

Unseren Leichnam, bedeckt mit zerfetzten Fahnen.

Und Gott hat keine Ungarn mehr.

Hier suchen wir nicht nach dem Namen des Dichtenden, sondern ahnen, daß die Stunde viele zu solchen erhoben hat. In ihnen leben ältere Freiheitslieder auf, wie das der 
Kuruzzen, der Anhänger Rákóczịs, das nach desseñ Niederlage (1708) entstanden ist:

Einsam ragend, treue Fahne!

Auf zerbrochnem Schaft der Rabe.

Streicht zerzaust sich das Gefieder;

Tränen quellen aus dem Aug' ihm,

Auf zerfetzten Dolman,

Auf die Fahne nieder,

Uber Toten weint der Rabe.

Solche Lieder der' Leidenschaft und Schwermut, gesungen oder wortlos hinausgetragen von der Stimme des Tárogató, der dunklen Hirtenschalmei; gewinnen heute ihren alten Sinn wieder...

Der schwarze Heerzug der Frauen, die, summend zuerst, dann aufsingend in der Nationalhymne "Gott segne Ungarn" ; an den Rohren der Panzer vorbei, vor Petöfis Denkmal ziehen, um im Chor seinen Schwur nachzusprechen, daß wir länger keine Sklaven, sind - wer vermöchte da noch zu sagen, wo Tat in Dichtung, wo Dichtung in Tat übergeht, da beides ein und dasselbe ist!

Süddeutsche Zeitung, München, 17. 12. 1956

ES BEGAB SICH ABER ZUU DER - ZEIT ....

Der jüngste Flüchtling, der bisher die ungarisch-österreichische Grenze überquert hatt, flóg gestern mit einer Maschine der amerikanischen Luftbrücke nach Amerika... Die Eltern des Kindes mußten aus Budapest fliehen, als die Polizei des. Kádár-Regimes in der Wohnung des Vaters erschien, um ihn zu verhaften. Drei Tage schon war er nicht mehr zu Hause gewesen, weil er einer Gruppe von Freiheitskämpfern angehörte, die ein Gebäude der Innenstadt verteidigte. Nachbarn verständigten ihn von der seiner Familie drohenden Gefahr... Sie fuhren mit einem überfüllten Zug nach Steinamanger, gingen zwei Tage zu FuB und kamen am 24. November in ein Dorf, wo sie sich einer Gruppe von 'zehn anderen Flüchtlingen anschlossen. Als sie sich bei Anbruch der Dunkelheit auf den Weg machten, setzten bei der jungen Frau die ersten Wehen ein. Sie hielt mit zusammengebissenen 
Zähnen aus, bis sie die Sperrkette der russischen Panzer hinter sich hatten. Dann konnte sie nicht mehr weiter... Das Hemd des Vaters war die erste Windel des kleinen Mädchens, sein Mantel wurde ihr Steckkissen.

Dann ging der Mann zurück ins das Dorf, wo er vor Stunden aufgebrochen war, und holte Hilfe... Eine Gruppe von Bauern machte sich mit einem Schlitten auf den Weg, um sie zu suchen. Sie fanden sie nicht mehr. Die Rufe der Helfer machten eine russische Streife aufmerksam, die zu schießen begann. Erst als es wieder still geworden war, hörten sie das schwache Wimmern des Kindes.

Vier Tage lang hieltẹn die Bauern die Flüchtlinge versteckt. Das ganze Dorf stiftete Nahrungsmitte und Kleider, mehr als nötig waren: Am fünften Tage brachte ein Pferdeschlitten die Familie an die Grenze. Wieder begann die Wanderung -durch den nächtlichen Wald, in dem jeden' Augenblick eine Streife auftauchen konnte. Ungarische Grenzsoldaten hielten sie an. Erst als sie das letzte Geld der Fliehenden in Empfang genommen hatten, erlaubten sie ihnen, den schmalen Steg über den Grenzfluß zu benützen...

Wir trafen die vier in einer amerikanischen Kaserne bei München, wo sie darauf warteten, zum Flug ins neue Leben aufgerufen zu werden. „Was nun aus uns werden soll, weiß ich nicht", sagte uns der junge Vater. "Wir wollen beide arbeiten, das ist alles, was ich weiß." $\mathrm{Er}$ ist ein Zimmermann. Die Soldaten der Kaserne nannten ihn. Joseph und zu seiner Frau sagten sie Maria.

Abendzeitung, München, 20.12.1956

SEIN REISEGEPACK: EINE HANDVOLL ERDE

66 ungarịsche Flüchtlinge flogen mit der US-Luftwaife in die neue Heimat

Von Dieter Zimpel

...Ganz am Ende der Platzreihen sitzt ein älterer, dunkelhaariger Mann. Er ist der einzige, der an der lebhaften Unterhaltung keinen Anteil nimmt. Stumm, etwas vornübergebeugt, brütet er vor sich hin. "Haben Sie Ihre 
Heimat schwer verlassen?" frage ich ihn. Er blickt mich kurz über seine altmodische Brille an. Langsam steht er auf, greift in das Gepäcknetz und holt seine Aktentasche heraus. Er sucht umständlich darin herum. Endlich findet er etwas. Es ist ein schmutziges Säckchen. Er öffnet es und sagt: "Meine Heimat." Als ich neugierig hineinsehe, ist es Erde, nichts als einfache, krümelige Erde. Der Ungar setzt sich langsam wieder in seinen Sessel, das unscheinbare Säckchen drückt er fest an seine Brust...
Abendzeitung, Munchen, 21. 12.1956
KADAR DROHT MIT DEM KONZENTRATIONSLAGER Gegner der Regierung können in Ungarn ohne Gerichts- verfahren interniert werden

Süddeutsche Zeitung, München, 21.12.1956

SCHULKINDER BEREITEN WEIHNACHTSFREUDE

München (Eig. Ber.). Die 7. Mädchenklasse der Tumblinger-Schule hatte drei ungarische Flüchtlingskinder eingeladen, um sie mit warmen Wintersachen, Wäsche, Spielzeug und Lebensmitteln zu beschenken.

Elisabeth (17), der kleine Géza (10) und die 7jährige Csöppi waren mit ihrer Mutter zu den Großeltern nach München geflüchtet. Vom Vater wissen sie zur Zeit nichts...Die Klaßlehrerin verteilte in einer kleinen Feierstunde mit vorweihnachtlichem Kerzenschimmer die Gaben an die ungarischen Kinder.

Münchner. Merkur, 22./23. 12. 1956

SIE FLIEGEN RUCKWÄRTS IN DIE FREIHEIT

Eine schwere Fracht Glück und Unglück über die Luftbrïcke nach Amerika

Von unserem nach New York entsandten Redaktionsmitglied Manfred Lütgenhorst

New York. Sie heißt Julianne und weint, als sei Weinen eine Freude. Ganz langsam, fast behutsam kommen die Tränen und überziehen die ungarischen Augen; bis sie zu glänzen anfangen, schwarz wie frisch ge- 
brochene Kohlen. Das Flugzeug hat zu 'brummen begonnen, die Propeller drehen sich langsam, schnell, noch schneller, sie wirbeln und glänzen wie scharf geschliffene Messer in der Morgensonne - da begreift das Mädchen Julianne, was Abschied heißt, Abschied von Ungarn und von Europa, und jetzt beginnen ihre Augen :zu: weinen, aber ihr Gesicht fragt: Sind es Tränen der Hoffnung?...

Sie fahren rückwärts dorthin, die Köpfe, dịe Gedanken auf Ungarn, auf das ins Nichts versinkende Europa gewandt. Die. Vorschrift in den riesigen Transportern der amerikanischen Luftwaffe lautet, daß die Sitze .rückwärts zür Flugrichtung aufgestellt werden müssen, damit es der Tod bei Bruchlandungen schwerer haben' soll. Und so fliegen die, aus. Ungarn .Geflüchteten rückwärts in die neue Welt; den Blick verwehend und wehmütig in die Vergangenheit verlierend...

Und am nächsten Tag stehen Julianne und ich auf dem höchsten -Gebäude der Welt, auf dem Empire State Building zu New York. Unter uns liègt die mächtigste Stadt der-Welt, liegt der Broadway, der. Times Square, unter uns liegt gewaltig Amerika. Ich bin mit Julianne durch die Straßen der Riesenstadt gegangen, durch die größten Kaüfhäuser der Welt, über den glitzernden.Broadway, und bin mit ihr am Times Square stehengeblieben, und Julianne, das Mädchen aus der. Puszta, hatte den Mund halb offen gehalten, ihre Kohlenaugen im überquellenden Licht der Stadt funkeln lassen, fast Erschrockenes gemurmelt, so, als fürchte sie sich.

Jetzt stehen wir auf dem Dach der Welt und schweigen lange. Dann. sagt Julianne verloren: "Und wo mag Ungarn liegen?" "Da", sage ich, "jenseits der Statue of $\mathrm{Li}$ berty." "Was ist die Statue of Liberty", sagt Julianne. „Die Säule der Freiheit." — "O.k." sagt das ungarische Mädchen.

Abendzeitung, München, 24.12.1956

AUFSTAND IIN EGER

Wien (UP). In einer großen Fahndung versucht die ungarische Geheimpolizei, aller "Aufstandsführer" habhaft 
zu werden, die in der nordostungarischen. Stadt Eger die Bevölkerung. zu „antisowjetischen Unruhen” aufgerufen haben sollen.

In Eger war es in der Zeit von 10. bis 12. Dezember zu dreitägigen, schweren Zusammenstößen, zwischen Aufständischèn und kommunistischen Truppen - und Polizeieinheiten gekommen. Die kommunistische Zeitung "Népszabadság" meldet, die Aufständischen seien "unter. Absingen religiöser. Lieder" gegen die kommunistische - Parteizentriale vorgedrungen und hätten auch die dortige sowjetische Kommandantur angegriffen :..

Süddeutsche Zeitung, München, 29. 12. 1956

FLUCCHT UBER DEN NEUSIEDLER SEE .

Ungarische Familie rettet sich nach Ợsterreich: Säugling erfroren

Wien (AP). In einem offenen Boot gelang einer ungarischen Familie über den Neusiedler See die Flucht nach Osterreich. Über 30 Stunden lang mußten die Flüchtlinge gegen Schneestürme und eisige Winde ankämpfen, bis sie das .rettende Ufer erreicht hatten. Dabei erlitt ein neun Monate altes Kind so schwere Erfrierungen, daß es bei der Ankunft des Bootes am österreichischen Ufer erfroren war. Die Eltern des"Kindes, ein Kaufmann aus Budapest, und seine Frau, mußten in bedenklichem Zustand in ein Krankenhaus gebracht werden $\therefore$. In voller A'usrüstung stellte sich ein ungarischer Soldat an der österreichischen Grenze den Grenzwachen. Um gegen alle unvorhergesehenen Zwischenfälle gesichert zu sein, hatte er sogar ein Maschinengewehr mitgenommen. Er. ließ sich entwaffnen und wurde interniert...

\section{0 ungarische Studenten in Westdeutschland}

München (SZ). Bis Anfang Januar 1957: werdeñ rund 1000 geflüchtete ungarische Studenten in der Bundesrepublik sein, teilte der Bevollmächtigte der westdeutschen Kultusminister, Oberregierungsrat Treppesch vom bayerischen Kultusministerium, mit... 
Süddeutsche Zeitung, München, 2.1.1957

RUHIGER JAHRESWECHSEL IN UNGARN

Vertreter der Nato-Mächte boykottleren Neujahrs-Empfang des Staatspräsidenten

Budapest (AP). Budapest verlebte einen friedlichen Neujahrstag, nachdem kurz nach Mitternacht- in der Stadt etwa eine Stunde lang Gewehr- und Maschinenpistolenfeuer zu hören war...

\section{"Time" Magazin, New York, 7.1.1957}

DAS LAND UND DIE LEUTE

... Zwischen den Magyaren und ihren slawischen Nachbain in den Balkanländern besteht keine völkische Verwandschaft. Die einzigen europäischen Völker, mit denen sie verwandt sind, sind die Finnen und die Esten. Erst verhältnismäßig spät tauchten sie in Mitteleuropa auf kühne Streiter und gewandte Reiter - und im Laufe der Jahrhunderte wurden sie aus ihrer ursprünglichen Heimat vertrieben und südwärts gedrängt, bis sie im Jahre 895 unter Arpád, ihrem Stammesoberhaupt, die Karpathen überschritten und sich in der weiten Ebene niederließen, die das heutige Ungarn umfaßt.

Durch die neue Heimat der Magyaren ... führten die Landverbindungen, auf denen einst die Kreuzritter der Christenheit gen Osten gezogen waren und die anstürmenden Wellen plündernder asiatischer Eroberer immer wieder ost- und südwärts gedrängt hattèn.

...Um ihre Herrschaft zu festigen, eroberten die Magyaren die angrenzenden Gebiete und dehnten ihr Reich weit. über die Gebirge hinweg aus,. so daß es ein Gebiet einschloß, das Rußlands heutige Satellitenstaaten im Balkan umfaßte.

1000 n. Chr. hatten Ungarns mächtige Herrscher den christlichen Glauben angenommen, und in diesem Jahr verlieh Papst Sylvester II dem Ur-Ur-Enkel Árpáds, König Stephan (dem späteren Heiligen) die Heilige Krone, die mit dem schiefen Kreuz heute noch Ungarns wertvollsten Schatz darstellt. (Nach dem 2. Weltkrieg wurde sie von der Regierung der USA in Gewahrsam genommen.) Im 
Jahre 1222, sieben Jahre nachdem die englischen Barone König John gezwungen hatten, ihre Magna :Charta zu unterzeichnen, veranlaßten die Freien Ungarns ihren König Andreas, ein beachtliches Dokument zu unterzeichnen, das als "Goldene Bulle" bekannt ist: die erste Charta der Menschenrechte, 'die es auf dem'europäischen Festland gab...

Die Revolution Kossuths (1848/49) brachte die Befreiung der Leibeigenen Ungarns zuwege und die damit verbundene Bewegung half dazu, daß $20 \mathrm{Jahre}$ später die Doppelmonarchie Osterreich-Ungarn errichtet wurde...

Ungarn, das im 1. Weltkrieg auf der falschen Seite gekämpft hatte, mußte nach dem Friedensvertrag die meisten der früher erroberten Gebiete wieder abgeben. Neue Staaten - die Tschechei und Jugoslawien - wurden aus Gebieten errichtet, die einst zu König Stephans Krone gehört hatten. Rumänien erhielt einen großen Teil, und. Ungarns Grenzen umschlossen nur noch ein Drittel des Karpathenbeckens, in dem sich Ârpád. einst niedergelassen hatte...

Im Jahre 1919, im Chaos der Niederlage und Demütigung, wurde Béla Kún, ein Anhänger Lenins, der aus einem russischen Gefangenenlager befreit und mit einem falschen $\mathrm{Pa}$ nach Ungarn zurückgeschickt wurde, an die Spitze einer Regierung roten Terrors gestellt, die sich fast vier Monate lang hielt.

Der fanatische Kún verstaatlichte jeden bäuerlichen Betrieb, der mehr als 100 Morgen Land umfaßte, schaffte alle Knechte $a b$, ließ den gesamten Schmuck beschlagnahmen und ordnete an, daß ein Mann nicht mehr als zwei Anzüge, vier Hemden und vier Paar Socken besitzen dürfe. Kúns Methoden fanden keinen Anklang bei den Bauern... Admiral Nikolaus Horthy ... organisierte eine Gegenrevolution, um Kún zu vertreiben, und... regierte bis 1944 mit der Vollmacht. eines Regenten, der einen leeren Thṛon auszufüllen versuchte...

Als sich die Deutschen im Jahre 1944 zurückzogen, überrannten wieder einmal Eroberer des Ostens die ungarische Tiefebene... 
Die folgenden Ungarn, sowie Personen ungarischer Abstammung, hàben sich einen Namen gemacht:

Musiker: Fránz Liszt, Béla Bartók, Zoltán Kodály, Eugene Ormandy, Joseph Szigeti und Sigmund Romberg.

Film und Theater: Alexander Korda, Ferenc Molnár, die Gábor-Schwestern, Ilona Massey und Leslie Howard (richtiger Name: Arpád Steiner).

Wissenschaftler: Nobel-Preisträger Albert Szent-Györgyi (der Entdecker des Vitamin C).

Mathematiker: John von Neumann.

Andere berühmte Persönlichkeiten: David Lilienthal, ehemaliger Vorsitzender dèr U. S. Atomenergie Kommission: Edward Teller, ein Pionier der H-Bombe; der Sozialist Eugene V. Debs, ...

\section{Abendzeitung, München, 12.-14.1.1957}

TODESSTRAFE FUR STREIK IN UNGARN

Budapest (AP). Nach einem neuen Regierungserlaß können alle Personen vor Standgerichte gestellt und binnen 24 Stunden zum Tode durch den Strang verurteilt werden, die "den Betrieb einer Fabrik durch ihre Anwesenheit oder durch irgendwelche anderen Mittel stören". Damit ist der Streik in Ungarn unter Todesstrafe gestellt. $\therefore$

Deutsche Woche, München, 16.1.1957

DIE UBERFLUSSIGE REVOLUTION

Kádárs Programm setzt die Reformen fort

Das jetzt vorgelegte Programm der Regierung Kádár gleicht dem Programm der Regierung agy, ehe diese von dem Radikalismus der Straße und der Kirche überrant wurde, wie ein Ei dem andern. Es erfüllt alle Wünsche und Forderungen, die von der ungarischen Bevölkerung im September schon an die damalige Regierung gerichtet worden waren... Das ungarische Volk zahlt selbst aber einen bitteren Preis für diese sinnlose Episode von Tor- $r$. heit und Niedertracht.

Die Revolution in Ungarn war historisch so überflüssig, daß sie nicht einmal eine reaktionäre Verhärtung derer hervorrief, gegen die sie sich richtete... 
Arbeiter-Zeitung, Wien (Broșchüre "Ein Atemzug Freiheit")

... Als er über die Verantwortlichen des Streiks sprach, sagte Kádár: „Ein Tiger kann nicht durch Leckerbissen gezähmt werden, er kann zahm und friedfertig nur da-, durch gemacht werden, daß er zu Tode geprügelt wird... Jeder Arbeiter hat sofort und bedingslos die Arbeit nach besten Kräften aufzunehmen und mit dem Entwerfen und Kritzeln von Forderungen aufzuhören."

\section{Neue Zürcher Zeitung, 19.1.1957}

\section{DIE UNGARISCHEN FLUCHTLINGE IN} SKANDINAVIEN

\section{Kommunistische Einschüchterungskąpagne}

...Auch in Dänemark sind die Organe des KádärRegimes, unterstützt von einer intensiven kommunistischen Hetzpropaganda, bestrebt, die Eingliederung der dortigen Flüchtlinge in den Arbeitsprozeß möglichst zu verhindern. So hat beispielsweise die Arbeiterschaft auf dem größten Arbeitsplatz Dänemarks, der Schiffswerft "Burmeister und Wain" in Kopenhagen, mit großer Mehrheit einen Beschluß gefaßt, wonach ungarische Flüchtlinge in diesem Unternehmen unerwünscht seien. Der Grund für diese Haltung ist nach Presseberichten aus Kopenhagen in einer kommunistischen Verdächtigungskampagne zu suchen, die geltend zu machen sucht, daß sich unter den nach Dänemark geflüchteten Ungarn befreite Raubmörder und Diebe aus den Gefängnissen von Budapest befänden. - eine Behauptung, die von der dänischen Flüchtlingsverwaltung als völlig grundlos zurückgewiesen wird. Nach diesen Berichten haben bis jetzt in Dänemark von mehr als 1000 Flüchtlingen nur etwa 50 Arbeit erhalten...

\section{Deutsche Presse-Agentur, Hamburg, 21.1.1957}

Kopenhagen. Die Schwierigkeiten in der Beschäftigung ungarischer Flüchtlinge in Dänemark dürften demnächst völlig überwunden sein, insbesondere als Folge einer 
Pressekampagne zu Gunsten des Einbaus der Ungarn in den Produktionsprozeß. Aus dem dänischen Sozialministerium verlautete: "Im Verlaufe der letzten Woche sind so viele Arbeitsangebote für Flüchtlinge eingegangen, daß wir begründete Hoffnung haben, alle beschäftigen zu können, die in Dänemark bleiben wollen. Vor einer Woche war die Lage noch katastrophal, aber dank der umfassenden Pressediskussion über das Problem der Beschäftigung deutet nun alles darauf hin, daß eine Lösung gefunden wird, ohne daß höhere Behörden einzugreifen brauchen."

Tages-Anzeiger, Zürich, 22.1.1957

NOCH KEINE WAHLEN IN UNGARN

Fiasko der Kommunisten soll verhindert werden. Hinrichtangen am laufenden Band.

Von unserem Korrespondenten

R. N. Wien, 20. Januar. ... Die GesamtzahI der Hinrichtungen betrage, wie man aus dem Untergrund hört, weit über $500 \ldots$

Der SpiegeI, Hamburg, 23. 1, 1957

HOHLSPIEGEL

Im Rahmen der Ungarnhilfe bieten wir einigen Mitarbeitern die Möglichkeit, sofort gut umzusetzen. Vorzustellen Samstag von 12 bis $15 \mathrm{Uhr}$ und Montag von 10 bis 13 Uhr bei O. L. Herrn Jorhann, Mariahilfplatz 2/I, rechts. (Anzeige aụs der "Süddeutschen Zeitung", München.)

\section{Süddeutsche Zeitung, München, 26. 1.1957}

\section{LESERBRIEFE}

\section{Ein Ungar sprang aus dem OrientexpreB}

Am 7. Dezember 1956 wurden 200 ungarische Flüchtlinge aus. Osterreich in ein französisches Lager gebracht mit dem Versprechen, daß diese von hier aus nach Ubersee in die gewünschten Länder auswandern können. Die Familien wurden getrennt. Wir Jugendlichen kamen nach Montlucon. In dieser Stadt sind 60 Prozent der Einwoh- 
ner Kommunisten. Es ist in mehreren Fällen passiert, daß die kommunistischen Einwohner Streit und Schlägereien provozierten: Auch heute liegen noch mehrere ungarische Flüchtlinge mit schweren Verletzungen im Krankenhaus. Die meisten Verletzungen stammen von Gummiknüppeln und Fußs'tößen von Algeriern. Am 24. Dezember, also am Weihnachtsabend, ereignete sich eine große Rauferei zwischen französischen Kommunisten und Ungarn, wobei die französische Polizei erneut Gummiknüppel benutzte und die Flüchtlinge mit Pistolen bedrohte. Danach wurden mehrere Franzosen und drei Ungarn ins Krankenhaus eingeliefert.

Seit diesem Vorfall dürfen die Flüchtlinge das Lager nicht mehr verlassen entsprechend einem Verbot des Lagerleiters. Die Lager werden mit starkem Polizeiaufgebot bewacht. Nach diesen Vorfällen meldeten sich 84 Flüchtlinge zur Rückkehr nach Ungarn mit der Begründung, sie sterben lieber in Ungarn als hier in diesem Kommunistennest... Tibor Boros, Kaserne Richmond, Montlucon, Frankreich.

\section{Süddeutsche Zeitung, München, 30.1.1957}

\section{WIEN: ZUWENIG UNGARNHILFE}

Genf (dpa). "Osterreich hat es satt, um jeden Dollar und jedes Pfund Sterling zur Betreuung der ungarischen Flüchtlinge zu feilschen und $\mathrm{zu}$ betteln“, erklärte der österreichische Innenminister Helmer vor dem Exekutivausschuß des UNO-Flüchtlingsfonds in Genf. Zusammen mit 70000 ungarischen Flüchtlingen und dẹn Flüchtilngen der Nachkriegszeit ernähre das Sieben-Millionen-Volk Osterreich insgesamt 250000 Ausländer ...

\section{Neue Zürcher Zeltung, 15. 2. 1957}

\section{DIE ANTIKOMMUNISTISCHE STIMMUNG IN DEN SCHULEN}

Der, in Budapest erscheinenden Zeitung "Magyar Ifjuságu. vom 2. Februar ist folgende Zuschrift einer kommunistischen Lehrerin entnommen:

„Wenn ich in das Konferenzzimmer eintrete, hören die 
anderen Lehrer auf zu sprechen. Eine eiskalte, undurchdringliche Mauer erhebt sich zwischen uns. Ich weiß, warum sich die Gesichter von mir abwenden - weil sie gehört haben, daß ich in die Partei eingetreten bin. Ich bin in unserer Schule. die einzige kommunistische Lehrerin.

Ich gehe und komme, als ob ich gebrandmarkt, wäre. Wie eine Fremde im vertrauten Familienkreis . .

Ich muß auf jedes Wort aufpassen. Die-Atmosphäre am mich herum ist derart, daß es in unserer. Klasse eine Sünde ist, den Namen Lenins auszusprechen. Das Unterrichtsministerium erklärte, daß es nicht Pflicht sei, überall die Geschichte der Oktoberrevolution und der Räterepublik vorzutragen. Die Instruktion lautet dahin, daß derjenige, der sie schön vortragen kann, die Oktoberrevolution in den Unterricht einschließen könne. Meine Kollegen fanden daraufhin, daß sie sie nicht schön vortragen könnten. Es ist für mich sehr schwer, allein die Stille, zu brechen und von Lenin zu reden, das Wort "Kommunnist". auszusprechen.

Dieser Tage kam ein aufgebrachter Vater zu mir. Er erzählte, daß sein Kind ihn neulich gefragt habe: „Vater, bist du ein Kommunist?" Der Vater antwortete: "Ja." "Dann bist du ein Schurke." Und die Anklage, daß der Bub die furchtbaren Worte in der Schule gelernt habe, ist wahr...

\section{Sthddeutsche Zeitung, München, 2. 3. 1957}

\section{MIT DEN AUGEN EINES UNGARN}

Kennt'der Westen für dié Flüchtlinge nur Lager und bürokratische Hemmnisse?

Von unserer Mitarbeiterin Eva Hungady

"Hungerstreik im Ungarnlager Passau" _ "Ungarnflüchtlinge schlagen sich mit der Grenzpolizei!" - "Neue Schwierigkeiten bei der Eingliederung der Flüchtlinge aus Budapest “ —... Der deutsche Bürger, der die Ereignisse der ungarischen Revolution mit Anteilnahme verfolgte, fragt sich, ob er denn nicht seine Hilfe an Unwürdige vergeudet habe...Die Attitüde der Ungarn- 
flüchtlinge ist wohl nur dem erklärlich, der sich Gedanken darüber machte, wie diese Leute die letzten zwölf Jahre verbrachten. Zwölf Jahre lang war zum Beispiel das Wort „Freiheit" für sie entweder eine leere Phrase oder ein Traum von einem System ohne Zwang und bürokratische Schikanen. Nun erleben sie die Wirklichkeit und können nicht verstehen, daß auch der sogenannte „freie Westen“ Fragebögen, Einschränkungen der Bewegungsfreiheit, lange Wartezeiten, beschränkte Arbeitsmöglichkeiten kennt. Für sie, die zwölf Jahre lang, wie .Gefangene innerhalb der Grenzen ihres kleinen Landes lebten, bedeutet jetzt das Wort Freiheit, die ganze Welt auf einmal zu besitzen, heute nach Sydney und wenn es dort nicht gefällt - morgen nach New York überzusiedeln. Freiheit bedeutet ferner nach zwölfjährigem Schweigen über alles und jedes hemmungslos schimpfen zu dürfen, auch über die, welche nach ihrer. Meinung ihnen zu helfen verpflichtet sind.

Der Westen ließ ihrer Meinung nach die Freiheitskämpfer im Stich. Also ist das wenigste, was sie als geflüchtete "Helden der Freiheit" in Anspruch nehmen können, eine vollständige und tadellos funktionierende moralische und finanzielle Unterstützung. Das tadellose Funktionieren wird vorausgesetzt. Man kann nämlich nicht unbeeinflußt zwölf Jahre lang in einem Wohlfahrtsstaat leben, und der ungarische Staàt kommunistischer Prägung war ein Wohlfahrtsstaat, wenn auch im schlechtesten Sinne des Wortes. In so einem Staat zu leben bedeutet, daß man sich daran gewöhnt hat, daß der Staat, die "Macht", für seine Bürger denkt, sorgt und die Wege vorschreibt. Für eigene Initiative war dort kein Raum vorhanden. Für Menschen, die so leben mußten, ist es schwer, sich in einem ganz anderen Staatssystem zurechtzufinden. Nur so ist es zum Beispiel verständlich, daß die Flüchtlinge darüber entsetzt sind, daß die Auswanderung nach den Vereinigten Staaten, durch private - und noch dazu mit durchaus verschiedenen Mittel und $\mathrm{Me}$ thoden arbeitende - Organisationen besorgt wird. Und allmählich tauchen aus dem Unterbewußtsein wieder die tausendmal gehörten, aber immer wieder mit überlege- 
nem Lächeln beiseite geschobenen antiwestlichen Phrasen der kommunistischen Propaganda auf.

Eine andere Komponente des Verhaltens ist die Angst! Zwar muß man sich... nicht mehr vor der Willkür der Geheimpolizei, vor Zwangsarbeit oder Deportation fürchten, aber der Druck, der während der vergangenen zwölf Jahre auf allen Sektoren des Landes lastete, weicht nicht von heute auf morgen.' Die Flüchtlinge haben Angst vor jeder Entscheidung, da sie es noch nicht fassen können, daß das Leben im Westen immer wieder neue Entscheidungen bietet und verlangt. Unter dem kommunistischen Regime kannte man den Begriff des Stellungswechsels fast nur in Form eines Abstiegs, einer Degradierung, also scheuen sie sich nun, auch nur vorübergehend eine Stellung anzunehmen, die ihrem geplanten Ziel nicht ganz entspricht.

Man denke zum Vergleich einmal an die Probleme, mit denen die heimkehrenden' Frontsoldaten zu kämpfen hatten. So mancher, der im Krieg ein großer. Held war, versagte trotzdem oder gerade deshalb im bürgerlichen Lèben. Auch darf man nicht vergessen, daß die meistën der aus Ungarn geflüchteten Jugendlichen bisher mehr oder minder straff organisiert waren. Nun haben sie diesen "Halt". verloren, der große Schwúng der Revolution trägt sie jedoch noch immer weiter, nur wissen sie jetzt nicht mehr wohin...

Die unnatürliche Lebénsweise in den Lagern verändèrt Menschen, Maßstäbe, Probleme und Lebensansichten. Man findet plötzlich sehr viel Zeit, dem .Verlorenen nachzuweinen. Begriffe wie Mutter, Frau, Heimat, Kind, ja oft nur der Gedanke an ein Paar "fast neue Schuhe", die mañ zurücklassen mußte, gewinnen jetzt eine kaum faßbare Wichtigkeit und erwecken eine ungeheure Sehnsucht. Die Tragödie der Nation und die Tragödie des Einzelmenschen werden eins. Für Außenstehénde sind die großen Worte, 'mit denen man diese Revolution so oft beschrieben hat, unvermeidlich $\mathrm{zu}$ allmählich sich, abnutzenden pathetischen Phrasen geworden."Für'die Mitwirkenden aber bleiben sie schmerzlich lebendig.

Das Problem wäre nicht völlig abgehandelt, würde 
man nicht auch die Situation der westlichen Gesellschaft, die diese Flüchtlinge beobachtet und aufnimmt, einer kurzen Analyse unterziehen. Man wird zugeben müssen, daß in der westlichen Gesellschaft von Anfang an das zweifellos aufrichtige Mitleid mit einem gewissen Prozentsatz von Sensationslust gemischt war. Die Ungarn, deren Tragödie für einige Wochen sogar die.pikanten Herzensangelegenheiten verschiedener gekrönter Häupter von den Titelseiten der Sensationsblätter verdrängte, wurden vielerorts als eine Art Wundertiere bestaunt. Wenn man aber eine große und ehrliche Sache zu einer Sensation macht, dann ereilt sie eines. Tages das Schicksàl aller Sensationen, das heißt: auf anfänglich brennendes Interesse folgt allmählich Gleichgültigkeit.

\section{Süddeutsche Zeitung, 'ünchen, 19. 2. 1957 \\ DER ERSTE GROSSE SCHAUPROZESS}

gegen Teilnehmer an dem ungarischen Volksaufstand begann am Montag in Budapest. Angeklagt sind die 25jährige Medizinstudentin Ilona Tóth, der 30jährige Journalist Obersovszky, der 27jährige Bühnenschriftsteller István Gáli und neun andere Ungarn, denen u. a. Mord, Mordversuch, Waffenbesitz und Aufhetzung zur Last gelegt werden. Zahlreiche Polizisten mit Maschinenpistolen. patrouillierten durch die Straßen rings um das Gebäude. Bei einer Vernehmung zur Person erklärte die angeklagte Studentin Ilona Tóth mit leiser Stimme, sie sei das einzige Kind eines Fabrikarbeiters. Als der 26jährige Schlosser Ferenc Gönczi gefragt wurde, ob sein Gesundheitszustand gut sei, erwiderte er: "Nein, die Russen haben mich furchtbar verprügelt." An dieser Stelle schnitt ihm der Richter das Wort ab und bedeutete ihm, jetzt nicht darüber zu sprechen.

Süddeutsche Zeituing, München, 16. 3.1957 (Bildunterschrift)

"Steh auf, Madjar! Es ruft dein Land..... Dieses Revolutionsgedicht des ungarischen Freiheitsdichters Petöfi spricht ein $16 j a ̈ h r i g e r$ auf improvisierter Bühne in einem 
Wiener Flüchtlingslager. Die aus ihrer Heimat geflüchte-ten Ungarn gedachten gestern, am Jahrestag dér Revolution von 1848; in Trauer und Schmerz des Freiheitskampfes ihres Volkes im vergangenen Herbst. - In Budapest riegelten Hunderte von Polizisten die Straßen $a b$, als die Führer der Kommunistischen Partei an den Denkmälern von Lajos Kossuth und Sándor Petöfi Kränze niederlegten. Nur etwa 300 geladene Gäste: waren zu der Feier zugelassen.

Neue Zürcher Zeitung, 15. 3.1957

DIE ANGST KÁDÅRS VOR DEM 15. MARZ Drohung mit einer sowjetischen Intervention

Frankfurter Allgemeine Zeitung, 25. 5. 1957.

PHILHARMONIA HUNGARICA

Geflüchtete ungarische Musiker bauen ein neues Orchester auf!

Ko. Wien, 24. Mai. In wenigen Wochen wird man auf den Plakatwänden westeuropäischer, auch deutscher Großstädte den Namen eines neuen Orchesters finden: "Philharmonia Hungarica" Freies Ungarisches Philharmonisches Orchester. Seine rund neunzig Mitglieder sind Flüchtlinge aus Ungarn. Fast alle sind Musiker, deren Können schon in ihrer Heimat unbestritten war. Sie kommen aus den Reihen der ungarischen Philharmoniker, vom Staatsopernorchester oder vom Budapester Rundfunkorchester, von dem fast die Hälfte aller Mitglieder nach Westén flüchtete...

Besucht man die ungarischen Philharmoniker an ihrer Geburts- und Werdestätte in Baden bei Wien und hört man in eben jenen Räumén des Badener Kursalons, die vor zwei Jahren noch Offizierskasino für das sowjetische Hauptquartier in Baden waren, ihrer intensiven Arbeit zu, so ist man zutiefst beeindruck. Künstler und Dirigenten, deren Urteil Gewicht hat, wie etwa Karl Böhm, Gottfried von Einem, und der Vorstand der Wiener Philharmoniker sparten nicht mit Lob und uneingeschränkter Anerkennung. Yehudi Menuhin eilte nach dem Divertimento für Streichorchester von Béla Bartók auf den jungen 
Dirigenten Zoltán Rozsnyay $\mathrm{zu}$, beglückwünschte ihn, dann drückte er dem Konzertmeister und den ersten Geigern die Hand und rief: "Wir sehen uns wieder! Bald! Ich werde mit euch spielen!" ...

Der Aufbau des ungarischen Orchesters ist Teil einer großangelegten Aktion, die von der Wiener kulturpolitischen Zeitschrift "Forum" ins Leben gerufen wurde, um den geflüchteten ungarischen Intellektuellen $\mathrm{zu}$ helfen. "Daß das Orchester zu großen künstlerischen Hoffnungen berechtigt, ' freut uns und krönt unsere Arbeit in den Augen der Offentlichkeit" ${ }^{\prime}$, sagt Tassilo Darócźi-Merhal, der Leiter der "Forum "-Kultur-Hilfe. "Aber es ist nicht das. Wesentliche. Viel wichtiger ist, daß wir hier versuchen, die Flüchtlingshilfe von einer ganz anderen Seite her anzupacken..."

So leben die 150. ungarischen Musiker, Schauspieler und Tänzer, die seit Anfang März im Hotel Esplanade in Baden untergebracht sind, um weniger als die Hälfte des normalen Pensionspreises in diesem erstklassigen Haus. Die Differenz trägt der Besitzer aus der eigenen Tasche. Jeder der in Baden lebenden Künstler hat nicht nur das Wohnen .und Essen frei, sondern er erhält noch ein monatliches Taschengeld von 400 Schilling (67 D-Mark). Kostenios hat die Stadtverwaltung den ungarischen Künstlern Räume für die Proben żur Verfügung gestellt. Neben dem Orchester arbeitet zur Zeit noch eine ausgezeichnete Ballettgruppe mit Tänzern der ungarischen Staatstheater und Schauspielerensemble, ..

\section{Abendzeitung, München, 21.6. 1957}

Neue Filme in München: "UNGARN IN FLAMMEN"

(Haff.) .... Hier wird nicht die Tragödie eines kleinen Zehnmillionen-Volkes nach billigen Schnulzenprinzipien verkauft, sondern mit nüchternem Ernst ein politischer Vorgang registriert, der einmal in den Geschichtsbüchern stehen. wird ... Ohne effektvoll konstruierte Dramatik blättert der Film die tausendjährige Geschichte Ungarns auf; eines Volkes, das die Rebellion gegen die Unterdrückung seinen Kindern weitervererbt hat - bis hin zu jenem 23. Oktober 1956, an dem der Eiserne Vorhang zer- 
riß, 'der sich nach einem furchtbaren Opfergang um so undurchdringlicher schloß ... Es müßte Wege geben, jeden Deutschen über 14 Jahren daran zu hindern, an diesem erschütternden Bilddokument vorüberzugehen.

Süddeutsche Zeitung, München, 23. 6. 1957

UNGARN VERLOR 208000 EINWOHNER

Genf (dpa). Ungarn hat durch den Aufstand im vergangenen Herbst und die folgende Flüchtlingswelle 208000 Menschen verloren. Das entspricht etwa dem natürlichen Bevölkerungszuwachs von zwei Jahren...

Süddeutsche Zeitung, München, 24.6.1957 FIFA BESTA TIGT UNGARN-SPERREN

(SZ) Der Exekutiv-Ausschuß der FIFA hat auf der Tagung in Zürich die vom ungarischen Verband über eine Reihe geflüchteter Spieler verhängten Sperren bestätigt. Damit sind Puskás, Czibor bis zum 3. April 1958, Kocsis, Grosics, Szolnok bis 3. Oktober 1957; sowie Garamvölgyi und Szabó bis zum 3. August 1957 gesperrt. Zu diesen Sperren tritt anschließend noch. eine einjährige Wartefrist, so daß Puskás und Czibor erst 1959 spielfrei werden...

Rhein-Neckar-Zeitung, Heidelberg, 26. 6. 1957

JUNGE UNGARN IN DEUTSCHLAND

Von Renate Schattler

Mehr als zehntausend ungarische Flüchtlinge sind in den vergangenen Monaten nach Westdeutschland gekommen, unter ihnen besonders viele Studenten und Jungarbeiter ...

"Wir hätten von Osterreich aus nach Amerika gehen können", sagen sie im persönlichen Gespräch, "aber diejenigen von uns, die sich damals im November für Amerika entschieden, suchten die Bequemlichkeit, das gute Leben. Wir, die wir uns für Deutschland entschieden, suchten etwas anderes... Das ,andere', das sie suchten, war das gleiche brennende Interesse an der politischen 
und geistigen Auselnandersetzung mit dem Osten, das sie erfüllt. Da wir ein geteiltes Land sind, glaubten sie, auch uns würden diese Fragen keine Ruhe Iassen, und mit ,uns' meinten sie nicht die Politiker und Journalisten, die darüber reden und schreiben, sondern die breite Masse des westdeuschen Volkes...

Sie dachten - auch das muß erwähnt werden! - auch noch an den deutschen philosophichsen Idealismus, und was sie suchten, war noch immer das Land Goethes und Schillers...

Was sie fanden, war ein Deutschland, das mit seiner bisherigen Geschichte scheinbar gebrochen hat, das nichts als Frieden will, und das zutiefst an sich selber zweifelt. Und sie deuten diesen Zweifel als Schwäche. Was sie weiter fanden, war ein Deutschland, in dem der "Lebensstandard" und die "soziale Sicherheit" ganz groß und das politische Interesse und - trotz aller Freundlichkeit und Freundschaft im persönlichen Bereich - das Interesse am Mitmenschen ganz klein geschrieben werden.

"Im Osten hat man sich bemüht, uns das Denken mit politischen Druckmitteln abzugewöhnen — ich fürchte hier wird es uns mit anderen Mitteln noch viel schneller abgewöhnt."

Das Bild des überarbeiteten Mannes, der sich zwar einen Volkswagen und Fernsehtruhe leisten kann, aber seine politische Meinung aus flüchtig überlesenen Schlagzeilen der Boulevardpressen bezieht, wird beschworen. Und es geht ihnen einfach nicht ein, daß wir hier anscheinend gleichgültig in einen guten Tag hineinleben, während ihnen unablässig der Gedanke an die gequälte Heimat und an das, was für sie Europa bedeutet, vorschwebt : : .

Noch ist auch ihr Wesen ganz aufgeschlossen, vertrauensvoll und von einer Wärme, die uns schmerzhaft deutlich klar werden läßt, wie gut wir Deutschen gelernt haben, uns voreinander zu verschließen. Aber werden sie sịch diese Aufgeschlossenheit ihres' Wesens erhalten, wenn sie auf sich selbst gestellt in einer Welt leben mūssen, in der der spontane Kontak't von Mensch. zu Mensch selten geworden ist?... 
Alphabetisches Verzeichnis der zitierten oder erwähnten Zeitungen, Zeitschriften und Nachrichtenagenturen:

Abendzeitung München, Allgemeiner Deutscher Nachrichtendienst (ADN), Arbeiter-Zeitung Wien, Associated Press (A.P), l'Aurore Paris.

Borba Belgrad, BZ (Berliner Zeitung).

Colloquium Berlin, Csepeli Ujság (Csepeler Zeitung) Budapest, Csillag (Der Stern) Budapest.

Daily Worker London, Deutsche Presse-Agentúr (dpa), Deutsche Woche (München)

Egyetemi Ifjuság (Akademische Jugend) Budapest, Englische Rundschau Köln, l'Express Paris.

Figaro Paris; Frankfurter Allg. Zeitung Frankfurt/M.

Gyỏri Munkás : (Györer Arbeiter) Györ/Ràab

Hamburger Abendblatt Hamburg, Hannoversche Presse Hannover, Hinter dem Eisernen Vorhang München, l'Humanité Paris.

Igazság (Die Wahrheit) Budapest, Irodalmi Ujság (Literarische Zeitung) Budapest.

Kis Ujság (Kleine Zeitung) Budapest.

Liberation Paris.

Magyar Füiggetlenség (Ungarische Unabhängigkeit) Budapest, Magyar Honvéd (Ungarischer Soldat) Budapest, Magyar Ifjuság (Ungarische Jugend) Budapest, Magyar Jövő (Ungarische Zukunft) Budapest, Magyar Nemzet (Ungarische Nation) Budapest, Magyar Szabadság (Ungarische Freiheit) Budapest, Magyar Távirati Iroda (Ungarisches Telegrafen-Büro), Magyar, Világ (Ungarische' Welt), Mittelbayerische Zeitung Regensburg, Münchner Merkur München.

National-Zeitung Basel, National-Zeitung Ost-Berlin, Neues O'sterreich' Wien, Neue Zürcher Zeitung Zürich, Népakarat (Volkswille) Budapest, Népszabadság Volksfreiheit) Budapest, Népszava (Volksstimme) Budapest, News Chronicle London, New York Times Nèw 'York. Osservatore Romano Vatikanstadt, Osterreichische Neue Tageszeitung Wien, Osț-Dienst Hamburg.

Paris-Match Paris, Politika Belgrad, . Populaire Paris,

Prawda Moskau.

Rhein-Neckar-Zeitung Heidelberg, Rudé Právo Prag, Reuter.

Der Spiegel Hamburg, Süddeutsche Zeitung München, Szabad Ifjuság (Freie Jugend) Budapest, Szabad Nép 
(Freies Volk) Budapest, Szabad Szó (Freies Wort) Budapest.

Tages-Anzeiger Zürich, The Times London, Time Magazin New York, TASS.

United Press (UP)

Valoság (Die Wirklichkeit) Budapest, VertriebenenAnzeiger München.

Die Welt Hamburg.

Zycie Warszawy Warschau.

\section{S T I C H W O R T VERZE I C H N I S}

Apró Antal, - S. 47

AVO, "Allam Védelmi Osztály" = Staats-SicherheïtsDepartement.

DISZ, "Dolgozó Jfjuság Szövetsége" $=$ (Kommunistischer Einheits-) Verband der Werktätigen Jugend

ELTE, "Eötvös Loránd Tudomány Eqyetem" = LorándEötvös-Universität der Wissenschaften, - S. 41/42

Erdei Ferenc, - S. 75

Farkas Mihály, - S. 7, 10

Geró Ernő, - S. 21, 7, 18, 19, 20, 23, 68

Háy Gyula, Schriftsteller, führende Persönlichkeit im Petỏfi-Kreis, - S. 17, 66

Horthy Miklós, vitéz Nagybányai -, - S. 113

Honvêd, Bezeichnung des ungarischen Soldaten $=$ "Heimatverteidiger"

Kádár János, von Jugend an Kommunist, 1945 stellvertretender Befehlshaber der Polizeikräfte in Budapest, 1948-1950 Ininenminister, 1951 verhaftet und gefoltert, 1945 freigelassen, 1955 Erster Sekretär des Parteikomitees des Komitats Pest, am 18. Juli 1956 Mitglied des ZK, am 19. Juli Sekretär des ZK, am 25. Okt. Erster Sekretär der Partei, - S. 23, 69, 71

Kéthly Anna, - S. 59, 61, 67

Kiss Károly, - S. 47

Komitat, ungarische Provinzen, mit verhältnismässig weitreichender, historisch bedingter Selbstverwaltung, am ehesten mit den französichen Departements vergleichbar. Ungarn besteht heute aus 19 Komitaten.

Kónya Albert, - S. 42

Kossuth Lajos, - S. 22, 24, 98, 113, 122

Kossuth-Wappen, (nach dem Staatsmann des ungarischen 
Freiheitskrieges 1848/49: Lajos Kossuth), das ungarische Nationalwappen ohne die darüber befindliche Stephanskrone, seit 1848/49 Symbol der demokratischen Republik, - siehe Bild auf S. 33

Kovács Bèla, - S. 66

Kún Béla, - S. 113

KPSU $=$ Kommunistische Partei der Sowjet-Union

15. März , Nationalfeiertag zum Gedächtnis an die von der akademischen Jugend und den Intellektuellen begonnenen Revolution von 1848/49, mit dem Namen Petöfis verknüpft

MEFESZ = Föderation ungarischer Universitäts- und Hochschulstudenten, gegründet im Oktober 1956

MTI, "Magyar Távirati Iroda" = Ungarisches Telegrafen-Büro (Nachrichtenagentur)

Mindszenty Jozsef, Fürstprimás von Ungarn -, S. $57,17,26,68,84,85,97$

Maléter Pál, genannt der Held von Budapest, geboren 1920, 1942 Leutnant, 1944 als Partisan an der Seite der Sowjets, 1947 Oberstleutnant, Kommandeur der Leibwache seit, 1949 im Verteidigungsministerium, S. 75

Münnich Ferenc, - S. 47/48, 69

MDP, "Magyar Dolgozók Pártja" = Ungarische Arbeiterpartei, die KP Ungarns.

Nagy Imre, - S. 21, 7, 8, 14, 19, 20, 48, 64, 75, 77, 85, 97, 101

6. Oktober, Nationalfeiertag, Gedenktag der Hinrichtung von 13 Generälen des Freiheitskrieges, 1849.

Pet̋fi Sándor (1823-49), einer der grössten Dichter, führende Persönlichkeit im Freiheitskampf von 1848/49, fjel als Major im Kampf gegen russiche Truppen welche die Freiheitsbewegưng niederschlagen halfen, - S. 51, 107, 121,122

Piros I_ászló, - S. 18

Rajk László, - S. 7, 14

Rálkosi Mátyás, - S. 21, 7, 10, 14, 68

Räterepublik 1919, - S. 21, 23, 113

Sőtér István, - S. 42

Szijártó Lajos, - S. 12

Szántó Zoltán, - S. 48

Tildy Zoltán, - S. 65

Ungarischer Schriftstellerverband, - S. 64, 76, 80 ZK = Zentralkomitee der Kommunistischen Partei 


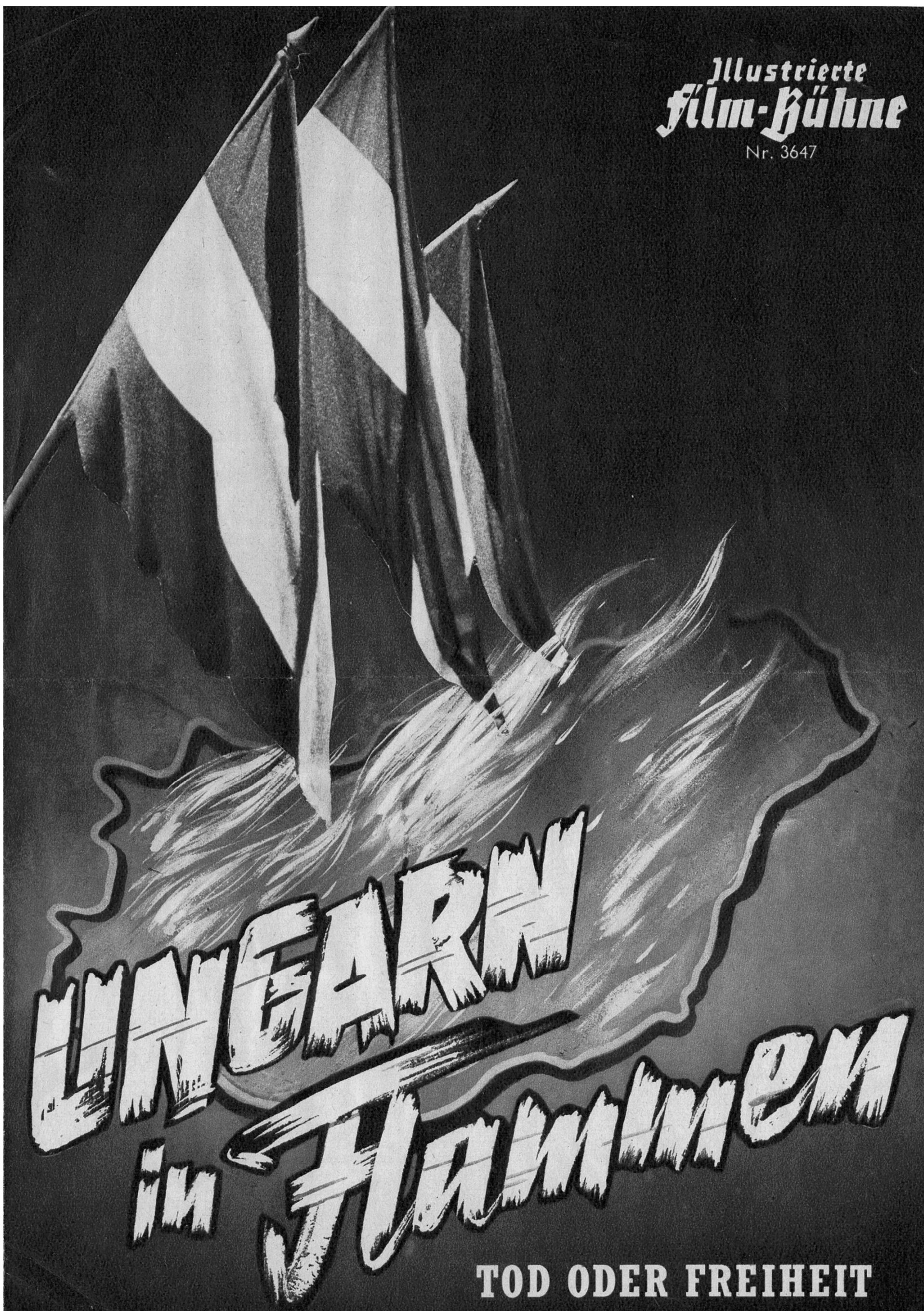




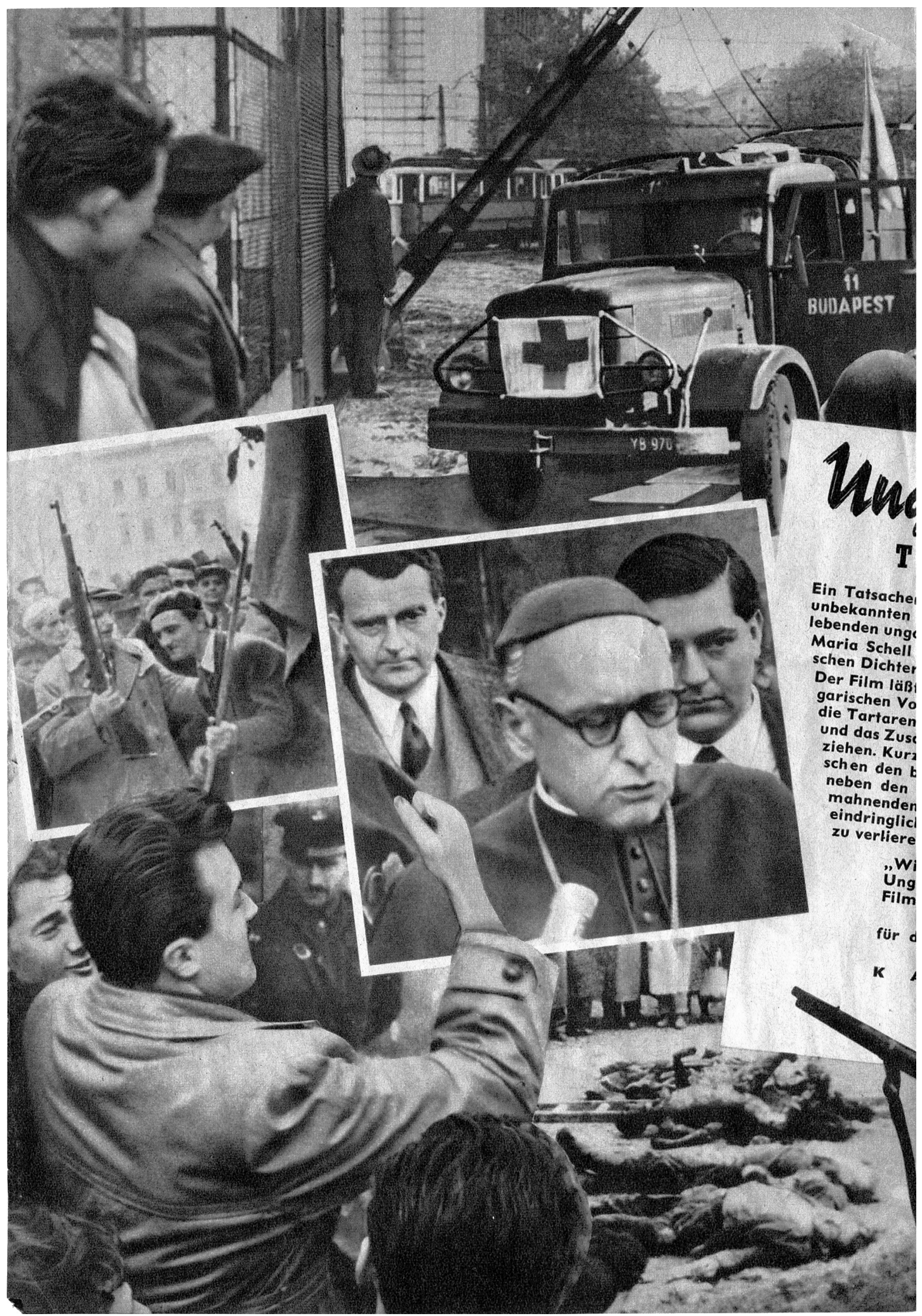




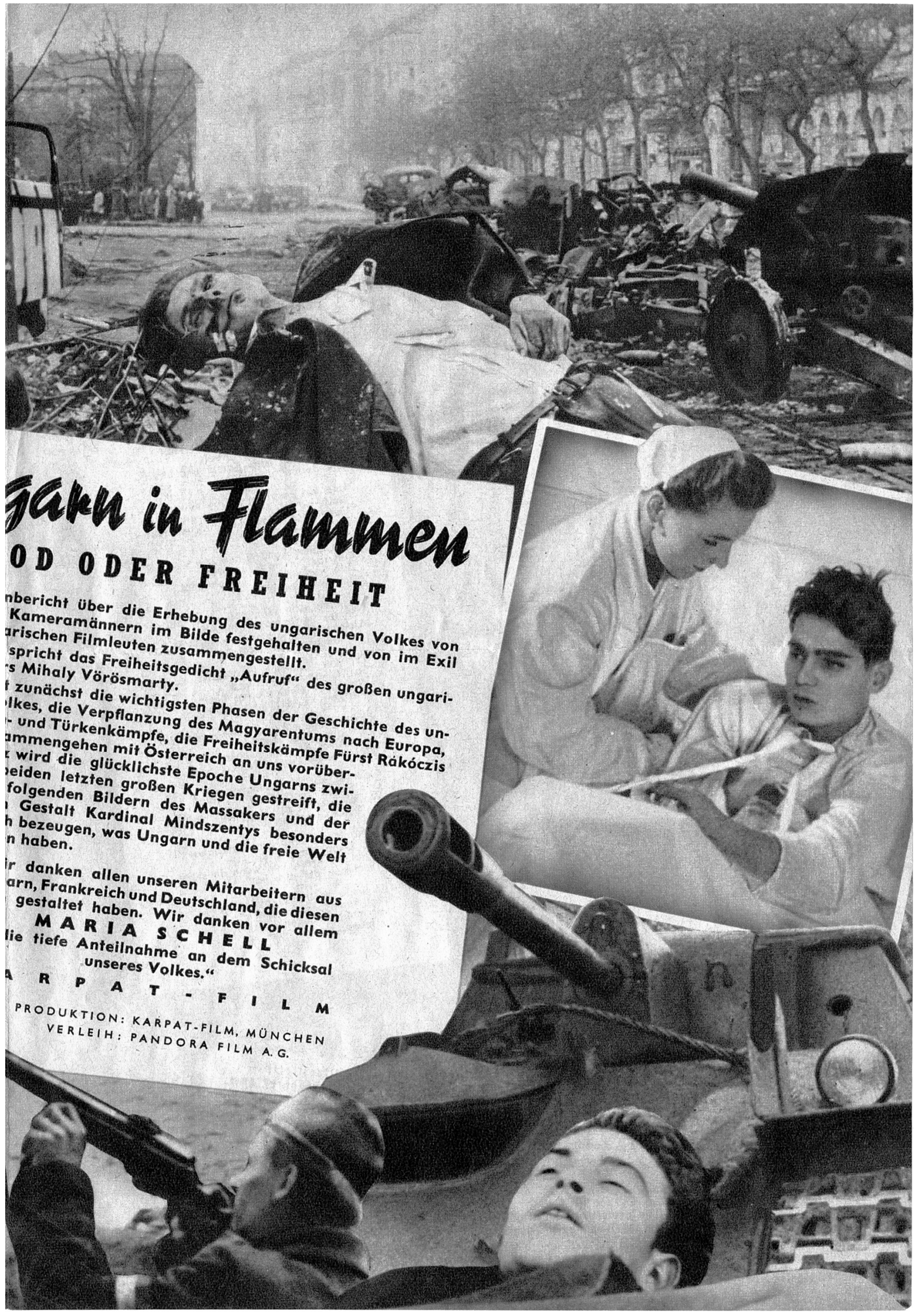




\section{Ergänzung}

\section{des ,Leitfadens zur Vor- und Nachbesprechung zum Dokumentarfilm „Ungarn in Flammen“}

(Zusammengestellt im September 1971)

Eine „Inhaltsangabe“ zum Film „Ungarn in Flammen" wurde im Jahre 1967 ausgegeben. Sie sollte auch ein Leitfaden zur Vor- und Nachbesprechung bei der Vorführung des Anfang 1957 hergestellten Filmes "Ungarn in Flammen" sein. Es ist angebracht, diesen Leitfaden mit objektiven Informationen über die inzwischen in Ungarn eingetretene Entwicklung zu ergänzen.

\section{Entwicklung in Ungarn und ihre Ursachen}

Es ist mit Freude fiestzustellen, daß das Leben in Ungarn in den letzten Jahren in drei wesentlichen Richtungen liberalisiert wurde:

1. Die Ungarn erhielten mehr Freiheit,

2. das allgemeine Lebensniveau hat sich verbessert und

3. die Ausreise nach dem Westen wurde erleichtert.

ad 1.

\section{Die Ungarn erhielten mehr Freiheit}

Einige Jahre nach dem ungarischen Volksaufstand hat die Budapester KadarRegierung die gehaßte politische Polizei (AVO) aufgelöst. Dadurch verschwand die ständige Angst der Bevölkerung von einer unerwarteten Verhaftung, Internierung usw. Die Ungarn benützen nun jede Möglichkeit, das System und seine Fehler zu kritisieren und ziemlich offen daruber zu spotten. Die kommunistische Regierung konnte diese 'Erleichterung gewähren und etwas mehr "Maulfreiheit" dulden, weil sie einen nochmaligen Aufstand nicht zu fürchten braucht. Sie wußte zwar, daß das Volk mit dem kommunistischen System weiterhin nicht einverstanden ist, aber sie ist sich auch dessen bewußt, daß das Volk keinen wesentlichen Widerstand mehr gegen das Regime leisten wird.

Die Gründe: Das Volk zog aus der blutigen Niederschlagung der OktoberRevolution die Lehre, daß es allein nicht genügend stark ist gegen dis noch immer in Ungarn stationierten russischen Besatzungstruppen zu bestehen. Weiterhin, weil es sah, daß die Westmächte auch der militärischen Intervention der Warschauer Pakt-Staaten in der Tschechoslowakei genau so tatenlos zusahen, wie beim Ungarnaufstand von 1956. Die inzwischen angekündigte 
„Breschnew-Doktrin“,*) die von den westlichen Regierungen ohne ernsthaften Widerspruch hingenommen wurde, hat auch die letzte Hoffnung auf eine freiheitliche Zukunft in absehbarer Zeit vom ungarischen Volke genommen.

Zwar hat das Regime die AVO abgeschafft. aber durch seine Monopolstellung bei den Massenmedien ist weiterhin die ganze Presse, Film, Rundfunk und TV in der Hand der alleinherrschenden Partei und kann so die ganze Bevölkerung, besonders aber die heranwachsende Jugend, ständig mit ihrer einseitigen und meistens unwahren Information, das heißt, Propaganda, in ihrem Sinne beeinflussen.

\section{ad 2.}

\section{Das allgemeine Lebensniveau hat sich verbessert}

In landwirtschaftlicher Hinsicht war Ungarn in früherer Zeit einer der reich-sten Länder Europas. Nach der Einführung des kommunistischen Systems, wurden zuerst die großen Gutsbesitzer, später auch die kleinsten Bauern enteignet und. in Kolchosen eingeteilt; wo der Bauer auf seinem früheren Boden nur als Arbeiter arbeiten konnte. Als Folge wurde in den Kolchosen nur ein Bruchteil dessen produziert, was früher die selbständigen Bauern bei einem freiheitlichen Wirtschaftssystem produzieren konnten. Die Konsequenz: Lebensmittelmangel in den Städten und oin allgemein sinkendes Lebensniveau; sogar Not. Auch die Verstaatlichung der Wirtschaft, Groß- und Kleinindustrie, hat viele negaitive Folge: die führenden Fachkräfte flohen teils ins Ausland, teils wurden sie eingekerkert und ihre Positionen wurden mit zuverlässigen Parteimitgliedern sehr oft ohne jeglicho Fachkenntnisse, besetzt. Es wurde die marxistische Planwirtschaft eingeführt, wo aber teils wegen der fehlenden Fachkräfte, teils durch Fehlplanungen ein heilloses Durcheinander entstand und die Produktion - Qualität und Quantität - weiter heruntersank. Auch der Umstand hat sich sehr nachteilig ausgewirkt, daß die russische Besatzungsmacht riesige Kriegsreparationsleistungen verlangte und das Land auf jede nur mögliche Weise ausbeutete.

Nach dem ungarischen Volksaufstand mußten selbst die Russen einsehen, daß sich eine solche. Ausbeutung auf die Dauer nicht aufrechterhalten läßt. Nach Erfüllung der Reparationen haben die Russen sich damit zufrieden gegeben, daß sie sich durch langfristige Wirtschaftsverträge mit der ungarischen Regierung einseitige wesentlich $\Theta$ Vorteile gesichert haben.

Dafür haben die Russen der — von ihren Standpunkt aus gesehen -erfolgreich arbeitenden Budapester Kadar-Regierung etwas mehr Freiheit, bzw. einen größeren wirtschaftlichen Spielraum gewährt. Darauf hat die ungarische Regierung zwei wichtige Wirtschaftsreformen eingeführt.

a) es wurde den Kolchos-Bauern erlaubt, bis zu 1 Joch Boden in unmittelbarer Nähe ihrer Wohnung als Privat-Benützungsland zu bebauen und zu verwalten. Dem Bauer wurde erlaubt, alles was er dort produzierte, bzw. züchtete (Naturalien und Kleinvieh), auf dem freien Markt zu verkaufen.

*) Diese Doktrin stellt die beschränkte Souveränität der ,sozialistischen Staaten" auf. Das heißt, ein Land, welchem Moskau schon ein kommunistisches Diktatursystem aufgezwungen hat, darf nicht zum freiheitlich-demokratischen System zurückkehren. Wenn nun dieses System von innerpolitischen Kräften bedroht wäre, sind alle benachbarten "sozialistischen" Staaten berechtigt (auf Befehl von Moskau sogar verpflichtet), dies auch mit Waffengewalt zu verhindern. 
Durch diese Maßnahmen wurden die ungarischen städte mit genügend Lebensmitteln versorgt und die Bauernschaft konnte ihr Lebensniveau spürbar verbessern. Bezeichnend ist, daß diese kleinen Benützungsgebiete, die insgesamt nur etwa $5 \%$ der gesamten landwirtschaftlichen Bodenfläche ausmachen, mehr und bessere Waren auf den Markt bringen, als die Kolchosen selbst.

b) In den Industrie- und Handelssektoren hat die ungarische Regierung ab 1. Januar 1968 grundlegende Wirtschaftsreformen unter dem Namen „Neuer Wirtschaftsmechanismus" eingefüht und damit eine der marxistisch-sozialistischen Grunddogmen, die Planwirtschaft abgeschafft. Durch diese Reformen wurde es ermöglicht, daß die einzelnen verstaatlichten Betriebe zwar im Rahmen eines zentralen Produktionsprogramms - eines eigenen Produktionsplan vorbereiteten und selbständig dafür sorgen konnten, daß nur marktgerechte Waren und zwar in der benötigten Menge, hergestellt wurden. Dadurch entstanden örtlichs Untermehmungsleitungen, die ihre Betriebe mit voller Verantwortung leiten konnten, und so entwickelte sich zwischen diesen Unternehmen ein gewisser Wettbewerb. Gleichzeitig wurde eingeführt, daß die Direktoren und führende Fachkräfte jährlich Gewinnanteile bekommen dürfen; das bedeutet eine weitere Abweichung vom sozialistischen Wirtschaftssystem. Durch diese Reformen verschwanden nach und nach die Parteigünstlinge aus den Unternehmungsleitungen und machten versierten Fachkräften Platz. Diese Reformen haben sich mit der Zeit mehr oder weniger bewährt. Die Produktion erhöhte sich wesentlich und auch die Qualität der Waren verbesserte sich. Diese Erfolge ermöglichten wiederum, daß sich auch die Löhne um 10-40\% verbesserten. Ein Beispiel: Vor dem Volksaufstand verdiente ein Arbeiter im Durchschnitt ca. 1400 Forint monatlich, umgerechnet ca. 140-200 sfr.; jetzt bekommt ein Arbeiter rund 2000-2400 Forint, das heißt, rund 200-300 sfr. monatlich.

c) Die ungarische Regierung hat in den letzten Jahren ca. 40.000 Gewerbeschein an Privatunternohmer ausgegeben und dadurch wurde der bis dahin katastrophale Handwerkermangel, der für die einzelnen Haushalte kaum noch erträglich war, im Wesentlichen behoben.

Diese Privatunternehmer (MASZEK genannt) dürfen aber höchstens nur zwei Angestellte beschäftigen. Diese wenigen Privatunternehmer und teilweise auch ihre Angestellten bilden zusammen mit den Parteifunktionären, führenden Wirtschaftsfachkräften und Direktoren eine neue Klasse, welche ein Vielfaches davon verdient, als die übrigen einfachen Staatsbürger.

\section{ad 3.}

\section{Die Ausreise in den Westen wurde erleichtert}

Während ihrer Bemühungen die - durch die Verstaatlichungen aufgetretenen wirtschaftlichen Schwierigkeiten zu beheben, erkannte die ungarische Regierung, daß sie ohne westliche Devisen den gewüschten Fortschritt nicht erreichen kann. Um die dringend benötigten Devisen zu erhalten, war es notwendig, entweder den Export in den Westen zu heben, oder (dem jugoslawischen Beispiel folgend) den Fremdenverkehr zu intensivieren. Nachdem die Exportförderung viel zu schwer ist; demgegenüber Ungarn viele Fremdenverkehrsattraktionen und Naturschönheiten (Plattensee, Pußta, Donau, Budapest usw.) zu bieten hat, entschloß sich die Regierung ein großangelegtes Fremdenverkehrsprogramm auszuarbeiten und zu verwirklichen. Seitdem jährlich einige hunderttausend westliche Touristen nach Ungarn kamen. Dies be- 
deutete aber für die Ungarn neben dem wirtschaftlichen Vorteil einen unmittelbaren Kontakt mit westlichen Besuchern und die Bevölkerung erkannte, wie viel besser die westlichen „Kapitalisten” leben. Die Folge: die Regierung konnte die bis dahin fast hundertprozentige "Einkerkerung“" hinter Stacheldraht und Minenfeldern nicht aufrechterhalten und mußte die Ausreisebestimmungen in den Westen erleichtern, was allerdings nur sehr vorsichtig und nur in einem bescheidenen Umfang gieschah; zuerst nur kontrollierte Gesellschaftsreise, später auch Einzelreisen. Heute können schon viele Ungarn die westlichen Länder besuchen. (Wer jedoch keine Ausreisegenehmigung bekommt, muß auch noch heute durch Stacheldraht und Minenfelder die Flucht wagen.)

All diess Erleichterungen haben selbstverständlich eine gewisse Freude bei den Ungarn hervorgerufen. Man kann ruhig sagen, daß die Ungarn gegenüber den anderen Ostblockstaaten heute freiere Leben haben und daß es in erster Linie an den Ungarnaufstand von $1956 \mathrm{zu}$ verdanken ist. Man kann auch behaupten, daß der jetzige Regierungschef, Janos Kadar - trotzdem er im Jahre 1956/57 als Werkzeug von Moskau eine traurige Henkerrolle gespielt hat - heute eine gewisse Popularität und Ansehen genießt. Die Ungarn glauben, daß nur er diese Erleichterungen für sie in Moskau aushandeln konnte. Man wünscht sogar, daß J. Kadar bleibt, weil die Bevölkerung fürchtet, nach dem Motto "etwas Besseres kommt selten nach", daß bei einem Führungswechsel die ganz schlimmen Zeiten wiederkehren könniten.

\section{Die negtive Seite:}

1. Russische Besatzung und Abhängigkeit von Moskau.

2. Keinerlei Pressefreiheit (offene Kritik und Opposition ist verboten).

3. Das Volk darf bei den Staatsgeschäften nicht mitreden. Die "Abgeordneten" im „Parlament" und in den "Gemeinderäten" werden nicht vom Volk" gewählt, sondern von der Partei ernannt - die sogenannten "Wahlen" sind nur befohlene Annahmen von vorgedruckten Einheitskandidatlisten.

4. Nachdem der Staat auf atheistisch- (gottlosen) marxistischen Prinzipien aufgebaut ist, werden die Kirchen als Staatsfeinde angesehen und Gläubige sind, vor allem wenn es um die Besetzung höherer Positionen um öffentlichen Leben geht, unerwiunscht. Noch werden die Kirchen geduldet, sind aber stark kontrolliert. Es gibt jedoch eine vom staat gegrundete und geförderte sogenannte „Friedenspriester"-Bewegung, durch die versucht wird, die Kirche als Propagandist für den "sozialistischen Staat“ zu mißbrauchen. 


\title{
Militärgeschichtliche Mitteilungen
}

\author{
Herausgegeben \\ vom Militärgeschichtlichen Forschungsamt
}

The Hungarian revolution twenty years after. Selected papers and perspectives.

Kingston, Ontario 1976. S. 71-210. (= The Canadian-American review of Hungarian studies. Vol. 3, No. 2. Special issue.)

Ubber 3000 Tote, 15000 Verwundete, 200000 Geflüchtete, 12000 Inhaftierte, 453 Hingerichtete (bis 1961). Diese Verluste, die das knapp 10 Millionen kleine ungarische Volk erlitt, sprechen für sich. Auf sowjetischer Seite: 2000 Gefallene und Verwundete ${ }^{1}$.

Regierungschef Imre Nagy hatte die "Weltöffentlichkeit« am 4. November 1956 alarmiert und um Schutz gebeten für die Neutralität seines Landes, das den Warschauer Pakt verlassen hatte ${ }^{2}$ : "Unsere Truppen stehen im Kampf; die Regierung ist auf ihrem Platz. "Doch der damalige ungarische Generalmajor Béla Király zerstört jetzt die gängige Auffassung, wonach Nagy spätestens an jenem Sonntag entschlossen gewesen sei zum Krieg für die gerechte Sache.

Der 1951 eingekerkerte, erst 1956 befreite Kommandeur der Budapester Kriegsakademie diente der Regierung Nagy, die nach dem Volksaufstand vom 23. Oktober gebildet worden war, als Hauptstadt-Kommandant und Oberbefehlshaber der Nationalgarde. 20 Jahre nach dem eher gemutmaßten als gewußten Hergang der zweiten ungarländischen bewaffneten Sowjetintervention hielt Király, inzwischen Professor für Militärgeschichte am Brooklyn College der Universität New York, einen klärenden kleinen Vortrag vor einer wissenschaftlichen Gesellschaft; das vorliegende Sonderheft der kanadisch-amerikanischen Fachzeitschrift für Hungarologie druckt ihn ab. Die Uberschrift (The first war between socialist states) ist der Schlüssel zur inneren Logik des Geschehens. Der quasi militärische Nachrichtendienst, den das Volk bis zur ungarischsowjetischen Grenze organisiert hatte, funktionierte tadellos. Mißtrauisch wurde im ganzen Land jede Bewegung der russischen Truppen beobachtet, sofort der nächsten Rundfunkstation mitgeteilt und von den Provinzsendern an die Hauptstadt gemeldet im Klartext, zur Orientierung für jedermann ${ }^{3}$; beschwichtigenden Erklärungen der Regierung und Marschall Schukows wurde öffentlich widersprochen in diesem einzigartigen Senderdialog ${ }^{4}$, weil doch Eisenbahner,

MGM 2/1978 
Straßenarbeiter, Bauern die Marschkolonnen und Kundschafter die Biwaklager sahen, und der Feindfunkverkehr mitgehört wurde von Studenten, die allesamt Russisch als Pflichtfach hatten. So geschah denn der Angriff keineswegs überraschend "im Morgengrauen" oder unvermittelt auf Budapest - berichtet Király -, sondern war die ganze Nacht hindurch im lärmenden Kampf vorgetragen worden. Aber Alt-Sozialist Nagy verweigerte den ihrer militärischen Führung beraubten Ungarn ${ }^{5}$ das letzte Instrument zur Befehlsübermittlung und Koordinierung, den Rundfunk. Királys Aussage ist klar, leidenschaftslos, grauenhaft:

"During the night of November 3-4, the advancing Soviet columns opened fire on the garrison at Kiskunhalas ${ }^{6}$. I at once relayed this information to Imre Nagy, with whom I had a direct telephone line. My reports became more and more frequent as the Soviet onslaught engulfed us." Es eilt: Nagy oder Király selbst müßten den strengen Befehl widerrufen, der den ungarischen Truppen das Schießen darum verbietet, damit die Russen keinen Kriegsvorwand bekämen; aber der Regierungschef erlaubt es nicht.

»Nagy told me that Soviet Ambassador Andropov . . . had assured him . . . that all that was happening was the result of a misunderstanding. The telephone was not picked up in Moscow, of course, when Nagy had tried to contact the Soviet government. «

Trotzdem: Nagy will auch keinen Verteidigungskrieg, will auch nicht ausgeflogen werden aus der mittlerweile zernierten Hauptstadt, der sein später Rundfunkappell nicht mehr helfen kann. Lageberichte möchte er nicht.

»Thank you. I don't need any more reports. « Király schließt: » Our troops are in combat<, he had said. That was neither an encouragement to fight nor advice to surrender . . . He left the decision to the individual freedom fighter and the judgment to history. «

Ob General Királys Männer dies erfuhren, mit denen er kämpfend bis Mitte November nach O'sterreich retirierte ${ }^{7}$, notiert der Historiograph Király nicht. Er fällt auch kein Urteil über den später hingerichteten ungarischen Regierungschef.

Bezüglich der sowjetischen bewaffneten Intervention wiederum steht heute fest: Chruschtschow wußte sich im voraus straffrei, nachdem Tito ihm eine Art Garantie für Washingtons Stillhalten gegeben hatte ${ }^{8}$. Für Tito selbst war früher alles besser verlaufen, erklärt Király (S. 150):

»When the Korean war broke out, the East Central European armies were poised to strike against Yugoslavia . . . The United Nations' resistance in Korea made it seem likely that an attack on Yugoslavia would also have been resisted, and Stalin was not ready to run that risk. «

Die verlorenen Aufständischen ahnten, daß sie - auf komplizierte Weise-der Entscheidung der Westmächte zum Opfer fielen, Truppen am Suezkanal einzusetzen ${ }^{9}$. Weil nicht Formalien den Ausgang des beschlossenen Geschehens bestimmten, mag zwar in praxi gleichgültig sein, ob Nagy den Warschauer Pakt am 1. November morgens oder nachmittags aufkündigte, doch vom historiographischen Standpunkt ist bedauerlich, daß P. Gosztony (S. 150) über Zeitpunkt wie Umstände des Schrittes unzutreffend berichtet ${ }^{10}$. Die Erschütterung von 1956 wirkte in Deutschland noch 10 Jahre später so stark nach, daß zum Jahrestag zwei dicke Bücher erscheinen konnten ${ }^{11}$; gewichtig das wissenschaftliche Sammelwerk, dessen Autoren aber, soweit Ungarn, fast ausnahmslos Emigranten von vor 1956 waren. Sie betrachteten diesen Freiheitskampf als eine von mehreren Etappen der gesamten Nachkriegsentwicklung, zusammen mit der politischen wie der Literaturgeschichte, Kirchen- und Rechtsgeschichte (staats- und völkerrechtliche Aspekte des Menschenrechtsgedankens behandelte ein Deutscher). 20 Jahre nach 1956 rentiert sich im deutschsprachigen Raum keine Gedenkschrift, und auch das vorliegende Hungarologie-Sonderheft kam nur durch kanadisch-bundesstaatliche Subvention sowie privates Geldsammeln zustande (Editor's foreword, S. 72). Hier nun schreiben 1956er Flüchtlinge, allerdings älteren Jahrgangs, noch nicht die Studenten und Oberschüler von damals, die auch schon am Lehrpult stehen. Ihr Bezugspunkt ist 1956, nicht 1945. Ihre Themen: Politik, erlebte Militärgeschichte, Volkswirtschaft, abermals Politik, prägnanter und härter als bei den Voraus-Emigrierten; und noch ein Wichtiges: Bibliographie. In 15jähriger systematischer Kleinarbeit sind alle Druckwerke 1956-1976 über die ungarische Revolution erfaßt, gleichwo erschienen. Erstaunlich, bestürzend: auf der ganzen Welt und mitgerechnet auch die kommunistischen Propagandaschriften und "Weißbücher « über die »konterrevolutionäre Verschwörung «, nur 730 Titel. Wieviel oder wie wenig bekannt wurde in der breiten, abstimmberechtigten "Weltöffentlich- 
schüre, schwedisch 2, slawische Sprachen 3 (nur kommunistischer Standpunkt), griechisch 1, italienisch 2, ungarisch 30 , deutsch 14 , französisch 15, spanisch und protugiesisch 7 , englisch 42. Ein erschreckendes Informationsgefälle und ein beträchtlicher Teil der Veröffentlichungen bewußte Desinformation.

Die 730 Titel und auch die Beiträge in den Gedenkschriften von 1976 wie 1966 geben dem damaligen Geschehen unentwegt andere Namen. War es eine Revolution, aus kommunistischer Sicht eben Konterrevolution? Volkserhebung, Putsch und Armeemeuterei, l'insurrection hongroise, revoluçao popular, Freiheitskampf, Krieg, la batalla, vielleicht nur tragische Affäre, les évènements de Hongrie? Diese wichtige Definition fehlte bislang und war schwierig, weil die Akteure selber sich unterschiedlich bezeichneten; sogar Nagy und der zu den Russen übergelaufene Kádár ${ }^{12}$ gerieten in terminologische Konkurrenz. Király (S. 115f.) stellt nunmehr klar:

"It was in fact a revolution in the proper sense of the word: force was unintentionally used by those demanding change, and quite intentionally, the old regime was replaced with a new one ... Revolutions are domestic affairs; . . . the revolutionary regime was destroyed by international war.«

Die Revolutionäre von 1956 erkoren das kronelose ungarische Wappen der Kossuth-Revolutionäre von 1849 als das Ihre. An L. Kossuths Ideen knüpfte auch das von Magyar Szabadság(Ungarische Freiheit) am 1. November 1956 veröffentlichte föderalistische Programm an, das P. Pilisi erörtert (La Révolution Hongroise de 1956 et l'idée de la Conféderation Danubienne). Mit diesem Beitrag, der auch deutschsprachiges Schrifttum ${ }^{13}$ nennt, wird der Rückblick zugleich Ausblick, der freilich seit 1956 verstellt ist wie einst: 1849 von 200000 Russen, die damals Wien zur Hilfe rief ${ }^{14}$.

Josef Gerhard Farkas

1 Budapest bezifferte lediglich die materiellen gewaltigen Verluste. Die neuen, modifizierten ausländischen Schätzungen der Menschenverluste nennt im vorliegenden Sonderheft P. Gosztony: The Hungarian revolution of 1956, S. 152.

2 J. G. Farkas: Die ungarische Revolution 1956. Bd 1: Rundfunk-Dokumente. München, Köln 1957, S. $115 \mathrm{f}$.

3 Ebd., S. 79 f., $81 \mathrm{f} ., 84,89,103$ f., 108-111.

4 Ebd., S. 79 f., $81 \mathrm{f} ., 84,101$.

5 Uber die Gefangennahme des Verteidigungsministers Generalmajor P. Maléter und seines Stabes auf dem Bankett, das die Sowjets nach Abschluß der langen Verhandlungen über Details des von ihnen versprochenen und ihnen zugesicherten ehrenvollen Truppenabzugs veranstalteten, s. V.v. Zsolnay: Zwanzig Jahre ungarische Geschichte von 1945-1965. In: Ungarn zehn Jahre danach 1956-1966. Ein wissenschaftliches Sammelwerk. Hrsg. von W. Frauendienst. Mainz 1966, S. 35.

6 Stadt im Bezirk Bács-Kiskun, $133 \mathrm{~km}$ südlich von Budapest, 30000 Einw.

7 Zur Geschichte der europäischen Volksarmeen. Hrsg. von P. Gosztony. Bonn-Bad Godesberg 1976, S. 179 Anm. 17.

8. Mit Zusatzmaterial neuen Datums belegt es Gosztony (s. Anm. 1), S. 149.

9 Farkas (s. Anm. 2), S. 124 und G. Urban: The Nineteen Days. A broadcaster's account of the Hungarian revolution. London, Melbourne, Toronto 1957, S. 280.

10 Vgl. Farkas (s. Anm. 2), S. 97 f. Mit dem Zeitplan der sowjetischen Invasion und dem Beginn der zweiten Intervention beschäftigte sich das Dezemberheft 1956 der »Wehrkunde», München.

11 Das von W. Frauendienst herausgegebene Sammelwerk (s. Anm. 5) und Der ungarische Volksaufstand in Augenzeugenberichten. Hrsg.: P. Gosztony. Düsseldorf 1966.

12 János Kádár erschien den Sowjets 1956 unter den vier heimlich übergelaufenen Ministern Nagys als der geeignetste Exekutionsgehilfe. Bis dahin stellvertretender Generalsekretär, ist inzwischen in seiner vita aufgehellt: 1.1949 gelang ihm das "Schuldgeständnis « seines Innenminister-Vorgängers Rajk, der hingerichtet und 1956 voll rehabilitiert wurde; 2. am 30.10.1956 formulierte er die angebliche Entschlossenheit des Nagy-Kabinetts zu selbstmörderischem Kampf; 3. am 4.11.1956 ernannte er sich im sowjetischen Uzhgorod zum Regierungschef Ungarns und protestierte bei der UNO gegen das Erörtern der »rein internen Angelegenheit der Ungarischen VR «; 4. seinem (de facto) Amtsvorgänger Nagy garantierte er freies Geleit aus dem Asyl der jugoslawischen Botschaft, doch führte dessen Weg zum Geheimprozeß und Schaffott. Dazu 1. Zsolnay (s. Anm. 5), S. 17 f.; 2. M. J. Lasky: Die ungarische Revolution. Ein Weißbuch. Deutsch von G. Löwenthal. Berlin 1958, S. 200, zitiert nach dem UNO-Untersuchungsbericht; 3. Gosztony (s. Anm. 1), S. 151 und F. A. Váli: Twenty years after. Kádár and his rule assessed, 1956-1976, S. 155; 4. ebd., S. 157.

$13 \mathrm{~J}$. Kühl: Föderationspläne im Donauraum und in Ostmitteleuropa. München 1958; R. Wierer: Der Föderalismus im Donauraum. Graz, Köln 1960; W. Lipgens: Europa-Föderationspläne der Widerstandsbewegungen 1940-1945. München 1968.

14 "Juri W. Andropow, Chef des sowjetischen Staatssicherheitsdienstes KGB . . hatte den Ungarnaufstand niedergeschlagen, $1968 \mathrm{dem}$ >Prager Frühling، ein Ende gesetzt. In Belgrad kann er jetzt einer Sowjet-Delegation als Sachverständiger in Menschenrechtsfragen zur Verfügung stehen. « Welt am Sonntag, Nr. 41 v. 9. 10. 1977, S. 1. 


\section{Josef-Gerhard Farkas \& Gabriele Farkas}

Katolikus Magyarok Vasárnapja, Catholic Hungarians'

Sunday (Katholischer Ungarn Sonntag) USA, Themenspektrum / thematic spectrum / témaspektruma

\section{Index 1956-1968 \& 1969-1979}

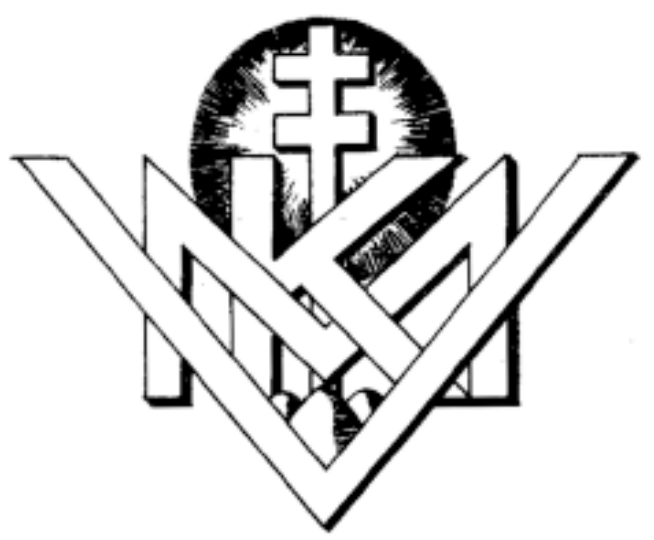

(C) 2010 \& Herausgabe/Publisher/Kiadó:

Gabriele Farkas; Habsburger Allee 10 A; D-76767 Hagenbach; Fax +49(0)7273-941173 — gabyfarkas@web.de

Druck: dbusiness.de gmbh $\cdot 10409$ Berlin 
Farkas, Josef-Gerhard

\section{Die „Népszava“ (Volksstimme), Spiegel des politischen Schicksals \\ Ungarns 1919 \& 1945-56.}

Titel der ersten Auflage:

Farkas, József Gert

Die Zeitung „Népszava“, ein Spiegel des politischen Schicksals Ungarns insbesondere in den Jahren 1919, 1945-56.

Berlin [West] 1961

\section{Inhalt}

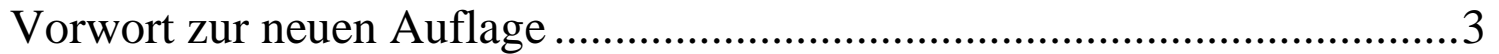

-- Übersetzungsvermerke. 3 unten, 29a, 141a --

Literaturverzeichnis

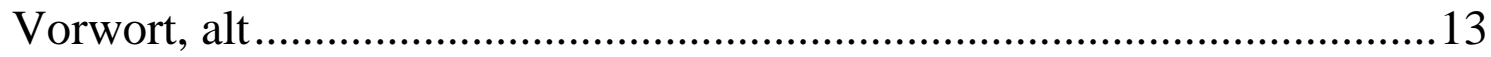

Historische Einleitung: Der Stand des ungarischen Pressewesens zur ....Zeitder

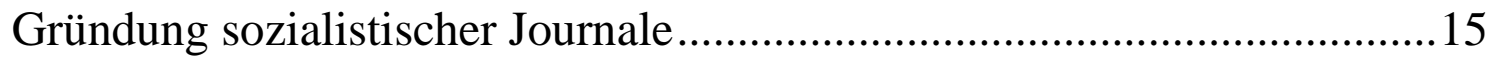

Von Táncsics über die "völkische" und Arbeiterpresse bis zur Tageszei-....tung

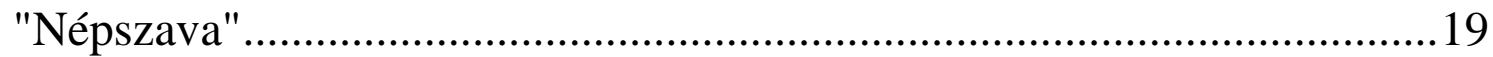

„Népszava“ bis zum Ersten Weltkrieg ...........................................................30

„Népszava“ und die Sozialdemokraten im 1. Weltkrieg.............................39

Wandlung der Presse unter Béla Kuns Räterepublik ..................................47

„Népszava“ bis Ende des Zweiten Weltkrieges. ............................................75

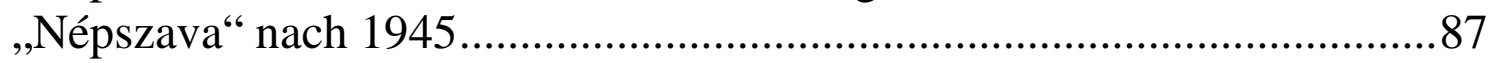

Nachwort: „Népszava“" vom 23. Oktober 1956 bis 1958 ............................142

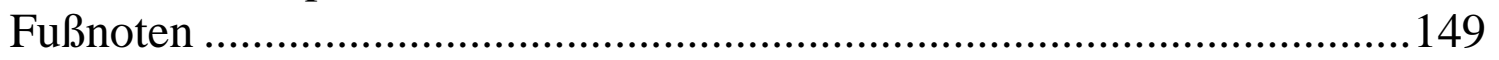


Farkas, József-Gerhard

\title{
A ,Népszava“, Magyarország politikai sorsának tükre 1919 \& 1945-1956-ban.
}

\section{Az első kiadás német címe lefordítva:}

Farkas, József Gert

\author{
A „Népszava“ újság, \\ Magyarország politikai sorsának tükre \\ különösen az 1919, 1945-56 években. \\ Berlin [Nyugat-] 1961
}

\section{Tartalom}

Előszó az új kiadáshoz $3 a$

-- Fordítási megjegyzések 3a lent, 29a, 141a --

Felhasznált munkák jegyzéke $4 \mathrm{a}$

Elöszó, régi $13 \mathrm{a}$

Történelmi bevezetés: A magyar sajtó állása a szocialista hírlapok alapí....tása idején $15 \mathrm{a}$

Táncsicstól a „népi“ és munkássajtón át a „Népszava“ napilapig. $19 \mathrm{a}$

„Népszava“ az első világháborúig .....................................................30a

„Népszava“ és a szociáldemokraták az 1. világháborúban .......................39a

A sajtó változása Kun Béla tanácsköztársasága alatt ...............................47a

„Népszava“ a második világháború végéig .........................................75a

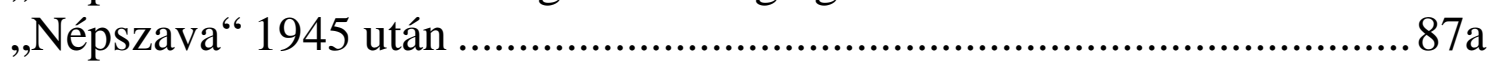

Utószó: „Népszava“ 1956 október 23-tól 1958-ig .................................142a

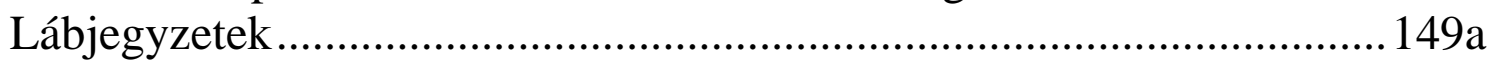


Michael de Ferdinandy (1912-93)

\section{Ungarn als Reich \\ der Heiligen Krone}

Seine Psychografie, von der Vorgeschichte bis 1956.

- Romantik als geschichtliche Form -

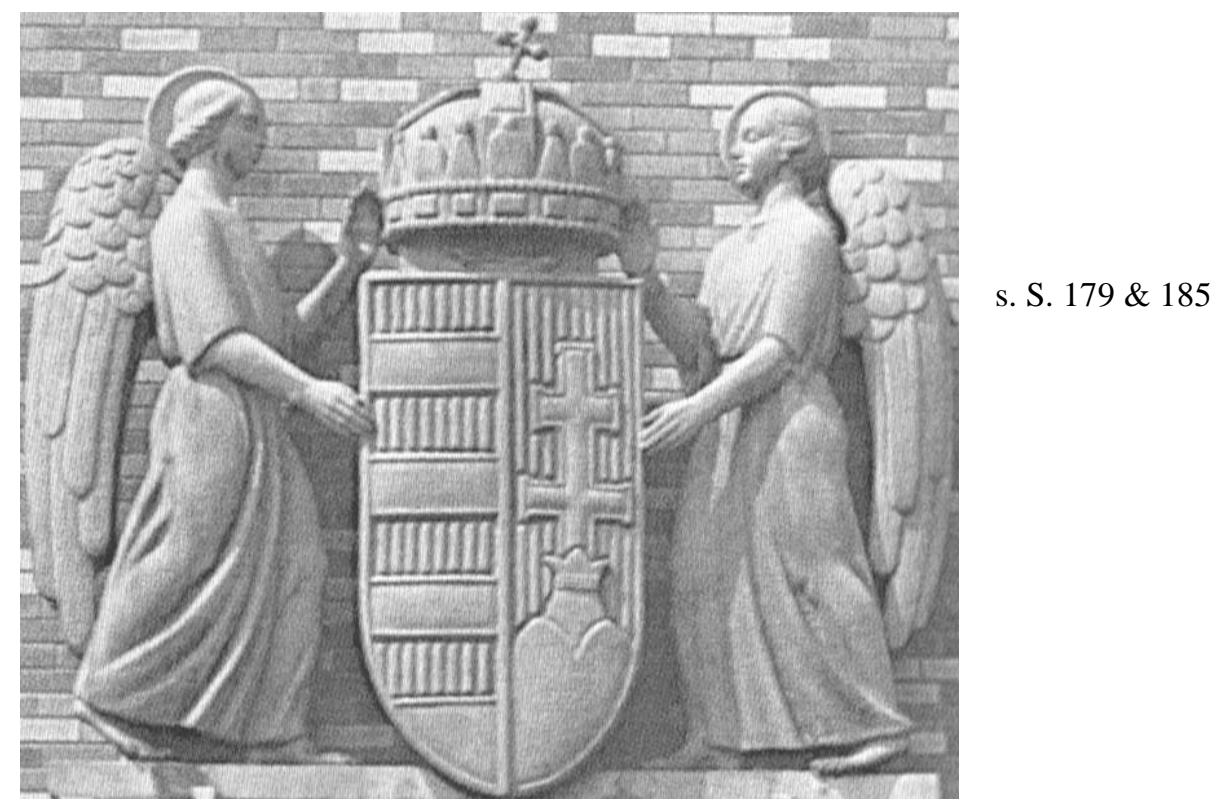

Redigiert von Josef-Gerhard Farkas

Herausgeber:

(C) Gabriele und Josef-Gerhard Farkas

Fax +49(0)7273-94 11 73; E-Mail: gabyfarkas@web.de Habsburger Allee 10 a; D-76767 Hagenbach

Druck: dbusiness 10409 Berlin 